\title{
Microplastics in the agroecosystem: effects of plastic mulch film residues on the soil-plant system
}

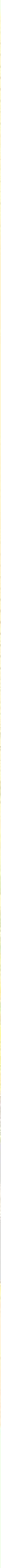




\section{Propositions}

1. The effects of plastic residues on the soil-plant system are type, size and dose specific.

(this thesis)

2. Biodegradable plastic mulch is not the solution for plastic pollution in agriculture.

(this thesis)

3. The sustainability of farming practices should be assessed by both economic interest and environmental impact.

4. Environmental science is too interdisciplinary to be scientific.

5. The more responsibilities you take proactively, the more freedom you will gain.

6. If you don't live as you dream, you'll dream as you live.

Propositions belonging to the thesis entitled:

Microplastics in the agroecosystem: effects of plastic mulch film residues on the soilplant system

Yueling Qi

Wageningen, 8 December 2020 

Microplastics in the agroecosystem: effects of plastic mulch film residues on the soil-plant system 


\section{Thesis committee}

\section{Promotor}

Prof. Dr V. Geissen

Professor of Soil Degradation and Land Management

Wageningen University \& Research

\section{Co-promotors}

Prof. Dr P. Garbeva

Senior researcher, Microbial Ecology

Netherlands Institute of Ecology (NIOO-KNAW)

Dr X. Yang

Lecturer at the Soil Physics and Land Management Group

Wageningen University \& Research

\section{Other members}

Prof. Dr M. C. Rillig, Freie Universität Berlin, Germany

Dr R. Zornoza, Universidad Politécnica de Cartagena, Spain

Dr E. Pulgisi, Università Cattolica del Sacro Cuore, Milan, Italy

Prof. Dr A. A. Koelmans, Wageningen University \& Research

This research was conducted under the auspices of the Research School for SocioEconomic and Natural Sciences of the Environment (SENSE) 


\section{Microplastics in the agroecosystem: effects of plastic mulch film residues on the soil-plant system}

\section{Yueling Qi}

Thesis

submitted in fulfilment of the requirements for the degree of doctor at Wageningen University by the authority of the Rector Magnificus

Prof. Dr A.P.J. Mol

in the presence of the

Thesis Committee appointed by the Academic Board

to be defended in public

on Tuesday 8 December 2020

at 4:00 p.m. in the Aula. 
Yueling Qi

Microplastics in the agroecosystem: effects of plastic mulch film residues on the soil-plant system, 154 pages.

PhD thesis, Wageningen University, Wageningen, the Netherlands (2020)

With references, with summary in English

ISBN: 978-94-6395-561-4

DOI: https://doi.org/10.18174/532052 


\section{Table of contents}

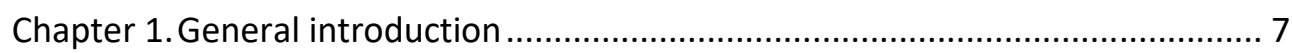

Chapter 2. Macro- and micro- plastics in soil-plant system: effects of plastic mulch film residues on wheat (Triticum aestivum) growth ............................ 21

Chapter 3. Effects of plastic mulch film residues on wheat rhizosphere and soil

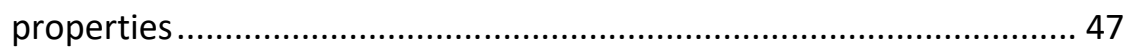

Chapter 4. Impact of plastic mulch film debris on soil physicochemical and hydrological properties ................................................................... 63

Chapter 5. Plastic mulch film residues in agriculture: impact on soil suppressiveness

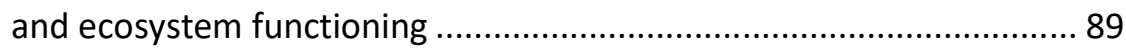

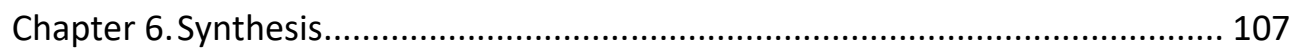

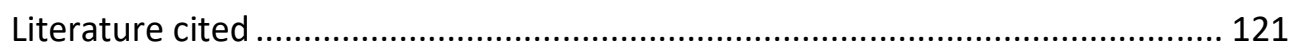

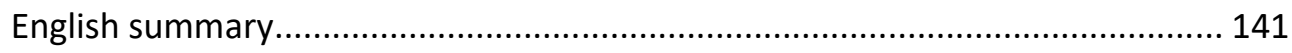

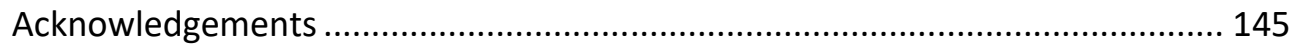

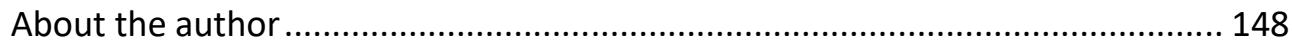

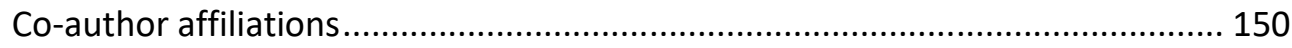





\section{General introduction}




\subsection{Why are microplastics such a hot topic?}

Before we talk about microplastics, let me first tell you something about plastics, since this is where the whole story started. No matter where you are right now, I'm sure that if you look around you will probably find some kind of plastic. We eat with plastic cutlery, drink out of plastic cups, wear clothes and shoes made out of plastics, live in houses built with plastic materials, travel in vehicles made with plastic components, and entertain ourselves with all kinds of plastic products. Just as Rome was not built in a day, plastics haven't become an indispensable part of human society overnight. It is not a big surprise, if we have checked the history how plastics revolutionized human society little by little.

It could start by going all the way back to when ancient Mesoamerican people made the first rubber balls around 3500 years ago (Hosler et al., 1999), but the story will be too long if we go back that far. Let's just look at a few more recent highlights in the development of plastics. Polystyrene (PS) was discovered in 1839 and polyvinyl chloride (PVC) in 1872. The first commercial synthetic plastic, named Bakelite, was invented by Leo Baekeland in 1907. Interestingly, the commercial production of PVC began in the 1920s which is a bit earlier than the production of PS which began in the 1930s. Polyethylene (PE), polyethylene terephthalate (PET) and polypropylene (PP) were discovered in 1933, 1941 and 1954, respectively. By 1954, the five main commodity plastics had all been discovered and account for around $90 \%$ of the current total demand for plastics (Andrady, 2003; Andrady and Neal, 2009; Thompson et al., 2009b). So, as I hope you can see, plastics are not just one single material but rather a large family of synthetic polymers.

From the 1950s on, the use of plastic grew exponentially. Global plastic production grew from around 1.5 million tonnes in 1950 to 260 million tonnes in 2007, with a growth rate of about $9 \%$ per year (PlasticsEurope, 2008). Because of a global financial crisis, we had a two year respite from this rapid growth in 2008 and 2009, with 245 million tonnes of plastic being produced in 2008 and 230 million tonnes in 2009 . Global plastic production increased again with 265 million tonnes being produced in 2010 and production has continued to grow steadily over the past decade (PlasticsEurope, 2009, 2010, 2011). According to the latest annual report from PlasticsEurope, global plastic production reached 359 million tonnes in 2018 (PlasticsEurope, 2019). Just as every coin has two sides, so does plastic use. Unfortunately, along with the enormous benefits we have reaped from our use of plastics, we have come face-to-face with one of our biggest challenges yet: managing post-consumer plastic wastes.

Ironically, longevity, which first started out as a beneficial characteristic of plastics, soon turned into one of its biggest challenges. Being inexpensive and easily accessible, items 
made from plastic are often easily and carelessly disposed of by consumers. With so many various types of plastics having so many different properties, it is impossible to make simple and uniform standards for recycling plastic wastes. Since plastics have been produced for different purposes with distinct lifespans, their service life could range from less than one year to more than 50 years. Single-use products account for the largest percentage of plastic use. In 2018, packing made up 39.9\% of overall European plastic use, followed by building \& construction with $19.8 \%$ (PlasticsEurope, 2019). Although the environmental awareness of consumers has increased and more effort is going into recycling single-use plastics, the remaining fraction, which goes into landfills or escapes monitoring, should not be ignored (Hopewell et al., 2009). The problems caused by the increased production of plastics combined with unsustainable management for post-consumer plastic wastes are just too conspicuous to ignore.

Soon after the pervasive expansion of plastic production began in the 1950s, plastic wastes were found in the stomachs of seabirds collected in New Zealand in the early 1960s (Harper and Fowler, 1987; Thompson et al., 2009a). More studies about the occurrence and effects of plastic debris in the marine environment were conducted over the following decades. The wide distribution of various types and shapes of plastic items (spherules, pellets, granules, etc.) were reported in ocean water, coastal areas, and beaches (Carpenter et al., 1972; Carpenter and Smith, 1972; Colton et al., 1974; Gregory, 1978). The ecological risk of plastic debris found in fish and seabirds was recorded and analysed during the same period (Carpenter et al., 1972; Ryan, 1987). Later on, increasing numbers of papers about plastic particles in the environment were published (Mato et al., 2001; Ryan and Moloney, 1993; Ryan et al., 2009; Ye and Andrady, 1991). You are probably wondering what all this has to do with microplastics.

Microplastics are commonly defined as plastic particles with diameter smaller than $5 \mathrm{~mm}$ from one of two sources: intentionally fabricated primary microplastics and unintentionally degraded secondary microplastics originating from larger plastic items (Cole et al., 2011; Hale et al., 2020; Law and Thompson, 2014). After reading this definition, I hope that everything falls into place for you. That is to say, microplastic is not a new material at all, it is just a new classification for smaller plastic particles. These particles used to be called plastic pellets, plastic granules, plastic fibres, small plastic fragments, small items of plastic debris, etc. Thompson et al. (2004) initiated the upsurge of interest in microplastics with a paper describing the widespread occurrence and accumulation of microscopic plastic debris in the ocean and sedimentary habitats (Law and Thompson, 2014; Rochman, 2018; Thompson et al., 2004). Since then, research about the occurrence, fate and behaviour of microplastics in aquatic ecosystems has substantially increased and it is widely 
acknowledged that microplastics pose various risks to aquatic life (Browne et al., 2007; da Costa et al., 2017; Koelmans et al., 2014; Koelmans et al., 2019).

Finally, I come to the answer to my question: "Why are microplastics such a hot topic?" It is because microplastics in environment has already been concerned by scientists for decades and now we are approaching a tipping point for this environmental crisis. We can see the clear trend that the abundance and occurrence of microplastics in the environment will keep increasing over the next decades, even centuries. It is imperative that researchers focus their attention and effort on microplastics.

\subsection{Microplastics in soil and terrestrial ecosystems}

Maybe you noticed that the studies mentioned above were all about microplastics or plastic debris found in water or along shorelines and there was nothing related to plastics found in soils at all. When people think about plastic pollution, their thoughts go to the things they can easily see, such as the bottles bobbing up and down in the ocean. However, just like the iceberg, the real danger lies beneath the surface. Research surrounding microplastics became increasingly popular at the beginning of 21st century. At that time, synthetic fibres were found to be abundant in sewage sludge and thus widely used as an indicator in sludge application (Habib et al., 1998; Zubris and Richards, 2005). The main end-of-life option for most plastic wastes was a landfill site (Barnes et al., 2009). Furthermore, direct dumping and disposing of plastic wastes on land (littering) was still common back then due to the lack of education and public engagement (Roper and Parker, 2006, 2008; Thompson et al., 2005). Although many scientists acknowledged that terrestrial plastic pollution was important, they admitted that to study in-depth the impacts of plastic debris at sea and shorelines already took their major efforts (Thompson et al., 2009a). In other words, the existence and accumulation of plastic debris and microplastics in soil ended up being the elephant in the room at the turn of the century.

Matthias C. Rillig (2012) was among the first to call for research on microplastics in terrestrial ecosystems and he also discussed the reasons why microplastics had not previously been studied in soil. In short, it was too complicated. Researchers had difficulties in propagating ideas from aquatic ecosystems to terrestrial ecosystems, difficulties in extracting and quantifying the microplastics in the complex soil matrix. There were difficulties in finding parallel systems since although shorelines were similar systems they were still not comparable to terrestrial ecosystems. There were difficulties in proving terrestrial ecosystems were also susceptible to microplastic accumulation even though most soil organisms were not filter-feeders which were common in aquatic environments 
(Rillig, 2012). It took time to address the conspicuous lack of knowledge on microplastics in soil. There was a dearth of publications on microplastics in soil that lasted for three years (Figure 1.1). In 2016, several reviews and research papers were published and by then the research about microplastics in soil entered a rapid growth stage till now.

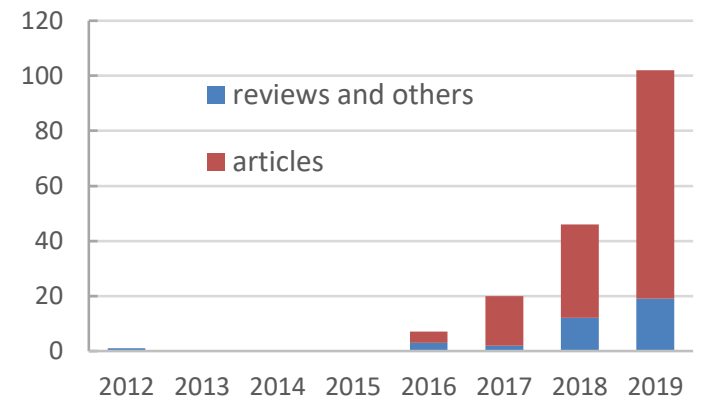

Figure 1.1 The number of publications concerning microplastics in soil per year from 2012 to 2019. (The total number of publications was 250 and classified into reviews and others and articles. Reviews include viewpoint, opinion, and regular review papers. Others includes editorial material, early access papers and letters. This graph was produced based on a search of the ISI Web of Science database for "microplastic* AND soil" within a date range from 1950 to 2020 carried out on the 17th of May, 2020. The graph only displays results published between 2012 to 2019, since no soil microplastic papers were found before 2012.)

Horton et al. (2017) estimated that the annual plastic release to land was 4 to 23 times that was released to oceans and he stressed the concerns for the transfer of plastic between environmental compartments. It's not surprising, as Nizzetto et al. already reported in 2016, that the estimations for microplastics stored in agricultural soils alone might be more than plastics stored in oceanic basins (Nizzetto et al., 2016a; Nizzetto et al., 2016b). After all, these are just predictions and estimations. Luckily, as of 2016, there has been more attention paid to microplastics in soil.

Esperanza Huerta Lwanga, a researcher in the Soil Physics and Land Management Group of Wageningen University \& Research, is one of the first soil scientists who started to work on microplastics in terrestrial ecosystems. With her colleagues, they conducted a series of studies about microplastics in soil such as developing methods for the extraction and identification of low-density microplastics from soil, exploring the effects of a concentration gradient of microplastics on earthworms, studying the transference of microplastics in the terrestrial food chain, restoring microplastic-polluted soils using earthworm gut bacteria and most recently, examining microplastics in sewage sludge and possible synergistic effects with pesticides (Corradini et al., 2019b; Huerta Lwanga et al., 2016, 2017a; Huerta Lwanga et al., 2017b; Huerta Lwanga et al., 2018; van den Berg et al., 2020; Yang et al., 2019; Zhang et al., 2018). Rillig and his team have also made crucial contributions to understanding microplastics in terrestrial ecosystems. They studied the transport of 
microplastics in soil by earthworms and Collembola (Maass et al., 2017; Rillig et al., 2017b), as well as the effects of microplastics on the soil biophysical environment (de Souza Machado et al., 2018b), plant performance (de Souza Machado et al., 2019), and soil aggregation (Lehmann et al., 2019). Most importantly, the insightful review papers wrote by Rillig and his team have far-reaching impacts for future research (de Souza Machado et al., 2018a; Rillig, 2012, 2018; Rillig et al., 2018; Rillig et al., 2017a; Rillig et al., 2019).

Beyond this, scientists have made even more remarkable progress on researching microplastics in soil and terrestrial ecosystems. New methods for quantifying and identifying microplastics in the soil have been developed and widely discussed (Blasing and Amelung, 2018; Corradini et al., 2019a; Fuller and Gautam, 2016; Moller et al., 2020; Shan et al., 2018). More field surveys measuring the status of microplastics in the soil have been conducted (Huang et al., 2020; Liu et al., 2018; Scheurer and Bigalke, 2018; Zhang and Liu, 2018; Zhou et al., 2020; Zhou et al., 2018). Microplastics were found in the digestive tracts of dead terrestrial birds (Zhao et al., 2016) and in the faeces of water birds collected in Spanish lakes (Gil-Delgado et al., 2017). Microplastics could act as vectors for other pollutants in the soil (Hodson et al., 2017). Earthworms (different species Eisenia fetida) were exposed to PS and PE microplastic and growth inhibition and the inflammation in their guts were observed (Cao et al., 2017; Rodriguez-Seijo et al., 2017). One of the studies found histological damage and changes in the gene expression of earthworms associated with microplastic exposure (Rodriguez-Seijo et al., 2017). Microplastic exposure was reported to disturb the collembolan gut microbiota and enhance the diversity of gut bacteria (Zhu et al., 2018b). So far, the knowledge of microplastics in soil is still very limited and it is a challenge to connect the dots to reveal the big picture in understanding the role that microplastics play in ecosystem services and functions.

Lastly, but perhaps most importantly, we need to address the different pathways by which microplastics enter the soil. Pathways for primary microplastics entering the soil are quite concise (Ng et al., 2018). Primary microplastics are mainly used in personal care products and therefore, go through waste water treatment plants and enter the soil either by irrigating farmland with waste water or sewage sludge application (Rocha-Santos and Duarte, 2015; Waldschlager et al., 2020). Secondary microplastics have some of the same pathways as primary microplastics, such as land application of sludge and organic composts (Corradini et al., 2019b; Zubris and Richards, 2005). And they have many other ways of getting into soil, as secondary microplastics could result from physical, chemical or biological abrasion of plastic items originally found on the soil surface or within the soil profile. Things like UV irradiation, wind erosion, ploughing and tilling, soil organisms foraging can break down plastics (Lambert and Wagner, 2016b; Ng et al., 2018; RochaSantos and Duarte, 2015). Domestic waste is still primarily disposed of in landfills (Barnes et 
al., 2009), and irresponsible littering and dumping of wastes happens too often (Barnes et al., 2009; Thompson et al., 2009a). In addition, atmospheric deposition and wind erosion may account for the occurrence of atmospheric microplastics in soil (Rezaei et al., 2019; Zhang et al., 2020b). After years of indiscriminate use, plastic mulch films are one of the main ways for microplastics to enter the soil, especially in agricultural soil, as seen in recent field surveys (Huang et al., 2020; Qi et al., 2020a).

\subsection{Plastic mulching techniques and plastic mulch film residues}

I meant no disrespect to plastic mulch films by calling them one of the main sources of microplastics in agricultural soil. These films have actually played a very important role in modern agriculture.

Humans have utilized mulching techniques for hundreds, even thousands of years. In agronomy, mulching is simply covering the area between the soil and crops with whatever material will form a physical barrier to prevent soil water evaporation, modify the microclimate around roots, suppress weed growth, protect the soil from wind and water erosion or simply to avoid having dirty plants. There has been a long history of benefits from using natural mulches derived from animal and plant materials to improve crop growth and yield (Kasirajan and Ngouajio, 2012). However, there have also been a few shortcomings when dealing with natural mulching materials like straw: the quality is difficult to keep uniform, large amounts are needed and not always available, it introduces weed seeds and insect eggs into the soil, etc. (Mooers et al., 1948; Summers et al., 2005). To solve the limitations of natural mulches, people started to look for new materials for mulching. Paper mulches took the stage for a short time in early 1920s, but the high economic and manual cost prevented them from being commercialized (Hopen and Oebker, 1976).

In 1948, Professor Emmert first used polyethylene (PE) as a greenhouse film to replace glass and he built the first plastic greenhouse a few years later (Anderson and Emmert, 1994; Wittwer, 1993). After the first use of plastic films in horticulture, PE films began to be used commercially in agriculture in the early 1960s (Kasirajan and Ngouajio, 2012). In 1960, comparisons among natural mulches, paper, PE films and other films were studied and researchers concluded that the most effective mulch material was PE film (Waggoner et al., 1960). By 1971, Israel already had extensive agricultural areas covered with plastic material, and some of that material was plastic mulch film (Wittwer, 1993). Initially, only developed countries used plastic mulch film but soon other countries also began using the film in agriculture. In 1958, China started using plastic film covers in the central and southern 
provinces to protect the soil from cold temperatures. By 1984, the plastic mulch film used in China covered 16,000 ha (Wittwer, 1993).

Early plastic mulch films were mainly designed to modify soil temperatures, but nowadays films are made with various additives, such as pigments, plasticisers, stabilisers and other polymers, to tailor them to all kinds of specific agronomic needs (Steinmetz et al., 2016). In addition to providing all the functions of natural mulches, the use of plastic mulch films consequently reduced the herbicide and fertiliser usage in modern agriculture (Espi, 2006). In addition, plastic mulch films are easy to process, inexpensive, durable, and resistant to chemicals as compared to previous mulch materials (Kasirajan and Ngouajio, 2012). Accordingly, plastic mulch films quickly overtook the market and have shown extraordinary benefits in modern agriculture.

The estimated consumption of agricultural plastics in America increased steadily from 0.26 million tons in 1994 to 0.5 million tons in 2001. 125,000 tons of plastic mulch films were used in Western Europe in 1997 (Kasirajan and Ngouajio, 2012). From 1991 to 2011, the amount of plastic mulch film used in China increased from 319,000 tons to $1,245,000$ tons and the area covered with film increased from 4,909,000 $\mathrm{hm}^{2}$ to $19,791,000 \mathrm{hm}^{2}$ (Liu et al., 2014). The nationwide application of plastic mulch film in the arid and semiarid regions of northern China and in the cold regions of southern China increased the crop productivity and quality enormously (Yan et al., 2014). There was a 20-35\% increase in grain crop yields and a $20-60 \%$ increase in cash crop yields with the use of plastic mulch film in China (Liu et al., 2014). The agronomic benefits of plastic mulching, such as enhancing root development and disease resistance as well as improving nutrient uptake and fruit quality, have been demonstrated by numerous studies carried out over the past decades (Abdul-Baki et al., 1992; Gao et al., 2019; Laugale et al., 2014; Li et al., 2018a; Overbeck et al., 2013; RuízMachuca et al., 2015; Singh, 1992; Wien et al., 1993). As a critical agricultural tool, plastic mulch films have made significant contributions to food security and modern agricultural development (Brodhagen et al., 2017).

As you can see, there are many benefits to using plastic films. Before long however, the other side of the coin was revealed. Since its emergence in the 1950s, the most common method used to dispose of plastic mulch films has been burying it in the soil, disposing of it in open fields, incinerating it, sending it to landfills, or, in very rare cases, recycling it. As demonstrated in many studies over the years, the degradation of PE under environmental conditions is extremely slow, if it happens at all (Kale et al., 2015; Restrepo-Flórez et al., 2014; Shah et al., 2008). Low-density PE (LDPE), linear LDPE and high-density PE are the most commonly used plastic mulch films, with LDPE being the main type commercially used (Kasirajan and Ngouajio, 2012). With the striking increase in the amount of plastic mulch 
films used and their extremely low degradability, the accumulation of plastic mulch film residues in agricultural soil has become a serious environmental problem. In 2011, the total amount of residual plastic mulch film in Xinjiang, China was estimated to be 343,000 tons and the maximum residual amount accumulated over the years could reach $502.2 \mathrm{~kg} \mathrm{ha}^{-1}$ according to a recent survey (Zhang et al., 2016). The detrimental effects of plastic residue accumulation in agricultural soil have been observed on soil quality and crop production (Dong et al., 2015; Jiang et al., 2017; Xiang et al., 1992; Xu, 1985; Zhao et al., 1998).

To make matters worse, building a proper management system for plastic mulch film residues is even more complex than for other plastic wastes in the environment. For instance, the removal of residual plastic mulch films proved to be laborious and timeconsuming. In most cases, fully removing plastic residues incorporated into the soil was impossible due to practical difficulties and high costs (Brodhagen et al., 2017; Steinmetz et al., 2016). Due to their increased weight from soil particles and contamination with agrochemicals, plastic mulch film residues are not suitable or safe for either landfills or recycling (Nerin et al., 1996; Scarascia-Mugnozza et al., 2011; Wang et al., 2013).

On the one hand, the enormous agronomic benefits brought by plastic mulching use will ensure the usage of plastic mulch films in the near future. On the other hand, the difficulties in collecting and recycling plastic mulch film residues, the evidently negative effects of accumulated plastic residues on plants and soil, and recent concerns about forming countless microplastics in long term, all need to be tackled cautiously to ensure sustainable agriculture. So, is there a way out of this dilemma?

\subsection{Biodegradable plastic mulch film: a solution or a fallacy?}

In theory, biodegradable plastic mulch film could be incorporated into the soil directly after harvest since it will supposedly completely degrade once in the soil. In this way, high labour and disposal costs could be saved without causing environmental pollution, which makes the concept of biodegradable plastic mulches very attractive. In practice however, the performance of biodegradable plastic mulch films could not always meet expectations. Therefore, despite the initial promises, biodegradable plastic mulch film has hardly been accepted as a practical alternative to traditional PE film so far (Kasirajan and Ngouajio, 2012; Sintim and Flury, 2017; Steinmetz et al., 2016).

The research and development of biodegradable plastic mulches began as early as the 1970s, or at least what was classified as degradable plastic mulches at the time (Otey et al., 1974). The progress was slow during the early stages. In the early 1990s, the application of 
starch-based biodegradable plastic films in agriculture had begun to show industrial promise, due to the increasing prices of conventional plastic films and the costs of removing plastic mulch film residues from fields after harvest (Aminabhavi et al., 1990; Huang et al., 1990). At the time, making uniform and standard test methods for biodegradation had already been recognized as a major problem in biodegradable plastic research, due to longlasting contradictions between lab tests and field studies (Aminabhavi et al., 1990; Huang et al., 1990). The development of biodegradable plastic mulch films over the following decades proved to be just as challenging as before. The costs of investing time and money in inventing novel synthetic materials was high (Mooney, 2009) and the sustainability of biodegradable plastic mulch films in the environment based on full life cycle assessment was still poorly studied (Gerngross, 1999; Steinmetz et al., 2016).

Although this thesis specifically focuses on biodegradable plastic mulch film, it's important to explain a bit more about the confusing terms currently on the market: bio-based plastic, biodegradable plastic and bioplastic. Briefly speaking, a bio-based plastic is partly or entirely made from renewable biological resources, such as starch from crops and vegetable oil. A biodegradable plastic means that it can be degraded by naturally occurring microorganisms such as bacteria, fungi, and algae. The claim of biodegradable plastic is basically meaningless without a defined environment and timeframe. Overall, bioplastic is an ill-defined term and refers to both the plastics of bio-based origin as well as the plastics with biodegradable characters (Lambert and Wagner, 2017; Meeks et al., 2015; van den Oever et al., 2017; Vert et al., 2012). For instance, starch blends, polylactic acid (PLA), polyhydroxyalkanoates (PHA), polybutylene succinate (PBS) are bio-based and biodegradable, of which starch blends account for $21.3 \%$ of the global production capacity for bioplastics in 2019 (European Bioplastics, 2020). Polybutylene adipate terephthalate (PBAT) are based on fossil resources and biodegradable, whereas bio-based PE, PP and PET are non-biodegradable (European Bioplastics, 2020).

The lack of regulations was another major problem for the development of biodegradable plastic mulch films. Before the release of the European Standard EN 17033: PlasticsBiodegradable mulch films for use in agriculture and horticulture-Requirements in 2018, there was no international standard that could be directly applied to biodegradable plastic mulch films in soil and the standards for the biodegradation under compost (e.g. ASTM D6400-19) were largely misinterpreted for soil (Briassoulis and Dejean, 2010; Briassoulis et al., 2010). However, a compostable plastic could undergo biological degradation during industrial composting, but it does not mean that this biological decomposition could happen under ambient environmental temperatures. Specifically, EN 17033 requires laboratory testing of biodegradable plastic mulch films for $\geq 90 \%$ biodegradation under aerobic conditions (i.e., conversion of organic carbon into $\mathrm{CO}_{2}$ ) in a natural topsoil from an 
agricultural field or forest at 20 to $28^{\circ} \mathrm{C}$ conditions within 2 years using a standardized test to measure $\mathrm{CO}_{2}$ respiration (Hayes and Flury, 2018).

Before the general population came to realize the problem surrounding microplastics, methods for assessing residues of biodegradable plastic mulch films were basically out of sight, out of mind. For instance, in a field study for biodegradable plastic mulch films in 2008, the collected soil samples were sieved through a $1.8 \mathrm{~cm}$ mesh and all of the residues that passed through the mesh were considered to be degraded (Kapanen et al., 2008). Therefore, the so-called biodegradable plastic mulch films of the past were likely to have degraded into microplastics and accumulated in soil (Barnes et al., 2009; Kasirajan and Ngouajio, 2012). With increasing environmental pressure and public awareness, extensive attention has been drawn to the reliable degradation of biodegradable plastic mulch films in recent years (Brodhagen et al., 2017; Rillig et al., 2017a; Thompson et al., 2019). Therefore, quite a few studies concerning the function and disintegration of biodegradable plastic mulch films have been conducted recently (Anzalone et al., 2010; Li et al., 2014b; Miles et al., 2017; Miles et al., 2012; Moreno et al., 2017; Yang et al., 2014b). However, the effects of biodegradable plastic mulch films on crop growth and soil quality have barely been studied so far (Bandopadhyay et al., 2018; Li et al., 2014a).

Ideally, biodegradable plastic mulch film should meet three requirements before being able to replace conventional PE mulches. Biodegradable plastic mulch film should 1) maintain performance comparable to PE mulches from installation to final harvest, 2) fully degrade after being incorporated into soil without forming any toxic residues and within a required time period, 3) be economically available to farmers. Although it is a big challenge to meet all of the requirements and the high expectations at the same time, the market for biodegradable plastic mulch films has been gradually increasing. In 2016, the European commission estimated that there was no more than 3000 tons of biodegradable plastic mulch films on the EU market each year and the total demand of plastic mulch film on the EU market was around 100,000 tons a year (European Commission, 2016). Due to the strong demand for degradability after use, the availability of biodegradable plastic mulch films will almost certainly keep increasing in the global market (Haider et al., 2019; Ren, 2003). To ensure the security and sustainability of their application in agroecosystems, comprehensive research about all aspects of biodegradable plastic mulch films is urgently needed before its commercialization. 


\subsection{Define research scope and objectives}

When this thesis started, studies on microplastics in agroecosystems were scarce and barely any experimental studies about microplastics in the soil-plant system had been done (Rillig, 2012; Rillig et al., 2017a). Agricultural soil plays a vital role in food security and it is the most vulnerable site for the entry and accumulation of microplastics via various routes (de Souza Machado et al., 2018a; Ng et al., 2018). Furthermore, negative effects of macro-sized plastic mulch film residues on crop growth and soil quality have been shown in many studies (Dong et al., 2015; Liu et al., 2014; Xiang et al., 1992; Zhao et al., 1998). Concerns surrounding these macro-sized plastic residues have been growing, since they may degrade into more microplastics over time, causing an exponential rise (Barnes et al., 2009). Biodegradable plastic mulch film was invented to overcome the problems caused by conventional plastic mulch film residues, namely being that they are hard to dispose of after use and are hard to degrade after being incorporated into the soil. Considering the fact that relevant studies were started early with great expectations, our lack of knowledge concerning biodegradable plastic mulch film is surprising.

This PhD thesis aims to fill some of the gaps in our knowledge of microplastics in agroecosystems and give new insights into the use of plastic mulching for sustainable agriculture. There are many open research questions regarding the impact of microplastics on terrestrial ecosystems. For example, what are the effects of microplastics on soil properties, soil (micro)organisms, belowground interactions, soil health and functioning, etc.? The effects of microplastics on the soil-plant system have been barely studied and how microplastics interact with plants and soil microbes remains unexplored. To make the best use of current knowledge, the focus of this thesis was confined to macro- and micro-sized plastic residues from one LDPE and one starch-based biodegradable mulch film. The laboratory and greenhouse experiments were conducted to provide direct evidence and contribute to a comprehensive understanding of the effects of plastic residues on the soilplant system. In this thesis, the effects of plastic residues on the soil-plant system were investigated with respect to plant growth, soil organisms, rhizosphere microbiome, rhizosphere volatile profiles, soil physicochemical and hydrological properties, and soil function.

\subsection{Outline of the thesis}

This PhD thesis comprises 6 chapters. Chapter 1 introduced background information as well as the research objectives of this thesis. Results of the laboratory and greenhouse experiments that were conducted appear in Chapters 2 through 5 to investigate the effects 
of plastic mulch film residues on the soil-plant system. These four chapters were prepared as standalone publications and can be read independently. The outline of this PhD thesis is summarized in Figure 1.2.

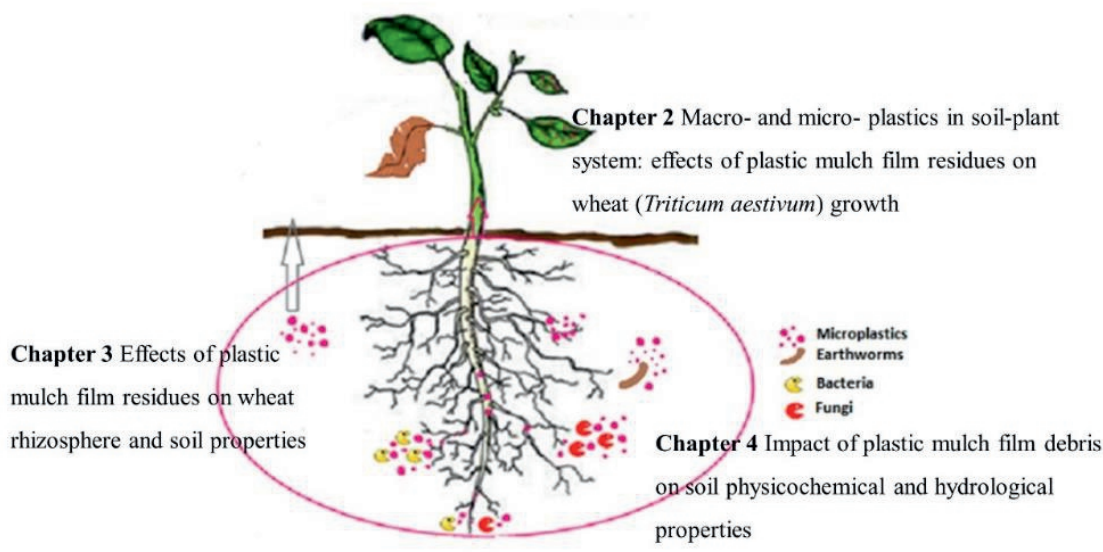

Chapter 5 Plastic mulch film residues in agriculture: impact on soil suppressiveness and ecosystem functioning

Figure 1.2 Outline of this PhD thesis.

Chapter 2 studies the effects of plastic residues on plant growth using a pot experiment, with wheat as the model plant and earthworms as the model soil organisms in the soil-plant system.

Chapter 3 further explores the effects of plastic residues on rhizosphere bacterial communities, rhizosphere volatile profiles and soil chemical properties based on Chapter 2 .

Chapter 4 investigates the effects of plastic residues on soil physicochemical and hydrological properties via mesocosm experiments conducted in the laboratory.

Chapter 5 discusses the effects of plastic residues on soil functions, taking soil suppressive to Fusarium culmorum in wheat as an example.

Chapter 6 summarizes the main findings of this thesis and discusses their implications within the soil-plant system. Furthermore, Chapter 6 gives an outlook on future research directions for studying microplastics in agroecosystems and offers recommendations for the sustainable use of plastic products. 


\section{Macro- and micro- plastics in soil-plant system: effects of plastic mulch film residues on wheat (Triticum aestivum) growth}

Plastic residues have become a serious environmental problem in the regions with intensive use of plastic mulching. Even though plastic mulch is widely used, the effects of macro- and micro-plastic residues on the soil-plant system and the agroecosystem are largely unknown. In this study, low density polyethylene and one type of starch-based biodegradable plastic mulch film were selected and used as examples of macro-and micro- sized plastic residues. A pot experiment was performed in a climate chamber to determine what effect mixing 1\% concentration of residues of these plastics with sandy soil would have on wheat growth in the presence and absence of earthworms. The results showed that macro- and micro- plastic residues affected both above-ground and belowground parts of the wheat plant during both vegetative and reproductive growth. The type of plastic mulch films used had a strong effect on wheat growth with the biodegradable plastic mulch showing stronger negative effects as compared to polyethylene. The presence of earthworms had an overall positive effect on the wheat growth and chiefly alleviated the impairments made by plastic residues.

Based on:

Qi, Y., Yang, X., Pelaez, A.M., Huerta Lwanga, E., Beriot, N., Gertsen, H., Garbeva, P. \& Geissen, V. 2018. Macro- and micro- plastics in soil-plant system: Effects of plastic mulch film residues on wheat (Triticum aestivum) growth. Science of the Total Environment, vol. 645, pp. 1048-1056. https://doi.org/10.1016/j.scitotenv.2018.07.229 


\subsection{Introduction}

Microplastic pollution has been a hot topic since 2004 when Thompson et al. (2004) published a paper describing the distribution of microscopic plastic debris in seawater. It is widely accepted that microplastics in aquatic ecosystems are serious threats that can have potentially negative effects on marine ecosystems, aquatic organisms and even human health (Sharma and Chatterjee, 2017; Syberg et al., 2015; Wright et al., 2013). Even though the term microplastic was already used in 1990 by Ryan and Moloney in their paper concerning surveys of South African beaches (Ryan and Moloney, 1990), 'microplastic' is still a poorly defined term without a universal standard so far (Law and Thompson, 2014). At present, the majority of the research performed in this area is focused on microplastics between $5 \mathrm{~mm}$ or $1 \mathrm{~mm}$ in size (Arthur et al., 2009; Browne et al., 2007; GESAMP, 2015; Verschoor, 2015).

Although soil, especially agricultural land, has become a major sink for microplastics (Browne et al., 2011; Mahon et al., 2017; Nizzetto et al., 2016a; Nizzetto et al., 2016b; Rillig, 2012; Zubris and Richards, 2005), most of the research done so far has been focused on microplastics in the aquatic ecosystem (Auta et al., 2017; Cole et al., 2011; Duis and Coors, 2016; Eerkes-Medrano et al., 2015; Koelmans et al., 2014; Koelmans et al., 2017; Nizzetto et al., 2016b). Plastics, especially polyethylene, are intensively used as mulch film in agriculture with the aim of improving the soil climate thus making it more beneficial to plant growth and increasing water use efficiency in (semi-) arid regions (Ekebafe et al., 2011). The current global usage of plastic mulch films is enormous and has been increasing in recent years (Brodhagen et al., 2017; Research, 2013). China has the biggest plastic mulch film usage worldwide with 19.8 million hectares of agricultural land covered by plastic mulch film (Liu et al., 2014; Yan et al., 2014). Although the use of plastic mulch has numerous economic benefits, one devastating side effect is that the plastic is left in the soil after harvest (Brodhagen et al., 2017). Any attempts to recycle the plastic residues have been hampered by practical difficulties and high costs (Brodhagen et al., 2017; Kasirajan and Ngouajio, 2012; Steinmetz et al., 2016). Year after year new plastic residue is added to the soil and this constant accumulation, coupled with traditional tillage practices, results in a huge amount of mega-, macro- and micro- plastic particles being incorporated into the agricultural soils (Liu et al., 2014; Rillig et al., 2017a; Steinmetz et al., 2016; Yan et al., 2014). The environmental concerns stemming from residual mulch film has aroused the interest of scientists and studies have shown that mulch film residues can reduce soil quality and crop production (Dong et al., 2015; Jiang et al., 2017; Zhang et al., 2016). Even though biodegradable plastic mulch films were invented in an attempt to decrease plastic residues in agricultural land and touted as promising alternatives to traditional polyethylene mulch films, these seemingly more environmentally friendly films have aroused debate concerning 
their use (Moreno et al., 2017; Ren, 2003; Sintim and Flury, 2017; Yan et al., 2014; Yang et al., 2014b).

In recent years, soil scientists have made progress in researching microplastics in terrestrial ecosystems and new techniques for quantifying and identifying microplastics in the soil have been developed, applied and debated (Blasing and Amelung, 2018; Claessens et al., 2013; Elert et al., 2017; Zhang et al., 2018). However, there are still only a few studies that have been focused on the effect of microplastics in the terrestrial environment (Chen, 2016; Zhang et al., 2018; Zhou et al., 2018). The presence of microplastics in the soil could change soil properties and microplastics may be transported by soil organisms or act as vectors for other soil pollutants (Hodson et al., 2017; Liu et al., 2017a; Maass et al., 2017; Rillig et al., 2017b). Recently, Huerta Lwanga et al. completed a series of research projects concerning microplastics in soil which examined the effects on earthworms on plastics in soil, transferability of plastics in a terrestrial food chain and the possibility of restoring microplastic-polluted soils using bacteria. (Huerta Lwanga et al., 2016, 2017a; Huerta Lwanga et al., 2017b; Huerta Lwanga et al., 2018; Zhu et al., 2018a). Zhu et al. (2018b) proved that microplastics can disturb the collembolan gut microbiota and enhance the diversity of gut bacteria. Even though there is a growing concern about the microplastic pollution in terrestrial ecosystems, so far there has been no experimental research concerning both macroplastics and microplastics in the soil-plant system and the effects that this could have on plant growth (Cao et al., 2017; Ng et al., 2018; Nizzetto et al., 2016a; Nizzetto et al., 2016b; Rillig, 2012).

With this current research, we aimed to take the first steps towards filling the gaps left by past studies and focused on the previously neglected area of research concerning microplastics in the soil-plant system. Here, we tested the effects of two different sizes of polyethylene and biodegradable plastic mulch film residues in a soil system with and without the presence of earthworms. Both earthworms and plastic residues are known to alter soil properties and they are likely to interact through various mechanisms (Bertrand et al., 2015; Cao et al., 2017; Huerta Lwanga et al., 2016, 2017a; Rillig et al., 2017b; van Groenigen et al., 2014). In the present study, we performed a greenhouse pot experiment using wheat (Triticum aestivum) as a model plant and low-density polyethylene and a starch-based biodegradable plastic with realistic filed concentration of $1 \%(\mathrm{w} / \mathrm{w})$ as the applied plastic residues (Chen, 2016; Tao et al., 2012; Zhang et al., 2018; Zhang et al., 2015). The experiment was performed with and without Lumbricus terrestris as the model earthworm. We hypothesized that the type (polyethylene / biodegradable) and the size (macro- / micro-) of the plastic residues as well as the presence or absence of earthworms effect plant growth and these effects are interactive. 


\subsection{Materials and methods}

\subsubsection{Experimental design}

\subsubsection{Facilities and soil}

A pot experiment was conducted to investigate the effects of different types and sizes of plastic mulch film residues on wheat (Triticum aestivum) in a climate chamber (Klima C7) at Unifarm, Wageningen University \& Research (WUR), the Netherlands. We harvested the wheat at two time points (after 2 and 4 months) in order to examine the effects of our experiments on both vegetative and reproductive growth. The sandy soil used in this study was obtained from the agricultural land in Wageningen, the Netherlands, collected by Unifarm, WUR. The soil consisted of $87 \%$ sand, $12 \%$ slit and $1 \%$ clay with an organic matter content of $4 \%$ (More information about the soil properties are presented in Figure S2.1). Before use, the air-dried soil was sieved through a $2 \mathrm{~mm}$ steel sieve.

\subsubsection{Plastic materials}

Two types of plastic mulch films were applied in this experiment: (1) low-density polyethylene (LDPE) and (2) starch-based biodegradable plastic (Bio). The biodegradable plastic film consisted of $37.1 \%$ Pullulan, $44.6 \%$ Polyethylene Terephthalate (PET) and $18.3 \%$ Polybutylene Terephthalate (PBT).

To obtain macroplastics (Ma), pieces of plastics were cut on a hard wooden board using sharp blades and scissors. The same procedures were carried out for both types of plastic films. After cutting, we randomly chose 100 pieces of plastic from each sort and measured their widths and lengths. For LDPE Ma, the average length was $6.92 \pm 1.47 \mathrm{~mm}$ and the average width was $6.10 \pm 1.39 \mathrm{~mm}$. For Bio $\mathrm{Ma}$, the average length was $6.98 \pm 1.61 \mathrm{~mm}$ and the average width was $6.01 \pm 1.31 \mathrm{~mm}$.

To obtain microplastics (Mi), the plastics were first cut into pieces, frozen with liquid nitrogen and then ground into a powder. After grinding, the resulting powder was sieved through $1 \mathrm{~mm}, 500 \mu \mathrm{m}, 250 \mu \mathrm{m}$ and $50 \mu \mathrm{m}$ sieves in order to divide the plastics into size categories. We mixed the selected categories of plastic using the following ratio: $12.5 \%$ of $1 \mathrm{~mm}$ to $500 \mu \mathrm{m}, 62.5 \%$ of $500 \mu \mathrm{m}$ to $250 \mu \mathrm{m}$ and $25 \%$ of $250 \mu \mathrm{m}$ to $50 \mu \mathrm{m}$. For LDPE Mi and $\mathrm{Bio} \mathrm{Mi}$, all the processing procedures were the same.

In this study, we used $1 \%(\mathrm{w} / \mathrm{w})$ content as the practicable and instructive setting to simulate the plastic mulch film residues in agricultural soil according to field survey and literature review (Chen, 2016; Tao et al., 2012; Zhang et al., 2018; Zhang et al., 2015). 


\subsubsection{Wheat seeds and pots}

Wheat seeds (Triticum aestivum) were provided by Unifarm, WUR. Before being sowed, the mass of each seed was measured and only the seeds with a mass between $0.04 \mathrm{~g}$ and 0.05 $\mathrm{g}$ were used. The germination rate in this experiment was high at more than $80 \%$ (Table S2.1). The pots used in the experiment were $18 \mathrm{~cm}$ high with a diameter of $10 \mathrm{~cm}$ at the bottom and $13 \mathrm{~cm}$ at the top and had a volume of 2 liters.

\subsubsection{Earthworms and litter}

We used the anecic earthworm Lumbricus terrestris in this study. L. terrestris were purchased from the Star Food Company (Barneveld, the Netherlands). From the 300 earthworms we received, we selected 100 adults with average weight of $3.72 \pm 0.55 \mathrm{~g}$. The biomass and mortality of earthworms were checked at the final harvest (Table S2.2). The commonly consumed plant litter for $L$. terrestris is Populus nigra, so we collected the leaves of this plant from natural areas in Wageningen, the Netherlands. These leaves were carefully cleaned and dried at $60^{\circ} \mathrm{C}$.

\subsubsection{Treatments and replicates}

Three factors were taken into consideration while planning the experiment: types of plastics (LDPE/Bio), sizes of plastic residues (Ma/Mi) and presence or absence of earthworms (WE: With Earthworms/NE: No Earthworms). A factorial experiment design $2^{3}$ (three factors with two levels) was adopted. In addition, two control treatments without any plastic residues were also examined. Overall the experiment consisted of 10 treatments (Table 2.1). Ten replicates were made for each treatment and a total of 100 pots of wheat were cultivated.

Table 2.1 Treatments setting for the experiment.

\begin{tabular}{|c|c|c|c|c|c|}
\hline \multirow{2}{*}{ Group } & \multirow{2}{*}{ Treatments } & \multicolumn{2}{|l|}{ TYPE } & \multicolumn{2}{|l|}{ SIZE } \\
\hline & & LDPE & Bio & Macro & Micro \\
\hline \multirow{5}{*}{ WE } & LDPE-Ma & $\mathrm{V}$ & & v & \\
\hline & LDPE-Mi & V & & & V \\
\hline & Bio-Ma & & V & v & \\
\hline & Bio-Mi & & $v$ & & $v$ \\
\hline & Control & / & / & / & / \\
\hline \multirow{5}{*}{ NE } & LDPE-Ma & V & & v & \\
\hline & LDPE-Mi & v & & & v \\
\hline & Bio-Ma & & v & v & \\
\hline & Bio-Mi & & $v$ & & v \\
\hline & Control & / & / & / & / \\
\hline
\end{tabular}




\subsubsection{Setting up and growth conditions}

\subsubsection{Setting up}

For each pot, $1500 \mathrm{~g}$ of sieved soil and $15 \mathrm{~g}$ of plastic material (except for the two Control treatments with no plastic) were weighed and manually mixed with $150 \mathrm{~g}$ of water. Before filling the pot with this mixture, a piece of geotextile was placed in the bottom of each pot to prevent earthworms from escaping and to let air and water flow freely. After all the pots were filled, the soil moisture was unified to $15 \%$ similar to the soil field capacity. All the pots were allowed to settle down for a period of one week before wheat seeds were sowed.

Ten days after sowing, two adult earthworms were added to the pots used in the WE treatment group to avoid the possibility of the worms eating the seeds before germination (Fründ et al., 2010). Around $12 \mathrm{~g}$ of litter (12.08 $\pm 0.06 \mathrm{~g}$ ) was added to the surface of each pot and water was sprayed on the litter to make it moist.

\subsubsection{Cultivation of wheats}

Five seeds were sowed in each pot and after two weeks of growth, 3 seedlings per pot were selected and retained for the experiment. The following controlled conditions were applied: temperature was set at $22{ }^{\circ} \mathrm{C}$ during the day and $17{ }^{\circ} \mathrm{C}$ during the night, day/night photoperiod $(14 / 10 \mathrm{~h})$ with a light intensity of $300 \mu \mathrm{mol} \mathrm{m} \mathrm{m}^{-2} \mathrm{~s}^{-1}$ and a relative humidity of $70 \%$ for both day and night. The pots were watered weekly with tap water and the soil moisture was kept at around $12 \%$ to $18 \%$ with respect to weight. $100 \mathrm{~mL}$ of a nutritive solution was added to each pot once a week during the fifth week and the tenth week after the seeds were sowed. Reagents and concentrations of compounds in the nutritive solution are presented in Figure S2.2. Pots were randomly placed within the climate chamber and their positions were shifted once a month.

\subsubsection{Measurements of wheat growth parameters}

Plant heights were measured regularly from the $14^{\text {th }}$ day after seeds were sowed to the $139^{\text {th }}$ day using a steel tape measure. The number of tillers were counted and recorded from the $20^{\text {th }}$ day until the $139^{\text {th }}$ day and the fruits were counted and recorded regularly from the $61^{\text {st }}$ day until the $139^{\text {th }}$ day.

The plants were harvested at two time points. For each treatment, five replicates were harvested at 2 months ( $61^{\text {st }}$ day) when the flag leaf appeared and the wheat started to bear fruit. The remaining 5 replicates were further cultivated and harvested at 4 months $\left(139^{\text {th }}\right.$ day) after mature wheat grains had developed. Plants were separated into shoots and roots 
at the 2 months harvest and shoots, fruits and roots at the 4 months harvest. Dry biomasses were recorded after drying at $70{ }^{\circ} \mathrm{C}$ to a constant weight.

For the 2 months harvest, the stem diameter, number of leaves, leaf area and relative chlorophyll content were measured and recorded. Stem diameters were measured using a vernier caliper. Leaf areas were measured using the LI-3100C Laboratory Leaf Area Meter (LI-COR Biosciences, USA). Relative chlorophyll content was measured using SPAD-502plus (Minolta, USA) at the middle and tip of three fully developed leaves on $61^{\text {st }}$ day for all three plants in each pot.

\subsubsection{Statistical analysis}

All statistical data analyses were performed using IBM SPSS Statistics 23 and CANOCO 5. Values from observations were recorded for each plant and were then averaged for each pot. All errors are indicated as standard deviations. The data were screened for normal distribution using q-q plots and Shapiro-Wilk tests and homogeneity of variance using Levene's test. Comparisons among treatments were performed by two independent one way ANOVA and followed by Tukey HSD test at the $p<0.05$ level (group WE/group NE). When data violated the assumption of homogeneity of variances, a Welch ANOVA and a Games-Howell test were carried out. Comparisons between WE and NE groups were performed by Independent-Samples $T$ Test at the $p<0.05$ level. The effects of all three factors (type of plastics, size of residues and earthworms) and their interactive effects were tested using a three way ANOVA. The contributions of the factors and their interactions on the parameters were calculated by dividing their sum of squares by the total sum of squares. The relationships between the treatment factors and the plant growth parameters were identified through Redundancy Analysis by CANOCO 5. The arrows represent the different plant growth parameters, and the direction of the arrows represents the correlations between each parameter and the axes as well as the relationships among the parameters. The length of the arrows represents the relative contribution of the parameters to the axes and the parameter-factor relationships.

\subsection{Results}

\subsubsection{Wheat development: plant height, number of tillers and fruits during the growth process}




\subsubsection{Plant height}

The Bio Ma and Bio Mi addition inhibited wheat growth with respect to plant height, while the addition of LDPE Ma and LDPE Mi showed no clear effects relative to the Control during the tillering stage of growth (around $14^{\text {th }}$ day until $40^{\text {th }}$ day) (Figure 2.1a, Figure $2.1 \mathrm{~b}$ ). During the stem extension stage (around $40^{\text {th }}$ day until $68^{\text {th }}$ day), wheat plants in Bio-Ma and BioMi treatments entered a rapid elongating period (Figure 2.1a, Figure 2.1b). At the 2 months harvest, wheat plants in the WE group showed no significant difference among treatments (Table S2.3). In group NE, wheat plants in the treatment Bio-Ma (491 $\pm 35.02 \mathrm{~mm}$ ) had the highest plant height and those in the LDPE-Ma $(415 \pm 27.40 \mathrm{~mm})$ treatment had the lowest plant height but none of the treatments showed significant differences from the Control $(451 \pm 30.89 \mathrm{~mm}$ ) (Table S2.3). At the 4 months harvest, the height of wheat plants in all treatments turned out to be similar and wheat plants in group NE (584 $\pm 27.86 \mathrm{~mm})$ had similar plant heights as group WE (578 $\pm 30.48 \mathrm{~mm})$ (Table S2.3, Table S2.4).

\subsubsection{Number of tillers}

Wheat in most of the treatments started tillering from the $20^{\text {th }}$ day on, while wheat in the Bio-Ma and Bio-Mi treatments in group NE had a two week delay in tillering compared to the other treatments (Figure 2.1c, Figure 2.1d). Overall, the number of tillers per plant grew stably during the process and no significant differences among treatments in group WE at the 4 months harvest were seen (Table S2.3). For the NE group, the number of tillers of wheat in the Control $(5.5 \pm 0.67)=$ LDPE-Ma $(5.5 \pm 0.71)=$ LDPE-Mi $(5.5 \pm 0.32)>$ Bio-Mi $(4.2$ $\pm 0.58)=$ Bio-Ma $(4.1 \pm 0.37)$ at the 4 months harvest (Table S2.3). At the final harvest, the wheat plants in group WE $(6.0 \pm 1.22)$ had significantly more tillers than those in group NE (5.0 \pm 0.86$)$ (Table S2.4).

\subsubsection{Number of fruits}

From $61^{\text {st }}$ day to $75^{\text {th }}$ day, most of the wheat plants entered the booting and heading stages and only a few fruits appeared (Figure 2.1e, Figure 2.1f). The number of fruits per plant then rapidly increased from $75^{\text {th }}$ day to $89^{\text {th }}$ day and it slowly increased between $89^{\text {th }}$ day and $117^{\text {th }}$ day (Figure 2.1e, Figure 2.1f). From $117^{\text {th }}$ day on, the number of fruits per plant became stable and then the final ripening stage began (Figure 2.1e, Figure 2.1f). At the 4 months harvest, wheat plants in group WE had borne a similar number of fruits; in group $\mathrm{NE}$, wheat plants in the treatment Bio-Ma $(2.8 \pm 0.16)$ bore significantly less fruits than those in treatments LDPE-Ma $(3.4 \pm 0.30)$ and LDPE-Mi $(3.6 \pm 0.30)$, but none of them showed a significant difference from the Control $(3.7 \pm 0.76)$ or Bio-Mi $(2.9 \pm 0.45)$ (Table S2.3). On average, wheat plants in group NE $(3.3 \pm 0.55)$ bore significantly less fruits than those in group WE (4.0 \pm 0.68$)$ (Table S2.4). 

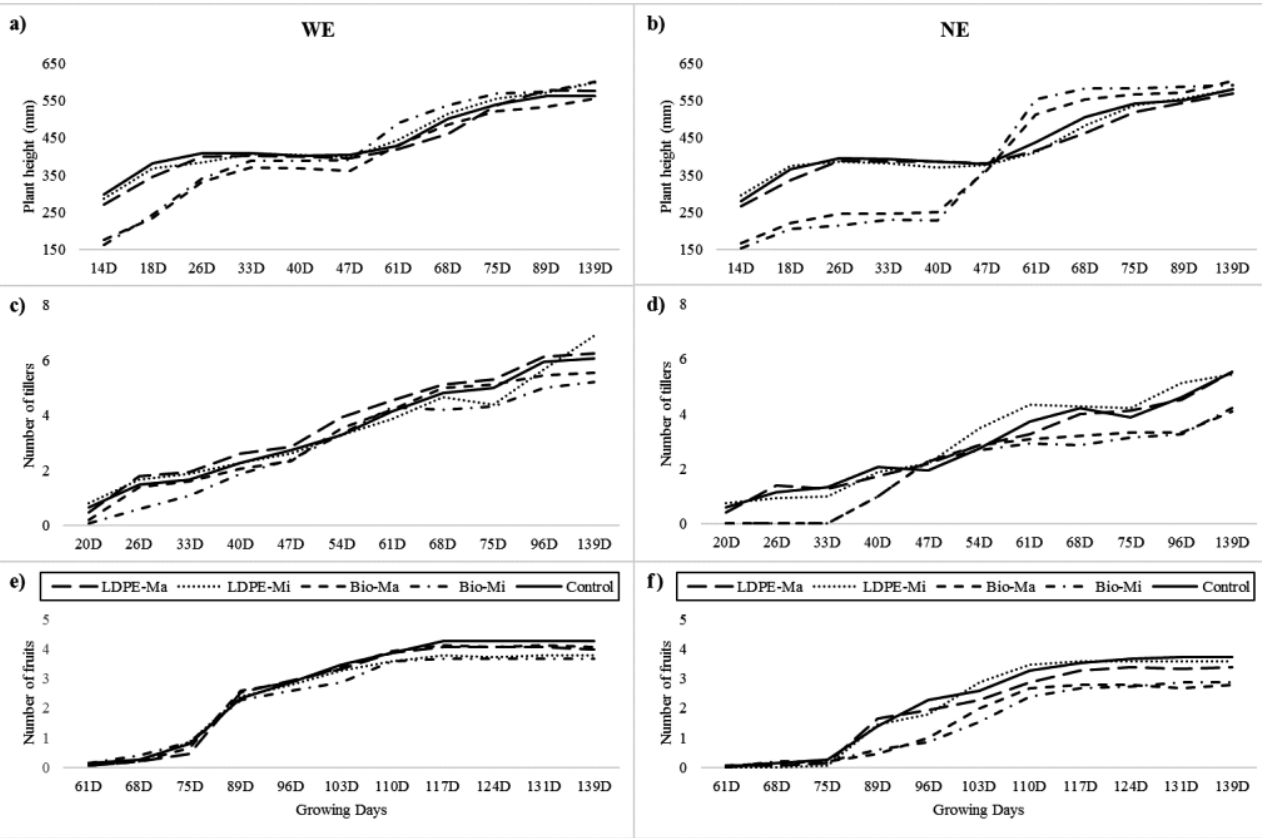

Figure 2.1 Plant height, number of tillers and fruits in the process of wheat growth; a) plant height for treatments in group with earthworms; b) plant height for treatments in group no earthworms; c) number of tillers for treatments in group with earthworms; d) number of tillers for treatments in group no earthworms; e) number of fruits for treatments in group with earthworms; $f$ ) number of fruits for treatments in group no earthworms.

\subsubsection{Plant biomass and its allocation: effects of plastic residues, earthworms and their interactions}

\subsubsection{Shoot biomass and root biomass}

At the 2 months harvest, both in group WE and NE, shoot biomass was significantly lower in treatments Bio-Ma and Bio-Mi and there was no significant difference in treatments LDPE-Ma and LDPE-Mi compared to the Control (Figure 2.2a). At the 4 months harvest, in group WE, only wheat plants in treatment Bio-Mi had significantly lower shoot biomass than in the Control. In group NE, only the treatment Bio-Ma had significantly lower shoot biomass than LDPE-Mi (Figure 2.2b).The presence of earthworms significantly enhanced the shoot biomass by $19.9 \%$ at the 2 months harvest and $18.6 \%$ at the 4 months harvest (Table S2.4).

There was no significant difference in root biomass in group WE relative to the Control in either harvest, but in group NE, with addition of plastic residues, all the wheat plants had 
significantly lower root biomass than the Control at the 2 months harvest (Figure 2.2c, Figure $2.2 \mathrm{~d}$ ). The presence of earthworms significantly increased root biomass by $22.3 \%$ at the 2 months harvest and the root biomass in group WE $(2.082 \pm 0.494 \mathrm{~g})$ was similar to group NE (1.921 $\pm 0.476 \mathrm{~g})$ at the 4 months harvest (Table S2.4).

a)
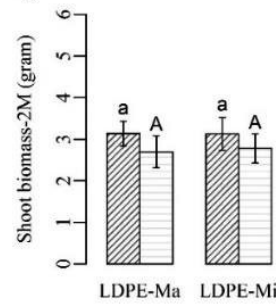

c)

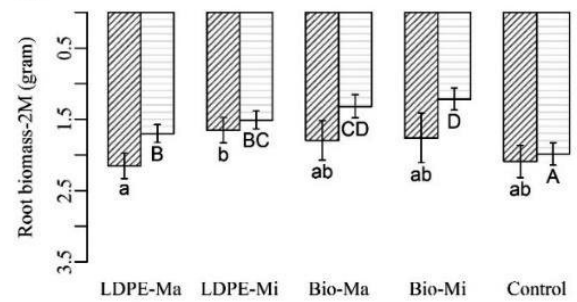

b)

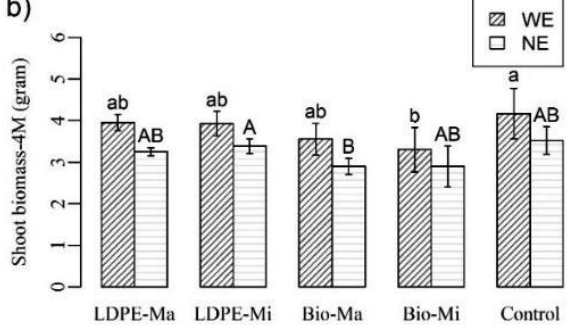

d)
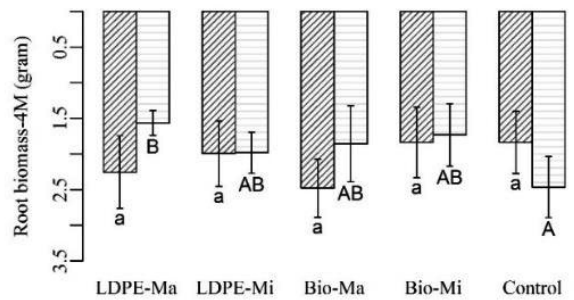

Figure 2.2 Shoot biomass and Root biomass (mean \pm standard deviation) of all the treatments at 2 months and 4 months harvests; a) shoot biomass for all the treatments at 2 months harvest; $b$ ) shoot biomass for all treatments at 4 months harvest; c) root biomass for all treatments at 2 months harvest; $d$ ) root biomass for all treatments at 4 months harvest. (2M: 2 months harvest, 4M: 4 months harvest, $p<0.05$ ).

\subsubsection{Total biomass, fruit biomass and root/shoot ratio}

Total plant biomass was significantly reduced by the addition of plastic residues and the BioMi treatment in group NE had the lowest biomass value at both the 2 months harvest $(2.633$ $\pm 0.220 \mathrm{~g}$ ) and the 4 months harvest (7.478 $\pm 1.015 \mathrm{~g})$ (Table S2.5, Table S2.6). For the WE group, the plant total biomass in treatments Bio-Ma (4.135 $\pm 0.382 \mathrm{~g})$ and Bio-Mi (3.710 \pm $0.671 \mathrm{~g}$ ) were significantly lower than the Control $(5.593 \pm 0.471 \mathrm{~g})$ at the 2 months harvest but no significant difference was found among treatments at the 4 months harvest (Table S2.5, Table S2.6). The presence of earthworms significantly increased the total biomass for wheat by $20.9 \%$ at the 2 months harvest and $26.2 \%$ at the 4 months harvest (Table S2.4).

Fruit biomass in Bio-Ma and Bio-Mi were significantly lower than in the Control in group NE and the addition of plastic residues exerted no significant effect on fruit biomass in group WE (Table S2.6). Wheats in group WE $(4.857 \pm 0.459 \mathrm{~g})$ had significantly higher fruit biomass than group NE (3.383 $\pm 0.401 \mathrm{~g})$ (Table S2.4). 
At the 2 months harvest, wheat plants in Bio-Mi had the highest root/shoot ratio (R/S) $(0.93$ \pm 0.172 in WE and $0.87 \pm 0.127$ in NE) and wheat plants in LDPE-Mi had the lowest R/S (0.54 \pm 0.083 in WE and $0.55 \pm 0.079$ in NE) (Table S2.5). At the 4 months harvest, wheat plants in Bio-Ma had the highest $\mathrm{R} / \mathrm{S}(0.30 \pm 0.057)$ and wheat plants in the Control had the lowest $\mathrm{R} / \mathrm{S}(0.20 \pm 0.043)$ in group WE, but no significant difference was found among treatments in group NE (Table S2.6). The presence of earthworms had no significant effect on $R / S$ at the 2 months harvest but significantly decreased R/S (0.24 \pm 0.060 in WE and $0.29 \pm 0.067$ in NE) at the 4 months harvest (Table S2.4).

2.3.2.3 Type and size of plastic residues, earthworms and their interactive effects on wheat biomass

The type of plastic had significant effects on almost all of the biomasses parameters except root biomass and R/S at the 4 months harvest and it explained $63.88 \%, 52.07 \%$ and $47.77 \%$ of the variability in the shoot biomass, total biomass and $R / S$ at the 2 months harvest, respectively (Table 2.2). The size of plastic residues only had significant effects on the root biomass and total biomass at the 2 months harvest which explained $9.55 \%$ and $4.14 \%$ of the variability found (Table 2.2). The presence of earthworms had significant effects on plant biomasses but not on R/S at both the 2 months and the 4 months harvest (Table 2.2). Root biomass and R/S at the 2 months harvest were significantly affected by the Type $\times$ Size interaction and root biomass and $R / S$ at the 4 months harvest were significantly affected by the Size $\times$ EW interaction. Neither Type $\times$ EW nor Type $\times$ Size $\times$ EW interactions had significant effects on the plant biomasses parameters. For root biomass and R/S at the 4 months harvest, the three factors and their interactions explained less than half of the variability according to the residual contributions to these parameters.

Table $2.2 p$-value and contribution of independent factors (type of plastics, size of plastic residues and earthworms) and their interactions to plant biomass parameters studied by three way ANOVA.

\begin{tabular}{|c|c|c|c|c|c|c|c|c|c|c|c|c|c|c|c|}
\hline & \multicolumn{2}{|l|}{ Type } & \multicolumn{2}{|l|}{ Size } & \multicolumn{2}{|l|}{ EW } & \multicolumn{2}{|c|}{ Type * Size } & \multicolumn{2}{|c|}{ Type * EW } & \multicolumn{2}{|c|}{ Size * EW } & \multicolumn{2}{|c|}{ Type * Size * EW } & \multirow{2}{*}{$\frac{\text { Residual }}{\%}$} \\
\hline & $\%$ & Sig. & $\%$ & Sig. & $\%$ & Sig. & $\%$ & Sig. & $\%$ & Sig. & $\%$ & Sig. & $\%$ & Sig. & \\
\hline SB2M & 63.88 & $<0.001$ & 1.44 & ns & 12.85 & $<0.001$ & 2.14 & ns & 0.41 & ns & 0.09 & ns & 0.00 & ns & 19.19 \\
\hline RB2M & 12.10 & 0.001 & 9.55 & 0.004 & 37.43 & $<0.001$ & 4.45 & 0.04 & 2.60 & ns & 0.81 & ns & 2.00 & ns & 31.06 \\
\hline TB2M & 52.07 & $<0.001$ & 4.14 & 0.01 & 24.10 & $<0.001$ & 0.10 & ns & 1.14 & ns & 0.31 & ns & 0.29 & ns & 17.84 \\
\hline RS2M & 47.77 & $<0.001$ & 0.00 & ns & 0.56 & ns & 14.47 & 0.001 & 0.09 & ns & 0.00 & ns & 0.83 & ns & 36.18 \\
\hline SB4M & 23.59 & $<0.001$ & 0.16 & ns & 35.90 & $<0.001$ & 0.86 & ns & 0.25 & ns & 1.12 & ns & 0.06 & ns & 38.06 \\
\hline FB & 3.93 & 0.01 & 0.04 & ns & 76.82 & $<0.001$ & 0.84 & ns & 0.87 & ns & 0.61 & ns & 0.32 & ns & 16.57 \\
\hline RB4M & 0.08 & ns & 2.64 & ns & 14.48 & 0.013 & 5.98 & ns & 0.01 & ns & 9.95 & 0.036 & 0.19 & ns & 66.67 \\
\hline TB4M & 6.50 & 0.008 & 0.25 & ns & 64.05 & $<0.001$ & 2.41 & ns & 0.16 & ns & 0.71 & ns & 0.14 & ns & 25.78 \\
\hline RS4M & 7.36 & ns & 1.84 & ns & 4.91 & ns & 3.68 & ns & 0.61 & ns & 9.82 & 0.045 & 0.00 & ns & 71.17 \\
\hline
\end{tabular}

Type: type of plastics; Size: size of plastic residues; EW: earthworms; SB2M: shoot biomass at 2 months harvest; RB2M: root biomass at 2 months harvest; TB2M: total biomass at 2 months harvest; RS2M: root/shoot ratio at 2 months harvest; SB4M: shoot biomass at 4 months harvest; RB4M: root biomass at 4 months harvest; TB4M: total biomass at 4 months harvest; RS4M: root/shoot ratio at 4 months harvest; $\mathrm{FB}$ : fruit biomass. 
2.3.3 Parameters of wheat vegetative growth: leaf area, number of leaves, relative chlorophyll content and stem diameter

In group NE, plants in treatments Bio-Ma and Bio-Mi had significantly smaller leaf areas than the Control. The addition of LDPE residues had no significant effects on leaf area compared to the Control (Figure 2.3a). In group WE, plants in treatments LDPE-Ma $\left(240.6 \pm 33.96 \mathrm{~cm}^{2}\right)$ had the largest leaf area, followed by the Control $\left(196.7 \pm 25.32 \mathrm{~cm}^{2}\right)=$ LDPE-Mi $(190.2 \pm$ $\left.13.30 \mathrm{~cm}^{2}\right)>$ Bio-Ma $\left(147.1 \pm 13.88 \mathrm{~cm}^{2}\right)=$ Bio-Mi $\left(127.7 \pm 9.56 \mathrm{~cm}^{2}\right)($ Table S2.7). The presence of earthworms significantly increased the leaf area of the wheat plants in group WE $\left(180.5 \pm 44.89 \mathrm{~cm}^{2}\right)$ compared to group NE $\left(153.4 \pm 35.11 \mathrm{~cm}^{2}\right)$ (Table S2.4).

In both groups WE and NE, plants in treatments Bio-Ma and Bio-Mi had significantly fewer leaves compared to the Control and plants in LDPE-Ma and LDPE-Mi had a similar number of leaves as the Control (Figure 2.3b). Wheat plants in group WE $(20.2 \pm 4.28)$ had significantly more leaves than those in group NE (17.0 \pm 3.29$)$ (Table S2.4).

Plants did not differ significantly in their relative chlorophyll content among treatments in both groups, but group WE $(46.2 \pm 2.75)$ had a significantly higher value than group NE $(42.3$ \pm 2.93 ) (Figure 2.3c, Table S2.4).

a)

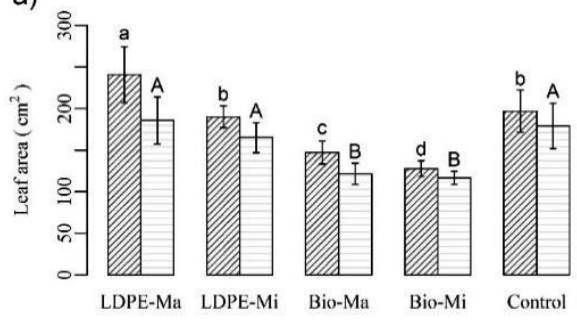

c)
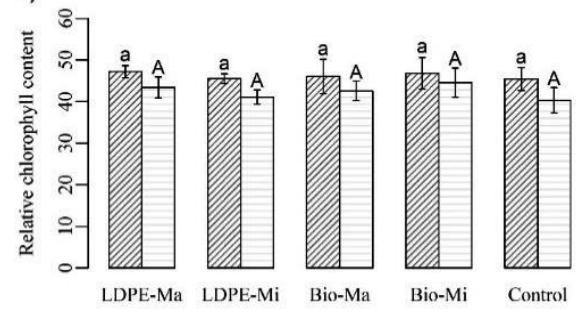

b)

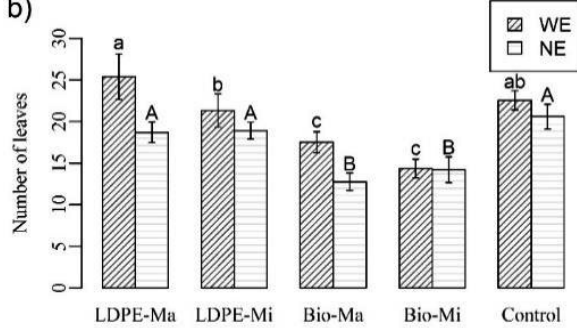

d)
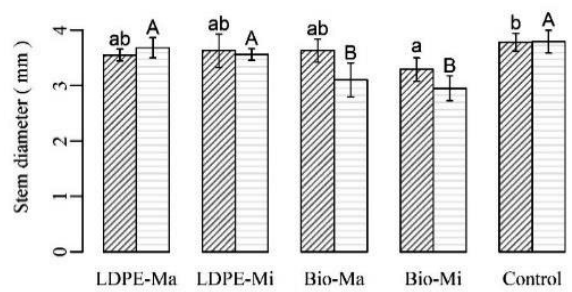

Figure 2.3 Leaf area, number of leaves, relative chlorophyll content and stem diameter (mean \pm standard deviation) for all treatments; a) leaf area for all treatments; $b$ ) number of leaves for all treatments; $c$ ) relative chlorophyll content for all treatments; d) stem diameter for all treatments, $p<0.05$. 
Wheat plants in Bio-Mi had the thinnest stems and the plants in LDPE-Ma and LDPE-Mi had a similar stem diameter as the Control in both groups (Figure 2.3d). Wheat plants in Bio-Ma had comparable stem diameters to the Control in group WE and significantly thinner stems than plants in the Control in group NE (Figure 2.3d). Stem diameters of wheat plants in group WE $(3.58 \pm 0.251 \mathrm{~mm})$ and NE $(3.42 \pm 0.390 \mathrm{~mm})$ showed no significant difference (Table S2.4).

\subsubsection{The relationships of treatment factors with wheat growth parameters}

The relationships among the measured parameters of wheat growth and treatment factors (plastic residues: LDPE-Ma, LDPE-Mi, Bio-Ma, Bio-Mi and Control, earthworms: WE and NE) is described in an ordination diagram (Figure 2.4). The Monte Carlo permutation tests indicated significant differences among all canonical axes $(p<0.01)$ and the first axis explained $54.91 \%$ of the variation in the parameter-factor relationships (Table S2.8). The groups WE and NE are completely opposed in the factorial plan and factor WE stand in the positive direction of fruit biomass, relative chlorophyll content, total biomass and other parameters. For treatment factors of plastic residues, Bio-Ma and Bio-Mi clustered together, while LDPE-Ma, LDPE-Mi and the Control clustered together in the opposite direction. Plant height and root/shoot ratio clustered together in the opposite direction of other plant growth parameters.

\subsection{Discussion}

Looking back at the original hypotheses, several key findings emerged from this study: 1) type of plastic mulch films has strong effects on wheat growth with the biodegradable film showing stronger negative effects compared to polyethylene; 2 ) size of plastic residues has weak effects on wheat growth with microplastics showing more negative effects than macroplastics; 3 ) presence / absence of earthworms has strong effects on plant growth and the presence of earthworms positively altered wheat growth status and chiefly alleviated the impairments made by plastic residues; 4 ) neither the interactions between two factors nor the interaction among three factors is notable in this experiment. 


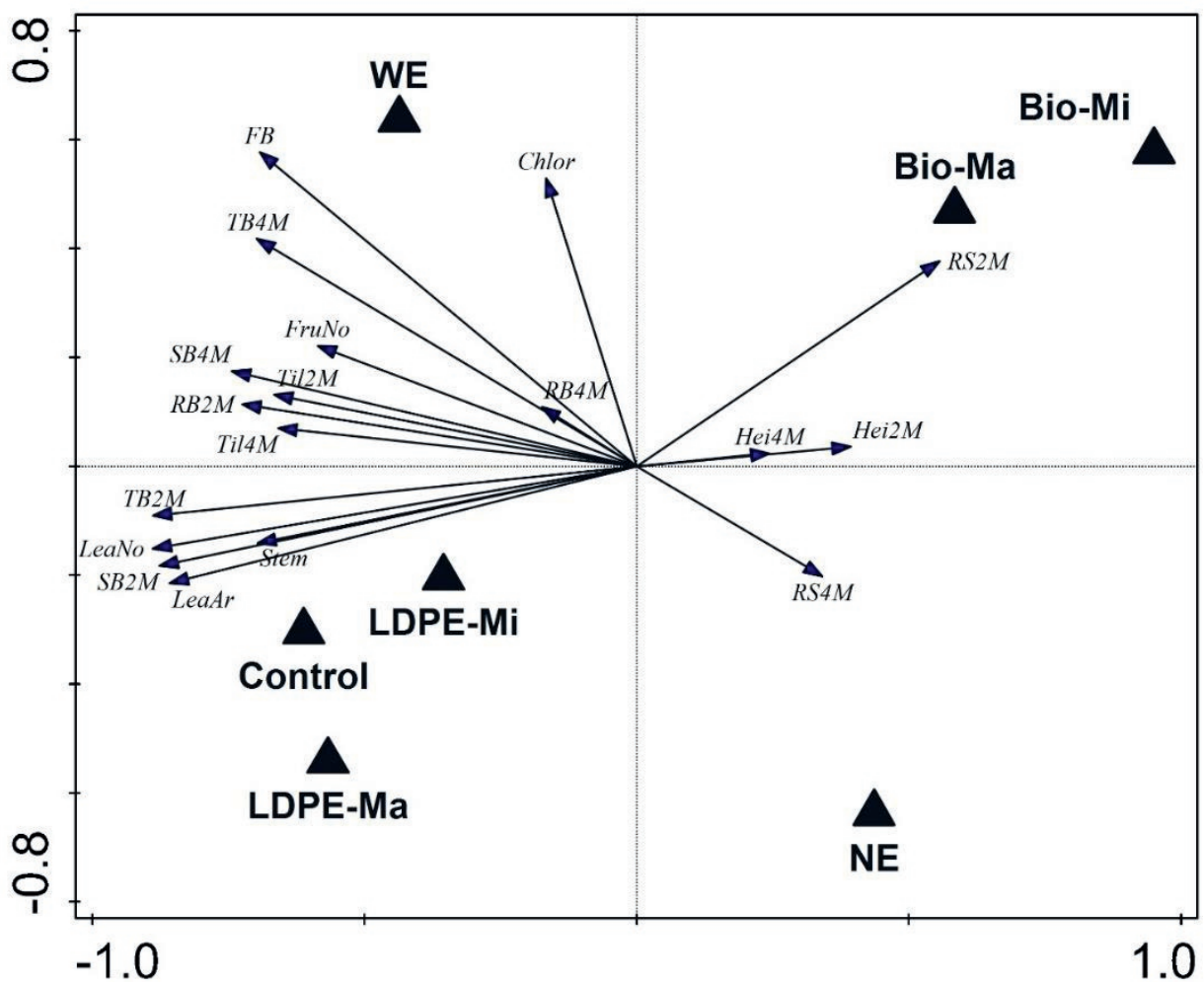

Figure 2.4 Redundancy analysis ordination diagram of plant growth parameters with treatment factors (Hei2M: plant height at 2 months harvest; Hei4M: plant height at 4 months harvest; Til2M: number of tillers at 2 months harvest; Til4M: number of tillers at 4 months harvest; FruNo: number of fruits; SB2M: shoot biomass at 2 months harvest; RB2M: root biomass at 2 months harvest; TB2M: total biomass at 2 months harvest; RS2M: root/shoot ratio at 2 months harvest; SB4M: shoot biomass at 4 months harvest; RB 4M: root biomass at 4 months harvest; TB4M: total biomass at 4 months harvest; RS4M: root/shoot ratio at 4 months harvest; FB: fruit biomass; LeaAr: leaf area; LeaNo: number of leaves; Chlor: relative chlorophyll content; Stem: stem diameter).

In this study, we only used one type of starch-based biodegradable plastic mulch film and one low density polyethylene film. This specific type of biodegradable plastic mulch film residue showed more severe effects on wheat growth than the polyethylene film in both macro and micro sizes. This result is admissible when the composition of this biodegradable film (37.1\% Pullulan, 44.6\% PET and 18.3\% PBT) has been taken into consideration. Even though deeper investigations should be conducted in order to study the underlying mechanisms, the plausible explanation that PET and PBT may have more negative effects on soil-plant system than LDPE could be drawn based on this study as well as other studies (Muroi et al., 2016; O'Hara et al., 2013; Parvathy et al., 2014). Even this type of biodegradable plastic should not be used to represent all the biodegradable plastic mulch 
films, it is merely one of the widely used types currently on the market (van den Oever et al., 2017). Despite all of the doubts about the cogency and rigor of these films, great expectations have been placed on these biodegradable plastic mulch films with the aim of solving plastic pollution in agricultural land (Kasirajan and Ngouajio, 2012; Moreno et al., 2017; Ren, 2003; Sintim and Flury, 2017; Yang et al., 2014b). Based on the results of this study, we should not be too optimistic about using biodegradable plastic mulch films in agriculture without first conducting in-depth studies. Also, with the current boom in the bioplastics market, newly developed biodegradable plastics have been applied as agricultural mulch films. Hence, the different types of synthetic polymers and bioplastics should be closely studied for their occurrence, fate and ecological effects in the soil and for their effects on the soil-plant system.

According to this study, macro- or micro- sizes of plastic residues showed slightly differing effects on wheat growth and microplastics showed more negative effects than macroplastics. So far, most research concerning LDPE mulch film residues have focused on larger sizes (length $>2 \mathrm{~cm}$ ) (Zhang et al., 2016). Dong et. al (2015) applied a mixture of three size classes of film residues $\left(0-25 \mathrm{~cm}^{2}: 25-100 \mathrm{~cm}^{2}: 100-200 \mathrm{~cm}^{2}=1: 1: 1\right)$ onto soil with a range of densities from 0 to $2000 \mathrm{~kg} \mathrm{hm}-2$ (representative for field after 141 years of mulching) and they found that cumulative residue could decrease cotton yield after 121 years of mulching (Dong et al., 2015). Tao et.al (2012) conducted a pot experiment using horse bean mixed with three molecular weights $(2000,5000$ and 10000$)$ of LDPE powder at different cumulants $(0.0028 \%, 0.028 \%, 0.14 \%$ and $0.28 \%$ representing for $1,10,50$ and 100 years). They found that accumulated LDPE powder may have the potential to improve the soil microenvironment (Tao et al., 2012). Zhang et. al (2015) had similar results from a field experiment using corn and found that large amounts of accumulated LDPE residues (with the maximum content of $0.35 \%$ ) may improve soil fertility (Zhang et al., 2015). Looking back at our results, with $1 \%$ LDPE residues in the soil, the growth of wheat plants was negatively affected. Thus, in order to have a comprehensive understanding of plastic residues in the soil-plant system, further studies need to examine a range of different sizes (from $5 \mathrm{~mm}$ to $5 \mathrm{~cm}$ ) and different concentration (from $0.2 \%$ to $1 \%$ ) of plastic residue. For future in-depth research, a range of different microplastics contents could be applied to soil to scrutinize the threshold values of no effect, slight effect and severe effect and lay foundations for the ecological risk assessment of microplastics in the terrestrial ecosystem.

From this study, it is clear that the presence of earthworms positively altered wheat growth status and chiefly alleviated the impairments caused by plastic residues. Compared to other relevant studies, the mortality of earthworms is relatively high in this study (Cao et al., 2017; Huerta Lwanga et al., 2016, 2017a), which may indicate that it is not wise to study both plants and fauna in one experiment. Considering the limited space in the pot, the growing 
roots and earthworms may have competed with each other which makes it very difficult to study this interaction mechanism profoundly (Blouin et al., 2013; van Groenigen et al., 2014). Still, the results gave some hints to the effects of plastic residues on earthworms in the soil-plant system. Even though earthworms in the treatments with biodegradable plastic residues (Bio-Ma and Bio-Mi) lost more weight than those in the treatments with low density polyethylene residues (LDPE-Ma and LDPE-Mi), newly born earthworms were only found in Bio-Ma and Bio-Mi and the Control. We could speculate that this biodegradable plastic had more effects on the growth of earthworms, while LDPE have more effects on their breeding. Based on this experiment and other relevant studies, we suggest that deliberate equipment should be developed in order to learn more about the interactions between plants and soil fauna in the soil-plant system (Huerta Lwanga et al., 2016, 2017a). In addition, studying different species of earthworms in the soil-plant system is needed in order to learn more about soil organisms interacting with plastic residues.

For the doubts at present, the underlying reason why the wheat growth was effected has not been traced. One possible explanation could be that the micro- and macro- plastic residues in the soil altered the soil properties. In addition, microorganisms, rhizosphere bacteria in particular, play an important role in plant growth (Kaushal and Wani, 2016). Therefore, an investigation into the structure and the diversity of the microbial community may shed light on this as well.

In the long term, the microplastics currently found in the soil have a large chance of forming nanoplastics (Huerta Lwanga et al., 2018; Lambert and Wagner, 2016a). Taking the nanoplastics found in aquatic ecosystem as references, nanoplastics have been shown to have an effect on the feeding behavior, growth, and reproduction of several aquatic organisms (Besseling et al., 2014; Wegner et al., 2012) as well as effects on the growth and/or photosynthesis of algae (Bhattacharya et al., 2010; Sjollema et al., 2016). With comparable properties to other nanoparticles, the nanoplastics may be transferred and accumulate in plants which have the risk of being ingested by humans (Larue et al., 2012; Rico et al., 2011). Hence, studying microplastics in the agricultural soil is of crucial importance to the ecological environment and human health.

Overall, our study revealed that macro- and micro- plastic residues of polyethylene and biodegradable mulch films have negative effects on both above-ground and below-ground parts of wheat and affect both vegetative and reproductive growth. Undoubtedly, more research is urgently needed in order to fully understand the effects of microplastics on the soil-plant system and the agroecosystem. 


\section{Acknowledgments}

Funding for this research came from the Fundamental Research Funds for the Central Universities (Z109021717), the State Key Laboratory of Soil Erosion and Dryland Farming on the Loess Plateau, China (A314021402-1702) and the EU Horizon 2020 project (ISQAPER: 635750). We are thankful for the financial support from the China Scholarship Council (CSC). Many thanks to Rinie Verwoert, Taede Stoker and Gerrit Stunnenberg for help cultivating plants in the climate chamber at Unifarm, WUR. Thanks to Harm Gooren and Piet Peters for help in transporting materials and setting up this experiment. Thanks to Bert Meurs for sharing the chlorophyll meter SPAD 502 plus. Thanks to Coleen Carranza for helping draw the graphs. Yueling Qi would like to thank Sanna Kosh for the company and support during the trial stage of this study. This is NIOO-KNAW publication number 6554 . 


\section{Supplementary Material}

BemestingsMonitor 0 BODEM

bunker overkant

Uw kdantnummer: 2211378

Unifarm De Haaff

Vollegrond

Bornsestg 48

6708 PE WAGENINGEN

\section{BLGG}

BLGG AgroXpertus

NL - 6700 AD Wageningen

T monstemame: Herman Dorrestelln: 065200211

$T$ xiantenservice: +31 (0) 838761010

E klantenservorgolgg.agroxpertus.n

blgg.agroxpertus.

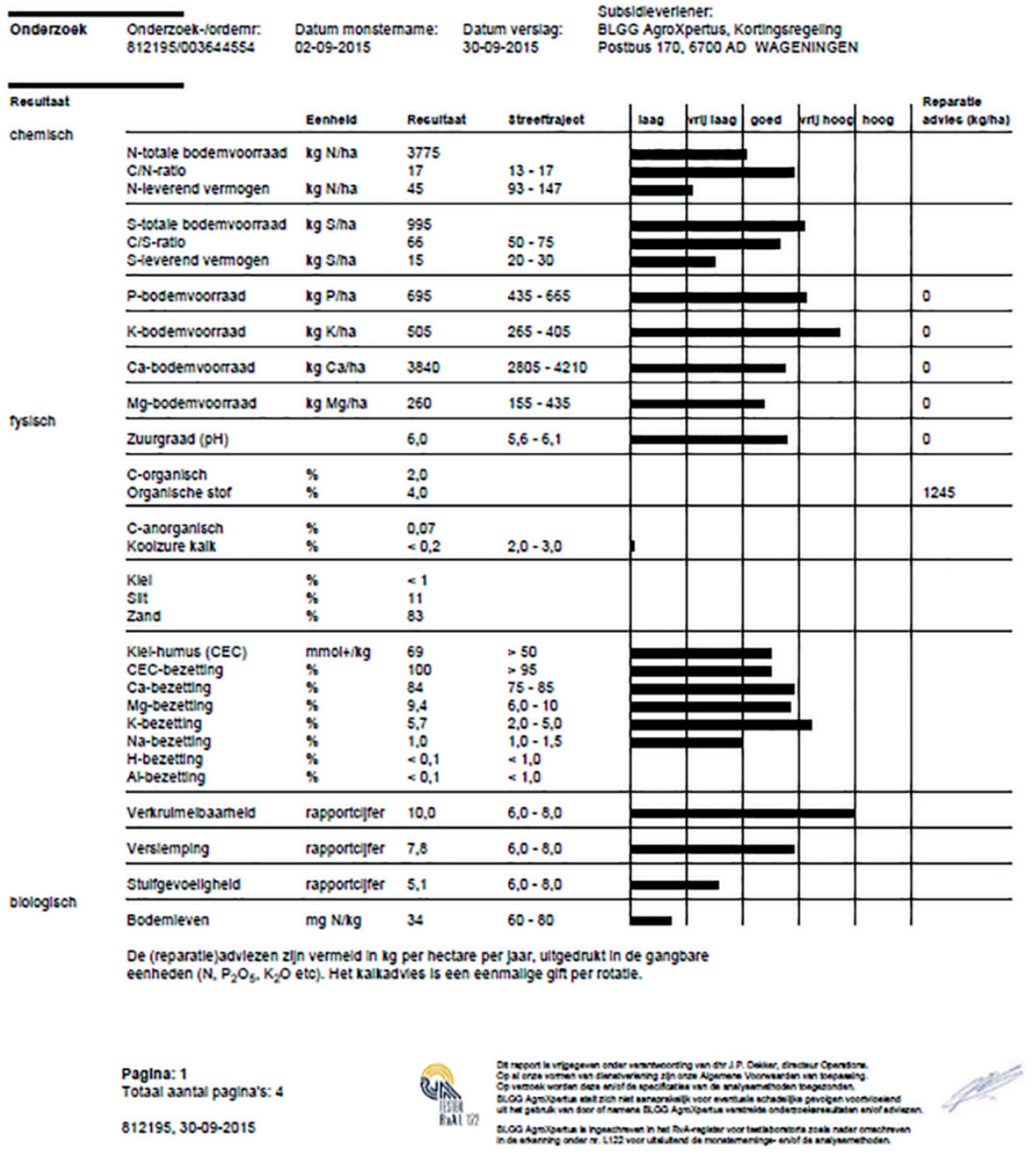

Figure S2.1 Detailed information about soil used in the experiment. 


\begin{tabular}{|c|c|c|c|c|c|c|c|c|}
\hline EC & 2. & $1 \mathrm{pH}$ & 5.5 & & Toma & stan & & \\
\hline $\mathrm{NH4}$ & & & & & & & & \\
\hline & 1,2 & & & & & & & \\
\hline & & & & & & & & \\
\hline K & 7,2 & & & Calsal & & 85,4 & $\mathrm{ml}$ & \\
\hline & & & & Amnitra & & 15,0 & $\mathrm{ml}$ & \\
\hline $\mathrm{Na}$ & & & & Salpete & rzuur & 43,0 & $\mathrm{ml}$ & \\
\hline & & & & Sulfakal & & 36,0 & $\mathrm{ml}$ & \\
\hline $\mathrm{Ca}$ & 4,0 & & & Fosforzl & uur & 11,8 & $\mathrm{ml}$ & \\
\hline & & & & Bascal & & 68,2 & $\mathrm{ml}$ & \\
\hline $\mathrm{Mg}$ & 1,82 & & & Magnes & & 84,6 & $\mathrm{ml}$ & \\
\hline & & & & & & & & \\
\hline NO3 & 12,4 & & & & & & & \\
\hline & & & & Macro & eleme & en in & $\mathrm{mol}$ & \\
\hline $\mathrm{Cl}$ & & & & Micro e & emen & en in 1 & cron & \\
\hline & & & & & & & & \\
\hline SO4 & 3,32 & & & & & & & \\
\hline & & & & & & & & \\
\hline $\mathrm{HCO} 3$ & & & & & & & & \\
\hline & & & & & & & & \\
\hline$P$ & 1,0 & & & & & & & \\
\hline & & & & & & & & \\
\hline $\mathrm{Si}$ & & & & & & & & \\
\hline $\mathrm{Fe}$ & 35,0 & & & & & & & \\
\hline $\mathrm{Mn}$ & 8,0 & & & & & & & \\
\hline $\mathrm{Zn}$ & 5,0 & & & & & & & \\
\hline$B$ & 20,0 & & & & & & & \\
\hline $\mathrm{Cu}$ & 0,5 & & & & & & & \\
\hline Mo & 0,5 & & & & & & & \\
\hline & & & & & & & & \\
\hline
\end{tabular}

Figure S2.2 Reagents and concentrations of the nutritive solution. 
Table S2.1 Germination rates of wheat seeds in all treatments

\begin{tabular}{llllllll}
\hline & & $4 \mathrm{D}$ & $5 \mathrm{D}$ & $6 \mathrm{D}$ & $7 \mathrm{D}$ & $8 \mathrm{D}$ & $9 \mathrm{D}$ \\
\hline \multirow{6}{*}{ WE } & LDPE-Ma & 0.96 & 0.96 & 0.96 & 0.96 & 0.96 & 0.96 \\
& LDPE-Mi & 0.88 & 0.92 & 0.92 & 0.92 & 0.92 & 0.92 \\
& Bio-Ma & 0.88 & 0.88 & 0.88 & 0.88 & 0.88 & 0.88 \\
& Bio-Mi & 0.92 & 0.92 & 0.92 & 0.92 & 0.92 & 0.92 \\
& Control & 0.72 & 0.8 & 0.8 & 0.8 & 0.8 & 0.8 \\
& LDPE-Ma & 0.76 & 0.84 & 0.84 & 0.84 & 0.84 & 0.84 \\
\multirow{4}{*}{ NE } & LDPE-Mi & 0.88 & 0.92 & 0.92 & 0.96 & 0.96 & 0.96 \\
& Bio-Ma & 0.92 & 0.96 & 0.96 & 0.96 & 0.96 & 0.96 \\
& Bio-Mi & 0.96 & 0.96 & 0.96 & 0.96 & 0.96 & 0.96 \\
& Control & 0.8 & 0.8 & 0.8 & 0.8 & 0.8 & 0.8 \\
\hline
\end{tabular}

Table S2.2 Biomass and mortality of earthworms at 4 months harvest.

\begin{tabular}{|c|c|c|c|c|c|c|}
\hline & \multicolumn{2}{|l|}{ Initial } & \multicolumn{2}{|l|}{ Final } & \multicolumn{2}{|c|}{ Comparison } \\
\hline & $\begin{array}{l}\text { No. per } \\
\text { treatment }\end{array}$ & $\begin{array}{l}\text { Biomass per pot } \\
\text { (g) }\end{array}$ & $\begin{array}{l}\text { No. per } \\
\text { treatment } \\
\text { (adult + new } \\
\text { born) }\end{array}$ & $\begin{array}{l}\text { Biomass } \\
\text { per pot } \\
\text { (g) }\end{array}$ & Mortality & $\begin{array}{l}\text { Biomass } \\
\text { loss per } \\
\text { pot }(\mathrm{g})\end{array}$ \\
\hline LDPE-Ma & 10 & $7.36 \pm 1.36$ & $7+0$ & $3.58 \pm 2.65$ & $30 \%$ & $2.80 \pm 1.35$ \\
\hline LDPE-Mi & 10 & $8.11 \pm 1.09$ & $6+0$ & $3.72 \pm 2.58$ & $40 \%$ & $3.70 \pm 1.30$ \\
\hline Bio-Ma & 10 & $7.63 \pm 0.81$ & $5+3$ & $3.12 \pm 2.83$ & $50 \%$ & $3.81 \pm 2.20$ \\
\hline Bio-Mi & 10 & $7.61 \pm 1.27$ & $6+3$ & $3.68 \pm 2.60$ & $40 \%$ & $5.21 \pm 1.52$ \\
\hline Control & 10 & $7.51 \pm 1.52$ & $9+2$ & $4.82 \pm 1.61$ & $10 \%$ & $3.39 \pm 1.78$ \\
\hline Sum & & $7.25 \pm 1.01$ & & $3.47 \pm 1.47$ & $34 \%$ & $2.47 \pm 3.78$ \\
\hline
\end{tabular}




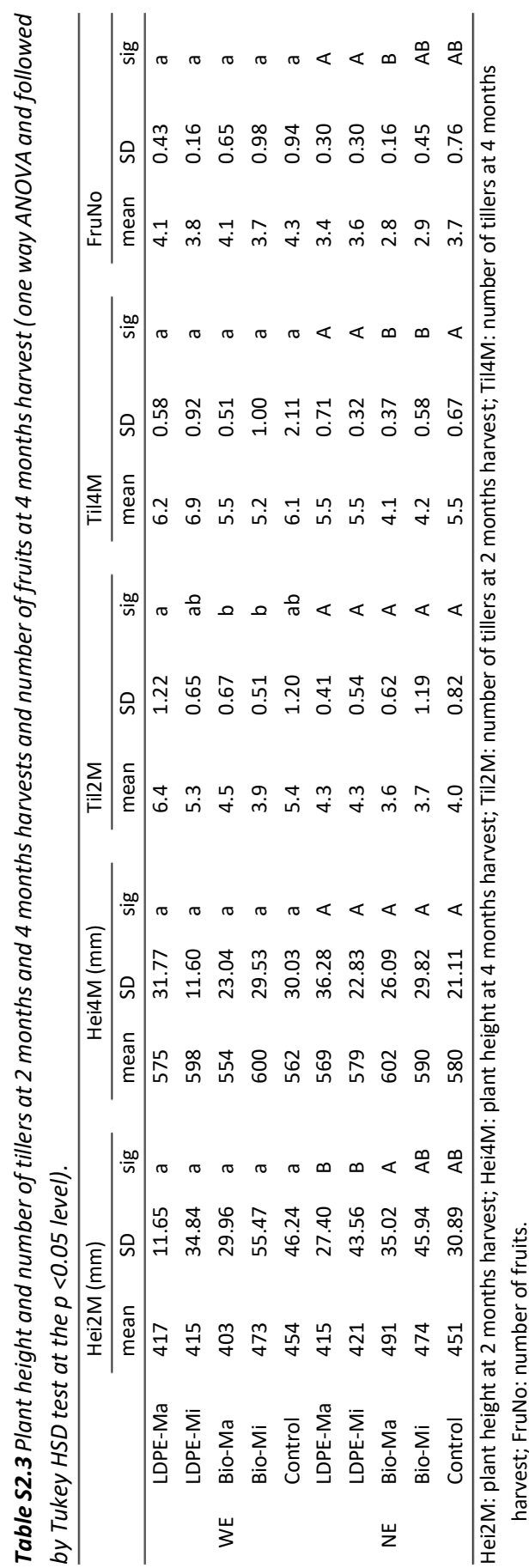




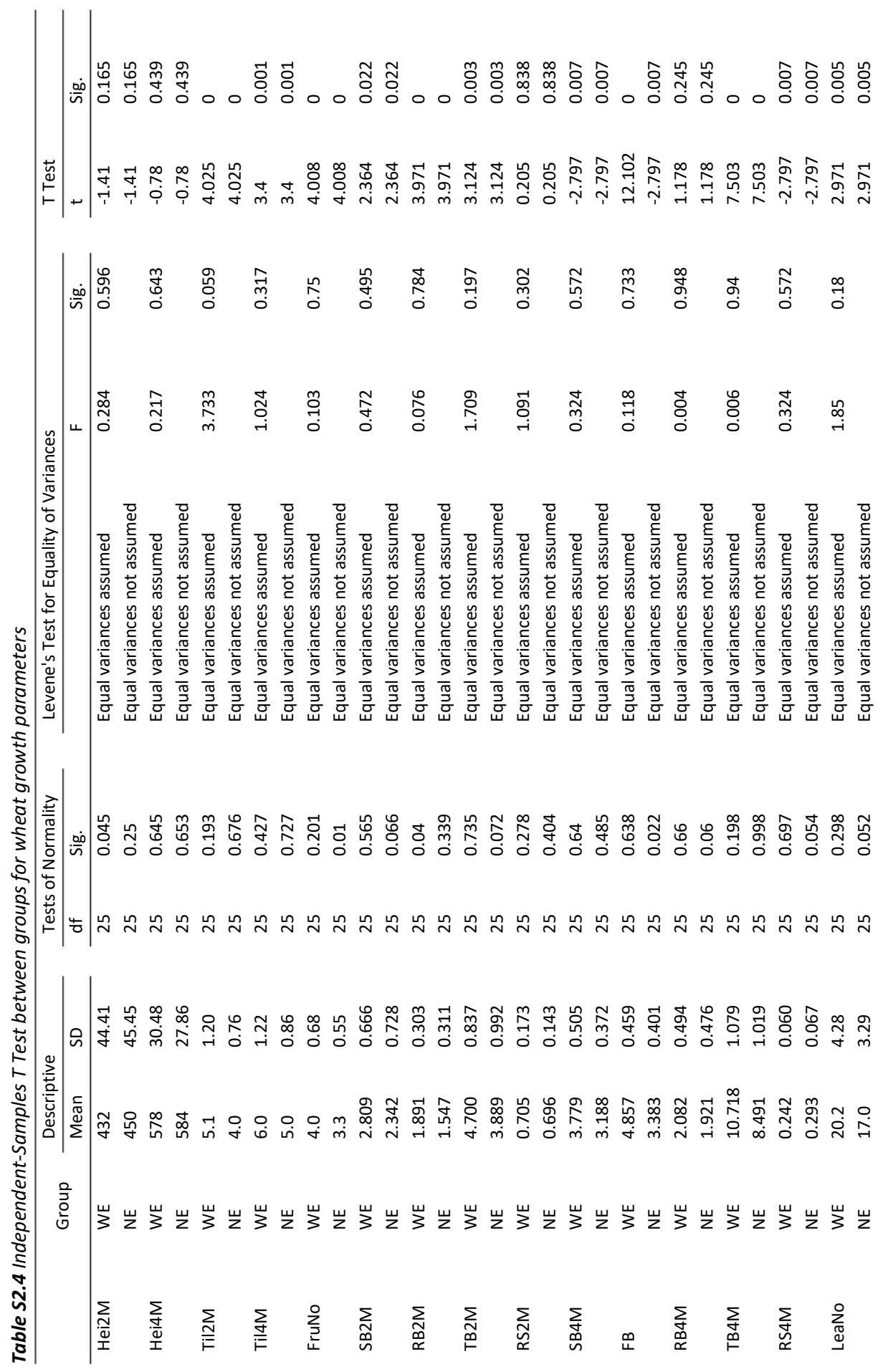



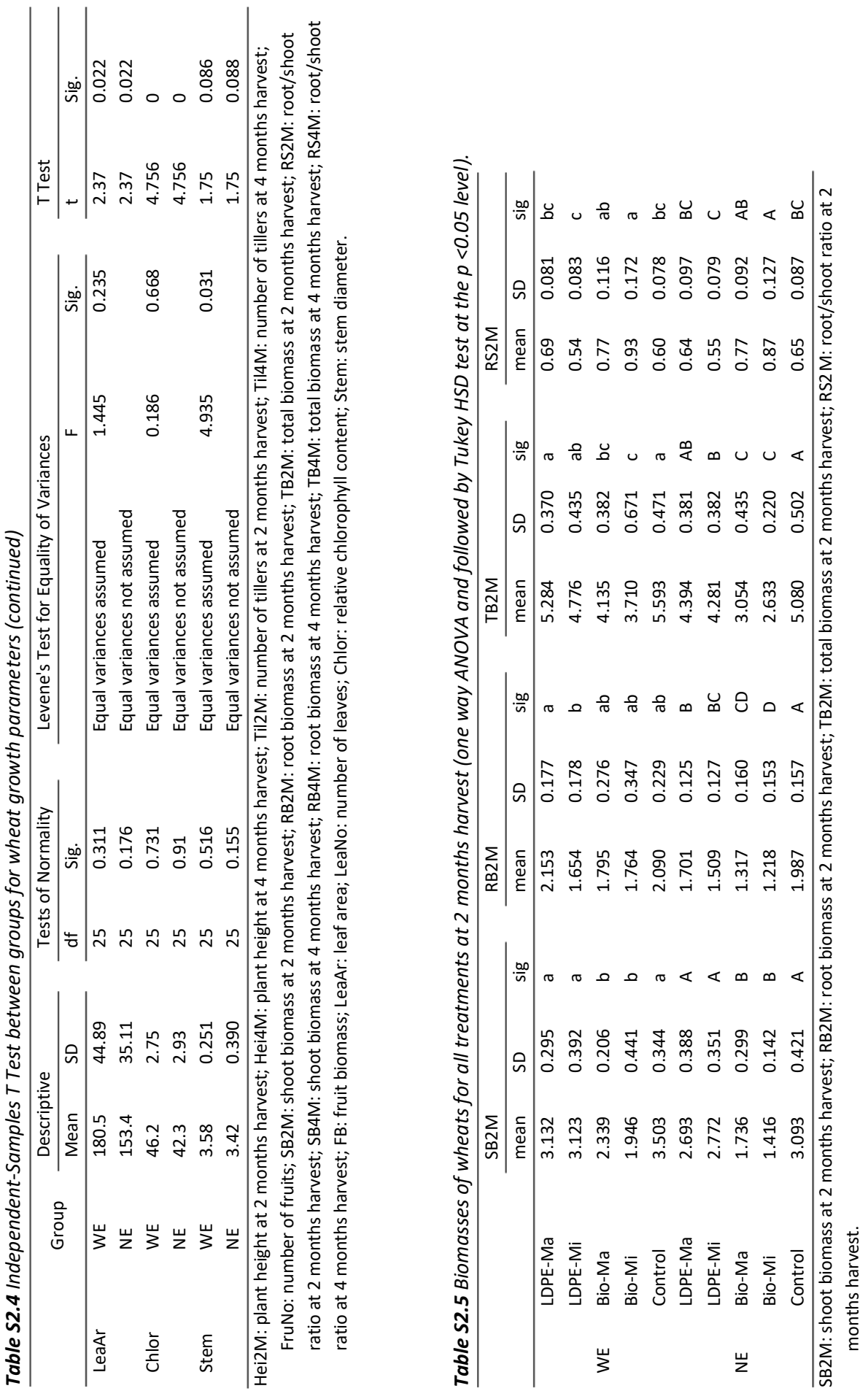

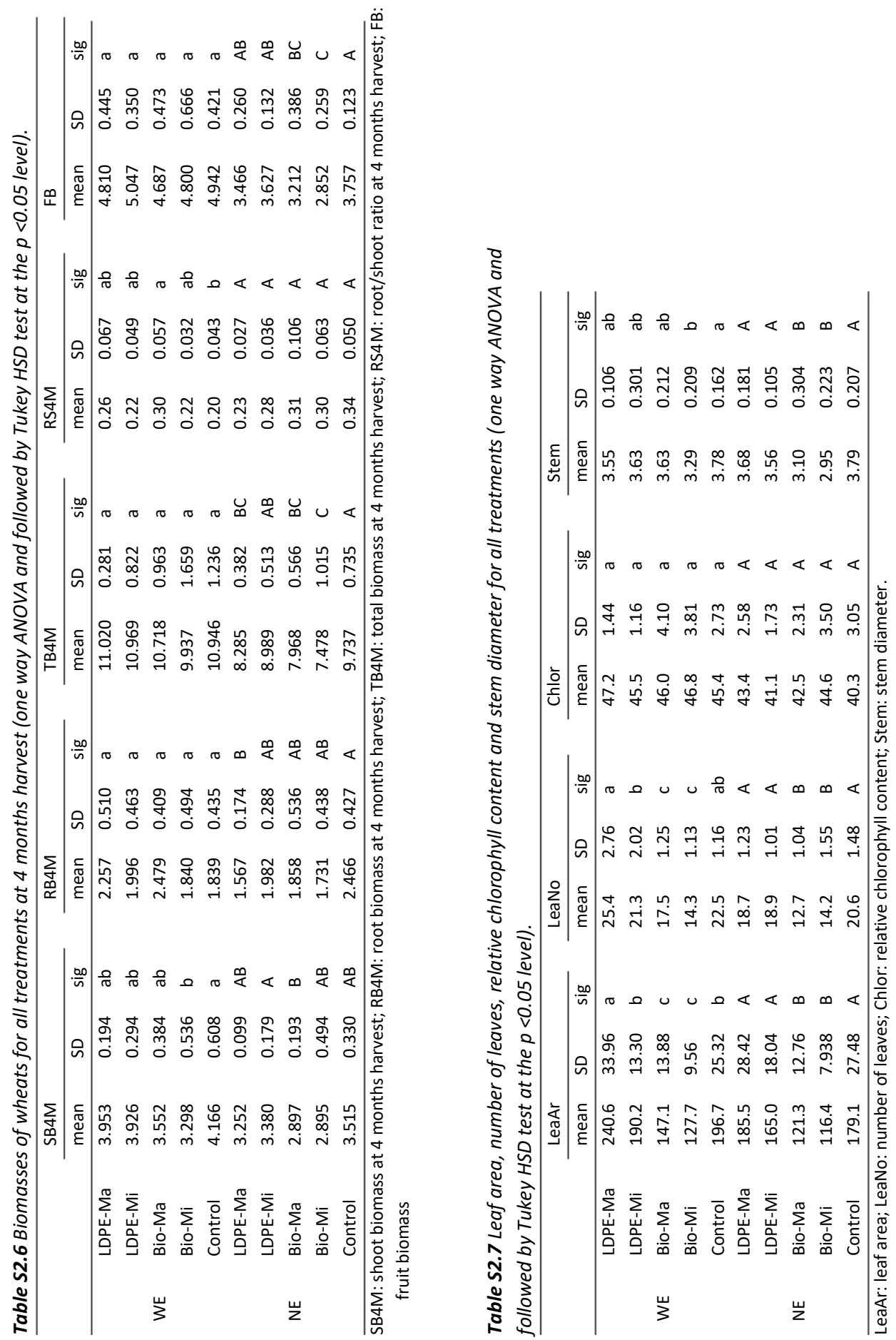
Macro- and micro- plastics in soil-plant system: effects of plastic mulch film residues on wheat (Triticum aestivum) growth

Table S2.8 Statistic summary of Redundancy analysis.

\begin{tabular}{lllll}
\hline Statistic & Axis 1 & Axis 2 & Axis 3 & Axis 4 \\
\hline Eigenvalues & 0.5491 & 0.0585 & 0.0187 & 0.0123 \\
Explained variation (cumulative) & 54.91 & 60.76 & 62.63 & 63.86 \\
Pseudo-canonical correlation & 0.9489 & 0.7738 & 0.5318 & 0.6671 \\
Explained fitted variation (cumulative) & 85.42 & 94.52 & 97.43 & 99.34 \\
\hline Permutation Test Results: & & & \\
On First Axis & pseudo-F=10.7, P=0.002 & & \\
On All Axes & pseudo-F=15.8, P=0.002 & & \\
\hline
\end{tabular}




\section{Effects of plastic mulch film residues on wheat rhizosphere and soil properties}

Plastic residues could accumulate in soils as a consequence of using plastic mulching, which results in a serious environmental concern for agroecosystems. As an alternative, biodegradable plastic films stand as promising products to minimize plastic debris accumulation and reduce soil pollution. However, the effects of residues from traditional and biodegradable plastic films on the soil-plant system are not well studied. In this study, we used a controlled pot experiment to investigate the effects of macro- and micro-sized residues of low-density polyethylene and biodegradable plastic mulch films on the rhizosphere bacterial communities, rhizosphere volatile profiles and soil chemical properties. Interestingly, we identified significant effects of biodegradable plastic residues on the rhizosphere bacterial communities and on the blend of volatiles emitted in the rhizosphere. For example, in treatments with biodegradable plastics, bacteria genera like Bacillus and Variovorax were present in higher relative abundances and volatile compounds like dodecanal were exclusively produced in treatment with biodegradable microplastics. Furthermore, significant differences in soil $\mathrm{pH}$, electrical conductivity and C:N ratio were observed across treatments. Our study provides evidence for both biotic and abiotic impacts of plastic residues on the soil-plant system, suggesting the urgent need for more research examining their environmental impacts on agroecosystems.

Based on:

Qi, Y., Ossowicki, A., Yang, X., Huerta Lwanga., E, Dini-Andreote., F, Geissen, V. \& Garbeva, P. 2020. Effects of plastic mulch film residues on wheat rhizosphere and soil properties. Journal of Hazardous Materials, vol. 387, 121711. https://doi.org/10.1016/j. jhazmat. 2019.121711 


\subsection{Introduction}

Microbial communities are essential for ecosystem functions and services including the decomposition of organic matter, toxin removal, nutrient cycling, plant growth promotion and soil-borne diseases suppression (Brussaard et al., 2007). These functions and services are the results of a multitude of interactions within distinct soil/rhizosphere microbial taxa and between microbial communities and plants (Bakker et al., 2014). Secondary metabolites (i.e. volatiles and non-volatiles) play important roles in belowground microbemicrobe and plant-microbe interactions (van Dam and Bouwmeester, 2016; Weisskopf et al., 2016). For example, plants have the ability to recruit specific soil microorganisms from a distance via root-emitted volatiles (Schulz-Bohm et al., 2018; van Dam et al., 2016). However, relatively little is known about the extent to which anthropogenic pollution such as microplastics (MPs) can affect belowground plant-microbe interactions and volatile profiles.

MPs (defined as plastic particles $<5 \mathrm{~mm}$ in diameter) are recognised as an emerging threat to both aquatic and terrestrial ecosystems (Cole et al., 2011; Rillig, 2012). However, the environmental impacts of MPs on terrestrial ecosystems remain largely unknown (de Souza Machado et al., 2018a; Ng et al., 2018). According to the recent literatures, farmlands may store more MPs than oceans (Nizzetto et al., 2016a; Nizzetto et al., 2016b; Van Sebille et al., 2015). The use of plastic mulch films is considered to be the main human activity that is contributing to microplastic pollution in agroecosystems (de Souza Machado et al., 2018a; $\mathrm{Ng}$ et al., 2018). Plastic mulch films have been used increasingly worldwide due to the wellknown short-term benefits (e.g., maintaining soil moisture and temperature, preventing weeds, limiting soil erosion), all of which ultimately contribute to the enhancement of crop productivity (Gao et al., 2019; Steinmetz et al., 2016). However, the threats posed by plastic debris accumulating in soil have only been pointed out in recent years (Liu et al., 2014; Yan et al., 2014). Studies have shown that the accumulation of plastic film residues can significantly affect soil quality and crop growth in a negative way (Dong et al., 2015; Qi et al., 2018)

Biodegradable (Bio) plastic mulch films are expected to degrade completely after being tilled into the soil (Brodhagen et al., 2017; Kasirajan and Ngouajio, 2012). However, the short- and long-term ecological impacts of Bio plastic mulch films on agroecosystem remain largely unknown (Bandopadhyay et al., 2018; Sintim and Flury, 2017). In general, knowledge concerning the degradation or persistence of MPs in soils is scarce, mostly due to the lack of established quantitative and qualitative analytical methods. Thus, so far, most of our knowledge is based on sporadic field surveys that examine MPs in terrestrial ecosystems (Liu et al., 2018; Scheurer and Bigalke, 2018; Zhang and Liu, 2018; Zhou et al., 2018). 
Furthermore, it is still unclear how plants respond to the presence of MPs in soil and how MPs affect plant-microbe interactions and the overall composition and function of the rhizosphere microbiome (Qi et al., 2018; Rillig et al., 2019). The rhizosphere is the critical interface between plant roots and the soil matrix where beneficial and harmful interactions between plants and microorganisms take place (Mendes et al., 2013). Moreover, it is important to realize that macro- (Ma) and micro- (Mi) sized plastic residues may affect plant-microbe interactions and the rhizosphere microbiome in a different manner. This is likely to occur due to differences in the physicochemical properties and surface/volume ratios of different sized residues (Brodhagen et al., 2017; de Souza Machado et al., 2018a).

Here we conducted a well-controlled pot experiment using wheat plants to test the effect of $\mathrm{Ma}$ and $\mathrm{Mi}$ sized low-density polyethylene (LDPE) and Bio plastic residues on the assembly of rhizosphere bacterial communities, emission of volatile organic compounds and soil properties. To this end, we used an environmentally relevant concentration of plastic residues (i.e., 1\%, w/w) (de Souza Machado et al., 2018b; Fuller and Gautam, 2016; Qi et al., 2018). We hypothesized that plastic residues affect the soil chemistry and biology, and these effects vary according to plastic types and sizes.

\subsection{Materials and Methods}

\subsubsection{Experimental design and soil sampling}

The experimental design comprised two types of plastic mulch films (LDPE and Bio) and two sizes of plastic residues ( $\mathrm{Ma}$ and $\mathrm{Mi}$ ). The Ma size residues were manually cut in rectangular pieces with side length ranging from $4 \mathrm{~mm}$ to $10 \mathrm{~mm}$, and the Mi size residues were frozen ground powders with size ranging from $50 \mu \mathrm{m}$ to $1 \mathrm{~mm}$. Additional information on these plastic materials are provided in Figure S3.1 and reported in a previous study (Qi et al., 2018). Control treatment without plastic residues was also included. In total, fifty pots were used to grow wheat (Triticum aestivum). They were divided into five treatments, as follows: (i) LDPE-Ma: addition of $1 \%(w / w)$ LDPE macroplastics; (ii) LDPE-Mi: addition of $1 \%(w / w)$ LDPE MPs; (iii) Bio-Ma: addition of $1 \%(w / w)$ Bio macroplastics; (iv) Bio-Mi: addition of $1 \%$ (w/w) Bio MPs; (v) Control.

The experiment was conducted in a climate chamber at Unifarm, Wageningen University \& Research (WUR), the Netherlands (March August, 2017). Our test soil was a sandy soil collected by Unifarm, WUR from the agricultural land in Wageningen, the Netherlands. Further information of the soil were presented in Figure S3.2 and reported elsewhere (Qi et al., 2018). To make $1 \%(\mathrm{w} / \mathrm{w})$ plastic residues mixture, we spiked $15 \mathrm{~g}$ of the respective 
plastic material in $1500 \mathrm{~g}$ test soil for each pot. Wheat seeds were sowed in the $2 \mathrm{~L}$ plastic pots and cultivated under the temperature and light controlled conditions. The temperature was set at $22^{\circ} \mathrm{C}$ during the day and $17^{\circ} \mathrm{C}$ during the night, day/night photoperiod $(14 / 10 \mathrm{~h})$ with a light intensity of $300 \mu \mathrm{mol} \mathrm{m} \mathrm{m}^{-2}$. Details of the materials and the cultivation of plants followed the same protocols as previously described (Qi et al., 2018). The experiment was harvested at two plant growth stages, i.e. 61st day ( 2 months) when the flag leaf appeared and 139th day (4 months) after seeds were sowed when the mature grains developed, representing for vegetative and reproductive growth. At each time point, five pots were harvested and plants were completely removed from the pots. Rhizosphere soil samples were collected after gently shaken the roots to remove the loosely adhered soil and they were immediately stored at $-20^{\circ} \mathrm{C}$ for further analysis. Bulk soil was sampled from pots without plants, air-dried and stored at room temperature.

\subsubsection{Measurements of soil properties and plant biomass}

The soil $\mathrm{pH}$, electrical conductivity $(\mathrm{EC})$ and $\mathrm{C}: \mathrm{N}$ ratio are fundamental soil properties which are closely related to soil chemistry and biology, and therefore they were measured for the collected bulk soil samples. Before the experiment started, soil $\mathrm{pH}, \mathrm{EC}$ and $\mathrm{C}: \mathrm{N}$ ratio of test soil were measured as the initial values. To determine the $\mathrm{pH}$ and EC, a SenTix meter and a conductivity cell TetraCon 325 was used with a soil-to-water ratio of 1:5. For the C:N ratio measurements, five to six milligrams of ground soil were filled in a small tin cup, gently folded into a solid ball and analyzed by FlashEA 1112 series NC Analyzer (Thermo Fisher Scientific, CA, USA). For both sampling points, plant shoot and root biomasses were obtained after drying the plant materials at $70^{\circ} \mathrm{C}$.

Statistical analyses were performed by IBM SPSS Statistics 23 and R version 3.5.0. Comparisons across treatments for soil properties were conducted by independent oneway analysis of variance (ANOVA), followed by Tukey HSD test. The level of significance was established at $p<0.05$.

\subsubsection{DNA extraction, Illumina sequencing and bioinformatics analysis}

Soil DNA was extracted using the QIAGEN DNeasy PowerSoil Kits (Qiagen Benelux B.V., Venlo, the Netherlands), following the manufacturer's protocol. The quantity and quality of extracted DNA samples were determined using a Nanodrop ND-2000 (Thermo Fisher Scientific, CA, USA), and the DNA integrity was checked by electrophoresis on agarose gel $(1 \% \mathrm{w} / \mathrm{v})$. The PCRs of bacterial 16S rRNA gene V3-V4 region was performed with the primer 
set 341F (5'-CCTACGGGNGGCWGCAG -3') and 785R (5'- GACTACHVGGGTATCTAATCC -3'). Sequencing was carried out on a single lane of Illumina MiSeq platform at BaseClear B.V. (Leiden, Netherlands).

The raw FASTQ files of bacterial sequences were analyzed using the Hydra pipeline (DOI: 10.5281/zenodo.597131). In brief, sequences were quality trimmed and chimeric sequences were removed. After the Hydra pipeline, sequences with $\geq 97 \%$ similarity were clustered into operational taxonomic units (OTUs). Taxonomic information of the OTUs representative sequences was assigned using the SILVA database. Prior to statistical analyses, samples were normalized using the cumulative sum scaling (CSS) method. To improve the normality and homogeneity of the variances, the OTUs table was z-score transformed. Predicted OTUs that significantly segregated across treatments were identified by random forest analysis using the Boruta feature selection (Breiman, 2001; Kursa and Rudnicki, 2010). All statistical inferences and data plotting were done in $\mathrm{R}$ version 3.5.0.

\subsubsection{Volatile trapping and measurement}

For the collection of volatiles, polydimethylsiloxane (PDMS)-silicone tubes were conditioned and buried in the wheat rhizosphere for $20 \mathrm{~min}$ before final harvest, as described by Huerta Lwanga et al. (2018). The PDMS tubes were stored at $-20^{\circ} \mathrm{C}$ before analyzed by GC-Q-TOF (Agilent 7890B GC and the Agilent 7200A QTOF, USA). The measuring conditions and parameters were previously described by Huerta Lwanga et al. (2018). The acquired mass spectra data were processed with MZmine 2.14.2 (Pluskal et al., 2010), in a similar way as described by Schulz-Bohm et al. (2015). The identification of volatile compounds was evaluated using the software AMDIS 2.72. The retention indexes were calculated and compared with those in the NIST 2014 database and using an available inhouse database. The statistical analysis was performed using MetaboAnalyst V4.0 (http://www.metaboanalyst.ca). 


\subsection{Results and Discussion}

\subsubsection{Effect of plastic residues on rhizosphere bacterial community}

To study the rhizosphere bacterial community, rhizosphere soils were sampled and examined by high throughput 16S rRNA amplicon sequencing at 2 and 4 months of wheat growth. The relative abundance of bacterial OTUs in the wheat rhizosphere at the phylum level varied among treatments (Figure 3.1). Across treatments, the bacterial community at the phylum level was dominated by Proteobacteria (35.9\% of the total on average) followed by Actinobacteria (14.0\%) and Acidobacteria (13.4\%) (Figure 3.1). This pattern in phyla composition aligns with what others have described for the wheat rhizosphere (Donn et al., 2015; Fan et al., 2018), which most likely occurs because these phyla also constitute the dominant strains found in soils on the global scale (Delgado-Baquerizo et al., 2018).

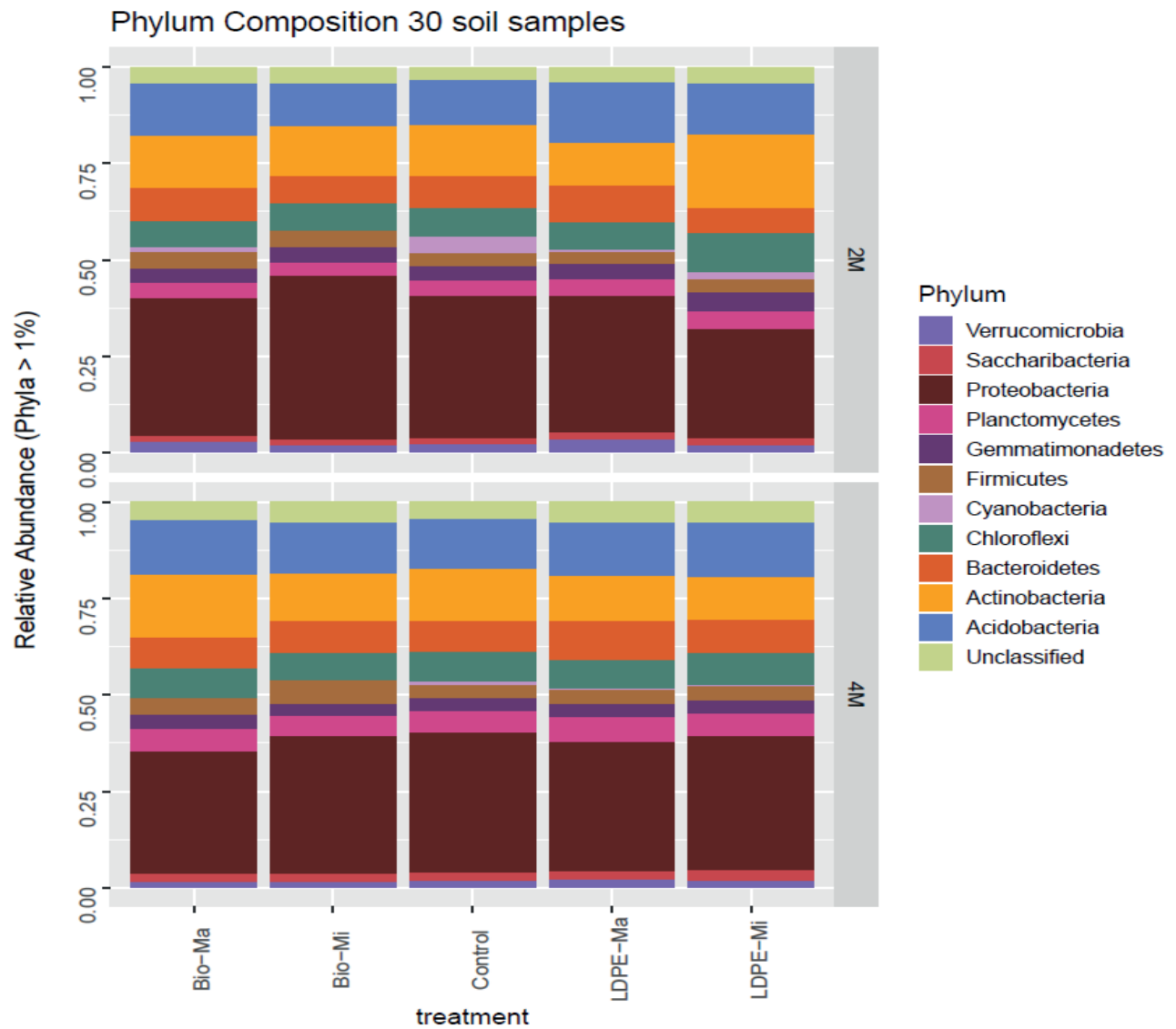

Figure 3.1 Bar charts displaying the most abundant bacterial phyla (phyla relative abundance > 1\%) in the community structure of each individual treatment at 2 and 4 months. 
The total plant biomass was significantly reduced with the addition of plastic residues at both time points and the treatments Bio-Ma and Bio-Mi revealed the strongest negative effect (Figure 3.2A). The negative effects of plastic residues on wheat development during the growth process were previously discussed and reported (Qi et al., 2018). Beta-diversity analysis based on Bray-Curtis distances were conducted to examine the separation among bacterial communities across treatments. The first principal coordinate axis showed that the rhizosphere soil at 2 and 4 months had distinct bacterial community structures (Figure 3.2B). The different treatments were clearly separated along the second principal coordinate axis and treatments exposed to plastic residues had significantly different bacterial communities compared to the Control, thus indicating that the presence of plastic residues in the soil had significant effects on the wheat rhizosphere bacterial communities (Figure 3.2B).

Furthermore, differential abundance analysis using random forest revealed that specific bacterial genera (e.g. Bacillus, Variovorax, Comamonadaceae, etc.) were present in higher relative abundances in treatments with Bio plastics, while some specific genera (e.g. Bradyrhizobium, Cellvibrio, etc.) significantly increased in relative abundances in the treatment Bio-Mi (Figure 3.2C). Collectively, these results indicate that plastic residues can impose selective pressure on distinct microbial taxa as anthropogenic substrates. In line with that, the presence of LDPE residues also had an effect on the assembly of the rhizosphere bacterial community. For instance, bacteria taxa affiliated with the genus Saccharibacteria were higher in relative abundance in the treatments with LDPE plastics (Figure 3.2C).

Regarding the effect of the sizes of plastic residues, bacterial community structures in the treatments Bio-Mi and Bio-Ma were clearly separated, as shown in the non-metric multidimensional scaling (NMDS) plot (Figure 3.2B). This suggests that different sizes of plastic residues may exert different influences on the rhizosphere microbiome. Plausibly, the physicochemical surface properties of plastic residues may play specific roles in their effects. Comparable results were reported for an aquatic ecosystem where the shape of plastic debris (i.e. plastic sheet and dolly rope) significantly affected the bacterial community composition of the biofilm formed on the plastic debris (De Tender et al., 2017). Considering numerous types, sizes and shapes of MPs in the ecosystem (Cole et al., 2011), it is critical to further study how the physical and chemical properties of plastic residues influence their environmental effects. 
A

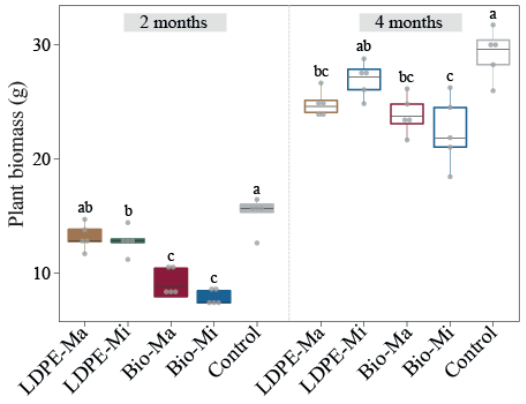

B

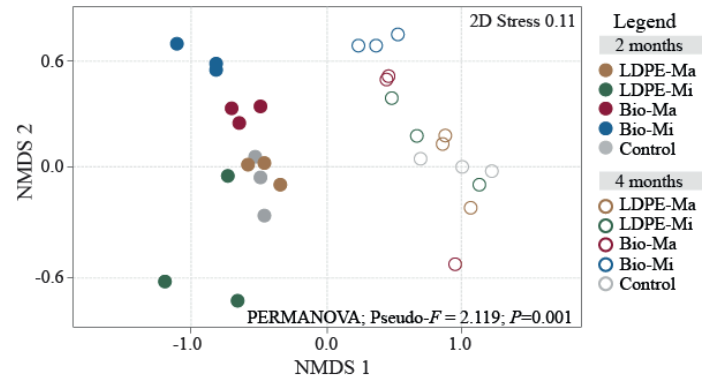

$\mathrm{C}$
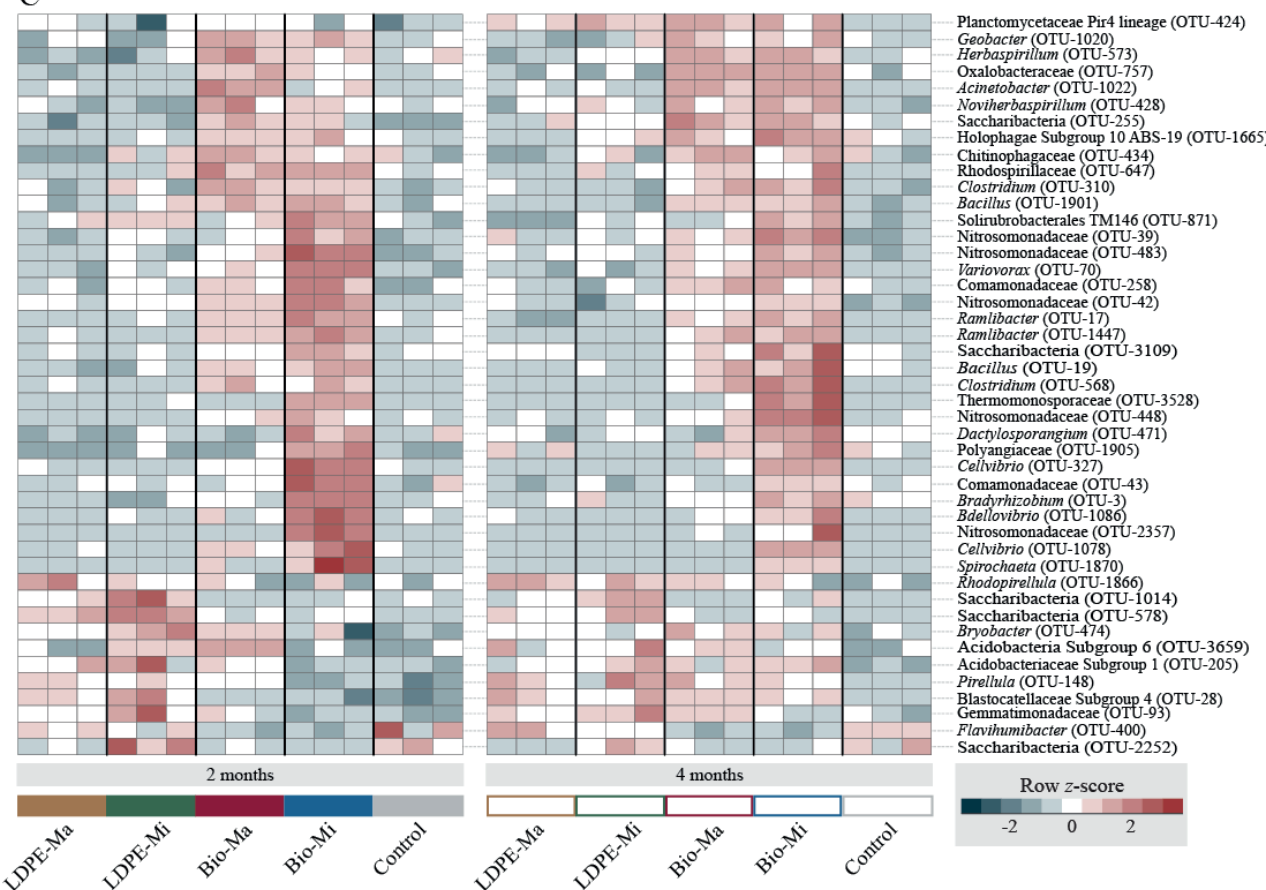

Figure 3.2 (A) Total biomass of wheat in each treatment for samples collected after 2 and 4 months. (B) Betadiversity biplot of bacterial communities displayed by non-metric multidimensional scaling (NMDS); (C) Relative abundance of significantly different OTUs across treatments identified by random forest analysis.

Overall, our results clearly revealed that Bio plastics had stronger effects on the composition of the wheat rhizosphere bacterial communities. One possible explanation is that the chemical composition of LDPE and Bio plastic are very different. The Bio plastics used in this study consisted mainly of pullulan, polyethylene terephthalate and polybutylene terephthalate, while the LDPE mulch film is a linear hydrocarbon polymer consisting of ethylene monomers. On the other hand, LDPE is a polymer resistant to degradation with remarkable chemical inertness (Restrepo-Flórez et al., 2014). Another possible explanation is the fact that our experiment was restricted to four months, so it is plausible that Bio 
plastics had a quick and abrupt effect on the soil microbial community and activity, especially the smaller sized Bio plastic residues ( $\mathrm{Mi}, 50 \mu \mathrm{m}-1 \mathrm{~mm}$ in this study) (Bandopadhyay et al., 2018; Haider et al., 2019).

Moreover, soil bacteria are known to be attracted to easily degradable root exudates and mucilage present in plant roots and in soil (Lugtenberg and Kamilova, 2009). Following this line of reasoning, it is also possible to speculate that the presence of Bio plastic residues in soil may also attract and/or favour specific bacterial taxa and interfere with belowground plant-microbe interactions. Although only bacterial communities were investigated in this study, it is likely that other organismal taxa (e.g. fungi, archaea and protists) within this system would also be affected, thus resulting in more complex impacts on biological interactions in the rhizosphere. (Fan et al., 2018). We propose that the negative effects on plant growth are - at least in part - caused by the influence of plastic residues on the rhizosphere microbiome and the potential disruption of beneficial plant-microbe interactions.

\subsubsection{Effect of plastic residues on rhizosphere volatile organic compounds}

Secondary metabolites (both volatile and non-volatile) play important roles in plantmicrobe interactions. More specifically, the chemical composition of volatile metabolites in the rhizosphere is crucial for soil below-ground interactions (Massalha et al., 2017). In this study, we collected and analysed the volatiles emitted in the rhizosphere of wheat at the end of the experiment. Our results revealed that the addition of plastic residues significantly affected the blend of volatiles emitted in the rhizosphere (Figure 3.3). The PLS-DA score plots showed that the treatments Bio-Ma and Bio-Mi had significantly different blends of volatile compounds compared to the LDPE and Control treatments (Figure 3.3A). The heatmap clearly displays that some compounds were exclusively produced in treatments with Bio plastics. Furthermore, differences in volatile profiles were observed between the treatments with different plastic sizes (Figure 3.3B). Interestingly, distinct volatiles were found only in the Bio-Mi treatment (Table S3.1), such as high amounts of dodecanal. Dodecanal is known to be produced by bacteria and have negative effects on both fungal and plant growth (Kai et al., 2007; Vespermann et al., 2007). In addition, a recent study indicated that some volatiles are the by-products of bacterial MPs decay in soil (Huerta Lwanga et al., 2018). Several studies conducted in the past decades have indicated that volatile compounds can have plant growth-inducing or growth-inhibiting effects, e.g. through the modulation of plant hormonal balance, metabolism, and nutrient acquisition (Fincheira and Quiroz, 2018). Although the mechanisms of differential volatile emissions in the rhizosphere remain largely unknown, the variations observed for volatiles in the 
presence of plastic residues might be - at least in part - another reason accounting for the observed negative effects of plastic residues on wheat growth.
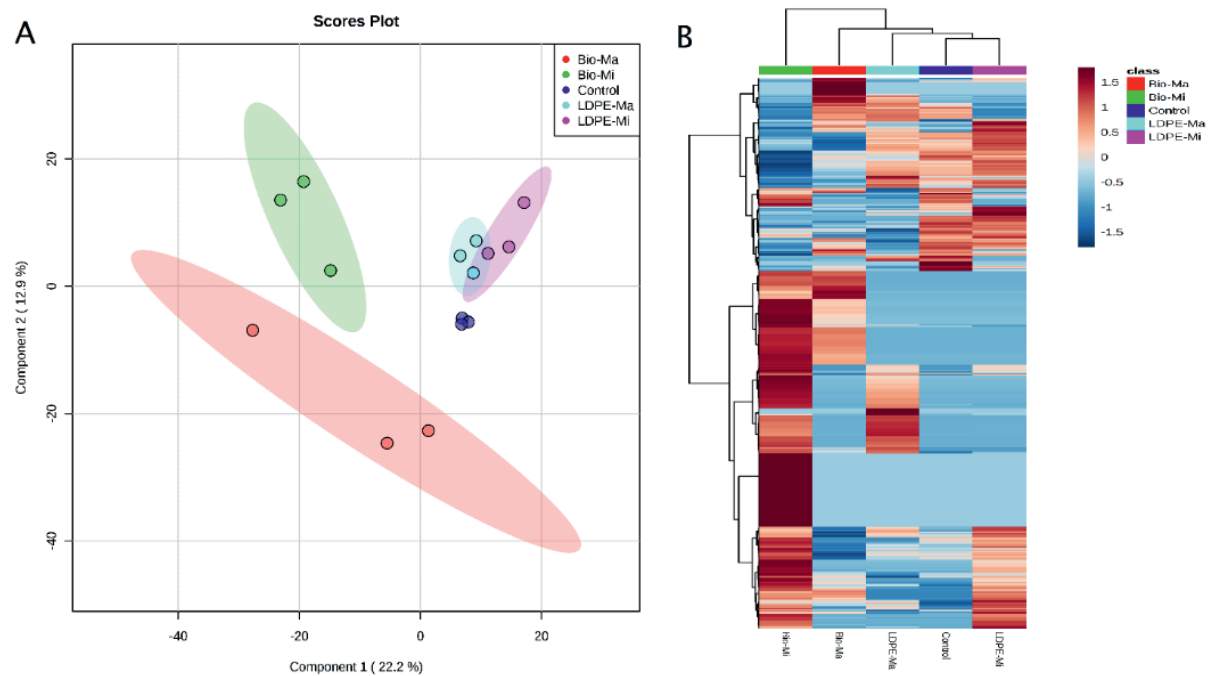

Figure 3.3 (A) Score plot based on partial least square-discriminant analysis (PLS-DA) of volatile profiles emitted in the rhizosphere of wheat at 4 months; (B) Heatmap displaying the volatile profiles in the rhizosphere of wheat. Each column represents three collated replicate measurements per treatment. Coloured cells on the map correspond to the concentration value per compound (blue: low abundance; red: high abundance).

\subsubsection{Effect of plastic residues on soil chemical properties}

In order to gain a comprehensive biogeochemical understanding of plastic residues in soil, there has been an increasing emphasis placed on examining the potential impacts of microplastic pollution on soil physicochemical properties (de Souza Machado et al., 2018b). Here, we specifically tested for variations in soil $\mathrm{pH}, \mathrm{EC}$ and $\mathrm{C}: \mathrm{N}$ ratio in our experimental system. For all treatments, an increase in $\mathrm{pH}$ and decrease in EC were observed as compared to the initial values (Table 3.1). For both time points, LDPE-Mi had the highest EC (390 \pm $119.39 \mu \mathrm{S} / \mathrm{cm}$ at 2 months, $179 \pm 76.73 \mu \mathrm{S} / \mathrm{cm}$ at 4 months) and Bio-Mi had the lowest EC (130 $\pm 48.42 \mu \mathrm{S} / \mathrm{cm}$ at 2 months, $75 \pm 15.58 \mu \mathrm{S} / \mathrm{cm}$ at 4 months) (Table 3.1). Although soil acidification and the decrease in EC are well-known challenges for sustainable agriculture (Miao et al., 2010), both soil pH and EC are influenced by many factors and they should not be directly correlated with crop growth (Atkinson et al., 2010; Humphreys et al., 2011). In addition, Dong et al. (2015) studied large sizes of plastic mulch film residues $\left(0-200 \mathrm{~cm}^{2}\right)$ in cotton fields with the density gradient ranging from 250 to $2000 \mathrm{~kg} \mathrm{hm}^{-2}$ and found that the increase of residual mulch films impacted soil quality, e.g. increased $\mathrm{pH}$, decreased organic matter, and negatively affected the overall nutrient availability. In that study, they proposed 
that the distinct tolerance to plastic residues of two varieties of cotton may be caused by their different root systems (Dong et al., 2015).

Table 3.1 Soil $\mathrm{pH}$, electrical conductivity (EC) and C:N ratio values measured for the bulk soil samples in each treatment collected at 2 and 4 months.

\begin{tabular}{|c|c|c|c|c|c|c|c|c|c|c|}
\hline & & \multicolumn{3}{|c|}{$\mathrm{pH}$ (initial 6.55 \pm 0.047 ) } & \multicolumn{3}{|c|}{ EC (initial $411 \pm 18.33) \mu \mathrm{S} / \mathrm{cm}$} & \multicolumn{3}{|c|}{ C:N ratio (initial $16.67 \pm 1.008$ ) } \\
\hline & & mean & SD & sig & mean & SD & sig & mean & SD & sig \\
\hline \multirow{5}{*}{$2 \mathrm{M}$} & LDPE-Ma & 6.74 & 0.059 & $b$ & 250 & 56.50 & bc & 16.28 & 1.015 & bc \\
\hline & LDPE-Mi & 6.79 & 0.137 & $a b$ & 390 & 119.39 & a & 23.32 & 5.130 & a \\
\hline & Bio-Ma & 6.81 & 0.115 & $a b$ & 182 & 86.01 & $\mathrm{~cd}$ & 15.56 & 0.577 & c \\
\hline & Bio-Mi & 6.90 & 0.045 & a & 130 & 48.42 & $d$ & 19.59 & 3.120 & $a b$ \\
\hline & Control & 6.72 & 0.075 & $b$ & 339 & 68.07 & $a b$ & 15.94 & 0.579 & c \\
\hline \multirow{5}{*}{$4 \mathrm{M}$} & LDPE-Ma & 6.86 & 0.064 & B & 136 & 54.05 & $A B$ & 15.98 & 0.804 & B \\
\hline & LDPE-Mi & 6.91 & 0.070 & $A B$ & 179 & 76.73 & A & 19.43 & 2.234 & A \\
\hline & Bio-Ma & 6.91 & 0.041 & $A B$ & 106 & 42.05 & B & 15.72 & 0.466 & B \\
\hline & Bio-Mi & 6.96 & 0.126 & $A B$ & 75 & 15.58 & B & 18.84 & 1.485 & A \\
\hline & Control & 7.01 & 0.094 & A & 103 & 52.38 & B & 15.84 & 0.593 & B \\
\hline
\end{tabular}

2M: 2 months harvest; 4M: 4 months harvest; SD: standard deviation; lowercase letters in column sig mean significant differences at 2 months; uppercase letters in column sig mean significant differences at 4 months, $p<0.05$.

For the $\mathrm{C}: \mathrm{N}$ ratio, treatments with $\mathrm{Mi}$ size residues (i.e. LDPE-Mi and Bio-Mi) had significantly higher values compared to the Control at both time points (Table 3.1). The treatment LDPE-Mi had the highest C:N ratio at $2(23.32 \pm 5.130)$ and 4 months $(19.43 \pm$ 2.234) across all treatments (Table 3.1). Together with the effects of plastic residues on rhizosphere bacterial communities and volatile profiles, our experiment provides strong evidence supporting the biotic and abiotic impacts of plastic residues on the soil-plant system. Recently, researchers also observed that exposing soil to four different types of MPs with concentrations of up to $2 \%$ affected microbial activity and soil physical properties (e.g. bulk density and water holding capacity) (de Souza Machado et al., 2018b). Although plastic particles have a relatively high content of carbon, most of it is relatively inert, which hinders the decomposition of MPs (Rillig, 2018). Thus, the carbon in plastic residues could affect the carbon cycle and soil microorganisms (Rillig et al., 2018). Furthermore, it was recently proposed that due to the slow degradation rate, the progressive accumulation of MPs in soils can result in a very wide $\mathrm{C}: \mathrm{N}$ ratio that leads to microbial immobilization (Rillig et al., 2019). 


\subsection{Conclusion}

Here we showed that both LDPE and Bio plastic mulch film residues have strong (albeit different) effects on wheat growth, rhizosphere bacterial community composition and structure, rhizosphere volatile profiles and soil chemical properties. Given the rapidly increasing global accumulation of plastic fragments in soils, a better understanding of the impact of such residues on complex interactions that take place in the soil-plant system is urgently needed. In this sense, this study provides evidence that highlights how plants, soil microbes and chemistry respond to plastic residues under controlled experimental conditions. As such, we advocate for further research efforts aiming at developing prospective experimental designs and field surveys to broaden our understanding of the mechanisms by which conventional and biodegradable plastics affect the soil ecosystem, particularly in agricultural settings.

\section{Acknowledgements}

This research was funded by the National Natural Science Foundation of China (41877072), the Natural Science Basic Research Plan in Shaanxi Province of China (2019JQ-639) and the EU Horizon 2020 project (ISQAPER: 635750). We are thankful for the financial support from the China Scholarship Council (CSC: 201604910510). We also thank Henny Gertsen for his assistance in preparing the plastic materials, and Mattias de Hollander for bioinformatics support. This is publication 6829 of the NIOO-KNAW. 


\section{Supplementary Material}

\author{
LDPE mulch film
}

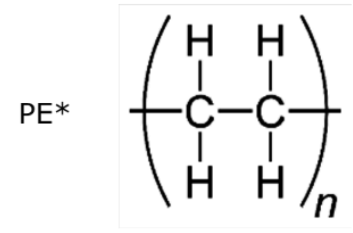

PE*: polyethylene
Bio mulch film

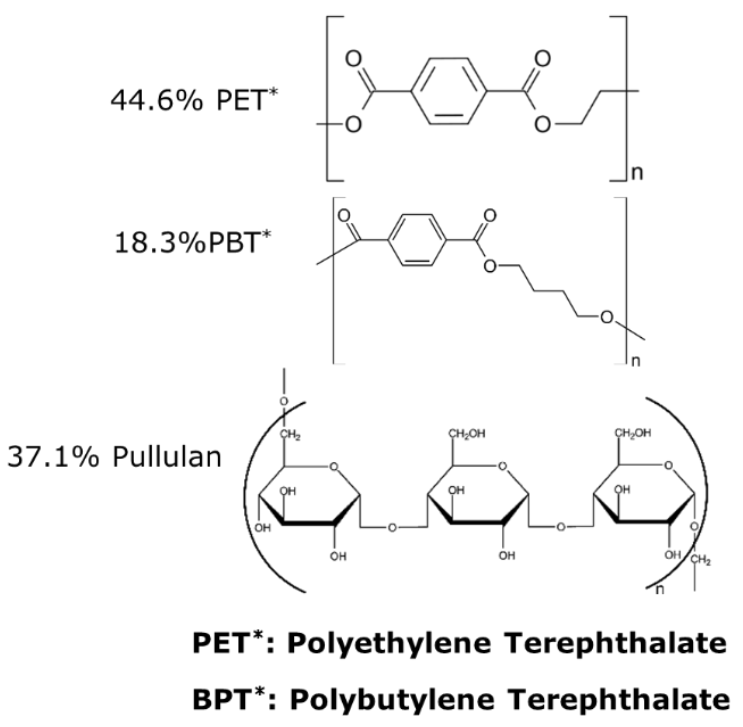

Figure S3.1 Composition of plastic mulch films used in the experiment. 
BemestingsMonitor BODEM

\section{bunker overkant}

Uw klantnummer: 2211378

Unifarm De Haaff

Vollegrond

Bornsestg 48

6708 PE WAGENINGEN

\section{BLGG}

BLGG AgroXpertus

$\mathrm{NL}$ - $6700 \mathrm{AD}$ Wageningen

T monstername: Herman Dorrestel|n: 065200211

Tlantenservice: +31 (0) $83876 \quad 1010$

E Klantensemoegoigg.agroxpertus.ni

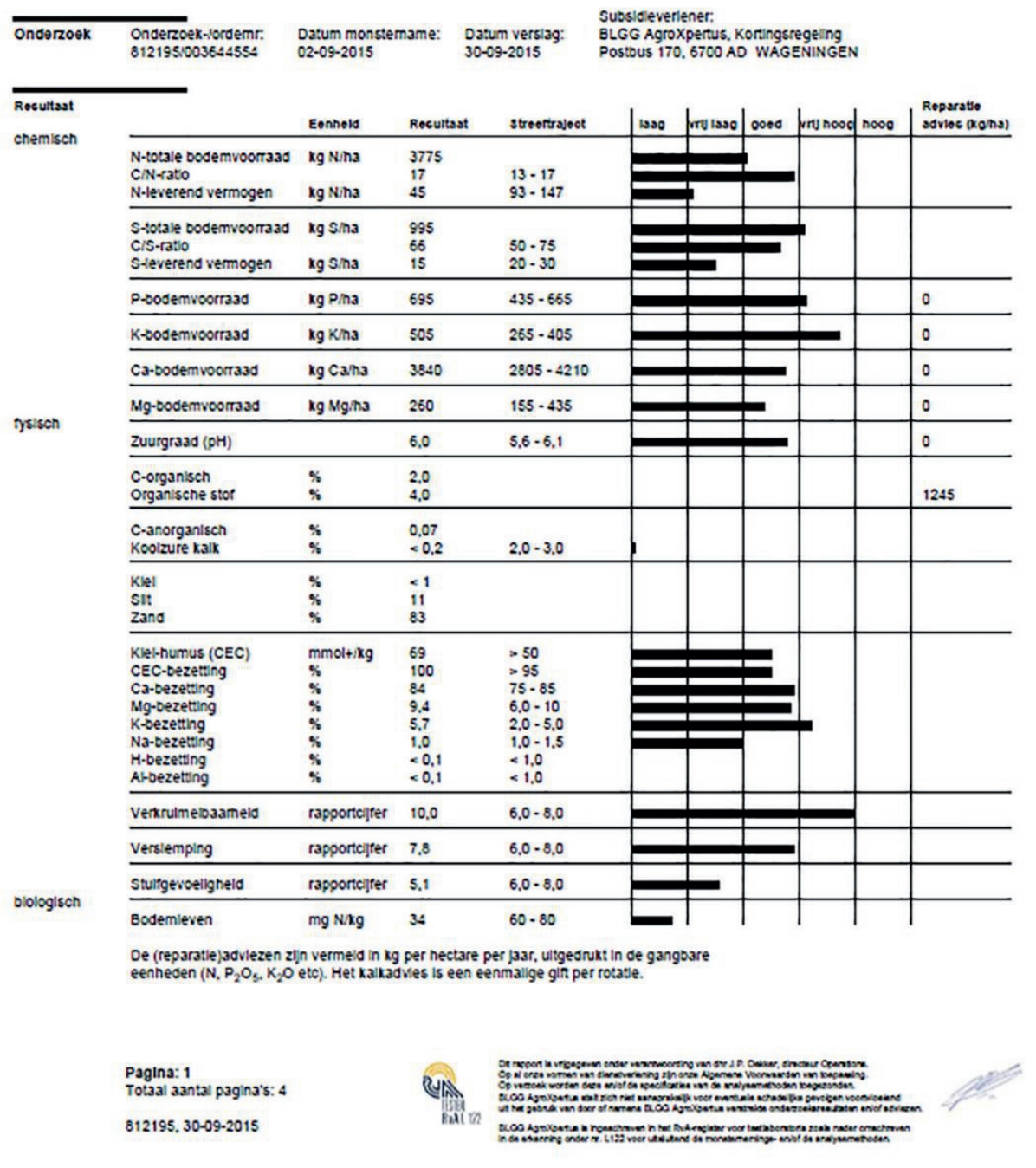

Figure S3.2 Detailed information about soil used in the experiment. 
Table S3.1 Identified volatile organic compounds only appeared in Bio-Mi treatment.

\begin{tabular}{llll}
\hline RT & RI & Name & Formula \\
\hline 17.83 & 1085 & 1-Octyn-3-ol, 4-ethyl & $\mathrm{C}_{10} \mathrm{H}_{18} \mathrm{O}$ \\
21.4 & 1172 & unknown & \\
28.5 & 1368 & 4,8-Decadienal, 5,9-dimethyl & $\mathrm{C}_{12} \mathrm{H}_{20} \mathrm{O}$ \\
29.6 & 1400 & unknown & \\
29.9 & 1408 & Dodecanal & $\mathrm{C}_{12} \mathrm{H}_{24} \mathrm{O}$ \\
30.08 & 1413 & diphenyl ether & $\mathrm{C}_{12} \mathrm{H}_{10} \mathrm{O}$ \\
31.8 & 1470 & unknown & \\
32.5 & 1489 & unknown & \\
35.81 & 1599 & 1-Hexadecane & $\mathrm{C}_{16} \mathrm{H}_{34}$ \\
39.3 & 1816 & Hexadecanal & $\mathrm{C}_{16} \mathrm{H}_{32} \mathrm{O}$ \\
\hline
\end{tabular}




\section{Impact of plastic mulch film debris on soil physicochemical and hydrological properties}

The plastic mulch films used in agriculture are considered to be a major source of the plastic residues found in soil. Mulching with low-density polyethylene (LDPE) is widely practiced and the resulting macro- and microscopic plastic residues in agricultural soil have aroused concerns for years. Over the past decades, a variety of biodegradable (Bio) plastics have been developed in the hope of reducing plastic contamination of the terrestrial ecosystem. However, the impact of these Bio plastics in agroecosystems have not been sufficiently studied. Therefore, we investigated the impact of macro (around 5 $\mathrm{mm}$ ) and micro (<1 $\mathrm{mm}$ ) sized plastic debris from LDPE and one type of starch-based Bio mulch film on soil physicochemical and hydrological properties. We used environmentally relevant concentrations of plastics, ranging from 0 to $2 \%(\mathrm{w} / \mathrm{w})$, identified by field studies and literature review. We studied the effects of the plastic residue on a sandy soil for one month in a laboratory experiment. The bulk density, porosity, saturated hydraulic conductivity, field capacity and soil water repellency were altered significantly in the presence of the four kinds of plastic debris, while $\mathrm{pH}$, electrical conductivity and aggregate stability were not substantially affected. Overall, our research provides clear experimental evidence that microplastics affect soil properties. The type, size and content of plastic debris as well as the interactions between these three factors played complex roles in the variations of the measured soil parameters. Living in a plastic era, it is crucial to conduct further interdisciplinary studies in order to have a comprehensive understanding of plastic debris in soil and agroecosystems.

\section{Based on:}

Qi, Y., Beriot, N., Gort, G., Huerta Lwanga, E., Gooren, H., Yang, X., Geissen, V. 2020. Impact of plastic mulch film debris on soil physicochemical and hydrological properties. $\begin{array}{llll}\text { Environmental Pollution, } & \text { vol. 266, }\end{array}$ https://doi.org/10.1016/j.envpol.2020.115097 


\subsection{Introduction}

In recent years, researchers have seen soil as a major sink for microplastics (MPs, particles with diameter $<5 \mathrm{~mm}$ ), which is a threat to sustainable agriculture and food security (de Souza Machado et al., 2018a; Ng et al., 2018; Nizzetto et al., 2016b; Rillig, 2012; Rillig et al., 2017a; Rillig et al., 2019; Rochman, 2018). Subsequent studies have filled certain knowledge gaps with regards to MPs in terrestrial ecosystems, particularly in agricultural soil. For instance, the effects of MPs on soil biota have been studied (Cao et al., 2017; Huerta Lwanga et al., 2016; Zhu et al., 2018b), as well as their effects on multiple trophic levels (Huerta Lwanga et al., 2017b; Zhu et al., 2018a), underground transport (Huerta Lwanga et al., 2017a; Maass et al., 2017; Yu et al., 2019), and their interactions with other soil pollutants (Hodson et al., 2017; Rodríguez-Seijo et al., 2019; Yang et al., 2018; Yang et al., 2019). Although these studies have answered many questions, the most fundamental questions concerning MPs in soil have gone unanswered. Several major problems remain unresolved: no sufficient methods to quantify diverse MPs (Blasing and Amelung, 2018; Corradini et al., 2019a; Fuller and Gautam, 2016; Schwaferts et al., 2019; Shan et al., 2018; Zhang et al., 2018), very limited field surveys measuring the status of MPs in the soil (Huang et al., 2020; Liu et al., 2018; Scheurer and Bigalke, 2018; Zhang and Liu, 2018; Zhou et al., 2020; Zhou et al., 2018), and lack of information concerning the impacts of MPs on soil physical, chemical and biological properties (de Souza Machado et al., 2018b; Liu et al., 2017b; Qi et al., 2020c). Moreover, recent studies have shown that MPs affected soil structure, hydraulic conductivity, water holding capacity, etc. (de Souza Machado et al., 2018b; Zhang et al., 2019). Therefore, it is crucial to study the impacts of MPs on soil physicochemical and hydrological properties to gain a better understanding of this emerging contaminant in soil and the agroecosystems.

As one of the main sources contributing to MPs in agricultural soil, plastic mulching practices play a crucial role in modern agriculture (Gao et al., 2019; Steinmetz et al., 2016). The use of plastic mulch film (PMF) to increase water use efficiency has been going on for years and thus it is relevant to study the effects of residual PMF on parameters related to soil water holding capacity. The prevailing use of plastics in agronomy started in the early 1950s (Espi, 2006). Since then, PMF has brought multiple benefits to agriculture such as instantly improving the quality and quantity of the harvests (Steinmetz et al., 2016). After decades of application, residual PMF fragments have accumulated in the soil and have had detrimental effects on soil quality and crop yield (Liu et al., 2014; Yan et al., 2014). With the highest amount of PMF usage in the world, China was the first to notice the plastic residue pollution in agricultural soil and has conducted many studies since the 1980s (Dong et al., 2015; Xiang et al., 1992; Xu, 1985; Zhao et al., 1998). In recent years, plastic residue in the soil has aroused intensifying concerns that the macroscopic plastic debris will eventually fragment 
into MPs (Barnes et al., 2009). From previous studies about residual PMF, researchers raised universal concerns about its long-term effects on farmland (Gao et al., 2019).

Due to the increasing global concern surrounding plastic pollution, a huge variety of biodegradable plastic mulch film (Bio PMF) was designed as a promising substitute for polyethylene films (Brodhagen et al., 2017; Kasirajan and Ngouajio, 2012). In 2016, the European commission estimated that among the 100,000 tonnes of PMF applied in Europe, 3,000 tonnes were Bio PMF (European Commission, 2016). Bio plastics are made of polymers and additives that should degrade into carbon dioxide and methane or form new biomass (van Ginkel, 2007). According to current standards (e.g. ISO 17556 and EN 13432), Bio plastic should reach at least $90 \%$ biodegradation in the soil within two years (Miles et al., 2017). However, studies warned that some polymers used in these films may not be biodegradable in soil conditions (Brodhagen et al., 2017; Thompson et al., 2019). The application of Bio PMF in agriculture has aroused fierce debate (Bandopadhyay et al., 2018; Sintim and Flury, 2017) and sparked controversies surrounding the fact that Bio plastics are not only used within agroecosystems (Haider et al., 2019; Ren, 2003). Furthermore, only scant studies have been performed to investigate the function and disintegration of Bio PMF (Anzalone et al., 2010; Kapanen et al., 2008; Li et al., 2014b; Miles et al., 2012; Moreno et al., 2017). Therefore, both fundamental and in-depth studies examining Bio PMF are urgently needed to ensure their safe and sustainable application in agroecosystems.

In this study, we conducted mesocosm experiments in the laboratory using both lowdensity polyethylene (LDPE) and Bio PMF. The LDPE and Bio PMF were made into macroand micro- sized debris to investigate the impacts of the plastic debris on soil physical, hydrological and chemical properties with a plastic content gradient $(0,0.5 \%, 1 \%$ and $2 \%$ $w / w)$. LDPE was chosen since it is the most common mulch material and Bio PMF was chosen because it has become increasingly popular in agricultural applications (Kasirajan and Ngouajio, 2012; Steinmetz et al., 2016). We hypothesized that (i) tested soil parameters would have predictable responses to the presence of plastic debris, e.g. a decrease of bulk density, increase of porosity, increase of water flow, increase of water repellence, and (ii) different types, sizes and content of the plastic debris may have distinct effects on soil physicochemical and hydrological properties. 


\subsection{Materials and methods}

\subsubsection{Experimental setup}

The mesocosm experiments were performed at $20^{\circ} \mathrm{C}$ and $35 \%$ humidity in the laboratory of the Soil Physics and Land Management Group, Wageningen University \& Research (WUR). Our test soil was a sandy soil ( $4 \%$ Organic matter, $\mathrm{pH}=6$ ) with $87 \%$ sand, $12 \%$ silt and $1 \%$ clay. It was collected from farmland at Unifarm, WUR and has been used for our previous studies (Qi et al., 2020c; Qi et al., 2018). More information about the soil properties can be found in Table S4.1.

LDPE and Bio PMF were bought from the plastic mulch producer. The company states that the Bio PMF is produced from a formulated compound consisting mainly of polybutylene adipate terephthalate, starch and about $5 \%$ polylactic acid, blended with a black carbon masterbatch using a copolyester as a carrier resin. The presence of polybutylene adipate terephthalate and starch was confirmed by Fourier transform infrared spectroscopy and Differential scanning calorimetry. Macro- and micro- sized debris from LDPE and Bio PMF were prepared as described in a previous study (Qi et al., 2018). Macro-sized pieces were made by cutting PMF into $5 \times 5 \mathrm{~mm}^{2}$ squares by hand and the micro-sized powder was made by freeze grinding the plastic with liquid nitrogen. The powder consisted $25 \%$ of particles between 50 and $250 \mu \mathrm{m}, 62.5 \%$ of particles between 250 and $500 \mu \mathrm{m}$ and $12.5 \%$ of particles between 500 and $1000 \mu \mathrm{m}$. The effects of two types and two sizes of plastic debris (i.e. LDPE-Mi, Bio-Mi, LDPE-Ma, Bio-Ma) were each tested in the experimental soil at three concentrations: $0.5 \%, 1 \%$ and $2 \%$ of soil dry weight (Table 4.1 ). This concentration gradient is environmentally relevant and was chosen based on previous studies (de Souza Machado et al., 2018b; Qi et al., 2020c). Soil without additional plastic was used as the Control.

In total, 13 treatments were tested and each treatment was replicated in three mesocosms. The three contents were always tested together with the Control treatment, during three different months making three incomplete blocks due to logistic reasons (Table 4.1).

The plastic debris was mixed with $2 \mathrm{~mm}$ sieved dry soil and water was added to reach a soil gravimetric water content of $20 \%$. Four $\mathrm{kg}$ of the mixture was then manually packed into each plastic pot ( $4 \mathrm{~L}, 16.5 \mathrm{~cm}$ high) with a wooden pressing tool (Figure S4.1). The compaction consisted of a define pattern of 10 hits repeated every kg of soil added. Each pot was covered loosely with a plastic lid and stored at $20^{\circ} \mathrm{C}$ for 30 days. Every week, the mesocosms were weighed and watered to compensate for evaporation (about $10 \mathrm{~g}$ per week). 
Table 4.1 Treatment settings for the mesocosm experiments

\begin{tabular}{lllll}
\hline Block & Treatment & Plastic type & Plastic size & Plastic content (w/w) \\
\hline \multirow{4}{*}{$1^{\text {st }}$} & Control & - & - & $0.0 \%$ \\
& LDPE-Mi_0.5 & LDPE & Micro & $0.5 \%$ \\
& Bio-Mi_0.5 & Bio & Micro & $0.5 \%$ \\
& LDPE-Ma_0.5 & LDPE & Macro & $0.5 \%$ \\
& Bio-Ma_0.5 & Bio & Macro & $0.5 \%$ \\
\hline \multirow{4}{*}{$2^{\text {nd }}$} & Control & - & - & $0.0 \%$ \\
& LDPE-Mi_1 & LDPE & Micro & $1.0 \%$ \\
& Bio-Mi_1 & Bio & Micro & $1.0 \%$ \\
& LDPE-Ma_1 & LDPE & Macro & $1.0 \%$ \\
& Bio-Ma_1 & Bio & Macro & $1.0 \%$ \\
\hline \multirow{4}{*}{$3^{\text {rd }}$} & Control & - & - & $0.0 \%$ \\
& LDPE-Mi_2 & LDPE & Micro & $2.0 \%$ \\
& Bio-Mi_2 & Bio & Micro & $2.0 \%$ \\
& LDPE-Ma_2 & LDPE & Macro & $2.0 \%$ \\
& Bio-Ma_2 & Bio & Macro & $2.0 \%$ \\
\hline
\end{tabular}

At the end of the experiment, four ring samples $(5 \mathrm{~cm}$ diameter) were taken at the $0-5 \mathrm{~cm}$ depth and four others at the 7-12 cm depth. All the ring samples were analysed for porosity, dry bulk density $\left(\rho_{b}\right)$, saturated hydraulic conductivity (ks), field capacity (FC) and water drop penetration time (WDPT). The $\mathrm{pH}$, electrical conductivity (EC) and aggregate stability index (ASI) were measured from $2 \mathrm{~mm}$ sieved, air dried soil samples at both soil depths (two samples at $0-5 \mathrm{~cm}$ and two others at 7-12 cm) for each pot.

\subsubsection{Measurements of soil parameters}

After sampling, ring samples were water saturated for $24 \mathrm{~h}$ and weighed. The ks was then measured on saturated ring samples using the flow induction with constant head method (Klute and Dirksen, 1986), described in Figure S4.2. Ring samples were then placed in a sandbox to measure the FC (Klute and Dinauer, 1986; Topp and Zebchuk, 1979), described in Figure S4.3. The suction was gradually increased to $\mathrm{pF} 2$ and the ring samples were weighed to measure the gravimetric water content. FC is defined as the gravimetric water content at pF 2. Soil water repellency was assessed on the ring samples at pF 2 using the WDPT method (Ritsema et al., 2008). An arbitrary WDPT threshold of 5 seconds was used to distinguish between hydrophilic (wettable) and hydrophobic (water-repellent) soils (Dekker et al., 2009). The ring samples were finally dried at $105^{\circ} \mathrm{C}$ for $48 \mathrm{~h}$. The dry mass was used to calculate the water content at saturation and at pF 2 . The porosity was estimated using the volume of water in a saturated sample divided by the total volume (Klute and Dinauer, 1986). The $\rho_{b}$ was measured using the dry mass of the sample and the ring volume (Klute and Dinauer, 1986). 
$\mathrm{pH}\left(\mathrm{H}_{2} \mathrm{O}\right)$ and $\mathrm{EC}$ were measured in a suspension (1:5) of $5 \mathrm{~g}$ of $2 \mathrm{~mm}$ sieved dry soil in $25 \mathrm{ml}$ demineralized water with a SenTix meter and a conductivity cell TetraCon 325, separately (Čapka et al., 2009). ASI was determined using an Eijkelkamp wet sieving apparatus with 4 $\mathrm{g}$ of $2 \mathrm{~mm}$ sieved soil and $\mathrm{NaOH} 2 \mathrm{~g} / \mathrm{L}$ as a dispersing solution (Almajmaie et al., 2017; Kemper and Rosenau, 1986).

\subsubsection{Statistical analysis}

The results of each parameter were analysed using a linear mixed effect model ( Eq.S4.1) implemented in $\mathrm{SAS}^{\circledR} 9.4$ (Littell et al., 2006). Measured variables (i.e. porosity, $\rho_{b}, \mathrm{ks}, \mathrm{FC}$, WDPT, $\mathrm{pH}, \mathrm{EC}$ and $\mathrm{ASI}$ ) were modelled while taking into account the content, type and size of the plastic debris applied to the soil and the soil depth of the sample. Random terms were included to correct for temporal (Block) and positional effects (Pot and Pot-Depth combination).

After fitting the mixed models, the distribution of standardized residuals was checked for approximate normality. Residuals for all parameters, except ks, loosely followed a normal distribution. The residuals for $\log _{10}(\mathrm{ks})$ followed a normal distribution, so $\log _{10}(\mathrm{ks})$ was used for the analysis of ks. For all parameters, the soil depth factor was relatively unimportant (Table 4.3). Therefore, we decided to present the results averaged over both soil depths. The contribution of the main effects of each factor and each factor's interaction with the fitted model was quantified, using F-values and p-values (Table 4.3). The variance components for the random terms (i.e. Block, Block×Pot, Block×Pot×Depth and Residual) were calculated. The random terms contributing to the total variance of the individual observation are shown in Table S4.2. Means and standard errors of means were estimated for all the parameters (Table S4.3). Estimated means and standard errors of means were plotted in R version 3.4.2 (Team, 2013).

For convenience, the model was reparametrized, aggregating factors Type, Size and Content into one single factor Comb (Eq.S4.2) with 13 levels (1 control and 12 factor level combinations). This reparametrized model allowed for simple comparisons of treatments with the Control treatment, as well as other pairwise comparisons, using t-tests (Table 4.2).

In addition, a principal component analysis was performed for the parameters with the most effects (porosity, $\rho b, k s, F C$ and WDPT) and the correlations between porosity, $\rho b$ and ks was further explored with linear regressions. Two equations were tested to fit the porosity and $\rho b$ data. These analyses are presented in supplementary materials. The raw data, the outcomes of the model and the R script used for the plots and calculation are 
available on the GitHub page (https://github.com/NGBeriot/Plastic mulchsoil_properties).

\subsection{Results}

\subsubsection{Soil structure parameters: porosity, dry bulk density $\left(\rho_{b}\right)$ and aggregate stability index (ASI)}

The estimated mean porosity for the Control was $0.43 \pm 0.02$ (Table S4.3). Porosity of the Control was not significantly different for plastic treatments with $0.5 \%$ content (Figure 4.1A). Size-wise comparisons for treatments with Bio plastics at both $1 \%$ and $2 \%$ showed that the macro-sized pieces had higher porosity than micro-sized particles (Table 4.2). Typewise comparisons showed that LDPE-Ma_2 had lower porosity than Bio-Ma_2. Contentwise comparisons for LDPE-Ma showed that porosity for $1 \%$ was higher than the Control, $0.5 \%$ and $2 \%$ contents. For LDPE-Mi, the porosity for $1 \%$ was higher than the Control and $0.5 \%$ content but not different from the $2 \%$ content. For Bio-Ma, the porosity at $1 \%$ and $2 \%$ were not significantly different but they were both higher than the Control.

$\rho_{b}$ of the Control was not significantly different from any of the plastic treatment with $0.5 \%$ content (Figure 4.1B). $\rho_{b}$ decreased with increasing $1 \%$ and $2 \%$ plastic content for all plastic debris except Bio-Mi. Size-wise comparisons showed that for LDPE_1\% and LDPE_2\%, the macro-sized debris had lower $\rho_{b}$ than the micro-sized ones (Table 4.2). Type-wise comparisons showed that for $2 \%$ content, LDPE had lower $\rho_{b}$ than Bio for both macro- and micro- sizes. Content-wise comparisons showed that the addition of LDPE-Ma significantly decreased $\rho_{b}$ as the increase of content went from $0.5 \%$ to $2 \%$.

The estimated mean value of ASI over all the treatments ranged from $0.48 \pm 0.045$ to 0.68 \pm 0.045 , with the Control being $0.56 \pm 0.045$ (Table S4.3). Bio-Mi_0.5 showed significantly higher ASI compared to Bio-Ma_0.5 and no other significant differences in ASI were observed among the treatments (Table 4.2). 

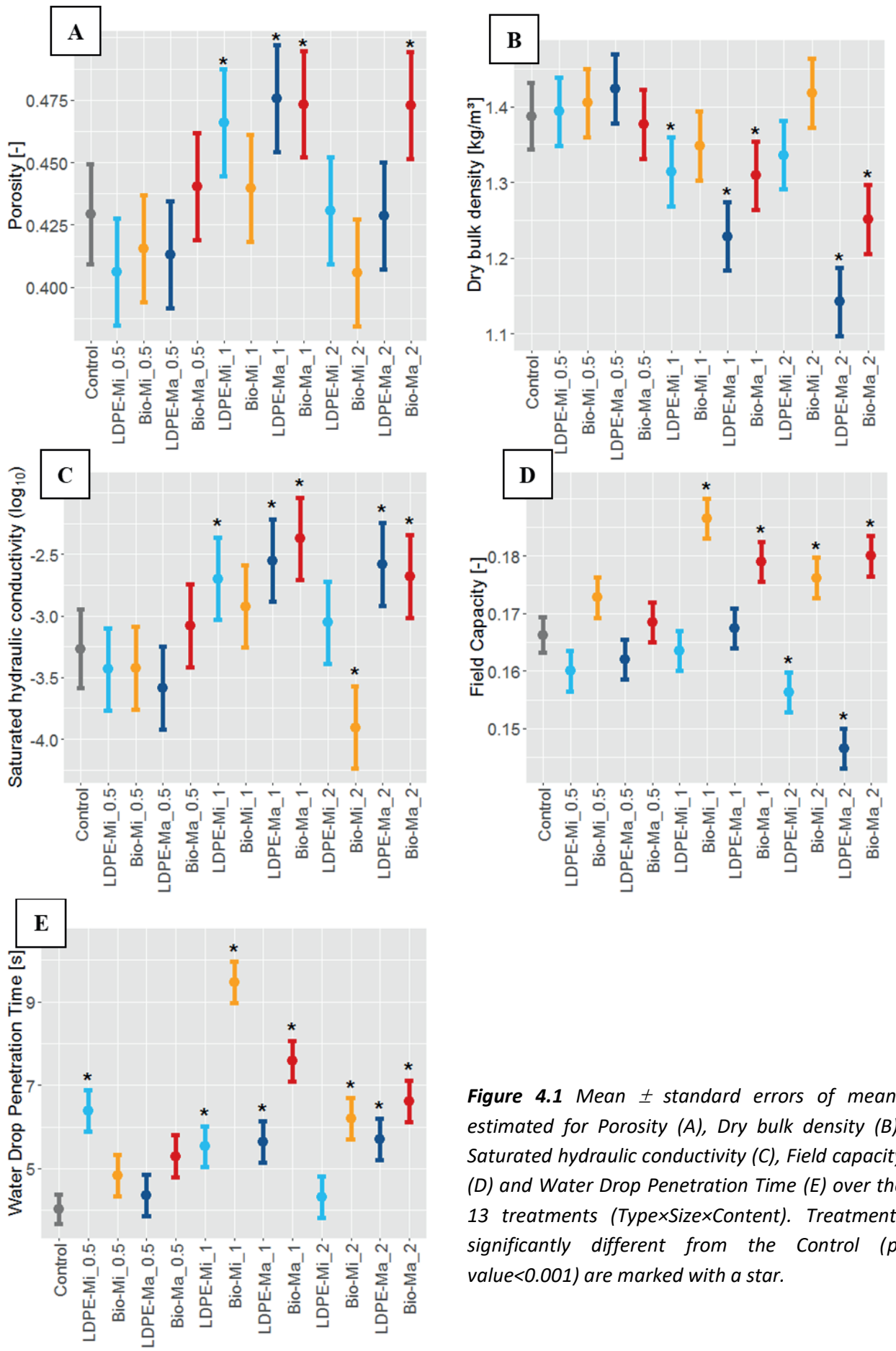

Figure 4.1 Mean \pm standard errors of means estimated for Porosity (A), Dry bulk density (B), Saturated hydraulic conductivity (C), Field capacity (D) and Water Drop Penetration Time (E) over the 13 treatments (TypexSizexContent). Treatments significantly different from the Control ( $p$ value $<0.001$ ) are marked with a star. 
Table 4.2 Estimates of differences between treatments associated with p-value $<0.001$.

\begin{tabular}{|c|c|c|c|c|c|c|c|c|}
\hline & $\begin{array}{l}\text { Porosity } \\
{[-]}\end{array}$ & $\begin{array}{l}\rho \mathrm{b} \\
{\left[\mathrm{kg} / \mathrm{m}^{3}\right]}\end{array}$ & $\begin{array}{l}\log _{10}(\mathrm{ks}) \\
{[-]}\end{array}$ & $\begin{array}{l}\text { FC } \\
{[-]} \\
\end{array}$ & $\begin{array}{l}\text { WDPT } \\
{[\mathrm{s}]}\end{array}$ & $\begin{array}{l}\mathrm{pH} \\
{[-]}\end{array}$ & $\begin{array}{l}\mathrm{EC} \\
{[\mu \mathrm{S} / \mathrm{cm}]}\end{array}$ & $\begin{array}{l}\text { ASI } \\
{[-]}\end{array}$ \\
\hline \multicolumn{9}{|c|}{ Comparison size-wise (Mi-Ma) ; same type, same content } \\
\hline LDPE-Mi_0.5 - LDPE-Ma_0.5 & . & . & . & . & 2.0 & . & . & . \\
\hline LDPE-Mi_1 - LDPE-Ma_1 & . & 0.09 & . & . & . & . & . & . \\
\hline LDPE-Mi_2 - LDPE-Ma_2 & . & 0.19 & -0.47 & 0.01 & . & . & . & . \\
\hline Bio-Mi_0.5 - Bio-Ma_0.5 & . & . & . & . & . & . & . & 0.16 \\
\hline Bio-Mi_1 - Bio-Ma_1 & -0.034 & . & -0.55 & 0.007 & 1.9 & -0.10 & . & . \\
\hline Bio-Mi_2 - Bio-Ma_2 & -0.067 & 0.17 & -1.23 & . & . & . & . & . \\
\hline \multicolumn{9}{|c|}{ Comparison type-wise (LDPE-Bio) ; same size, same content } \\
\hline LDPE-Mi_0.5 - Bio-Mi_0.5 & . & . & . & -0.01 & 1.5 & . & . & . \\
\hline LDPE-Mi_1 - Bio-Mi_1 & . & . & . & -0.02 & -3.9 & . & . & . \\
\hline LDPE-Mi_2 - Bio-Mi_2 & . & -0.08 & 0.85 & -0.02 & -1.9 & . & . & . \\
\hline LDPE-Ma_0.5 - Bio-Ma_0.5 & . & . & -0.51 & . & . & . & . & . \\
\hline LDPE-Ma_1 - Bio-Ma_1 & . & -0.08 & . & -0.01 & -1.9 & . & . & . \\
\hline LDPE-Ma_2 - Bio-Ma_2 & -0.044 & -0.11 & . & -0.03 & . & . & . & . \\
\hline \multicolumn{9}{|c|}{ Comparison content-wise $(0.5-1,0.5-2,1-2)$; same type, same size } \\
\hline LDPE-Mi_0.5 - LDPE-Mi_1 & -0.060 & 0.08 & -0.73 & . & . & . & . & . \\
\hline Bio-Mi_0.5 - Bio-Mi_1 & . & . & . & -0.01 & -4.6 & . & . & . \\
\hline LDPE-Ma_0.5 - LDPE-Ma_1 & -0.062 & 0.20 & -1.03 & . & . & . & . & . \\
\hline Bio-Ma_0.5 - Bio-Ma_1 & . & . & -0.70 & -0.01 & -2.3 & . & . & . \\
\hline LDPE-Mi_0.5 - LDPE-Mi_2 & . & . & . & . & . & . & . & . \\
\hline Bio-Mi_0.5 - Bio-Mi_2 & . & . & . & . & . & . & . & . \\
\hline LDPE-Ma_0.5 - LDPE-Ma_2 & . & 0.28 & -1.01 & 0.015 & . & . & . & . \\
\hline Bio-Ma_0.5 - Bio-Ma_2 & . & 0.13 & . & -0.01 & . & . & . & . \\
\hline LDPE-Mi_1 - LDPE-Mi_2 & . & . & . & . & . & . & . & . \\
\hline Bio-Mi_1 - Bio-Mi_2 & . & . & 0.98 & 0.01 & 3.3 & . & . & . \\
\hline LDPE-Ma_1 - LDPE-Ma_2 & 0.047 & 0.09 & . & 0.021 & . & . & . & . \\
\hline Bio-Ma_1 - Bio-Ma_2 & . & . & . & . & . & . & . & . \\
\hline
\end{tabular}

\subsubsection{Water infiltration parameter: saturated hydraulic conductivity (ks)}

ks of the Control was not significantly different from any of the plastic treatments with $0.5 \%$ content (Figure 4.1C). Size-wise comparisons showed that for Bio_1\% and Bio_2\%, the macro- sized debris had higher ks than the micro-sized ones (Table 4.2). Type-wise comparison showed that treatments LDPE-Ma_0.5 had lower ks than Bio-Ma_0.5, but LDPEMi_2 had higher ks than Bio-Mi_2. Content-wise comparisons showed that the increase from $0.5 \%$ to $1 \%$ of plastic debris increased ks, but not all the differences were statistically significant. There was no further increase of ks with the increase from $1 \%$ to $2 \%$ plastic debris. 


\subsubsection{Soil water retention parameter: field capacity $(F C)$}

FC of the Control was not significantly different from any plastic treatments with $0.5 \%$ content (Figure 4.1D). However, Bio_1\% and Bio_2\% of both macro- and micro- sizes had higher FC than the Control and LDPE_2\% had lower FC than the Control. Size-wise comparisons showed that for Bio_1\% and LDPE_2\%, the macro-sized had lower FC than micro-sized ones (Table 4.2). Type-wise comparisons showed that the treatments with LDPE macro- and micro- sizes had lower FC as compared to Bio. Content-wise comparisons showed that the FC of Bio-Mi at $1 \%$ was higher than the Control, $0.5 \%$ and $2 \%$.

\subsubsection{Soil water repellency parameter: Water Drop Penetration Time (WDPT)}

The WDPT was higher for all of the treatments with plastic residues as compared to the Control (Figure 4.1E). Size-wise comparisons for LDPE_0.5\% and Bio_1\% showed that WDPT was lower for the macro-sized plastics than for the micro-sized plastics (Table 4.2). Typewise comparisons showed that most of the treatments with LDPE had lower WDPT as compared to the treatments with Bio. Content-wise comparisons showed that the WDPT for Bio-Mi at $1 \%$ was higher than the Control, $0.5 \%$ and $2 \%$ contents. The WDPT for LDPEMi decreased with increasing content from $0.5 \%$ to $2 \%$, but the differences were not statistically significant. All treatments, except for the Control, Bio-Mi_0.5, LDPE-Ma_0.5 and LDPE-Mi_2, were above the $5 \mathrm{~s}$ threshold defining water repellent soils.

\subsubsection{Soil chemical properties: $\mathrm{pH}$ and electrical conductivity (EC)}

The estimated mean value of $\mathrm{pH}$ over all of the treatments ranged from $6.28 \pm 0.052$ to 6.42 \pm 0.052 , with the Control at $6.33 \pm 0.052$ (Table S4.3). The estimated mean value of EC over all the treatments ranged from $431 \pm 65$ to $532 \pm 65$, with the Control at $492 \pm 65$ (Table S4.3). We did not observe important variation of $\mathrm{pH}$ and EC caused by the addition of the plastic debris (Table 4.2).

\subsubsection{Main factors and interactions}

The main factor affecting porosity, $\rho b$ and $\log _{10}(\mathrm{ks})$ was the size of the plastic whereas it was the type of the plastic for FC, WDPT and $\mathrm{pH}$ (Table 4.3). Both the type and the size of the plastic had important impacts on $\rho b$. The type of plastic itself did not affect the porosity and the $\log _{10}(\mathrm{ks})$ very much but the TypexSize interaction was responsible for a lot of 
Table 4.3 Tests of Fixed Effects for the four factors and the factor interactions F-value (p-value).

\begin{tabular}{|c|c|c|c|c|c|c|c|c|c|}
\hline $\begin{array}{l}\text { Factor and } \\
\text { Interaction }\end{array}$ & $\begin{array}{l}\text { DF num, } \\
\text { DF den }\end{array}$ & Porosity & $\rho b$ & $\log _{10} k s$ & FC & WDPT & $\mathrm{pH}$ & EC & ASI \\
\hline Content & 2,32 & $\begin{array}{c}11.33 \\
(0.0002)\end{array}$ & $\begin{array}{c}26.13 \\
(<.0001)\end{array}$ & $\begin{array}{c}15.67 \\
(<.0001)\end{array}$ & $\begin{array}{c}12.1 \\
(0.0001)\end{array}$ & $\begin{array}{c}8.3 \\
(0.0017)\end{array}$ & $\begin{array}{c}0.48 \\
(0.62)\end{array}$ & $\begin{array}{c}0.56 \\
(0.57)\end{array}$ & $\begin{array}{c}0.55 \\
(0.65)\end{array}$ \\
\hline Type & 1,31 & $\begin{array}{c}1.51 \\
(0.22)\end{array}$ & $\begin{array}{c}51.42 \\
(<.0001)\end{array}$ & $\begin{array}{c}2.42 \\
(0.12)\end{array}$ & $\frac{506.95}{(<.0001)}$ & $\begin{array}{c}\underline{64.65} \\
(<.0001)\end{array}$ & $\begin{array}{c}\underline{18.59} \\
(0.0002)\end{array}$ & $\begin{array}{c}3.56 \\
(0.063)\end{array}$ & $\begin{array}{c}0.19 \\
(0.66)\end{array}$ \\
\hline Size & 1,31 & $\frac{40.38}{(<.0001)}$ & $\frac{164.62}{(<.0001)}$ & $\begin{array}{c}\underline{71.4} \\
(<.0001)\end{array}$ & $\begin{array}{c}6.09 \\
(0.019)\end{array}$ & $\begin{array}{c}2.33 \\
(0.13)\end{array}$ & $\begin{array}{c}2.63 \\
(0.12)\end{array}$ & $\begin{array}{c}0.27 \\
(0.60)\end{array}$ & $\begin{array}{c}5.32 \\
(0.027)\end{array}$ \\
\hline Depth & 1,31 & $\begin{array}{c}0.17 \\
(0.68)\end{array}$ & $\begin{array}{c}1.77 \\
(0.19)\end{array}$ & $\begin{array}{c}4.63 \\
(0.038)\end{array}$ & $\begin{array}{c}6.72 \\
(0.014)\end{array}$ & $\begin{array}{c}11.16 \\
(0.0021)\end{array}$ & $\begin{array}{c}4.9 \\
(0.034)\end{array}$ & $\begin{array}{c}1.35 \\
(0.25)\end{array}$ & $\begin{array}{c}0.77 \\
(0.39)\end{array}$ \\
\hline $\begin{array}{c}\text { Content } x \\
\text { Type }\end{array}$ & 2,31 & $\begin{array}{c}7.04 \\
(0.0030)\end{array}$ & $\begin{array}{c}27.89 \\
(<.0001)\end{array}$ & $\begin{array}{c}17.5 \\
(<.0001)\end{array}$ & $\begin{array}{c}38.44 \\
(<.0001)\end{array}$ & $\begin{array}{c}31.28 \\
(<.0001)\end{array}$ & $\begin{array}{c}1.69 \\
(0.20)\end{array}$ & $\begin{array}{c}0.41 \\
(0.66)\end{array}$ & $\begin{array}{c}1.11 \\
(0.34)\end{array}$ \\
\hline $\begin{array}{l}\text { Content } x \\
\text { Size }\end{array}$ & 2,31 & $\begin{array}{c}1.76 \\
(0.19)\end{array}$ & $\begin{array}{c}72.08 \\
(<.0001)\end{array}$ & $\begin{array}{c}18.82 \\
(<.0001)\end{array}$ & $\begin{array}{c}0.49 \\
(0.62)\end{array}$ & $\begin{array}{c}12.06 \\
(0.0001)\end{array}$ & $\begin{array}{c}10.03 \\
(0.0004)\end{array}$ & $\begin{array}{c}2.51 \\
(0.089)\end{array}$ & $\begin{array}{c}1.47 \\
(0.24)\end{array}$ \\
\hline Type $\times$ Size & 1,31 & $\begin{array}{c}25.26 \\
(<.0001)\end{array}$ & $\begin{array}{c}0.17 \\
(0.69)\end{array}$ & $\begin{array}{c}29.07 \\
(<.0001)\end{array}$ & $\begin{array}{c}0.75 \\
(0.39)\end{array}$ & $\begin{array}{c}0.23 \\
(0.63)\end{array}$ & $\begin{array}{c}6.66 \\
(0.015)\end{array}$ & $\begin{array}{c}0.0 \\
(0.98)\end{array}$ & $\begin{array}{c}6.15 \\
(0.018)\end{array}$ \\
\hline $\begin{array}{l}\text { Content } \times \\
\text { Type } \times \text { Size }\end{array}$ & 2,31 & $\begin{array}{c}4.8 \\
(0.015)\end{array}$ & $\begin{array}{c}6.55 \\
(0.0042)\end{array}$ & $\begin{array}{c}1.05 \\
(0.36)\end{array}$ & $\begin{array}{c}22.84 \\
(<.0001)\end{array}$ & $\begin{array}{c}16.3 \\
(<.0001)\end{array}$ & $\begin{array}{c}1.45 \\
(0.24)\end{array}$ & $\begin{array}{c}0.93 \\
(0.39)\end{array}$ & $\begin{array}{c}2.42 \\
(0.10)\end{array}$ \\
\hline $\begin{array}{l}\text { Depth } x \\
\text { Content }\end{array}$ & 2,33 & $\begin{array}{c}3.46 \\
(0.043)\end{array}$ & $\begin{array}{c}2.55 \\
(0.0 .93)\end{array}$ & $\begin{array}{c}1.94 \\
(0.16)\end{array}$ & $\begin{array}{c}3.83 \\
(0.032)\end{array}$ & $\begin{array}{c}1.1 \\
(0.34)\end{array}$ & $\begin{array}{c}3.53 \\
(0.041)\end{array}$ & $\begin{array}{c}1.07 \\
(0.35)\end{array}$ & $\begin{array}{c}6.49 \\
(0.0042)\end{array}$ \\
\hline $\begin{array}{l}\text { Depth } \times \\
\text { Type }\end{array}$ & 1,33 & $\begin{array}{c}0.83 \\
(0.37)\end{array}$ & $\begin{array}{c}0.66 \\
(0.42)\end{array}$ & $\begin{array}{c}1.81 \\
(0.19)\end{array}$ & $\begin{array}{c}4.19 \\
(0.049)\end{array}$ & $\begin{array}{c}0.52 \\
(0.48)\end{array}$ & $\begin{array}{c}12.79 \\
(0.0011)\end{array}$ & $\begin{array}{c}1.74 \\
(0.19)\end{array}$ & $\begin{array}{c}1.47 \\
(0.23)\end{array}$ \\
\hline $\begin{array}{l}\text { Depth } \times \\
\text { Size }\end{array}$ & 1,33 & $\begin{array}{c}2.1 \\
(0.16)\end{array}$ & $\begin{array}{c}13.7 \\
(0.0008)\end{array}$ & $\begin{array}{c}8.92 \\
(0.0053)\end{array}$ & $\begin{array}{c}13.06 \\
(0.001)\end{array}$ & $\begin{array}{c}6.89 \\
(0.013)\end{array}$ & $\begin{array}{c}0.07 \\
(0.80)\end{array}$ & $\begin{array}{c}0.02 \\
(0.89)\end{array}$ & $\begin{array}{c}0.19 \\
(0.67)\end{array}$ \\
\hline $\begin{array}{c}\text { Depth } x \\
\text { Content } x \\
\text { Type }\end{array}$ & 2,33 & $\begin{array}{c}2.45 \\
(0.10)\end{array}$ & $\begin{array}{c}3.75 \\
(0.034)\end{array}$ & $\begin{array}{c}5.13 \\
(0.012)\end{array}$ & $\begin{array}{c}6.57 \\
(0.004)\end{array}$ & $\begin{array}{c}1.55 \\
(0.23)\end{array}$ & $\begin{array}{c}4.29 \\
(0.022)\end{array}$ & $\begin{array}{c}1.49 \\
(0.23)\end{array}$ & $\begin{array}{c}1.35 \\
(0.27)\end{array}$ \\
\hline $\begin{array}{c}\text { Depth } \times \\
\text { Content } \times \\
\text { Size }\end{array}$ & 2,33 & $\begin{array}{c}1.45 \\
(0.25)\end{array}$ & $\begin{array}{c}0.45 \\
(0.64)\end{array}$ & $\begin{array}{l}1.12 \\
(0.34)\end{array}$ & $\begin{array}{c}2.32 \\
(0.11)\end{array}$ & $\begin{array}{c}0.1 \\
(0.90)\end{array}$ & $\begin{array}{c}1.11 \\
(0.34)\end{array}$ & $\begin{array}{c}0.94 \\
(0.40)\end{array}$ & $\begin{array}{c}1.21 \\
(0.31)\end{array}$ \\
\hline $\begin{array}{c}\text { Depth } \times \\
\text { Type } \times \text { Size }\end{array}$ & 1,31 & $\begin{array}{c}4.6 \\
(0.040)\end{array}$ & $\begin{array}{c}0.27 \\
(0.60)\end{array}$ & $\begin{array}{c}0.47 \\
(0.50)\end{array}$ & $\begin{array}{c}5.31 \\
(0.028)\end{array}$ & $\begin{array}{c}0.12 \\
(0.73)\end{array}$ & $\begin{array}{c}10.27 \\
(0.003)\end{array}$ & $\begin{array}{c}1.17 \\
(0.28)\end{array}$ & $\begin{array}{c}0.63 \\
(0.43)\end{array}$ \\
\hline $\begin{array}{c}\text { Depth } \times \\
\text { Content } \times \\
\text { Type } \times \text { Size }\end{array}$ & 2,33 & $\begin{array}{c}0.12 \\
(0.88)\end{array}$ & $\begin{array}{c}2.2 \\
(0.13)\end{array}$ & $\begin{array}{c}3.31 \\
(0.049)\end{array}$ & $\begin{array}{c}1.48 \\
(0.24)\end{array}$ & $\begin{array}{c}3.63 \\
(0.038)\end{array}$ & $\begin{array}{c}4.19 \\
(0.0239)\end{array}$ & $\begin{array}{c}1.6 \\
(0.21)\end{array}$ & $\begin{array}{c}1.73 \\
(0.19)\end{array}$ \\
\hline
\end{tabular}

DF num and DF den are the degrees of freedom for numerator and denominator for the F-tests, respectively. $\rho b:$ dry bulk density ; ks: saturated hydraulic conductivity ; FC: field capacity ; WDPT: water drop penetration time ; EC: electrical conductivity; ASI: aggregates stability index. Bold values have $p<0.001$. Underlined values are the highest per parameter when $p<0.001$. 
variation. The content of the plastic played a major role in the porosity, $\rho b, \log _{10}(k s), F C$ and WDPT and always interacted with the Type factor. For each of these five parameters, more than one factor interaction had a significant impact and the 3-factor interaction ContentxTypexSize was significant except for $\log _{10}(\mathrm{ks})$. The soil depth and its interactions with other factors was relatively unimportant. Overall, the studied factor had small effects on EC and ASI.

To further explore the correlation between parameters which were mostly affected by the main factors and their interactions, the principal component analysis for the parameters porosity, $\rho \mathrm{b}, \mathrm{ks}, \mathrm{FC}$ and WDPT were conducted as additional information. The first, second and third principal components explained $89 \%$ of the variance (Table S4.5). The first and second principal components showed that porosity and ks were likely to be positively correlated, while both were likely to be negatively correlated to pb (Figure S4.4A). The correlations porosity/ $\mathrm{pb}$, porosity/ks and $\mathrm{\rho b} / \mathrm{ks}$ had a coefficient of determination of 0.33 , 0.54 and 0.65 , respectively (Figure S4.5). The correlation fit the data except for the treatment LDPE-Ma_2 which had values below the regression lines porosity/pb and $\rho b / k s$. Additionally, the equations Eq.S4.6 and Eq.S4.7 showed that the plastic content plays a minor role in explaining the correlation between porosity and $\rho b$.

\subsection{Discussion}

The present study provides clear experimental evidence that incorporating PMF residues into the tested sandy soil aroused multiple effects on studied soil properties (Figure 4.1). Differences were observed for physicochemical and hydrological parameters, when compared to the treatments with plastic additions and/or with the Control (Table 4.2). The size, type and content of plastic debris presented idiosyncratic effects on tested soil parameters. These soil parameters are closely related with soil type and we only used one sandy soil in this study. Nevertheless, our research aligns with previous studies, suggesting that further research is urgently needed to develop a comprehensive understanding of plastic pollution in agroecosystems.

\subsubsection{Effects of the size, type and content of plastic debris on soil and agroecosystems}

So far, only a few studies have been carried out that examine the effects of plastic residues on soil properties and the research was either focused on macro- or micro-sized debris (de Souza Machado et al., 2018b; Dong et al., 2015; Jiang et al., 2017). In this study, both macro- 
and micro-sized plastic residues had significant impacts on studied soil parameters. Significant differences between the Control and treatments were observed more frequently in treatments with macro-sized debris. In the research of de Souza Machado et al. (2018b), researchers found that MPs affected the $\rho_{b}$, water holding capacity, hydraulic conductivity and water stable aggregates. Dong et al. (2015) found that plastic film residues $\left(0-100 \mathrm{~cm}^{2}\right)$ affected soil moisture content, porosity, $\mathrm{pH}$, organic matter and worsened soil quality. Jiang et al. (2017) demonstrated that residual PMF fragments changed soil properties, e.g. soil water content, $\rho_{b}$, ks and porosity, and altered soil water distribution involved with plant roots. Since different conditions were used for these studies, it is hardly feasible to directly compare the results.

In a previous study, using the same kind of soil and plastic materials, the addition of $1 \%$ plastic residues had significantly negative effects on crop growth and micro-sized plastic residues showed more negative effects than macro-sized residues (Qi et al., 2018). In the current experiment, with the same plastic type and content, treatments with micro-sized residues showed significantly lower porosity and ks, and higher $\rho_{b}$, FC and WDPT, in some cases. Although the changes, even if statistically significant, were relatively small, we hypothesized that the changes in these soil properties brought about by the addition of plastic residues may negatively affect soil quality and plant growth. In the long run, plastic debris could be eventually degraded into micro- and nanoplastics due to various biotic and abiotic stressors (Barnes et al., 2009; Singh and Sharma, 2008). Studies about plastic debris in different sizes are needed to assess the long term effects of microplastics in soil.

In this study, we found that Bio and LDPE plastic debris showed significantly different effects on soil properties even with the same size and content. Correspondingly, with the same soil and plastic materials (at content 1\%), Qi et al. (2018) concluded that Bio plastic debris had stronger negative effects on crop yield and growth than LDPE. Hence, the negative effects on plant growth could be partly explained by the effects of plastic debris on soil properties. Regarding different types of plastic debris, de Souza Machado et al. (2018b) tested four different types of MPs and found that polyester fibres showed the most noticeable impacts on the soil biophysical environment as compared with polyacrylic fibres, polyamide beads and polyethylene fragments. Unfortunately, previous studies of Bio mulch films mainly focused on their performance in agriculture (Anzalone et al., 2010; Kapanen et al., 2008; Miles et al., 2012) or their degradation and deterioration patterns (Li et al., 2014b; Moreno et al., 2017). Li et al. (2014a) buried two starch-based mulches, one polylactic acid mulch and one cellulose-based mulch, in a field for 18 months and suggested that the Bio mulch films had minor effects on the soil quality during the evaluation period. As Sintim and Flury discussed (2017), although Bio mulch films may be encouraging substitutes for traditional polyethylene films, in-depth and comprehensive studies, focussing on the potential release of micro- and nanoplastics during degradation processes among others, should be 
conducted before they are widely utilized. Overall, Bio plastics should not be considered as the panacea for plastic pollution in agroecosystems without in-depth research.

In our experiment, we set the same gradient for the four kinds of plastic debris tested, i.e. $0.5 \%, 1 \%, 2 \%$ and the Control at $0 \%$. It is difficult to concisely summarize the content-wise effects of different plastic debris on various soil parameters since quite a few low-content plastic debris showed stronger effects than high-content debris even if the plastic sizes and types were all the same. Similarly, de Souza Machado et al. (2018b) added a series of concentrations for different MPs ranging from $0.05 \%$ to $2.00 \%$ to the soil and they found the apparent nonmonotonic dose responses of soil biophysical proxies. Although de Souza Machado et al. (2018b) suggested that it was unrealistic to assess this nonmonotonicity based on current experimental data, they intensively discussed the potential interactions among plastic particles and natural matter in the heterogeneous terrestrial ecosystem. The addition of plastic debris in the soil would affect multiple soil processes and the interactions between plastic particles and natural matter were unpredictable (de Souza Machado et al., 2018b).

Regrettably, to the best of our knowledge, there are no experiments that have been carried out on the effects of the MPs content gradients on crop growth so we could not estimate the dose responses of crops to MPs in the soil. Nevertheless, there are quite a few studies that have been conducted in China on the impacts of macroplastic residue gradients (from 0 to $1440 \mathrm{~kg} \mathrm{hm}^{-2}$ ) on crop growth and soil quality (Huang et al., 2019; Nan et al., 1996; Zhang et al., 2014; Zhao et al., 1998). For instance, Zhao et al. (1998) found monotonic responses of crop yield, $\rho_{b}$ and porosity to the gradient of residual PMF weight $(0,37.5,75$, $150,225,300,375$ and $450 \mathrm{~kg} \mathrm{hm}^{-2}$ ). While Huang et al. (2019) also observed glaring adverse effects of plastic residues on the growth and yield of potato, they did not find any linear correlation between the yield and the residual amount of PMF $(0,90,180,360$ and $720 \mathrm{~kg}$ $\mathrm{hm}^{-2}$ ). Regardless, considering the undeniable nonmonotonicity in the responses of the soil matrix to plastic debris, further studies using a series of gradients are urgently needed to elucidate the mechanisms and dose responses.

\subsubsection{Limitations and wider implications for ecological assessment of plastic debris in soil}

We have asserted that the types, sizes and contents of the plastic debris has had distinct effects on selected soil properties in our study and interactions mattered in some cases. Parameters of soil structure, water infiltration, water retention and soil water repellency all responded vigorously during the experimental period, but not many effects were measured 
in the soil chemical parameters, i.e. $\mathrm{pH}$ and EC. On one hand, one month might be too short for plastic debris to initiate chemical alterations in the soil. On the other hand, other soil chemical parameters may react more swiftly than $\mathrm{pH}$ and EC. It is difficult to explain the variations of parameters in the presence of plastic debris in the soil. For instance, the effects of plastic debris on porosity and $\rho b$ cannot be explained by the lower density of plastic compared to the soil particles using Eq.S4.6 and Eq.S4.7. In this study, only the effective porosity was measured using the saturation method and only a sandy soil was tested. Therefore, more tests using different soil textures are required to understand how plastic debris may affect the soil's physical and hydrological parameters.

We did not expect the plastic to undergo significant degradation during this one-month experiment. PMF was designed to keep its integrity over the crop growing season (> 1 month) and exposure to UV irradiation from the sun is a significant factor in plastic degradation (Napper and Thompson, 2019). The properties of plastic will change during degradation and therefore, we could expect they may have different interactions with the soil. Further studies should take into account the degradation of plastics in long-term experiments and aging plastic debris could be used to compare with virgin debris.

With regards to soil properties, a soil's biological trait is a vital aspect, along with soil physical and chemical parameters (Bünemann et al., 2018). With the same plastic materials and soil, Qi et al. (2020b) found that the rhizosphere bacterial communities were significantly affected by the presence of Bio PMF residues. When Li et al. (2014a) investigated the effects of mulch film residues on soil quality, they calculated the soil quality index based on microbial biomass carbon, $\beta$-glucosidase, EC, total organic carbon and $\mathrm{pH}$, so that the alterations of soil quality among treatments could be clearly presented by numerical comparisons. While scientists try to obtain an overall soil quality index for comparisons, as Bünemann et al. (2018) critically reviewed, an assessment framework based on a logical-sieve method would be useful for the assessment of targeted soil threats. Hence, establishing an assessment framework which can be applied universally for plastic debris in soil would be profoundly pragmatic for further studies.

\subsection{Conclusion}

Overall, we saw that both LDPE and Bio PMF debris in either macro- or micro- sizes had noticeable effects on soil physicochemical and hydrological parameters and these properties of tested sandy soil nonmonotonically responded to residual amounts of PMFs. For instance, the presence of LDPE debris decreased field capacity, while Bio plastic debris increased it. Macro-sized plastic debris presented more differences between the Control, 
compared to micro-sized ones. Special attention should be paid to the fundamental properties of soil in order to gain a comprehensive understanding of the potential effects of plastic residues on soils. Concerning their conspicuous mischief and long-term existence, we eagerly call on further interdisciplinary studies for various types, sizes and contents of plastic debris in soil and agroecosystems.

\section{Acknowledgements}

This research was funded by the National Natural Science Foundation of China (41877072), the Natural Science Basic Research Plan in Shaanxi Province of China (2019JQ-639) and the EU Horizon 2020 project (ISQAPER: 635750). We are thankful for the financial support from the China Scholarship Council (CSC: 201604910510). We acknowledge Taede Stoker from Unifarm of Wageningen University \& Research for providing the soil, the pots and helpful information. Many thanks to Klaas Oostindie and Piet Peters from the SLM group (WUR) for their expertise in water repellency and soil aggregate stability, respectively. Thanks to Henny Gertsen for helping prepare the plastic materials. We acknowledge Maarten van der Zee from the Agrotechnology \& Food Science group of WUR for his expertise about plastics. We are very grateful to Robin Palmer for the language editing. 


\section{Supplementary Material}

\section{S4.1 Experimental set up}

Table S4.1 Detailed information about soil used in the experiment.

\begin{tabular}{lll}
\hline soil parameters & unit & results \\
\hline Total nitrogen & $\mathrm{kg} / \mathrm{ha}$ & 3775 \\
$\mathrm{C} / \mathrm{N}$ ratio & & 17 \\
Available nitrogen & $\mathrm{kg} / \mathrm{ha}$ & 45 \\
Total sulfur & $\mathrm{kg} / \mathrm{ha}$ & 995 \\
$\mathrm{C} / \mathrm{S}$ ratio & & 66 \\
Available sulfur & $\mathrm{kg} / \mathrm{ha}$ & 15 \\
Total phosphorus & $\mathrm{kg} / \mathrm{ha}$ & 695 \\
Total potassium & $\mathrm{kg} / \mathrm{ha}$ & 505 \\
Total calcium & $\mathrm{kg} / \mathrm{ha}$ & 3840 \\
Total Magnesium & $\mathrm{kg} / \mathrm{ha}$ & 260 \\
pH & & 6 \\
Organic carbon & $\%$ & 2 \\
Organic matter & $\%$ & 4 \\
Inorganic carbon & $\%$ & 0.07 \\
Carbonated lime & $\%$ & $<0.2$ \\
clay & $\%$ & 1 \\
silt & $\%$ & 12 \\
sand & $\%$ & 87 \\
\hline
\end{tabular}

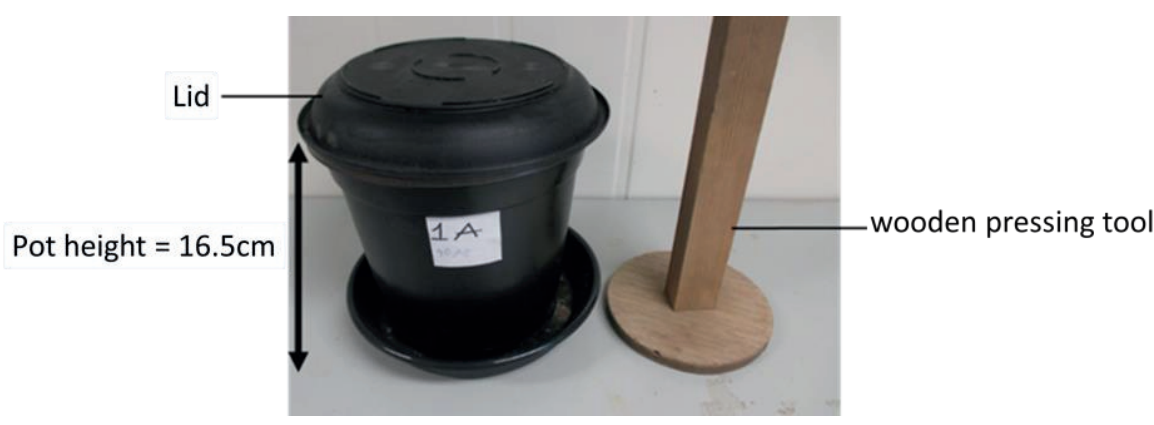

Figure S4.1 Pot and wooden pressing tool. 


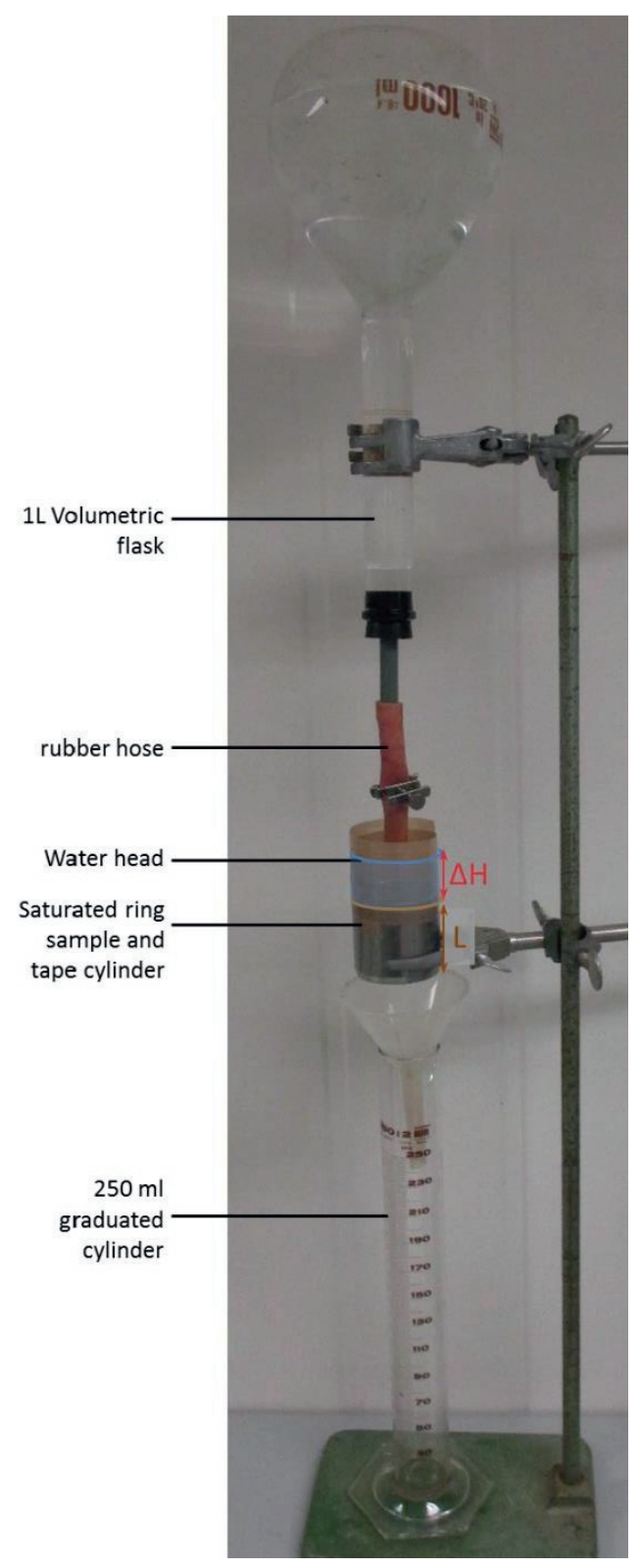

Figure S4.2 Experimental set-up for measuring the saturated hydraulic conductivity with free outflow. The inverted flask with the tube reaching down to within the taped rim (brown) serves as a Mariotte flask that Maintains a constant water level above the sample (grey cylinder). 


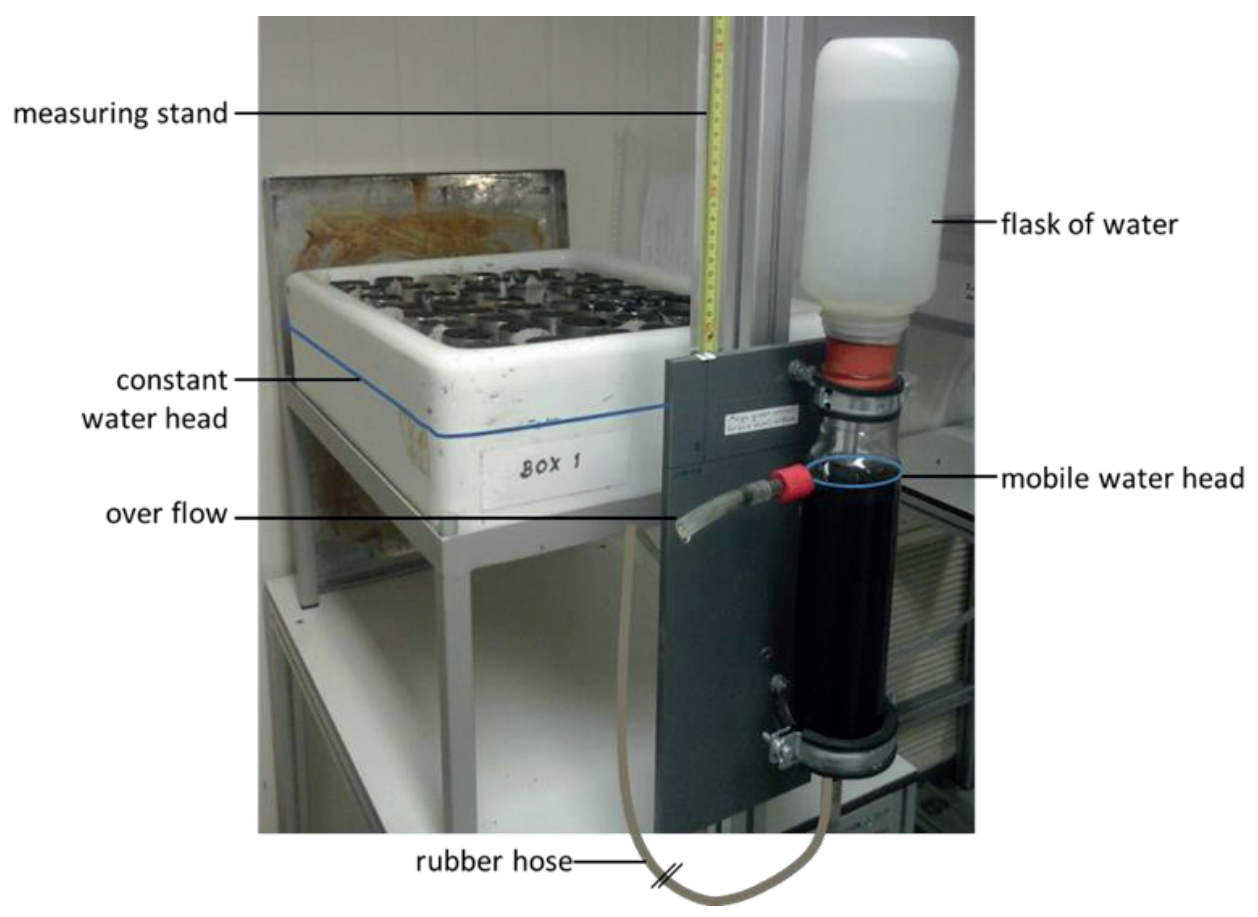

Figure S4.3 Experimental set-up for measuring the field capacity.

\section{S4.2 Linear mixed effect model}

Eq.S4.1: Factorial mixed effect model

$$
\begin{aligned}
Y= & \text { Content }+ \text { Type }+ \text { Size }+ \text { Depth } \\
& + \text { Content } \times \text { Type }+ \text { Content } \times \text { Size }+ \text { Content } \times \text { Depth } \\
& + \text { Type } \times \text { Size }+ \text { Type } \times \text { Layer }+ \text { Size } \times \text { Depth } \\
& + \text { Content } \times \text { Type } \times \text { Size }+ \text { Content } \times \text { Type } \times \text { Depth } \\
& + \text { Content } \times \text { Size } \times \text { Depth }+ \text { Type } \times \text { Size } \times \text { Depth } \\
& + \text { Content } \times \text { Type } \times \text { Size } \times \text { Depth } \\
& + \text { Random }+\varepsilon
\end{aligned}
$$

Random $=$ Block + Block $\times$ Pot + Block $\times$ Pot $\times$ Depth

In this model, $\mathrm{Y}$ represents the measured variable (i.e. porosity, dry bulk density, saturated hydraulic conductivity, water retention, $\mathrm{pH}$, electrical conductivity, and Aggregation Stability Index). Content, Type, and Size are fixed factors for the content, type and size, respectively, of the plastic debris added to the soil and Depth represents the position of the 
sample, either top depth $(0-5 \mathrm{~cm})$ or bottom depth $(7-12 \mathrm{~cm})$. Random terms were included to correct for temporal (Block) and positional effects (Pot and Pot-Depth combination). Block refers to an (incomplete) block of the experiment during a specific month, during which the Control treatment and one of the three levels of the content factor was investigated. Block $\times$ Pot refers to the set of observations stemming from one individual pot (eight observations for ring samples, and four observations for air dried soil samples). Block $\times$ Pot $\times$ Depth combination refers to the set of observations stemming from one part (top or bottom) of a pot (four observations for ring samples, two for air dried soil samples). The resulting analysis is a type of split-plot analysis with factors Content, Type and Size assigned to pots (forming the "main plots"), making pots the experimental units for these factors. Factor Depth has two distinct values within each pot, making the pot-depth combinations the experimental unit (forming the "subplots"). The individual sample (ring or air dried sample) form the measurement units at the lowest level of the hierarchy.

Factors Content, Type and Size were aggregated into a single treatment factor leading to the following model:

Eq.S4.2: Reparametrized Mixed model with aggregated treatment factor.

$Y=C o m b+$ Depth + Comb $\times$ Depth + Random $+\varepsilon$ Eq.

Random $=$ Block + Block $\times$ Pot + Block $\times$ Pot $\times$ Depth

Comb represents the combination of factors Type, Size and Content into one single factor. There are two Type levels (LDPE and Bio), two Size levels (Ma and Mi), three Content levels $(0.5 \%, 1 \%, 2 \%)$ and one control so Comb has 13 levels in total.

Table S4.2 Variance component percentage of each random term for all parameters. Bold values are the highest per parameter.

\begin{tabular}{lllllllll}
\hline & Porosity & $\mathrm{pb}$ & $\log 10(\mathrm{ks})$ & $\mathrm{FC}$ & $\mathrm{pH}$ & $\mathrm{EC}$ & $\mathrm{ASI}$ & WDPT \\
\hline Block & $75 \%$ & $83 \%$ & $82 \%$ & $67 \%$ & $73 \%$ & $59 \%$ & $6 \%$ & $17 \%$ \\
Block*Pot & $5 \%$ & $2 \%$ & $3 \%$ & $10 \%$ & $1 \%$ & $0 \%$ & $5 \%$ & $2 \%$ \\
Block*Pot*Depth & $1 \%$ & $3 \%$ & $4 \%$ & $3 \%$ & $13 \%$ & $25 \%$ & $16 \%$ & $6 \%$ \\
Residual & $19 \%$ & $11 \%$ & $11 \%$ & $20 \%$ & $13 \%$ & $16 \%$ & $73 \%$ & $75 \%$ \\
\hline
\end{tabular}


Table S4.3 Estimated Mean and Standard Error of the estimated mean (SE) for all the parameters.

\begin{tabular}{|c|c|c|c|c|c|c|c|c|}
\hline & $\begin{array}{l}\text { Porosity } \\
{[-]}\end{array}$ & $\begin{array}{l}\rho b \\
{\left[\mathrm{~g} / \mathrm{cm}^{3}\right]}\end{array}$ & $\begin{array}{l}\log 10(k s) \\
{[-]}\end{array}$ & $\begin{array}{l}\text { FC } \\
{[-]}\end{array}$ & $\begin{array}{l}\text { ASI } \\
{[-]}\end{array}$ & $\begin{array}{l}\text { WDPT } \\
{[\mathrm{s}]}\end{array}$ & $\begin{array}{l}\mathrm{pH} \\
{[-]}\end{array}$ & $\begin{array}{l}\mathrm{EC} \\
{[\mu \mathrm{S} / \mathrm{cm}]}\end{array}$ \\
\hline $\mathrm{Ck}$ & 0.43 & 1.39 & -3.27 & 0.166 & 0.56 & 4.0 & 6.33 & 492 \\
\hline LDPE-Mi_0.5 & 0.41 & 1.39 & -3.43 & 0.160 & 0.59 & 6.4 & 6.32 & 462 \\
\hline LDPE-Ma_0.5 & 0.41 & 1.42 & -3.59 & 0.162 & 0.59 & 4.4 & 6.35 & 466 \\
\hline Bio-Mi_0.5 & 0.42 & 1.40 & -3.42 & 0.173 & 0.65 & 4.8 & 6.38 & 445 \\
\hline Bio-Ma_0.5 & 0.44 & 1.38 & -3.08 & 0.169 & 0.48 & 5.3 & 6.42 & 463 \\
\hline LDPE-Mi_1 & 0.47 & 1.31 & -2.70 & 0.164 & 0.60 & 5.5 & 6.32 & 532 \\
\hline LDPE-Ma_1 & 0.48 & 1.23 & -2.55 & 0.167 & 0.64 & 5.6 & 6.35 & 524 \\
\hline Bio-Mi_1 & 0.44 & 1.35 & -2.92 & 0.187 & 0.68 & 9.5 & 6.32 & 517 \\
\hline Bio-Ma_1 & 0.47 & 1.31 & -2.37 & 0.179 & 0.62 & 7.6 & 6.41 & 448 \\
\hline LDPE-Mi_2 & 0.43 & 1.34 & -3.05 & 0.156 & 0.61 & 4.3 & 6.36 & 490 \\
\hline LDPE-Ma_2 & 0.43 & 1.14 & -2.58 & 0.147 & 0.56 & 5.7 & 6.28 & 519 \\
\hline Bio-Mi_2 & 0.41 & 1.42 & -3.91 & 0.176 & 0.61 & 6.2 & 6.36 & 431 \\
\hline Bio-Ma_2 & 0.47 & 1.25 & -2.68 & 0.180 & 0.59 & 6.6 & 6.35 & 505 \\
\hline SE & 0.021 & 0.046 & 0.34 & 0.0035 & 0.045 & 0.50 & 0.052 & 65 \\
\hline
\end{tabular}


Table S4.4 Estimates of differences between treatments ( $p$-value) for porosity, dry bulk density ( $\rho b)$, saturated hydraulic conductivity ( $k s)$, field capacity ( $F C$ ) in table A. and water drop penetration time (WDPT), electrical conductivity (EC), aggregates stability index (ASI) in table $B$. The values associated with $p$-value < 0.001 are in darker color.

\begin{tabular}{|c|c|c|c|c|}
\hline A. & $\begin{array}{l}\text { Porosity } \\
{[-]}\end{array}$ & $\begin{array}{l}\rho b \\
{\left[\mathrm{~kg} / \mathrm{m}^{3}\right]}\end{array}$ & $\begin{array}{l}\log _{10}(\mathrm{ks}) \\
{[-]}\end{array}$ & $\begin{array}{l}\text { FC } \\
{[-]}\end{array}$ \\
\hline \multicolumn{5}{|c|}{ Comparison with the control } \\
\hline LDPE-Mi_0.5 - Control & $-0.023(0.015)$ & $0.006(0.709)$ & $-0.17(0.198)$ & $-0.006(0.003)$ \\
\hline Bio-Mi_0.5 - Control & $-0.014(0.136)$ & $0.017(0.268)$ & $-0.16(0.226)$ & $0.007(0.002)$ \\
\hline LDPE-Ma_0.5 - Control & $-0.016(0.083)$ & $0.036(0.026)$ & $-0.32(0.017)$ & $-0.004(0.037)$ \\
\hline Bio-Ma_0.5 - Control & $0.011(0.238)$ & $-0.01(0.503)$ & $0.19(0.141)$ & $0.002(0.257)$ \\
\hline LDPE-Mi_1 - Control & $0.037(0.0001)$ & $-0.074(<.0001)$ & $0.57(<.0001)$ & $-0.003(0.138)$ \\
\hline Bio-Mi_1 - Control & $0.01(0.236)$ & $-0.039(0.01)$ & $0.35(0.006)$ & $0.02(<.0001)$ \\
\hline LDPE-Ma_1 - Control & $0.046(<.0001)$ & $-0.159(<.0001)$ & $0.72(<.0001)$ & $0.001(0.536)$ \\
\hline Bio-Ma_1 - Control & $0.044(<.0001)$ & $-0.079(<.0001)$ & $0.89(<.0001)$ & $0.013(<.0001)$ \\
\hline LDPE-Mi_2 - Control & $0.001(0.891)$ & $-0.051(0.002)$ & $0.21(0.099)$ & $-0.01(<.0001)$ \\
\hline Bio-Mi_2 - Control & $-0.024(0.014)$ & $0.03(0.06)$ & $-0.64(<.0001)$ & $0.01(<.0001)$ \\
\hline LDPE-Ma_2 - Control & $-0.001(0.939)$ & $-0.246(<.0001)$ & $0.69(<.0001)$ & $-0.02(<.0001)$ \\
\hline Bio-Ma_2 - Control & $0.043(<.0001)$ & $-0.137(<.0001)$ & $0.59(<.0001)$ & $0.014(<.0001)$ \\
\hline \multicolumn{5}{|c|}{ Comparison size-wise (Mi-Ma); same type, same content } \\
\hline LDPE-Mi_0.5 - LDPE-Ma_0.5 & $-0.007(0.441)$ & $-0.03(0.057)$ & $0.15(0.231)$ & $-0.002(0.313)$ \\
\hline LDPE-Mi_1 - LDPE-Ma_1 & $-0.01(0.297)$ & $0.085(<.0001)$ & $-0.15(0.248)$ & $-0.004(0.051)$ \\
\hline LDPE-Mi_2 - LDPE-Ma_2 & $0.002(0.831)$ & $0.194(<.0001)$ & $-0.47(0.0007)$ & $0.01(<.0001)$ \\
\hline Bio-Mi_0.5 - Bio-Ma_0.5 & $-0.025(0.01)$ & $0.028(0.08)$ & $-0.35(0.01)$ & $0.004(0.038)$ \\
\hline Bio-Mi_1 - Bio-Ma_1 & $-0.034(0.0007)$ & $0.039(0.016)$ & $-0.55(0.0001)$ & $0.007(0.0006)$ \\
\hline Bio-Mi_2 - Bio-Ma_2 & $-0.067(<.0001)$ & $0.167(<.0001)$ & $-1.23(<.0001)$ & $-0.004(0.063)$ \\
\hline \multicolumn{5}{|c|}{ Comparison type-wise (LDPE-Bio); same size, same content } \\
\hline LDPE-Mi_0.5 - Bio-Mi_0.5 & $-0.009(0.306)$ & $-0.012(0.457)$ & $-0.01(0.938)$ & $-0.013(<.0001)$ \\
\hline LDPE-Mi_1 - Bio-Mi_1 & $0.026(0.006)$ & $-0.034(0.033)$ & $0.22(0.084)$ & $-0.023(<.0001)$ \\
\hline LDPE-Mi_2 - Bio-Mi_2 & $0.025(0.01)$ & $-0.081(<.0001)$ & $0.85(<.0001)$ & $-0.02(<.0001)$ \\
\hline LDPE-Ma_0.5 - Bio-Ma_0.5 & $-0.027(0.005)$ & $0.047(0.005)$ & $-0.51(0.0003)$ & $-0.007(0.002)$ \\
\hline LDPE-Ma_1 - Bio-Ma_1 & $0.002(0.801)$ & $-0.08(<.0001)$ & $-0.18(0.165)$ & $-0.012(<.0001)$ \\
\hline LDPE-Ma_2 - Bio-Ma_2 & $-0.044(<.0001)$ & $-0.109(<.0001)$ & $0.1(0.438)$ & $-0.034(<.0001)$ \\
\hline \multicolumn{5}{|c|}{ Comparison content-wise $(0.5-1,0.5-2,1-2)$; same type, same size } \\
\hline LDPE-Mi_0.5 - LDPE-Mi_1 & $-0.06(<.0001)$ & $0.079(0.0007)$ & $-0.73(0.0002)$ & $-0.004(0.205)$ \\
\hline Bio-Mi_0.5 - Bio-Mi_1 & $-0.024(0.061)$ & $0.057(0.011)$ & $-0.5(0.007)$ & $-0.014(<.0001)$ \\
\hline LDPE-Ma_0.5 - LDPE-Ma_1 & $-0.062(<.0001)$ & $0.195(<.0001)$ & $-1.03(<.0001)$ & $-0.005(0.053)$ \\
\hline Bio-Ma_0.5 - Bio-Ma_1 & $-0.033(0.012)$ & $0.068(0.003)$ & $-0.7(0.0003)$ & $-0.01(0.0005)$ \\
\hline LDPE-Mi_0.5 - LDPE-Mi_2 & $-0.025(0.066)$ & $0.057(0.014)$ & $-0.38(0.042)$ & $0.004(0.196)$ \\
\hline Bio-Mi_0.5 - Bio-Mi_2 & $0.01(0.456)$ & $-0.013(0.565)$ & $0.48(0.011)$ & $-0.003(0.225)$ \\
\hline LDPE-Ma_0.5 - LDPE-Ma_2 & $-0.016(0.236)$ & $0.282(<.0001)$ & $-1.01(<.0001)$ & $0.015(<.0001)$ \\
\hline Bio-Ma_0.5 - Bio-Ma_2 & $-0.033(0.017)$ & $0.126(<.0001)$ & $-0.4(0.032)$ & $-0.011(0.0003)$ \\
\hline LDPE-Mi_1 - LDPE-Mi_2 & $0.035(0.008)$ & $-0.022(0.298)$ & $0.36(0.047)$ & $0.007(0.012)$ \\
\hline Bio-Mi_1 - Bio-Mi_2 & $0.034(0.011)$ & $-0.07(0.002)$ & $0.98(<.0001)$ & $0.01(0.0006)$ \\
\hline LDPE-Ma_1 - LDPE-Ma_2 & $0.047(0.0007)$ & $0.087(0.0003)$ & $0.03(0.867)$ & $0.021(<.0001)$ \\
\hline Bio-Ma_1 - Bio-Ma_2 & $0(0.97)$ & $0.058(0.01)$ & $0.31(0.086)$ & $-0.001(0.713)$ \\
\hline
\end{tabular}

pb: dry bulk density; ks: saturated hydraulic conductivity; FC: field capacity 


\begin{tabular}{|c|c|c|c|c|}
\hline B. & $\begin{array}{l}\text { WDPT } \\
{[\mathrm{s}]}\end{array}$ & $\begin{array}{l}\mathrm{pH} \\
{[-]}\end{array}$ & $\begin{array}{l}\mathrm{EC} \\
{[\mu \mathrm{S} / \mathrm{cm}]}\end{array}$ & $\begin{array}{l}\text { ASI } \\
{[-]}\end{array}$ \\
\hline \multicolumn{5}{|c|}{ Comparison with the control } \\
\hline LDPE-Mi_0.5 - Control & $2.36(<.0001)$ & $-0.009(0.723)$ & $-30.28(0.459)$ & $0.031(0.528)$ \\
\hline Bio-Mi_0.5 - Control & $0.82(0.064)$ & $0.059(0.026)$ & $-47.53(0.246)$ & $0.088(0.08)$ \\
\hline LDPE-Ma_0.5 - Control & $0.34(0.427)$ & $0.02(0.425)$ & $-25.62(0.531)$ & $0.037(0.445)$ \\
\hline Bio-Ma_0.5 - Control & $1.28(0.005)$ & $0.092(0.0009)$ & $-29.53(0.47)$ & $-0.075(0.132)$ \\
\hline LDPE-Mi_1 - Control & $1.51(0.0006)$ & $-0.001(0.963)$ & $39.46(0.301)$ & $0.04(0.367)$ \\
\hline Bio-Mi_1 - Control & $5.45(<.0001)$ & $-0.009(0.715)$ & $24.55(0.519)$ & $0.124(0.01)$ \\
\hline LDPE-Ma_1 - Control & $1.62(0.0003)$ & $0.027(0.251)$ & $32.38(0.395)$ & $0.083(0.071)$ \\
\hline Bio-Ma_1 - Control & $3.55(<.0001)$ & $0.089(0.0006)$ & $-43.62(0.253)$ & $0.067(0.139)$ \\
\hline LDPE-Mi_2 - Control & $0.29(0.5)$ & $0.039(0.128)$ & $-1.95(0.962)$ & $0.048(0.326)$ \\
\hline Bio-Mi_2 - Control & $2.17(<.0001)$ & $0.032(0.216)$ & $-61.2(0.137)$ & $0.057(0.247)$ \\
\hline LDPE-Ma_2 - Control & $1.67(0.0004)$ & $-0.048(0.066)$ & $27.13(0.507)$ & $0.008(0.874)$ \\
\hline Bio-Ma_2 - Control & $2.6(<.0001)$ & $0.028(0.267)$ & $13.38(0.743)$ & $0.03(0.532)$ \\
\hline \multicolumn{5}{|c|}{ Comparison size-wise (Mi-Ma); same type, same content } \\
\hline LDPE-Mi_0.5 - LDPE-Ma_0.5 & $2.01(<.0001)$ & $-0.029(0.248)$ & $-4.67(0.908)$ & $-0.006(0.878)$ \\
\hline LDPE-Mi_1 - LDPE-Ma_1 & $-0.11(0.797)$ & $-0.028(0.262)$ & $7.08(0.86)$ & $-0.043(0.317)$ \\
\hline LDPE-Mi_2 - LDPE-Ma_2 & $-1.38(0.002)$ & $0.087(0.001)$ & $-29.08(0.47)$ & $0.04(0.345)$ \\
\hline Bio-Mi_0.5 - Bio-Ma_0.5 & $-0.46(0.271)$ & $-0.033(0.188)$ & $-18(0.654)$ & $0.163(0.0005)$ \\
\hline Bio-Mi_1 - Bio-Ma_1 & $1.89(<.0001)$ & $-0.098(0.0004)$ & $68.17(0.093)$ & $0.057(0.187)$ \\
\hline Bio-Mi_2 - Bio-Ma_2 & $-0.43(0.306)$ & $0.003(0.894)$ & $-74.58(0.067)$ & $0.027(0.531)$ \\
\hline \multicolumn{5}{|c|}{ Comparison type-wise (LDPE-Bio); same size, same content } \\
\hline LDPE-Mi_0.5 - Bio-Mi_0.5 & $1.54(0.0007)$ & $-0.068(0.011)$ & $17.25(0.668)$ & $-0.058(0.18)$ \\
\hline LDPE-Mi_1 - Bio-Mi_1 & $-3.94(<.0001)$ & $0.008(0.764)$ & $14.92(0.711)$ & $-0.083(0.056)$ \\
\hline LDPE-Mi_2 - Bio-Mi_2 & $-1.88(<.0001)$ & $0.008(0.764)$ & $59.25(0.144)$ & $-0.009(0.833)$ \\
\hline LDPE-Ma_0.5 - Bio-Ma_0.5 & $-0.93(0.03)$ & $-0.072(0.007)$ & $3.92(0.922)$ & $0.112(0.012)$ \\
\hline LDPE-Ma_1 - Bio-Ma_1 & $-1.94(<.0001)$ & $-0.062(0.018)$ & $76(0.062)$ & $0.016(0.708)$ \\
\hline LDPE-Ma_2 - Bio-Ma_2 & $-0.92(0.032)$ & $-0.076(0.005)$ & $13.75(0.732)$ & $-0.023(0.595)$ \\
\hline \multicolumn{5}{|c|}{ Comparison content-wise $(0.5-1,0.5-2,1-2)$; same type, same size } \\
\hline LDPE-Mi_0.5 - LDPE-Mi_1 & $0.85(0.162)$ & $-0.008(0.82)$ & $-69.75(0.216)$ & $-0.01(0.889)$ \\
\hline Bio-Mi_0.5 - Bio-Mi_1 & $-4.63(<.0001)$ & $0.067(0.059)$ & $-72.08(0.201)$ & $-0.036(0.614)$ \\
\hline LDPE-Ma_0.5 - LDPE-Ma_1 & $-1.27(0.039)$ & $-0.007(0.839)$ & $-58(0.303)$ & $-0.046(0.517)$ \\
\hline Bio-Ma_0.5 - Bio-Ma_1 & $-2.28(0.0005)$ & $0.003(0.931)$ & $14.09(0.802)$ & $-0.142(0.066)$ \\
\hline LDPE-Mi_0.5 - LDPE-Mi_2 & $2.07(0.002)$ & $-0.048(0.186)$ & $-28.33(0.626)$ & $-0.017(0.808)$ \\
\hline Bio-Mi_0.5 - Bio-Mi_2 & $-1.35(0.035)$ & $0.027(0.452)$ & $13.67(0.814)$ & $0.031(0.662)$ \\
\hline LDPE-Ma_0.5 - LDPE-Ma_2 & $-1.33(0.038)$ & $0.068(0.065)$ & $-52.75(0.365)$ & $0.029(0.681)$ \\
\hline Bio-Ma_0.5 - Bio-Ma_2 & $-1.32(0.039)$ & $0.064(0.082)$ & $-42.92(0.461)$ & $-0.105(0.165)$ \\
\hline LDPE-Mi_1 - LDPE-Mi_2 & $1.22(0.048)$ & $-0.04(0.25)$ & $41.41(0.461)$ & $-0.007(0.915)$ \\
\hline Bio-Mi_1 - Bio-Mi_2 & $3.28(<.0001)$ & $-0.04(0.25)$ & $85.75(0.129)$ & $0.067(0.352)$ \\
\hline LDPE-Ma_1 - LDPE-Ma_2 & $-0.06(0.922)$ & $0.075(0.036)$ & $5.25(0.925)$ & $0.075(0.298)$ \\
\hline Bio-Ma_1 - Bio-Ma_2 & $0.96(0.116)$ & $0.061(0.086)$ & $-57(0.311)$ & $0.037(0.602)$ \\
\hline
\end{tabular}

WDPT: water drop penetration time; EC: electrical conductivity; ASI: aggregates stability index.

\section{S4.3 Principal component analysis and linear regression analysis}

A principal component analysis was performed for the parameters with the most effects (porosity, pb, ks, FC and WDPT) with the function prcomp() and plotted in R version 3.5.0. 
Table S4.5 Importance of components and Eigen vector from the principal component analysis for the parameters porosity, dry bulk density, saturated hydraulic conductivity, field capacity and water drop penetration time.

\begin{tabular}{llllll}
\hline & PC1 & PC2 & PC3 & PC4 & PC5 \\
\hline Importance of components & & & & & \\
Standard deviation & 1.56 & 1.13 & 0.84 & 0.61 & 0.45 \\
Proportion of Variance & 0.49 & 0.26 & 0.14 & 0.07 & 0.04 \\
Cumulative Proportion & 0.49 & 0.75 & 0.89 & 0.96 & 1.00 \\
\hline Eigen vectors & & & & & \\
Porosity & -0.5025 & -0.1969 & 0.4645 & -0.7013 & -0.0338 \\
Dry bulk density & 0.5812 & 0.0452 & 0.2173 & -0.3196 & 0.7147 \\
Saturated Hydraulic conductivity & -0.5711 & -0.1812 & 0.0212 & 0.4420 & 0.6670 \\
Field capacity & 0.2794 & -0.6257 & 0.5909 & 0.3765 & -0.1989 \\
Water drop penetration time & 0.0738 & -0.7313 & -0.6225 & -0.2625 & 0.0582 \\
\hline
\end{tabular}
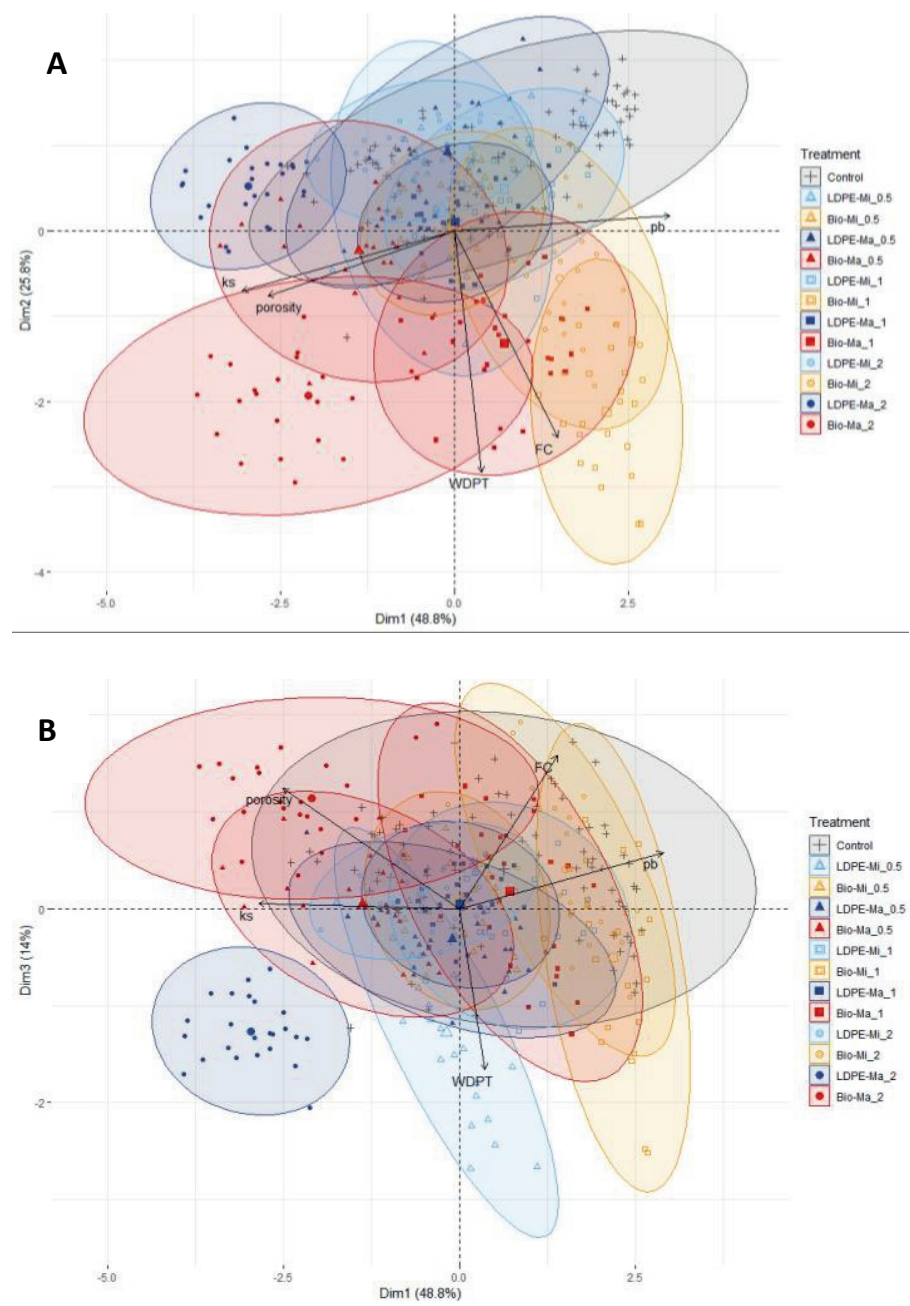

Figure 54.4 will be continued on next page 


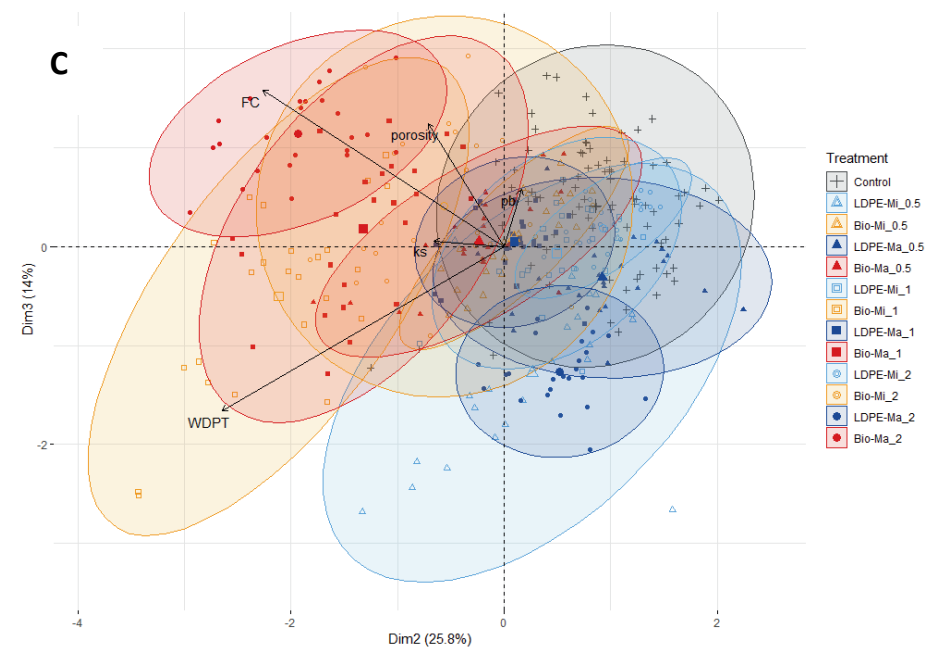

Figure S4.4 Diagrams for the first 3 components of the principal component analysis for the parameters porosity, dry bulk density, saturated hydraulic conductivity, field capacity and water drop penetration time. A: components 1 and 2, B components 1 and 3, C: components 2 and 3.

The correlations between porosity, $\rho b$ and ks was further explored with linear regressions. The linear correlation equations and coefficient of determination (Figure. S4.5) were calculated with the function $\operatorname{Im}()$ in R. Equations Eq.S4.4 and Eq.S4.5 were tested to fit the porosity and $\rho$ b data. Eq.S4.4 is derived from Eq.S4.5, taking into account that the plastic particles incorporated with the soil particles have a lower density than the soil particles. The normalised root-mean-square deviation for the EqS4.1, EqS4.2 and the linear regression equation between porosity and $\rho$ b were respectively $5.83 \%, 5.09 \%$ and $5.25 \%$

Supporting equations:

Eq.S4.1: Porosity.

porosity $=\frac{V_{w}(\text { sat })}{V_{T}}=\frac{m_{s a t}-m_{d}}{\rho_{w} \cdot V_{T}}$

Eq.S4.2: Dry bulk density.

$\rho_{b}=m_{d} / V_{T}$

Eq.S4.3: Plastic content.

$\theta_{P}=\frac{\text { mass (plastic) }}{\text { mass (sandy soil) }}=\frac{m_{P}}{m_{S}}=\frac{\rho_{P} V_{P}}{\rho_{S} V_{S}}$

Eq.S4.4: Relationship between dry bulk density and porosity considering soil particles only. $\rho_{b}=(1-$ porosity $) \rho_{S}$ 
Eq.S4.5: Relationship between dry bulk density and porosity considering soil particles and plastic.

$\rho_{b}=\left(1-\right.$ porosity) $\frac{m_{P}+m_{S}}{V_{P}+V_{S}}=(1-$ porosity $) \frac{m_{S}\left(\theta_{P}+1\right)}{V_{S}\left(\frac{\theta_{P} \rho_{S}}{\rho_{p}}+1\right)}=(1-$
porosity) $\frac{\rho_{S} \rho_{p}\left(\theta_{P}+1\right)}{\theta_{P} \rho_{S}+\rho_{p}} \Leftrightarrow=\rho_{b}=(1-$ porosty $)\left(\theta_{P}+1\right) \frac{\rho_{P} \rho_{S}}{\theta_{P} \rho_{S}+\rho_{P}}$

$m_{\text {sat }}:$ mass of saturated ring samples

$V_{w}(s a t)$ : volume of water in saturated sample $m_{d}$ : mass of dry ring samples

$\rho_{w}$ : density of water
$V_{T}$ : volume of ring

$m_{S}$ : mass of sandy soil

$V_{S}$ : volume of sandy soil particles

$\rho_{S}$ : density of sandy soil particles
$\theta_{P}$ : Plastic content $m_{P}$ : mass of plastic $V_{P}$ : volume of plastic $\rho_{P}$ : density of plastic

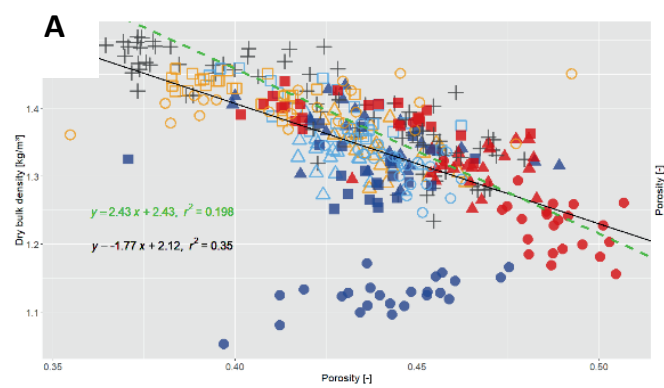

B
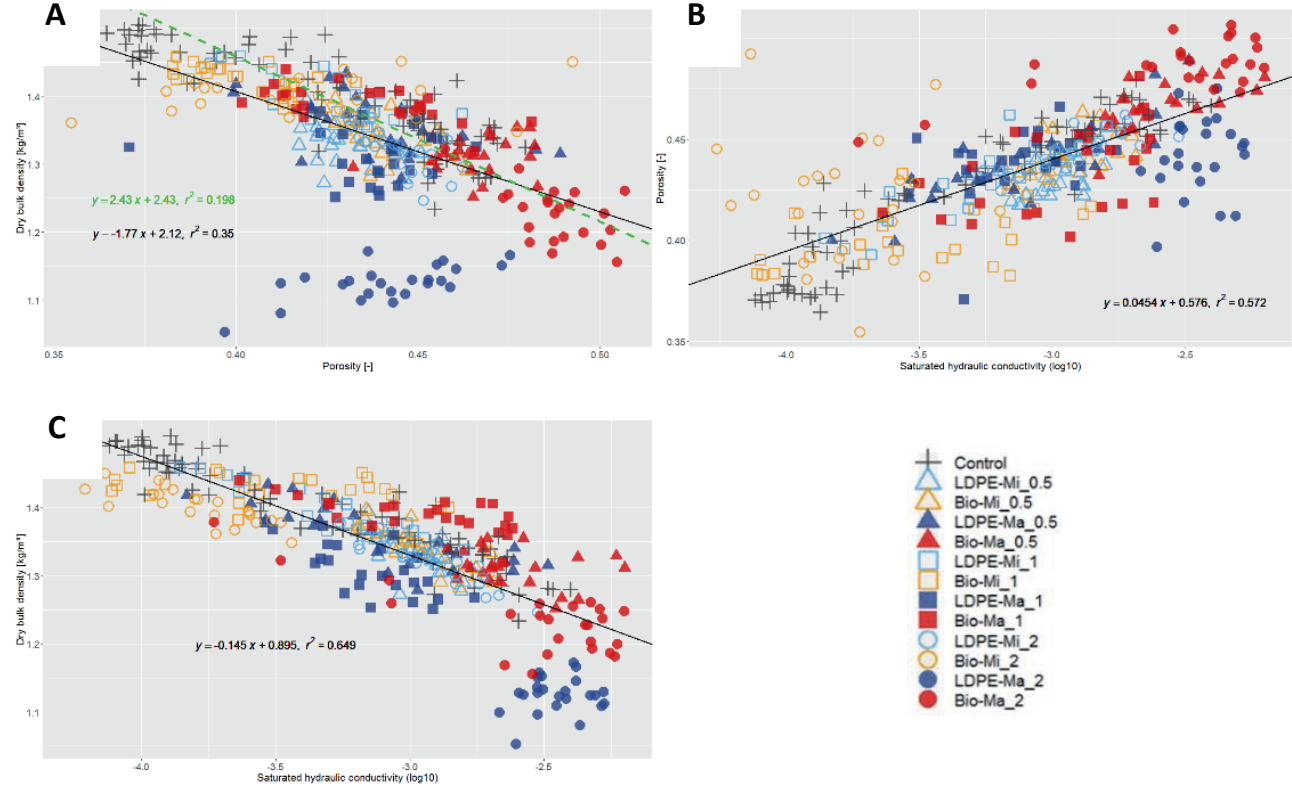

Figure S4.5: Linear regression and coefficient of determination between porosity and dry bulk density (A), porosity and saturated hydraulic conductivity $(B)$ and dry bulk density and saturated hydraulic conductivity (C). 


\section{Plastic mulch film residues in agriculture: impact on soil suppressiveness and ecosystem functioning}

Plastic mulch film residues have been accumulating in agricultural soils for decades, but so far, little is known about its consequences on soil microbial communities and functions. Here, we tested the effects of plastic residues of low-density polyethylene and biodegradable mulch films on soil suppressiveness and microbial community. Soil suppressiveness is a microbial-driven phenomenon important for sustainable agriculture. The level of soil suppressiveness, plant biomass and nutrient status and microbial communities in rhizosphere and plastisphere were investigated using a controlled pot experiment in soil suppressive to Fusarium culmorum. The addition of $1 \%$ plastic residues to the suppressive soil did not affect the level of suppressions and the disease symptoms index. However, we did find that plant biomasses decreased, and that plant nutrient status changed in the presence of plastic residues. We did not observe significant changes in bacterial and fungal rhizosphere communities. Nonetheless, bacterial and fungal communities closely attached to the plastisphere were very different from the rhizosphere communities. The plastisphere revealed a high abundance of specific bacterial phyla (Actinobacteria, Bacteroidetes, and Proteobacteria) and fungal genera (Rhizoctonia and Arthrobotrys). Our work revealed new insights and raises emerging questions for further studies on the impact of microplastics on the agroecosystems.

Based on:

Qi, Y., Ossowicki, A., Yergeau, É., Vigani., G, Geissen, V. \& Garbeva, P. 2020. Plastic mulch film residues in agriculture: impact on soil suppressiveness and ecosystem functioning. To be submitted. 


\subsection{Introduction}

Soil plays a central role in supporting life and possess the highest microbial diversity known to date. Microbial communities are essential for promoting plant growth and suppressing soil-borne diseases (Cha et al., 2016a; Lugtenberg et al., 2017). Plants are exposed to various abiotic and biotic stresses throughout their lives, yet certain soil microbes can actually help plants to overcome different stresses and improve growth (Gouda et al., 2018; Ilangumaran and Smith, 2017; Jochum et al., 2019). Hence, it is crucial for plants to recruit, activate and assemble protective microbiomes.

Along with the abiotic and biotic stresses that can occur sequentially or simultaneously, plants also are challenged by anthropogenic soil pollution. Environmental pollution in soil caused by agrochemicals or the disposal of waste coming from industrial or urban sources may interfere with plant-microbe interactions and communication. One critical type of pollution emerging in agriculture is the increasing load of microplastics (defined as plastic particles < $5 \mathrm{~mm}$ ) (de Souza Machado et al., 2018a). Whereas the problems with microplastics in the functioning of aquatic ecosystems have been intensively studied, their environmental impacts on the terrestrial ecosystem remain largely unexplored. According to recent literature, agricultural land may store more microplastics than oceans (Nizzetto et al., 2016a; Nizzetto et al., 2016b). This is due to the fact that there are multiple ways for microplastics to get into soil ( $\mathrm{Ng}$ et al., 2018). Plastic mulching is one of the major sources contributing to the accumulation of microplastics in agroecosystems (Huang et al., 2020).

Plastic mulch films were applied to farmland for several purposes: retaining soil moisture, warming the soil and preventing weeds (Steinmetz et al., 2016). Unfortunately, it has not been technically feasible for farmers to remove or recycle most of the mulch films used in the fields because the films are usually very thin $(0.01-0.05 \mathrm{~mm}$ ) (Kasirajan and Ngouajio, 2012). Biodegradable plastics were developed as promising environmentally sustainable alternatives to conventional low-density polyethylene plastics (Kasirajan and Ngouajio, 2012; Sintim and Flury, 2017). Biodegradable plastics are tilled into soil where they are expected to be degraded by microbes. The accumulation of residual plastic mulch films in agricultural soils has raised concerns because it decreases soil productivity by blocking water infiltration, impeding soil gas exchange, and constraining root growth (Dong et al., 2015; Jiang et al., 2017; Qi et al., 2020b). Plastic pollution is considered to be an emerging threat to soil ecosystem health and function (Zhang et al., 2020a). However, their impact on soil and rhizosphere microbiome, the interactions between beneficial microbes and soilborne pathogens and the level of soil disease suppressiveness are largely unknown. 
Disease suppressive soils protect plants from root pathogens despite the presence of favourable conditions for disease development (Deacon, 1984). Enhancing soil suppressiveness is of great agronomic interest to achieve sustainable management for plant disease control (Ghorbani et al., 2008; Singh and Vyas, 2009). The relationship between soil disease suppressiveness and the soil microbiome has been established in many studies and summarized in review articles (Kinkel et al., 2011; Schlatter et al., 2017; Weller et al., 2002). For instance, some microbial taxa were connected to the development of soil suppressiveness (Gomez Exposito et al., 2017) and the disturbance in microbiome composition lead to losing the ability of microbiome to protect plants (Carrión et al., 2019; Cha et al., 2016b).

In a previous study, we revealed that microplastics could have strong effects on plant growth, the blend of volatiles emitted in the rhizosphere, and the assembly of the rhizosphere communities (Qi et al., 2020c). In this study, we took these ideas one-step further in order to better understand the impact of microplastic pollution on the level of soil disease suppressiveness and plant nutrient status.

Recently, Ossowicki et al. (2020) collected soils from 28 different sites in the Netherlands and Germany to screen them for their level of suppressiveness to Fusarium culmorum. Soil from four fields revealed clear and reproducible disease suppressiveness and the microbiological basis of the suppressiveness was studied and confirmed (Ossowicki et al., 2020). Based on this research, we conducted an experiment to test if the addition of plastic residues could affect the level of soil disease suppressiveness, change rhizosphere microbial communities and alter plant growth. In addition, we analysed the microbiome of so-called plastisphere, which may host a distinct microbial colony on the plastic debris. We hypothesise that plastisphere plays a role in altering soil microbial communities and attract distinct microbial taxa compared to the rhizosphere soil.

\subsection{Materials and Methods}

\subsubsection{Growth conditions and materials}

A pot experiment was conducted in a growth cabinet (MC 1750 VHO-EVD, Snijders Labs) with photoperiod of $12 \mathrm{~h}$ day $/ 12 \mathrm{~h}$ night at $20^{\circ} \mathrm{C}$ and $60 \%$ relative humidity. Plants were watered every two days and supplemented weekly with a 0.5 Hoagland solution $(1 \mathrm{ml}$ per $80 \mathrm{cc}$ of the soil, $0.5 \mathrm{M} \mathrm{Ca}\left(\mathrm{NO}_{3}\right)_{2} \cdot 4 \mathrm{H}_{2} \mathrm{O}, 1 \mathrm{M} \mathrm{KNO}_{3}, 1 \mathrm{M} \mathrm{KH}_{2} \mathrm{PO}_{4}, 0.5 \mathrm{M} \mathrm{MgSO}_{4} \cdot 7 \mathrm{H}_{2} \mathrm{O}$ and 98.6 $\mathrm{mM}$ ferric EDTA). 
The disease-suppressive soil (S11) used in this study was found to be highly suppressive against $F$. culmorum in wheat (Ossowicki et al. 2020). Soil was collected in agricultural field, air-dried at room temperature, homogenized, sieved through a $4 \mathrm{~mm}$ sieve, and stored at $4^{\circ} \mathrm{C}$. The soil was sandy with an organic matter content of $3.48 \pm 0.47 \%$ and a $\mathrm{pH}$ of $7.28 \pm$ 0.19 . We used a gamma-sterilized sand collected near Bergharen, the Netherlands as a standard substrate. More information about the suppressive soil and Bergharen sand is provided in Table S1. Wheat seeds (Triticum aestivum, JB Asano variety) were obtained from Agrifirm (the Netherlands). Seeds were surface sterilized and pregerminated on sterile moist filter paper in order to use in the experiment.

Two types of plastic mulch films were used in this study: a low-density polyethylene (LDPE) and a starch-based biodegradable plastic (Bio). Two sizes of plastic residues (macro and micro) were prepared as described in a previous study (Qi et al., 2018). Macro-sized plastic pieces were made by cutting PMF into $5 \mathrm{~mm} \times 5 \mathrm{~mm}$ squares by hand. The micro-sized powders were obtained through cryogenic grinding, then sieved to obtain a powder size ranging from $50 \mu \mathrm{m}$ to $1 \mathrm{~mm}$. All plastic materials were sprayed with $70 \%$ ethanol and airdried in a fume cupboard to minimize microbial contamination.

The fungal pathogen F. culmorum PV was propagated on 1/4 Potato dextrose agar (PDA) and incubated at $20{ }^{\circ} \mathrm{C}$ for two weeks. Plugs with a diameter of $6 \mathrm{~mm}$ were cut from the border zone of $F$. culmorum hyphae. One plug was mixed with $10 \mathrm{cc}$ of soil for treatments and, in controls without the pathogen, sterile 1/4 PDA plugs were used instead.

\subsubsection{Experimental setup}

Prior to the experiment, the soil was "activated" to induce microbial activity by growing wheat for two weeks. Afterwards, plants along with the whole root system were removed and the soil was mixed and prepared as follows. The suppressive soil was mixed 2:1:1 in volume with sterile Bergharen sand and sterile vermiculite (Agra-vermiculite, The Netherlands). Sterile Bergharen sand was mixed with vermiculite 3:1 in volume for negative controls. For each pot, $140 \mathrm{~g}$ of the soil mixture, $1.4 \mathrm{~g}$ of the plastic residues (except for the controls) and plugs with or without the pathogen were added to pots and manually mixed. One pre-germinated wheat seed was transferred into each pot and grown for three weeks. After this time, disease symptoms were assessed and rhizosphere samples collected.

\subsubsection{Treatments and replicates}

Four types of plastic residues were mixed separately with suppressive soil at $1 \%(w / w)$. This concentration is environmentally relevant and consistent with our previous studies (Qi et 
al., 2018). Two positive controls with only suppressive soil and without the addition of plastic residues were used to control for disease suppressiveness (S11_FC and S11_NF). Two negative controls with sterilized Bergharen sand were used to control for the pathogenicity of F. culmorum (BS_FC and BS_NF). In total, 8 treatments were tested with 10 replicates (Table 5.1).

Table 5.1 Treatments setting for the pot experiment.

\begin{tabular}{llll}
\hline Treatments & Plastic residues & F. culmorum & Soil \\
\hline LDPE_Ma & LDPE macro & $\checkmark$ & S11 (Suppressive soil) \\
LDPE_Mi & LDPE micro & $\checkmark$ & S11 (Suppressive soil) \\
Bio_Ma & Bio macro & $\checkmark$ & S11 (Suppressive soil) \\
Bio_Mi & Bio micro & $\checkmark$ & S11 (Suppressive soil) \\
S11_FC & $/$ & $\checkmark$ & S11 (Suppressive soil) \\
S11_NF & $/$ & $/$ & S11 (Suppressive soil) \\
BS_FC & $/$ & $\checkmark$ & Bergharen sand \\
BS_NF & $/$ & $/$ & Bergharen sand \\
\hline
\end{tabular}

\subsubsection{Disease symptoms assessment and analysis of plant biomass and plant nutrient status}

To assess the disease symptoms the wheat plants were carefully removed, the excess of soil was shaken off, and the roots were cleaned with water. The root system was visually inspected for brown/black lesions or rotting and the stem base/coleoptile was inspected for rotting and the presence of pink-white fungal hyphae. Plants were scored from 0-5 for disease symptoms (Ossowicki et al., 2020). Statistical differences in disease symptoms between treatments and controls were assessed using the chi-square test, with an alpha cutoff of $p<0.05$.

After the screening, plants were separated into shoots and roots. Dry biomass was recorded after drying at $70{ }^{\circ} \mathrm{C}$ for $48 \mathrm{~h}$. Dried shoot and root tissues were then digested using $65 \%$ $\mathrm{HNO}_{3}$ at $120^{\circ} \mathrm{C}$. The mineralized samples were transferred into polypropylene test tubes. Samples were diluted 1:40 in MILLI-Q water and the concentration of metal elements was measured by Inductively Coupled Plasma-Mass Spectrometry ICP-MS (BRUKER Aurora- M90 ICP-MS) as previously described (Martín-Sánchez et al., 2020; Vigani et al., 2017). Differences among the mean values of inter-groups were analyzed by one-way ANOVA and the post-hoc tests considered were: Tuckey HSD (in the case of Levene's test $p>0.05$ ) and Tamhane (in the case of Levene's test $p<0.05$ ). 


\subsubsection{DNA extraction for rhizosphere soil and plastisphere}

For six randomly selected replicates in each treatment, rhizosphere soil samples were collected. After the plants were taken out of the pots, the excess soil was removed and the root system with adhering soil was placed in a sterile paper bag. Soil particles (rhizosphere) were detached from the roots by rigorously shaking. Rhizosphere soil samples were stored at $-4{ }^{\circ} \mathrm{C}$ and the DNA was isolated using a DNeasy PowerSoil Kit (QIAGEN, the Netherlands) within one week.

Six to ten pieces of macroplastics were collected from each pot of treatments LDPE_Ma and Bio_Ma. The plastic pieces were stored in Eppendorf tubes in glycerol stock at $-80^{\circ} \mathrm{C}$ before DNA extraction. DNeasy PowerSoil Kit was used to extract the DNA from plastic pieces.

\subsubsection{Amplicon sequencing and microbial community analysis}

The PCRs of the bacterial 16S rRNA gene V3-V4 region were performed with the primer set 515F (5'-GTGCCAGCMGCCGCGGTAA-3') and 806R (5'-GGACTACHVGGGTWTCTAAT-3'). The PCRs of the fungal rDNA gene ITS region were performed with the primer set ITS1F $\left(5^{\prime}\right.$ CTTGGTCATTTAGAGGAAGTAA-3') and 58A2R (5'-CTGCGTTCTTCATCGAT-3'). Sequencing was carried out on an Illumina MiSeq platform with 4 biological replicates per treatment at the McGill University and Genome Québec Innovation Centre (Montréal, Canada).

Adapter sequences were removed using cutadapt 2.10 [DOI:
[D https://doi.org/10.14806/ej.17.1.200] and the quality of reads was evaluated using FastQC 0.11 .9 [DOI: 10.1371/journal.pone.0100930]. All the subsequent work on sequencing data was performed in an R 4.0.1 environment using packages specified further. Amplicon sequencing variants (ASVs) were constructed using dada2 1.16.0 (DOI: 10.1038/nmeth.3869) and taxonomically classified based on the SILVA v132 database for bacterial 16 S genes or the UNITE ver8 database for fungal ITS sequences. Read counts were rarefied for further analysis using a Vegan 2.5-6 package. Analyses of alpha diversity and differential abundance were performed using phyloseq 1.32.0 and DESeq2 1.28.1 packages and visualized using Ampvis2 2.6.0 and ggplot2 3.3.2. 


\subsection{Results}

5.3.1 Effect of plastic residues on the level of disease suppressiveness, plant biomass and plant nutrient status

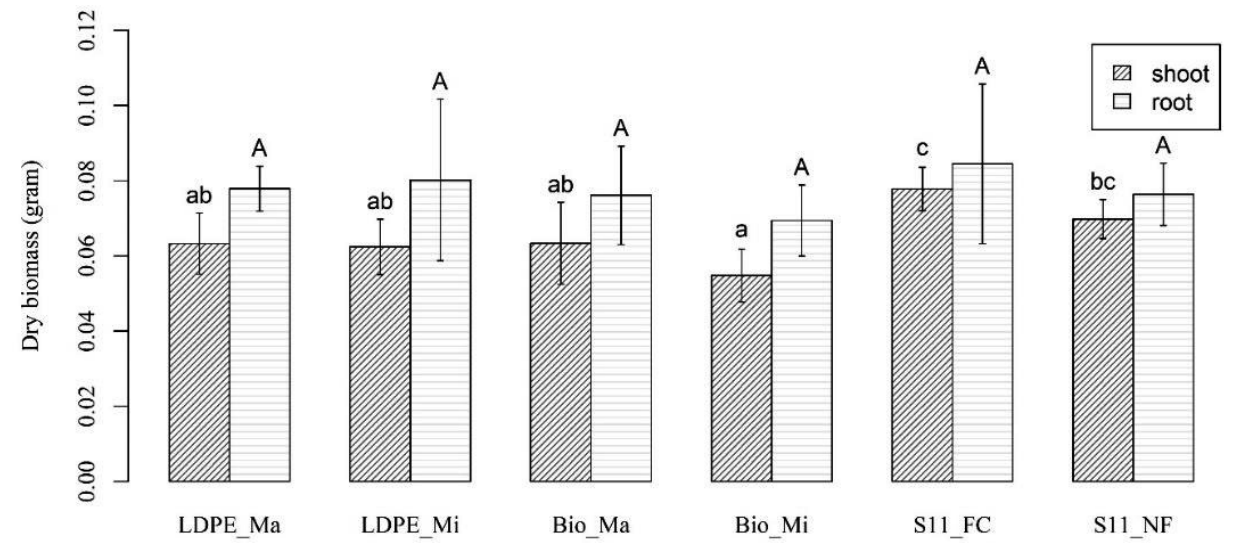

Figure 5.1. Shoot and root biomass of wheat in suppressive soil with and without plastic residues. The bars indicate the mean values of each treatment, with the error bars representing the standard deviation. Letters above the bars represent statistically significant differences based on ANOVA, $p<0.05$.

A significant effect on plant biomass was observed only for shoot biomass in the treatment Bio_Mi as compared to controls without plastic additions (Figure 5.1). No significant difference in root biomass was observed.

The results of testing the impact of plastic residues on soil suppressiveness are presented in Figure 5.2. It showed that the pathogen was infectious when comparing controls BS_FC to BS_NF and that the soil S11 was suppressive and could significantly reduce disease symptoms (controls BS_FC vs. S11_FC). The presence of plastic residues in suppressive soil did not significantly affect the level of suppressiveness (Figure 5.2). 


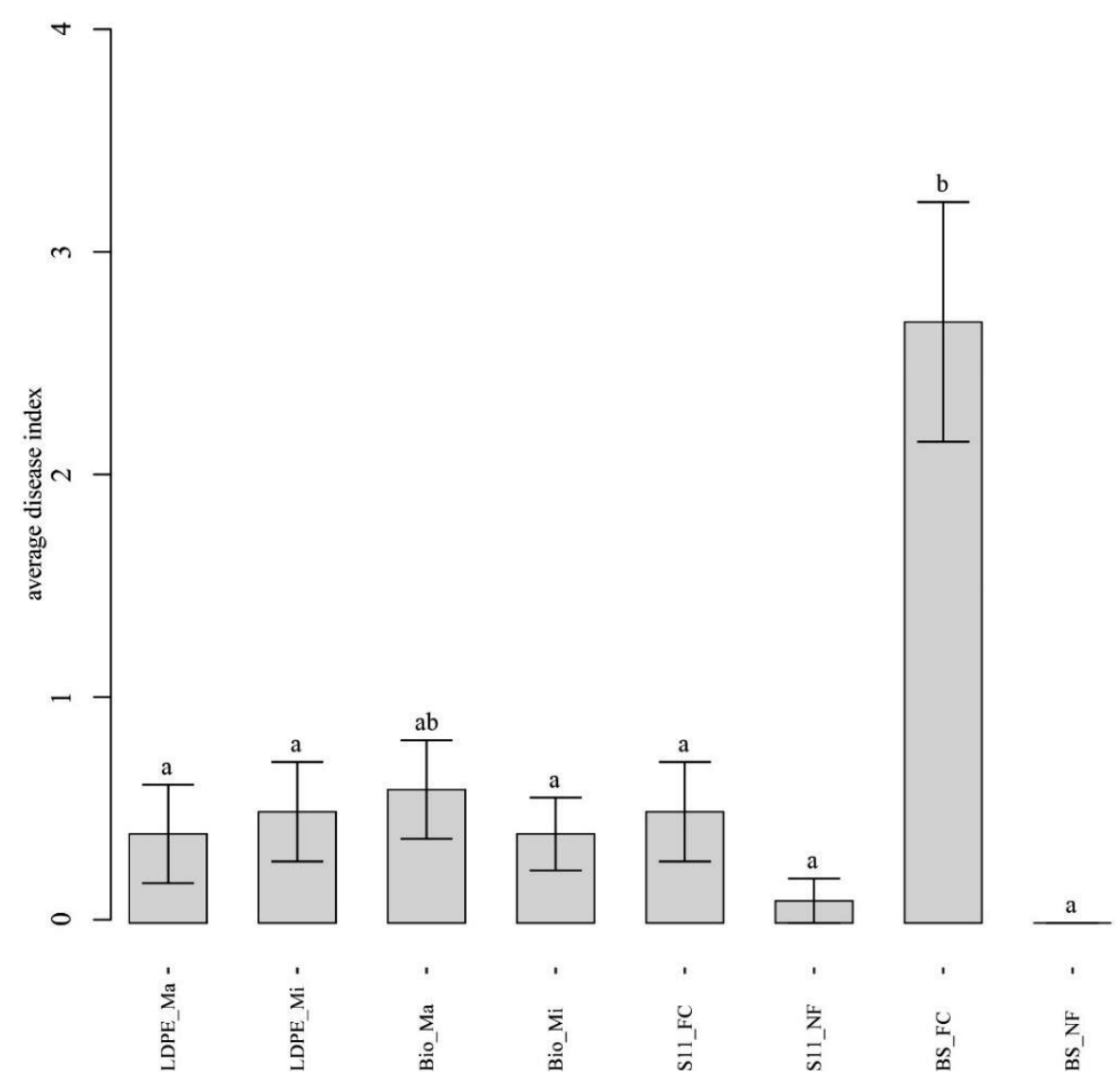

Figure 5.2 Disease symptoms observed in wheat inoculated with F. culmorum grown in substrates with plastic and without plastic as controls. The bars indicate the average of the disease symptoms index, with the error bars representing the standard error. Letters above the bars represent significance levels based on the chi-square test.

In addition, we performed an analysis of the mineral nutrient content of shoots and roots, defined as plant ionome. The Principal Component Analysis (PCA) performed on the macronutrient $(\mathrm{Mg}, \mathrm{K}, \mathrm{Ca})$ content of the shoots revealed a clear separation between LDPE_Ma and LDPE_Mi samples along both components (Figure 5.3a). The PCA performed on the micronutrient $(\mathrm{Mn}, \mathrm{Fe}, \mathrm{Zn}, \mathrm{Mo}, \mathrm{Cu}$ ) content of the shoots revealed the separation between LDPE_Ma and LDPE_Mi samples along Component 2 (Figure 5.3b). In the shoots, we observed a significant difference in $\mathrm{K}$ content between treatments LDPE_Ma and LDPE_Mi and the Mn contents of both treatments were higher than the controls (Table S5.2). The PCA revealed different macro- and micro- nutrient composition in the roots of the treatment LDPE_Mi (Figure 5.3c and 5.3d). Treatment LDPE_Mi showed higher $\mathrm{Cu}$ content in root tissues (Table S5.3). 

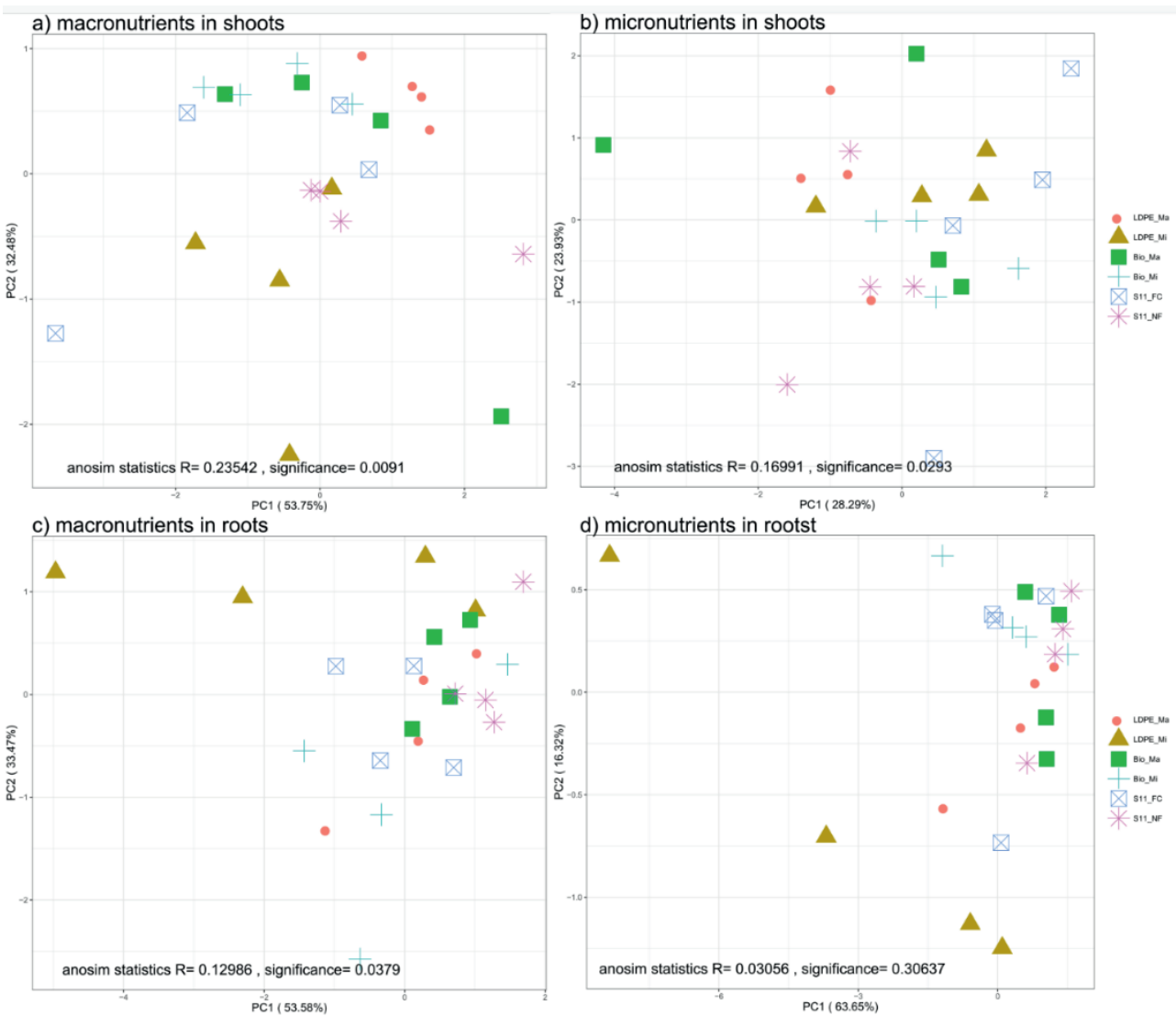

Figure 5.3 Principal component analysis (PCA) of the macronutrient and micronutrient content in shoots and roots of wheat. ANOSIM statistics is indicated in the left-bottom corner of each plot.

\subsubsection{Effect of plastic residues on the rhizosphere bacterial and fungal communities}

The analysis of bacterial and fungal rhizosphere communities was based on 16S rRNA and ITS amplicons sequencing. The effect of the addition of the plastic residues may be seen as a change between treatments (LDPE_Ma, LDPE_Mi, Bio_Ma, Bio_Mi ) and control S11_FC all with pathogenic fungus added.

The diversity of bacterial and fungal community based on Shannon index revealed that, as compared to control (S11_FC), there was no statistically significant change due to the addition of plastic (Figure 5.4, Table S5.4 and S5.5). Moreover, looking at the abundance of the major bacteria phyla and fungal genera (Figure 5.5 and Figure 5.6 respectively), there was only a small significant change in the abundance Chloroflexi between LDPE_Ma 
treatment and control. Altogether, the addition of LDPE and Bio plastic residues to soil did not have a direct impact on bacterial and fungal rhizosphere community. These results are also supported by PCA analysis (Figure S5.1).
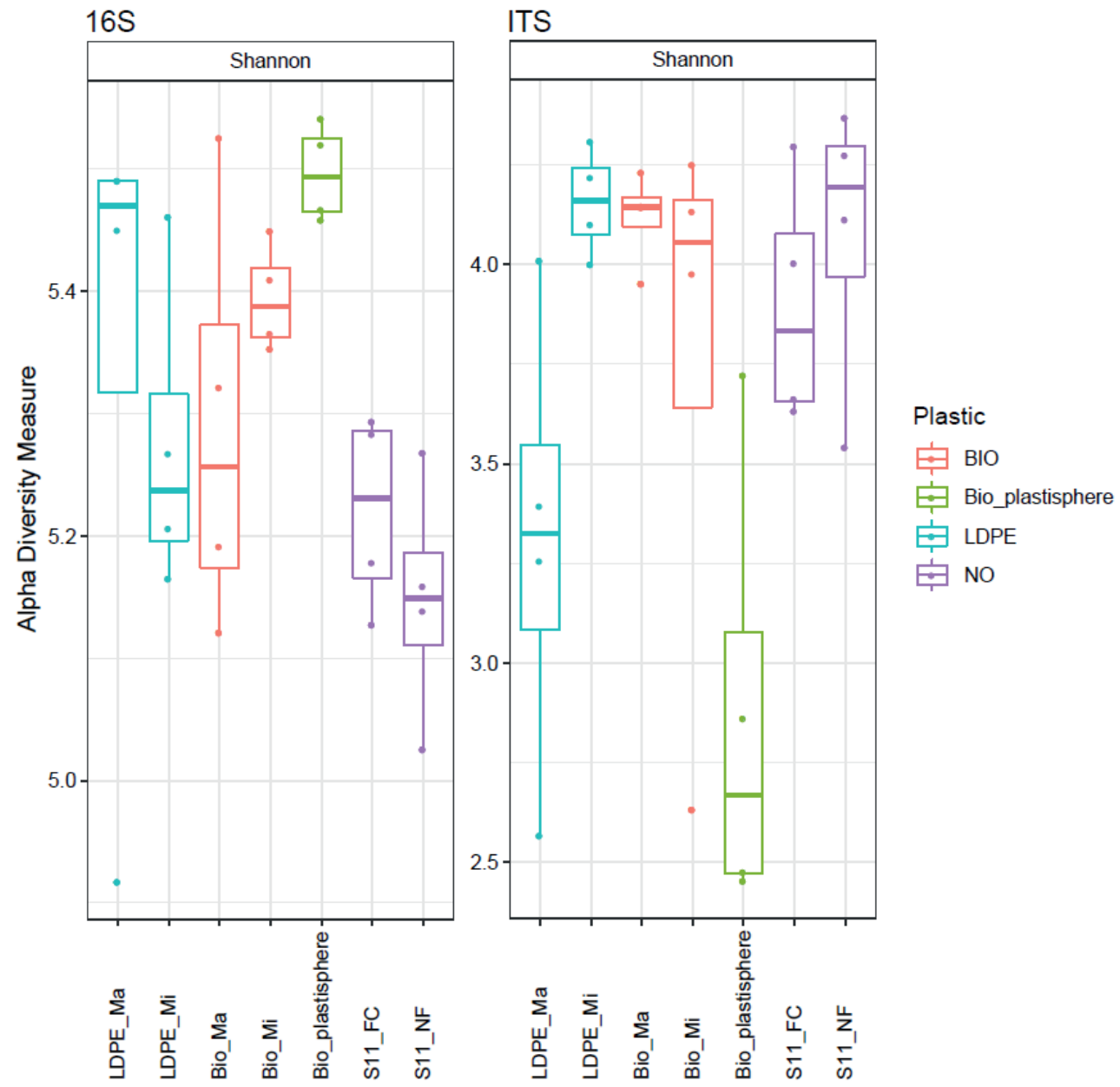

Figure 5.4 Alpha diversity of bacterial (16S) and fungal (ITS) communities based on ASVs presented as Shannon index. 


\subsubsection{Microbial communities in the plastisphere}

\begin{tabular}{|r|c|c|}
\hline & \multicolumn{3}{|c|}{ BIO } \\
\hline Proteobacteria - & 37.5 & 40.3 \\
\hline Acidobacteria - & 21.1 & 17.7 \\
\hline Chloroflexi - & 18.1 & 18.2 \\
\hline Actinobacteria - & 5.6 & 7.9 \\
\hline Bacteroidetes - & 4.4 & 3.8 \\
\hline Verrucomicrobia - & 4.7 & 4.4 \\
\hline Planctomycetes - & 4.5 & 3.8 \\
\hline Firmicutes - & 0.7 & 0.8 \\
\hline & $\sum_{1}^{\infty}$ & $\bar{\vdots}$ \\
\hline & $\frac{1}{\infty}$ & $\circ$ \\
\hline
\end{tabular}

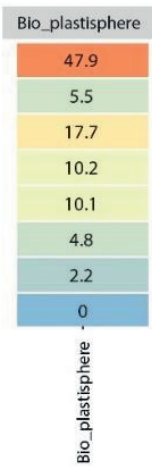

\begin{tabular}{|c|c|}
\hline \multicolumn{2}{|c|}{ LDPE } \\
\hline 37.1 & 34.9 \\
\hline 21.3 & 21.4 \\
\hline 14.4 & 19.1 \\
\hline 7.7 & 6.9 \\
\hline 4.7 & 4.3 \\
\hline 5.3 & 4.2 \\
\hline 5 & 4.3 \\
\hline 1.1 & 0.6 \\
\hline 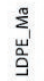 & $\begin{array}{l}\sum_{u} \\
\underline{\omega} \\
\vdots\end{array}$ \\
\hline
\end{tabular}

\begin{tabular}{|c|c|}
\hline \multicolumn{3}{|c|}{ NO } \\
\hline 37.7 & 35.6 \\
\hline 20.8 & 24.1 \\
\hline 17.8 & 19.5 \\
\hline 7.9 & 5.8 \\
\hline 2.9 & 3.1 \\
\hline 3.6 & 3 \\
\hline 3.9 & 4.1 \\
\hline 1.6 & 1.4 \\
\hline$\dot{4}$ & 先 \\
\hline 玄 & $\overline{\bar{n}}$ \\
\hline
\end{tabular}

Figure 5.5 Heatmap showing the relative abundance of the top eight bacteria phyla across the samples. The headers of columns indicate the type of plastic used, "NO" indicates controls without the addition of plastic.

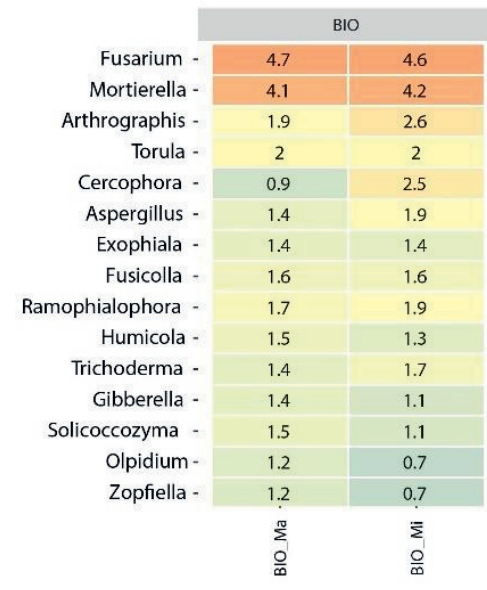

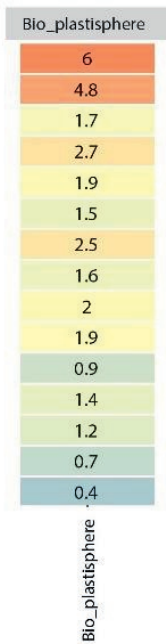

\begin{tabular}{|c|c|}
\hline \multicolumn{2}{|c|}{ LDPE } \\
\hline 5.5 & 5.9 \\
\hline 3.2 & 4.2 \\
\hline 2.1 & 1.4 \\
\hline 2.1 & 2.1 \\
\hline 1.6 & 1.6 \\
\hline 1.2 & 1.9 \\
\hline 1.7 & 1.3 \\
\hline 2 & 1.4 \\
\hline 1.1 & 0.9 \\
\hline 1.4 & 1.2 \\
\hline 1.4 & 1.4 \\
\hline 1.4 & 1 \\
\hline 1.3 & 0.9 \\
\hline 1.3 & 1.8 \\
\hline 0.9 & 1.1 \\
\hline $\begin{array}{l}\sum_{1}^{\pi} \\
\text { w. } \\
0\end{array}$ & $\begin{array}{l}\sum_{1} \\
u_{0}^{\prime} \\
9\end{array}$ \\
\hline
\end{tabular}

\begin{tabular}{|c|c|}
\hline \multicolumn{3}{|c|}{ NO } \\
\hline 4.9 & 3.9 \\
\hline 4.2 & 4.1 \\
\hline 2.2 & 2.2 \\
\hline 1.5 & 1.6 \\
\hline 1.9 & 1.6 \\
\hline 1.3 & 2 \\
\hline 1.2 & 1.6 \\
\hline 1.3 & 1.4 \\
\hline 1.5 & 1.3 \\
\hline 1.2 & 1.3 \\
\hline 1.3 & 1.6 \\
\hline 1.1 & 1.1 \\
\hline 0.8 & 0.8 \\
\hline 0.7 & 1 \\
\hline 1.4 & 1.1 \\
\hline$亡$ & $\underline{z}$ \\
\hline $\bar{\hbar}$ & $\bar{\hbar}$ \\
\hline & \\
\hline
\end{tabular}

Figure 5.6. Heatmap showing the relative abundance of the top fifteen fungal genera across the samples. The headers of columns indicate the type of plastic used, "NO" indicates controls without the addition of plastic..

We compared the bacterial and fungal communities inhabiting the surface of Bio_Ma plastic residues and compared them to the rhizosphere communities of plants from which these residues were extracted. The analysis of bacterial community in the Bio_plastisphere compared to Bio_Ma rhizosphere showed an increase in diversity in "plastisphere" (Figure 5.4) and a significantly higher relative abundance of bacteria phyla Actinobacteria, Bacteroidetes, and Proteobacteria and a lower relative abundance of Acidobacteria and Planctomycetes (Figure 5.7). 
We found that the diversity of fungal community (Shannon index) in "plastisphere" was significantly lower comparing to rhizosphere (Figure 5.4). The "plastisphere" was vastly dominated by three fungal genera Rhizoctonia, Arthrobotrys and Fusarium (on average around $50 \%$ of relative abundance) where the first two genera were significantly enriched compared to the rhizosphere community (Figure 5.8). The results of differential abundance comparison revealed also statistically significant higher relative abundance of fungal genera Torula and Exophiala and lower abundance of Zoptelia. Significantly, a higher relative abundance of the fungal genera Rhizoctonia and Arthrobotrys were measured in the Bio_plastisphere (Figure 5.8).

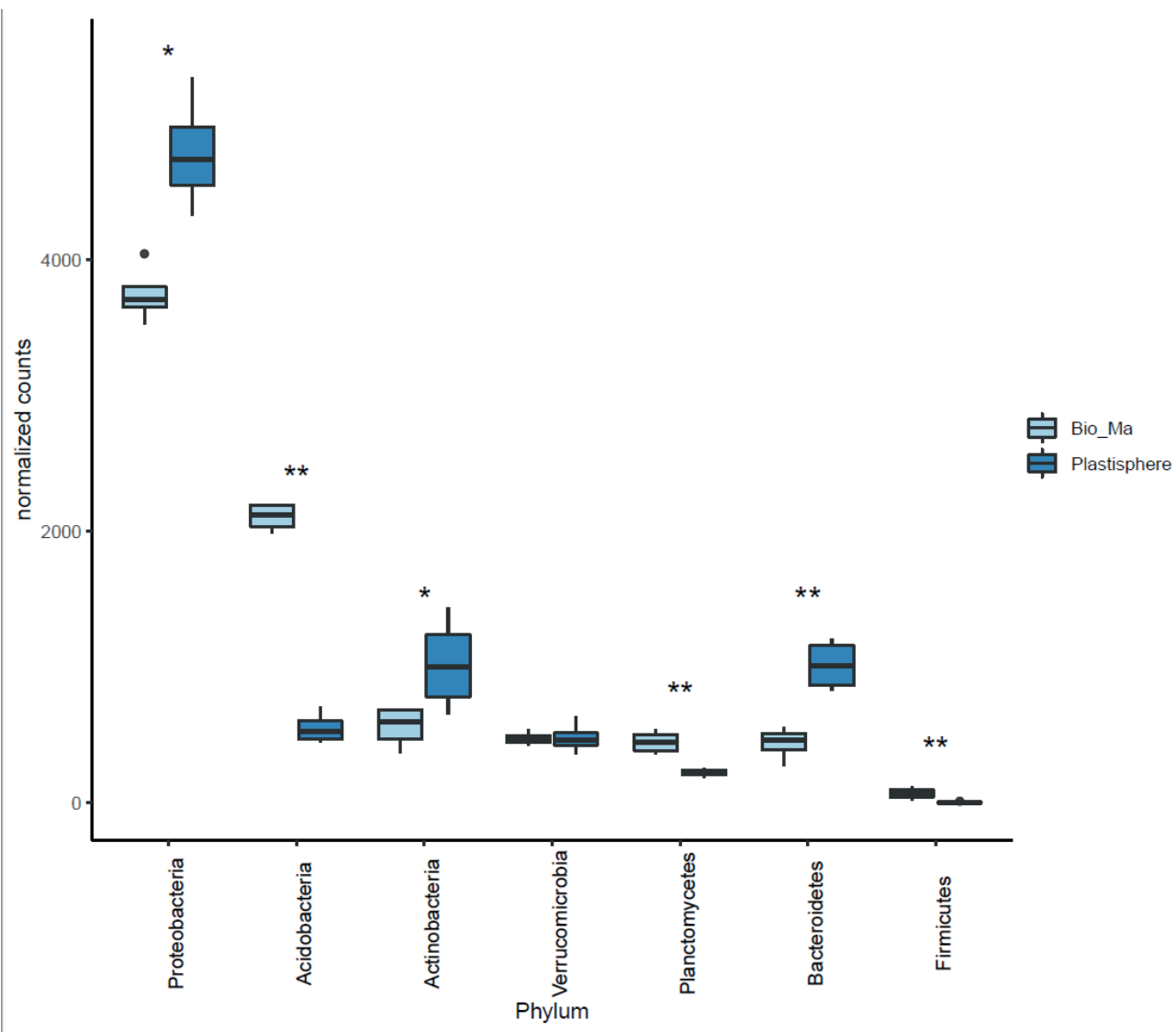

Figure 5.7 Boxplots displaying the relative abundance of bacteria phyla between bioplastic plastisphere and the rhizosphere of wheat grown in soil with the addition of bioplastic. Statistically significant differences based on deseq2 analysis are marked with a single asterisk $(p<0.05)$ or with a double asterisk $(p<0.01)$. 


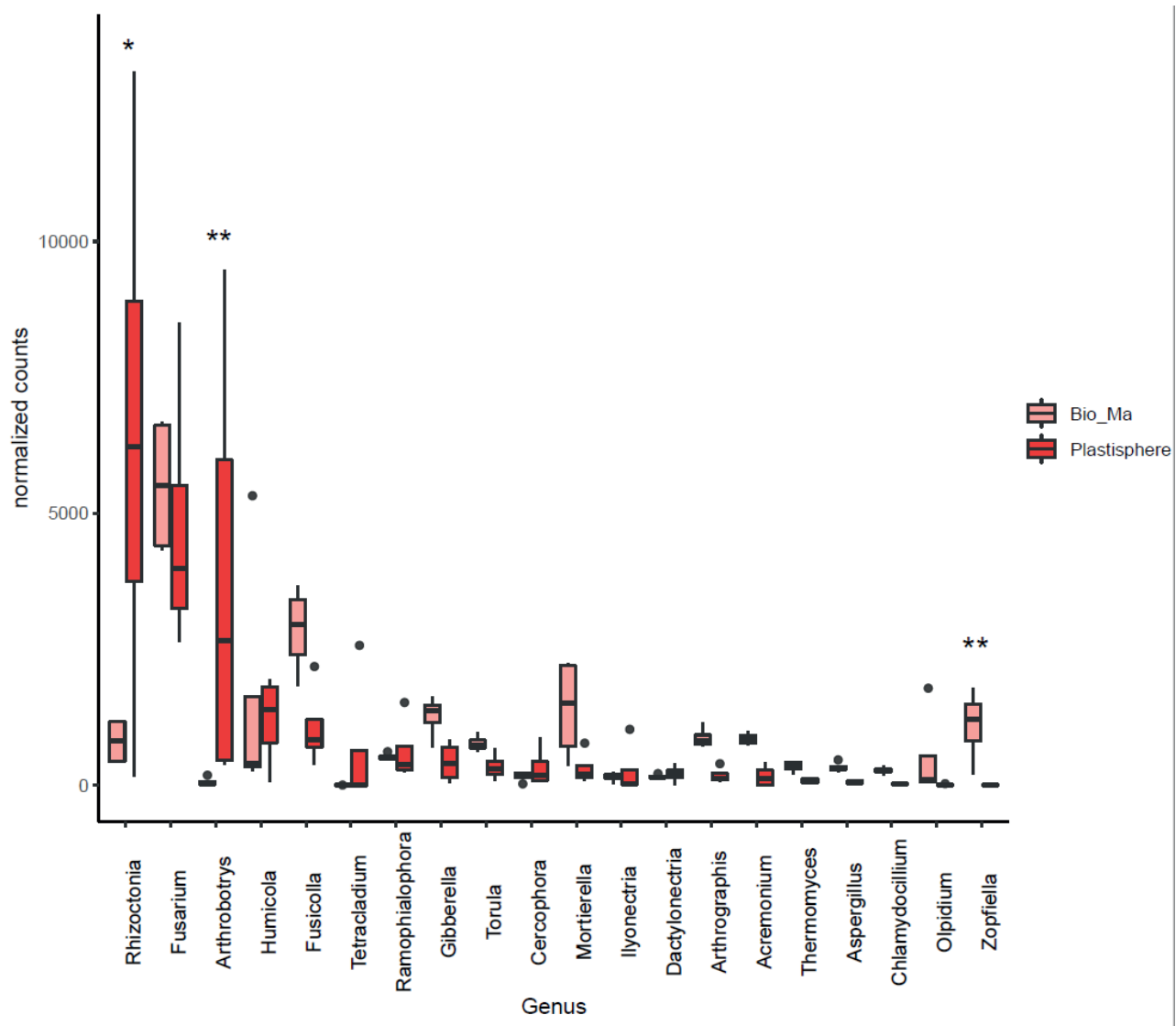

Figure 5.8 Boxplots displaying the relative abundance of fungal genera between bioplastic plastisphere and the rhizosphere of wheat grown in soil with the addition of bioplastic. Statistically significant differences based on deseq 2 analysis are marked with a single asterisk $(p<0.05)$ or with a double asterisk $(p<0.01)$.

\subsection{Discussion}

One of the greatest challenges of our generation is to consolidate or even increase current agricultural yields and nutritional quality while reducing the input of fertilizers and pesticides. As a critical agricultural tool, plastic mulch films have made significant contributions to food security and modern agricultural development (Espi, 2006; Kasirajan and Ngouajio, 2012). However, we tend to ignore the impact of plastic pollution on agricultural yields and soil functions, which may represent a hidden danger for soil organisms, plants and humans (Rillig and Lehmann, 2020; Zhang et al., 2020a). Due to the ubiquitous distribution and biochemical activity, microplastic pollution is increasingly recognized as a global concern (Hale et al., 2020). Initial quantifications suggest that background concentrations of microplastics might be as high as $0.03 \%-6.7 \%$ in agricultural 
and industrial soils (Fuller and Gautam, 2016). A promising approach to overcome the accumulation of residual polyethylene mulch films in soils is to use biodegradable mulch films composed of polymers designed to be degraded by soil microorganisms. Biodegradable plastics are often mistaken for pure polymers. However, biodegradable plastics are a family of various polymers, e.g. starch blends, poly(lactic acid), poly(butylene adipate terephthalate), polyhydroxyalkonates, etc. In addition, they contain substantial amounts of chemical additives, such as plasticizers, which could be physically and chemically hazardous to soil (micro)organisms and hence, deter soil functioning. Our work is the first to explore the impact of plastic mulch film residues (both LDPE and Bio) on the level of soil disease suppressiveness and plant nutrient status. The results of our study did not reveal major effect of either microplastic or macroplastic residues on the level of soil suppressiveness against $F$. culmorum. The addition of LDPE or Bio microplastics caused slight (but not significant) increases in the average disease index. A significant effect was observed on plant shoot biomass in treatment Bio_Mi but not in the other treatments. This indicates that different types and sizes of plastic residues may cause different effects. For example, the addition of LDPE_Mi affected the macro- and micro- nutrient composition in the roots. The mineral nutrient content profile of a plant can be considered to be a signature of the nutrient status of plants under stressed conditions (Martín-Sánchez et al., 2020; Pii et al., 2015). Our findings are based on a short-term experiment (two weeks for activation and three weeks for infection), however, it is plausible that in the long-term, the effects on the plant biomass, plant nutrient content and level of soil suppressiveness could be stronger. For example, in our previous study we observed a significant negative effect on plant biomass after 2 and 4 months (Qi et al., 2018).

Both soil and plants depend heavily on their microbiome for specific functions and traits (Berg, 2009; Liu et al., 2020). The rhizosphere, the narrow zone surrounding and influencing plant roots, is considered to be one of the most dynamic interfaces on earth (Philippot et al., 2013). Since large parts of the soil have limited nutrient access, the rhizosphere represents an oasis for soil microorganisms due to the release of rhizodeposits by plant roots. These rhizodeposites, which are a mixture of easily available organic nutrients and signaling compounds, include root exudates, border cells and mucilage (Jones et al., 2009; Philippot et al., 2013; Raaijmakers et al., 2009). However, our recent study revealed that the addition of microplastics could have strong effects on the rhizosphere bacterial community (Qi et al., 2020c). In the current study, we did not observe significant changes in bacterial or fungal rhizosphere communities (diversity and assembly) among rhizosphere soil samples. Nonetheless, bacterial and fungal communities that were closely attached to the Bio_Ma plastics (plastisphere) were very different from the rhizosphere communities in the Bio_Ma treatment. The Bio_Ma plastispheres revealed a high abundance of specific bacteria phyla (Actinobacteria, Bacteroidetes, and Proteobacteria) and fungal genera 
(Rhizoctonia and Arthrobotrys). Providing new habitats for microorganisms, the microbial ecology of the plastisphere is an important area to explore. Despite the increasing interest in this topic, very few studies have been conducted on the plastisphere in the aquatic ecosystem (Amaral-Zettler et al., 2020; Yang et al., 2020). Due to the technical limitations, we were only able to obtain qualified DNA from the plastisphere of the Bio_Ma treatments for amplicon sequencing. It is of great interest to further study the plastispheres that can form around different plastic types and sizes. The addition of microplastics to soil could actually be a source of nutrients and extra surfaces that could be very attractive for certain microbes, thus, affecting microbial behaviour and processes. Taking into consideration that many species belonging to two fungal genera dominating the "plastisphere" (Rhizoctonia and Fusarium) are pathogenic, we can speculate that this habitat may act as a reservoir of pathogens. Hence, it would be important in the future to study the effect of plastic residues on the abundance of soil borne pathogens.

In the current study, the addition of plastic mulch film residues to suppressive soil, did not reveal significant effects on disease symptoms in wheat inoculated with $\mathrm{F}$. culmorum, nor on the plant-associated bacterial and fungal community composition, structure and diversity. However, we observed changes in the plant biomass and mineral nutrient content. Moreover, the analysis of "plastisphere" revealed substantially different bacterial and fungal taxonomic patterns and diversity as compared to the rhizosphere soil. Based on our results, we suggest that the introduction of plastic into the soil would create a new niche "plastisphere" that harbours a distinct microbial community. Such findings highlight the importance to characterize the plastisphere in soil and to unravel its impact on the plantsoil system.

\section{Acknowledgements}

This research was funded by the Natural Sciences and Engineering Research Council of Canada Discovery grant RGPIN-2014-05274 and Strategic grant for projects STPGP 494702. We are thankful for the financial support from the China Scholarship Council (CSC: 201604910510). 


\section{Supplementary Material}

Table S5.1 Detailed information about suppressive soil (S11) and Bergharen sand.

\begin{tabular}{|c|c|c|c|}
\hline soil parameters & unit & S11 & BS \\
\hline $\mathrm{pH}$ & / & $7.28 \pm 0.19$ & $7.53 \pm 0.05$ \\
\hline OM & $\%$ & $3.48 \pm 0.47$ & $0.24 \pm 0.04$ \\
\hline $\mathrm{Fe}$ & $\mathrm{mg} / \mathrm{kg}$ & 0.11 & $0.19 \pm 0.01$ \\
\hline K & $\mathrm{mg} / \mathrm{kg}$ & $68.77 \pm 1.1$ & $2.02 \pm 0.32$ \\
\hline $\mathrm{Mg}$ & $\mathrm{mg} / \mathrm{kg}$ & $56.43 \pm 0.58$ & 0 \\
\hline $\mathrm{P}$ & $\mathrm{mg} / \mathrm{kg}$ & $5.43 \pm 0.04$ & $0.11 \pm 0.03$ \\
\hline S & $\mathrm{mg} / \mathrm{kg}$ & $1.17 \pm 0.15$ & 0 \\
\hline C & $\%$ & $1.99 \pm 0.88$ & $0.05 \pm 0.01$ \\
\hline$N$ & $\%$ & $0.16 \pm 0.07$ & 0 \\
\hline $\mathrm{C}: \mathrm{N}$ & / & 12.44 & NA \\
\hline
\end{tabular}

Table S5.2 Content of some mineral nutrients in shoot of wheat plants. The content of $\mathrm{Mg}, \mathrm{K}$ and Ca are expressed as $\mathrm{mg} \mathrm{g}^{-1} \mathrm{DW}$ while the content of $\mathrm{Mn}, \mathrm{Fe}, \mathrm{Cu}, \mathrm{Zn}$, Mo are expressed as $\mu \mathrm{g} \mathrm{g}{ }^{-1} \mathrm{DW}$. Nutrients displaying significant differences among treatment $(p<0.05)$ are reported in bold.

\begin{tabular}{|c|c|c|c|c|c|c|}
\hline & LDPE_Ma & LDPE_Mi & Bio_Ma & Bio_Mi & S11_FC & S11_NF \\
\hline $\mathrm{Mg}$ & $1.88 \pm 0.11$ & $2.06 \pm 0.26$ & $1.97 \pm 0.51$ & $1.64 \pm 0.11$ & $1.77 \pm 0.18$ & $2.06 \pm 0.23$ \\
\hline K & $52.29 \pm 1.89 b$ & $40.44 \pm 2.76 a$ & $48.38 \pm 3.71 a b$ & $44.12 \pm 3.61 \mathrm{ab}$ & $39.98 \pm 10.36 a b$ & $45.51 \pm 5.11 \mathrm{ab}$ \\
\hline $\mathrm{Ca}$ & $3.67 \pm 0.09$ & $3.03 \pm 0.31$ & $3.32 \pm 0.39$ & $3.20 \pm 0.35$ & $3.02 \pm 0.58$ & $3.61 \pm 0.36$ \\
\hline $\mathrm{Mn}$ & $19.48 \pm 3.90 b$ & $21.10 \pm 2.05 b$ & $17.94 \pm 2.09 \mathrm{ab}$ & $17.45 \pm 4.27 \mathrm{ab}$ & $11.17 \pm 1.47 a$ & $23.54 \pm 3.25 b$ \\
\hline $\mathrm{Fe}$ & $154.26 \pm 25.42$ & $121.76 \pm 40.00$ & $165.48 \pm 131.78$ & $95.33 \pm 16.73$ & $91.87 \pm 17.02$ & $130.03 \pm 26.49$ \\
\hline $\mathrm{Cu}$ & $9.15 \pm 2.89$ & $6.67 \pm 2.47$ & $11.12 \pm 7.24$ & $11.59 \pm 9.56$ & $8.14 \pm 4.13$ & $8.46 \pm 2.28$ \\
\hline $\mathrm{Zn}$ & $42.25 \pm 1.84$ & $30.45 \pm 6.21$ & $37.72 \pm 5.16$ & $35.33 \pm 2.40$ & $35.05 \pm 16.77$ & $42.80 \pm 8.15$ \\
\hline Mo & $11.54 \pm 1.90$ & $5.32 \pm 0.52$ & $13.68 \pm 9.37$ & $9.06 \pm 1.24$ & $6.53 \pm 2.49$ & $7.03 \pm 0.22$ \\
\hline
\end{tabular}

Table S5.3 Content of some mineral nutrients in root of wheat plants. The content of $\mathrm{Mg}, \mathrm{K}$ and Ca are expressed as $\mathrm{mg} \mathrm{g}^{-1} \mathrm{DW}$ while the content of $\mathrm{Mn}, \mathrm{Fe}, \mathrm{Cu}, \mathrm{Zn}, \mathrm{Mo}$ are expressed as $\mu \mathrm{g} \mathrm{g}^{-1} \mathrm{DW}$. Nutrients displaying significant differences among treatment $(p<0.05)$ are reported in bold.

\begin{tabular}{ccccccc}
\hline & LDPE_Ma & LDPE_Mi & Bio_Ma & Bio_Mi & S11_FC & S11_NF \\
\hline $\mathrm{Mg}$ & $6.31 \pm 3.58$ & $19.51 \pm 14.65$ & $5.54 \pm 2.16$ & $7.33 \pm 5.85$ & $5.19 \pm 2.04$ & $3.08 \pm 1.41$ \\
$\mathrm{~K}$ & $16.71 \pm 2.26$ & $15.39 \pm 2.23$ & $15.31 \pm 1.18$ & $18.42 \pm 3.06$ & $16.65 \pm 0.94$ & $14.84 \pm 1.48$ \\
$\mathrm{Ca}$ & $2.99 \pm 0.33$ & $3.96 \pm 1.41$ & $2.88 \pm 0.21$ & $2.94 \pm 0.52$ & $3.40 \pm 0.70$ & $2.39 \pm 0.19$ \\
$\mathrm{Mn}$ & $51.71 \pm 14.81$ & $101.06 \pm 69.58$ & $43.80 \pm 8.81$ & $58.83 \pm 23.78$ & $56.67 \pm 8.04$ & $41.27 \pm 8.36$ \\
$\mathrm{Fe}$ & $2773.92 \pm 1581$. & $7516.81 \pm 6038$. & $2285.71 \pm 723.1$ & $3320.64 \pm 2228$. & $2825.24 \pm 728.2$ & $1758.14 \pm 633.5$ \\
$\mathrm{Cu}$ & $\mathbf{1 8 . 1 0} \pm 6.61 \mathrm{a}$ & $\mathbf{3 5 . 3 8} \pm 7.98 \mathrm{~b}$ & $\mathbf{1 3 . 9 4} \pm \mathbf{3 . 1 7 a}$ & $\mathbf{1 3 . 8 2} \pm \mathbf{2 . 4 0 a}$ & $\mathbf{1 5 . 9 2 \pm 5 . 9 6 a}$ & $\mathbf{1 2 . 4 5 \pm 4 . 8 8 a}$ \\
$\mathrm{Zn}$ & $46.43 \pm 6.40$ & $66.12 \pm 19.37$ & $40.40 \pm 0.45$ & $49.08 \pm 6.25$ & $52.29 \pm 6.27$ & $41.44 \pm 0.79$ \\
$\mathrm{Mo}$ & $1.28 \pm 0.45$ & $0.92 \pm 0.31$ & $0.91 \pm 0.19$ & $0.87 \pm 0.34$ & $0.80 \pm 0.37$ & $0.86 \pm 0.35$ \\
\hline
\end{tabular}


Table S5.4 One-way ANOVA analysis of bacteria 165 community alpha diversity based on Shannon index.

\begin{tabular}{|l|l|l|l|l|l|}
\hline & Df & Sum Sq & Mean Sq & F value & $\operatorname{Pr}(>\mathrm{F})$ \\
\hline Treatments & 6 & 0.3144 & 0.05240 & 2.488 & 0.0561 \\
\hline Residuals & 21 & 0.4422 & 0.02106 & & \\
\hline
\end{tabular}

Table S5.5 One-way ANOVA and Tuckey posthoc analysis of fungi ITS community alpha diversity based on Shannon index.

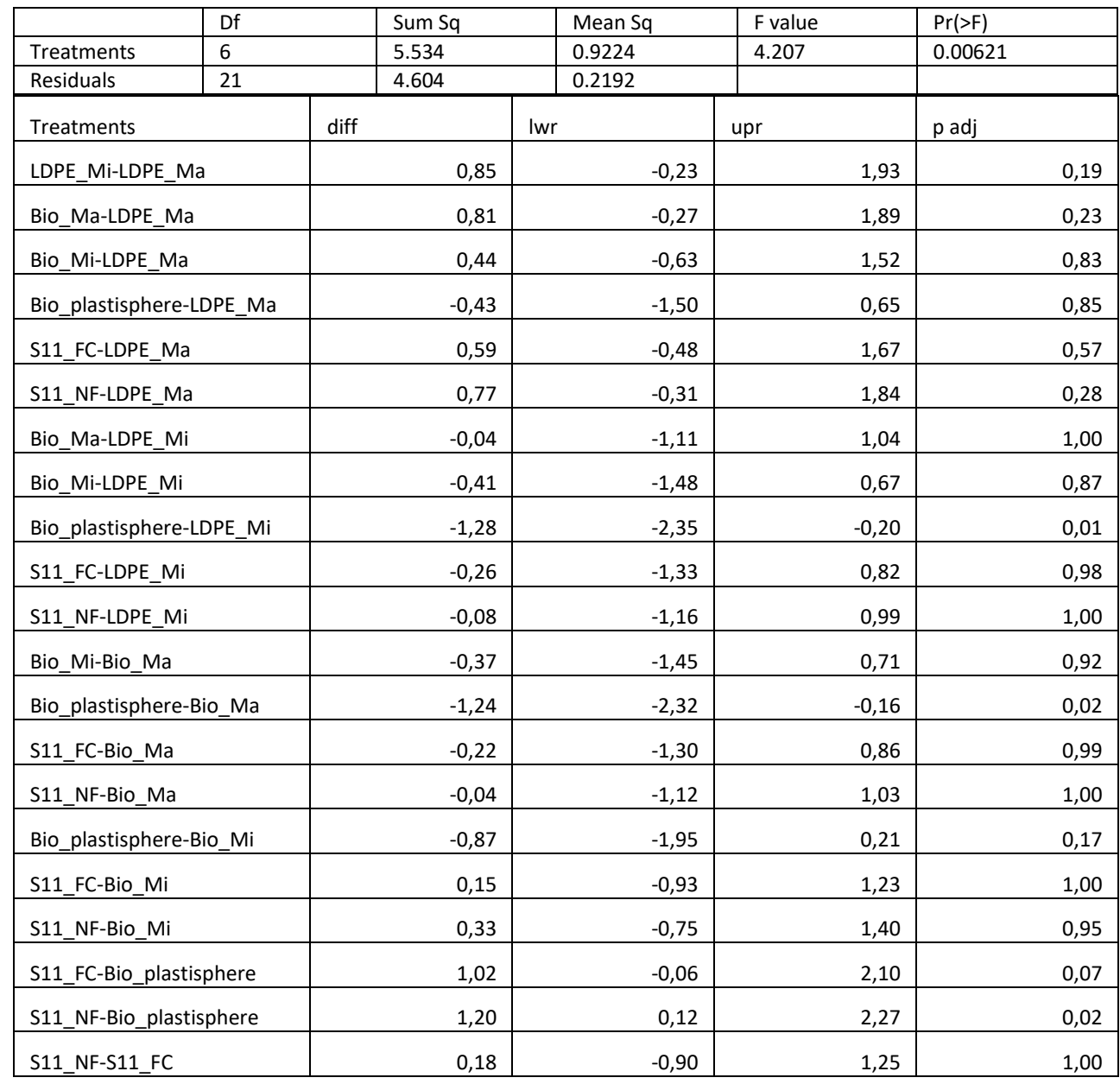



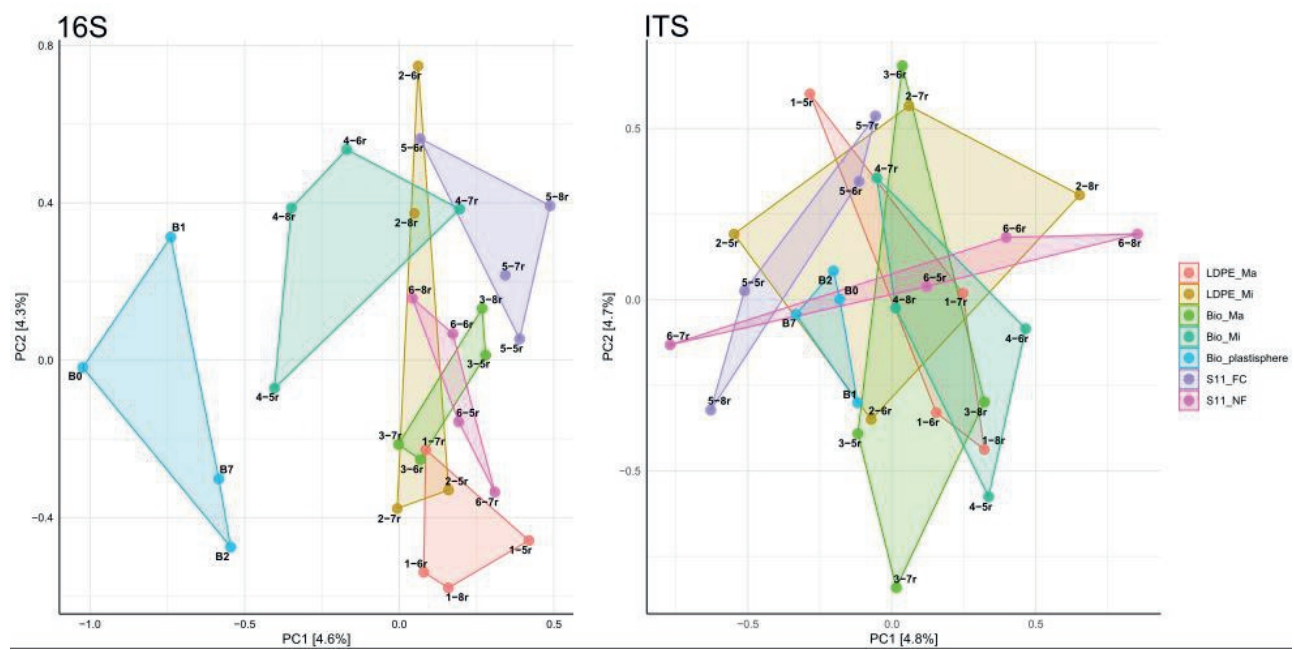

Figure S5.1 Principal Component Analysis of bacterial (16S) and fungal (ITS) communities 
6. Synthesis 


\subsection{General conclusions}

The evidence collected from laboratory and greenhouse experiments during this $\mathrm{PhD}$ research has helped to provide new insights into the effects of plastic mulch film residues on the soil-plant system. By focusing on macro- and micro-sized plastic residues of LDPE and starch-based biodegradable plastic mulch film, this research has filled some knowledge gaps and contributed to further understanding the effect of microplastics in the agroecosystem. This thesis explores the effects of plastic residues on various aspects of the soil-plant system (Figure 6.1), and the main findings of this thesis have been summarized in Table 6.1 and further discussed in this chapter.
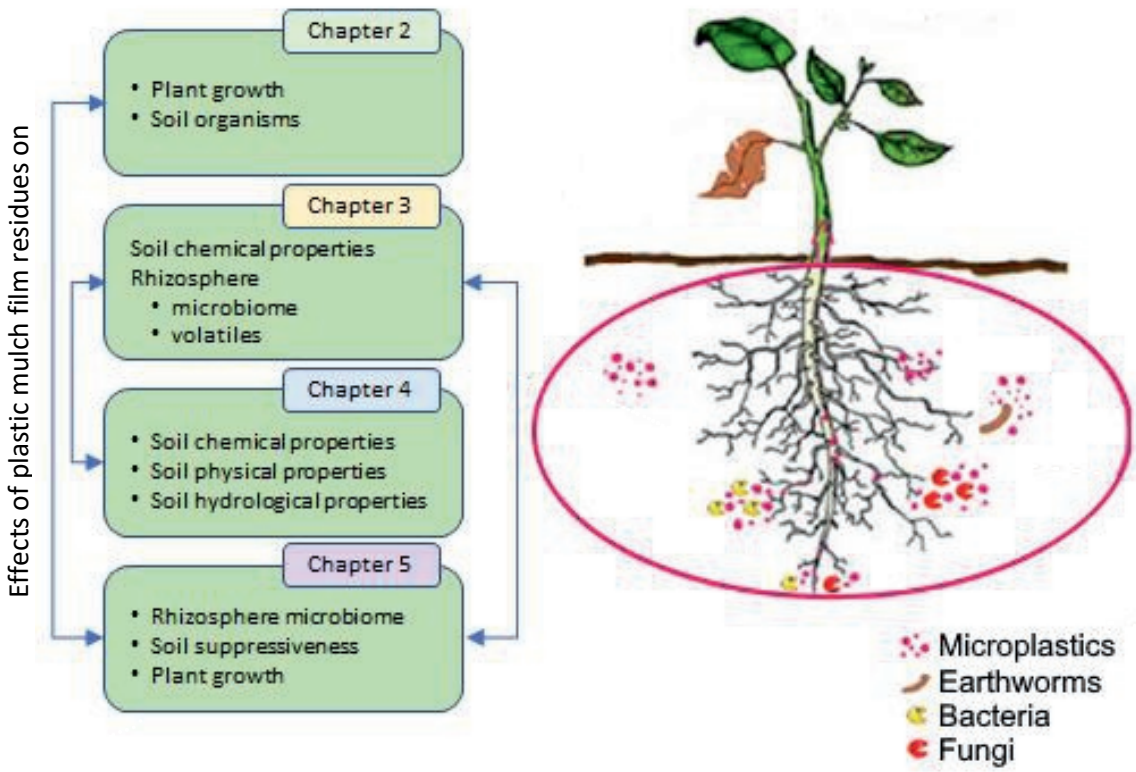

Figure 6.1 Outline of the main findings in the thesis

In this study, the different plastic types (LDPE and biodegradable plastic) and plastic sizes (microplastic and macroplastic) were the main factors that were taken into account. $1 \%$ $(w / w)$ of plastic content was used as the practicable and instructive setting to simulate the plastic mulch film residues in agricultural soil according to the literature review and unpublished data from field surveys conducted by colleagues in Soil Physics and Land Management Group, WUR. We used $1 \%$ w/w of plastic added to soil for all the experiments and in Chapter 4, we explored the effects of a gradient of plastic residues on soil properties, i.e. $0.5 \%, 1 \%$ and $2 \% \mathrm{w} / \mathrm{w}$ of plastic. Nonmonotonic responses were observed in the experiments conducted in Chapter 4 and this result reminded us again that a heterogeneous soil matrix is very different from an aquatic ecosystem. The presence of plastic debris in the 
soil could affect various soil processes and the potential interactions among plastic particles and natural matter are still unpredictable based on current knowledge. Since our knowledge about the ecological impacts of microplastics on the soil-plant system is still in its infancy, the conclusions should be largely confined to the specific soil-plant system model defined for this thesis. Further research needs to be carried out before the findings of this thesis can be applied in the field.

In Chapter 2, both macro- and micro-sized plastic residues of LDPE and biodegradable mulch films affected above- and below-ground biomass of wheat during both vegetative and reproductive growth. The biodegradable plastic mulch film residues showed stronger negative effects as compared to the same amount of LDPE ones. Earthworms showed significantly positive effect on the wheat growth and chiefly alleviated the impairments caused by the presence of plastic residues. The stronger effects observed in treatments with biodegradable plastic residues might be caused by the noticeable different compositions for LDPE and biodegradable mulch films. We speculated that the alterations of soil properties and soil microbiome could explain the underlying reasons why the wheat growth was negatively affected by the addition of plastic residues.

Consequently, Chapter 3 and Chapter 4 further explored the potential biotic and abiotic reasons for the negative effects of plastic residues on wheat growth observed in Chapter 2 . The mortality rate of earthworms observed in Chapter 2 was relatively high compared to other studies and it indicated that the growing roots and earthworms may have competed with each other for space in the pot. In addition, the interactions between the earthworms and the plastic residues were not significant in this model system. Therefore, we exclude the soil organism factor for further mechanistic research.

Chapter 3 revealed that the composition and structure of wheat rhizosphere bacterial communities were strongly changed by the presence of plastic residues, especially biodegradable ones, and different sizes of the same type of plastic residues exerted different impacts on the rhizosphere microbiome. Specific bacterial genera (e.g. Bacillus, Variovorax, Comamonadaceae, etc.) were present in higher relative abundances in treatments with biodegradable plastics, while bacteria taxa affiliated with the genus Saccharibacteria were higher in relative abundance in the treatments with LDPE plastics. Variations were also observed for rhizosphere volatiles and other abiotic parameters (i.e. $\mathrm{pH}$, electrical conductivity, and $\mathrm{C}: \mathrm{N}$ ratio). It is speculated that the presence of biodegradable plastics in soil could quickly affect rhizosphere microbiome and belowground plant-microbe interactions, compared to the remarkable chemical inertness of LDPE mulch films. 
In Chapter 4, effects of the presence of plastic residues on soil structure, water infiltration, soil water retention, soil water repellency and soil chemical properties were studied with a content gradient $(0.5 \%, 1 \%$ and $2 \% \mathrm{w} / \mathrm{w})$ under laboratory conditions. The bulk density, porosity, saturated hydraulic conductivity, field capacity and soil water repellency were altered significantly in the presence of the four kinds of plastic debris, while $\mathrm{pH}$, electrical conductivity and aggregate stability were not substantially affected. The type, size and content of plastic debris as well as the interactions between these three factors played complex roles in the variations of the measured soil parameters. The presence of all plastic residues increased water repellency compared to control. The presence of LDPE debris decreased field capacity, while biodegradable plastic debris increased it. Overall, both LDPE and biodegradable plastic mulch film in either macro- or micro- sizes had noticeable effects on soil physicochemical and hydrological parameters and these soil properties nonmonotonically responded to the residual amounts of plastic.

In Chapter 5, the presence of $1 \%(\mathrm{w} / \mathrm{w})$ plastic mulch film residues did not affect the level of disease infection of wheat in soil suppressive to Fusarium culmorum. However, the shoot biomass of wheat was reduced, and the plant nutrient content was affected by the presence of plastic residues. Interestingly, the rhizosphere bacterial and fungal communities were not significantly changed but the plastispheres formed very different microbial communities. The fact that in Chapter 5, we did not observe a significant effect of plastic residues on the rhizosphere microbiome might be due to the fact that we performed a short-term experiment (two weeks for activation and three weeks for infection). However, it is plausible that in the long term, the presence of plastic residues may cause strong effects. The fact that the plastispheres attracted and possibly activated specific microorganisms indicates the potential of plastic pollution to influence the soil microbiome.

To conclude, this thesis provided experimental evidence that plastic residues could affect physical, chemical, and biological processes in the soil-plant system. With the same residual amount, biodegradable plastic mulch films had a stronger effect on the soil-plant system as compared to LDPE mulch films. The size of plastic debris (macro- and micro- sizes) also showed different effects on plant growth and soil properties. Despite the lack of knowledge, it is clear with the incipient evidence that microplastics derived from plastic mulch films could be detrimental to agricultural productivity, soil biodiversity and soil biogeochemical cycles. Moreover, the insights of this $\mathrm{PhD}$ research are a valuable contribution to a framework for systematic analysis of the effects of microplastics on the soil-plant system. 
Table 6.1 The summary of main findings in the thesis

\begin{tabular}{|c|c|c|c|c|c|c|c|c|c|c|c|c|}
\hline \multirow{2}{*}{ Parameters } & \multicolumn{3}{|c|}{ LDPE Ma (\%) } & \multicolumn{3}{|c|}{ LDPE Mi (\%) } & \multicolumn{3}{|c|}{ Bio Ma (\%) } & \multicolumn{3}{|c|}{ Bio Mi (\%) } \\
\hline & 0.5 & 1 & 2 & 0.5 & 1 & 2 & 0.5 & 1 & 2 & 0.5 & 1 & 2 \\
\hline \multicolumn{13}{|l|}{$\begin{array}{l}\text { Plant growth } \\
\text { (with earthworms) }\end{array}$} \\
\hline $\begin{array}{r}\text { Shoot biomass } 2 \\
\text { months }\end{array}$ & & \pm & & & \pm & & & - & & & - & \\
\hline $\begin{array}{r}\text { Root biomass } 2 \\
\text { months }\end{array}$ & & \pm & & & \pm & & & \pm & & & \pm & \\
\hline $\begin{array}{r}\text { Shoot biomass } 4 \\
\text { months }\end{array}$ & & \pm & & & \pm & & & \pm & & & - & \\
\hline $\begin{array}{r}\text { Root biomass } 4 \\
\text { months }\end{array}$ & & \pm & & & \pm & & & \pm & & & \pm & \\
\hline Fruit biomass & & \pm & & & \pm & & & \pm & & & \pm & \\
\hline \multicolumn{13}{|l|}{$\begin{array}{l}\text { Plant growth } \\
\text { (no earthworms) }\end{array}$} \\
\hline $\begin{array}{r}\text { Shoot biomass } 2 \\
\text { months }\end{array}$ & & \pm & & & \pm & & & - & & & - & \\
\hline $\begin{array}{r}\text { Root biomass } 2 \\
\text { months }\end{array}$ & & - & & & - & & & - & & & - & \\
\hline $\begin{array}{r}\text { Shoot biomass } 4 \\
\text { months } \\
\end{array}$ & & \pm & & & \pm & & & \pm & & & \pm & \\
\hline $\begin{array}{r}\text { Root biomass } 4 \\
\text { months }\end{array}$ & & - & & & \pm & & & \pm & & & \pm & \\
\hline Fruit biomass & & \pm & & & \pm & & & - & & & - & \\
\hline \multicolumn{13}{|l|}{ Soil organisms } \\
\hline Final biomass & & - & & & - & & & - & & & - & \\
\hline Mortality & & + & & & + & & & + & & & + & \\
\hline $\begin{array}{r}\text { New born } \\
\text { earthworms } \\
\end{array}$ & & - & & & - & & & + & & & + & \\
\hline $\begin{array}{l}\text { Rhizosphere } \\
\text { microbiome }\end{array}$ & \multicolumn{12}{|c|}{$\begin{array}{l}\text { Different types and sizes of plastic residues exerted different impacts on rhizosphere } \\
\text { bacterial communities. }\end{array}$} \\
\hline Rhizosphere volatiles & \multicolumn{12}{|c|}{$\begin{array}{l}\text { The addition of plastic residues affected the blend of volatiles emitted in the } \\
\text { rhizosphere. }\end{array}$} \\
\hline \multicolumn{13}{|l|}{$\begin{array}{l}\text { Soil chemical } \\
\text { properties }\end{array}$} \\
\hline $\mathrm{C}: \mathrm{N}$ ratio 2 months & & \pm & & & + & & & \pm & & & + & \\
\hline C: $N$ ratio 4 months & & \pm & & & + & & & \pm & & & + & \\
\hline pH 2 months & & \pm & & & \pm & & & \pm & & & + & \\
\hline pH 4 months & & - & & & \pm & & & \pm & & & \pm & \\
\hline EC 2 months & & \pm & & & \pm & & & - & & & - & \\
\hline EC 4 months & & \pm & & & + & & & \pm & & & \pm & \\
\hline $\mathrm{pH}$ one month & \pm & \pm & \pm & \pm & \pm & \pm & + & + & \pm & \pm & \pm & \pm \\
\hline EC one month & \pm & \pm & \pm & \pm & \pm & \pm & \pm & \pm & \pm & \pm & \pm & \pm \\
\hline
\end{tabular}

Table 6.1 will be continued on next page 
Table 6.1 The summary of main findings in the thesis (continued)

\begin{tabular}{|c|c|c|c|c|c|c|c|c|c|c|c|c|}
\hline \multirow{2}{*}{ Parameters } & \multicolumn{3}{|c|}{ LDPE Ma (\%) } & \multicolumn{3}{|c|}{ LDPE Mi (\%) } & \multicolumn{3}{|c|}{ Bio Ma (\%) } & \multicolumn{3}{|c|}{ Bio Mi (\%) } \\
\hline & 0.5 & 1 & 2 & 0.5 & 1 & 2 & 0.5 & 1 & 2 & 0.5 & 1 & 2 \\
\hline \multicolumn{13}{|l|}{$\begin{array}{l}\text { Soil physical } \\
\text { properties }\end{array}$} \\
\hline Porosity & \pm & + & \pm & \pm & + & \pm & \pm & + & + & \pm & \pm & \pm \\
\hline Dry bulk density & \pm & - & - & \pm & - & \pm & \pm & - & - & \pm & \pm & \pm \\
\hline Aggregate stability & \pm & \pm & \pm & \pm & \pm & \pm & \pm & \pm & \pm & \pm & \pm & \pm \\
\hline \multicolumn{13}{|l|}{$\begin{array}{l}\text { Soil hydrological } \\
\text { properties }\end{array}$} \\
\hline Water infiltration & \pm & + & + & \pm & + & \pm & \pm & + & + & \pm & \pm & - \\
\hline Field capacity & \pm & \pm & - & \pm & \pm & - & \pm & + & + & \pm & + & + \\
\hline Water repellency & \pm & + & + & + & + & \pm & \pm & + & + & \pm & + & + \\
\hline Soil suppressiveness & & \pm & & & \pm & & & \pm & & & \pm & \\
\hline \multicolumn{13}{|l|}{ Plant growth } \\
\hline $\begin{array}{r}\text { Shoot biomass } 3 \\
\text { weeks }\end{array}$ & & - & & & - & & & - & & & - & \\
\hline $\begin{array}{r}\text { Root biomass } 3 \\
\text { weeks }\end{array}$ & & \pm & & & \pm & & & \pm & & & \pm & \\
\hline \multicolumn{13}{|l|}{ Plant nutrients } \\
\hline Mn in shoot & & + & & & + & & & \pm & & & \pm & \\
\hline $\mathrm{Cu}$ in root & & \pm & & & + & & & \pm & & & \pm & \\
\hline $\begin{array}{l}\text { Rhizosphere } \\
\text { microbiome }\end{array}$ & \multicolumn{12}{|c|}{$\begin{array}{l}\text { The rhizosphere bacterial and fungal communities were not significantly changed with } \\
\text { presence of plastic residues. }\end{array}$} \\
\hline $\begin{array}{l}\text { Plastisphere } \\
\text { microbiome }\end{array}$ & \multicolumn{12}{|c|}{$\begin{array}{l}\text { The plastisphere on biodegradable macro pieces formed very different microbial } \\
\text { communities from rhizosphere soils. }\end{array}$} \\
\hline
\end{tabular}

The colors represent for different chapters: Chapter 2 (green), Chapter 3 (yellow), Chapter 4 (blue) and Chapter 5 (purple). + means the value of the parameter is significantly higher than control. - means the value of the parameter is significantly lower than control. \pm means the value of the parameter is not significantly different from control. Empty cells means not investigated.

\subsection{General discussion}

Hopefully, the findings of this thesis will contribute to a better understanding of the effects of plastic mulch film residues on the soil-plant system. The mechanistic understanding of what happened is still vague due to the huge knowledge gap, so most of this study could only describe what happened in the experiments. To gain a comprehensive understanding of the environmental consequences of plastic residues, especially microplastics in the agroecosystem, further research in all disciplines is urgently needed. The concerns which are closely related to this $\mathrm{PhD}$ research are discussed below to justify the interpretation of this thesis. 


\subsubsection{Biodegradable plastic mulch film used in this thesis}

In this soil-plant system model, more severe effects on plant growth were observed in treatments with biodegradable plastic mulch film residues as compared to LDPE treatments. Although great expectations have been placed on biodegradable plastic mulch films, namely that they will replace conventional PE films, studies about the effects of these biodegradable plastics on crop growth and soil quality have barely been carried out so far (Bandopadhyay et al., 2018; Li et al., 2014a). Previous studies of biodegradable plastic mulch films mainly focused on their performance in agriculture (Anzalone et al., 2010; Kapanen et al., 2008; Miles et al., 2012) or their degradation and deterioration patterns (Li et al., 2014b; Moreno et al., 2017). In this thesis, the presence of biodegradable plastic residues showed significantly different effects on the rhizosphere microbiome and soil properties as compared to LDPE treatments. As we discussed in previous chapters, biodegradable plastics are a family of various polymers (e.g. PLA, PHA, PBS, PBAT, etc.) and the starch blend is the most widely used type. Considering the workload, we only used one starch-based biodegradable plastic mulch in this PhD research. The chemical composition of LDPE and biodegradable plastic mulch films was believed to be the major explanation for the different effects. Therefore, it is not reasonable to expect the same effects from other types of biodegradable plastic mulch films.

The plastic mulch films used in this thesis were purchased from the plastic mulch producer that supplies Unifarm, WUR. When we contacted the manufacturer about the starch-based biodegradable plastic mulch films for the first time in 2017, they replied that they could not share the chemical properties and composition of the film because of the many different competitors on the European market. Consequently, the composition of the biodegradable plastic mulch films was further investigated using Fourier transform infrared spectroscopy (FTIR) and the best spectra match (84\% match) was obtained for a composition of $44.6 \%$ PET, 18.3\% Polybutylene Terephthalate (PBT) and 37.1\% Pullulan. I chose to present the measured composition of the films in this $\mathrm{PhD}$ research, rather than provide the tradename and manufacturer of the film. In this way, I aimed to put emphasis on the actual composition of the film, which was more relevant to the scientific interest, not the social impacts on the company.

At the end of 2019, we received a complaint from a businessman concerning our first publication (Chapter 2 ) and he insisted that the chemical composition of the biodegradable plastic mulch film we provided was a false/misleading claim. Therefore, we got in touch with the manufacturer again in early 2020 and they gave us more information than before (Figure 6.2). We consulted an expert in FTIR about the conflicting information and learned that FTIR was not suitable for the quantitative determination of fractions of various 
polymers, especially not in a "black box" product which you did not polymerize and further process into film yourself. The spectra for PBAT and PBT and PET are very much alike because they all contain the terephthalate monomer. The ethylene, butylene, and adipate monomers are all short aliphatic spacer molecules. In an FTIR spectrum, it is impossible to calculate relative concentrations of polymers, especially if the polymers are co-polyesters for which you do not know the incorporation ratio of adipate versus terephthalate.

Compositions measured by FTIR ( $84 \%$ match)

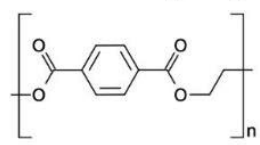

PET: Polyethylene Terephthalate (44.6\%)

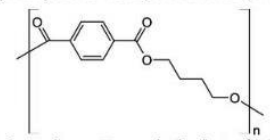

PBT: Polybutylene Terephthalate (18.3\%)

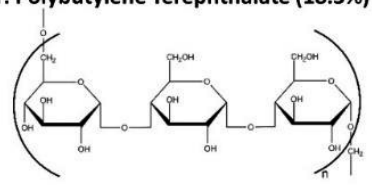

Pullulan (37.1\%)

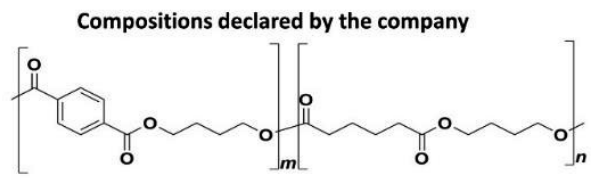

PBAT: polybutylene adipate terephthalate

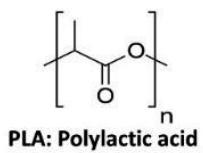

This film is formulated with a compound made with mainly PBAT and starch and a low content PLA (around 5\%) blended with the black Carbon masterbatch using copolyester as carrier resin.

Figure 6.2 The chemical composition of biodegradable plastic mulch film used in this thesis

Therefore, we adjusted our description in Chapter 4 to read: "The company states that the Bio PMF is produced from a formulated compound consisting mainly of polybutylene adipate terephthalate, starch and about $5 \%$ polylactic acid, blended with a black carbon masterbatch using a copolyester as a carrier resin." I did not explore this issue further since we did not have a clear hypothesis concerning the composition of plastic mulch film residues and their effects on the soil-plant system anyway. When interpreting our results, the time limitation of our experiments should also be considered. The longest period of our experiments was four months and the experiments conducted in Chapter 4 were restricted to one month. It is plausible that biodegradable plastics had a quick effect on the soil-plant system in the short term, while the long-term effects have not been explored yet.

Nowadays, it is quite common to describe the plastic materials used in research by listing their tradename and company. Mistakes made by researchers trying to identify the composition of materials can now be totally avoided. But further integrating and comparing different studies will be severely limited by the various commercial brands and the information released from companies. This concern comes along with the lack of regulations for biodegradable plastic mulch films on the market. Conventional plastic mulch 
films consist mostly of LDPE and linear LDPE with small amounts of additives. However, the composition of biodegradable plastic mulch films is diverse and usually protected under business patents. Until the release of the European Standard EN 17033 in 2018, there was no international standard which could be directly applied to biodegradable plastic mulch films in soil and the standards for the biodegradation under compost were largely misinterpreted for soil (Briassoulis and Dejean, 2010; Briassoulis et al., 2010). Although this standard is an important achievement, there are still many limitations and no standard is designed to reproduce actual field conditions (Hayes and Flury, 2018). There is still a long way to go to achieve a sustainable application of plastic mulch films in agriculture; a joint effort is needed from policymakers, industries and scientists to solve the problem.

\subsubsection{Effects of macro- and micro- sized plastic residues on the soil-plant system}

The microplastics used in this thesis came in the form of a plastic powder with particles that ranged in size from $50 \mu \mathrm{m}$ to $1 \mathrm{~mm}$ and the macroplastics were $5 \mathrm{~mm}$ square pieces of plastic (More detailed descriptions were presented in Chapter 2). Returning to the definition of a microplastic from Chapter 1, I would like to point out the flaw in that definition. When we said that microplastics were 'commonly' defined as plastic particles with diameters smaller than $5 \mathrm{~mm}$, it meant that the definition for microplastics has varied from study to study. Another popular standard is smaller than $1 \mathrm{~mm}$. In other studies, the microplastic diameters were smaller than $10 \mathrm{~mm}, 5 \mathrm{~mm}$, or $2 \mathrm{~mm}$ (Cole et al., 2011). Many researchers have pointed out the importance of establishing a scientific and unified standard for microplastics and a nomenclature for plastic residues (e.g. nano-, micro-, meso-, macro-, mega- plastics) (Andrady, 2011; Cole et al., 2011; GESAMP, 2015; Qi et al., 2020a). However, the scientific community has not yet reached consensus on the standards for microplastics or the classification of plastic residues. The transport and potential toxicity of plastic particles are closely related to their sizes; for instance, $150 \mu \mathrm{m}$ and $6 \mathrm{~nm}$ were generally considered as the thresholds for particles penetrating cell membranes and cell walls (Carpita et al., 1979; de Souza Machado et al., 2018a; Hussain et al., 2001). Therefore, it is necessary to keep a clear record of the exact sizes of plastic materials used for each study. Otherwise, it will be nearly impossible to compare results among different studies.

In this thesis, the size of plastic residues caused the variations in plant growth, rhizosphere microbiomes and volatile profiles, as well as in soil physicochemical and hydrological properties. For instance, microplastics showed more negative effects than macroplastics on wheat growth for both LDPE and biodegradable ones, and the differences were statistically significant in some cases (Chapter 2). For bacterial community structures and volatile profiles in the rhizosphere, different sizes of plastic residues clearly exerted different 
influences (Chapter 3). Significant differences in soil properties between controls and treatments were observed more frequently in treatments with macroplastics (Chapter 4). In the long run, macro-sized plastic debris could be degraded into microplastics and nanoplastics due to various biotic and abiotic stressors (Barnes et al., 2009; Singh and Sharma, 2008). With the increased surface/volume ratio and biochemical activity, the interactions of small plastic particles will be more dynamic and complex than large plastic particles in soil. This highlights the fact that research is urgently needed to clarify the environmental fate and the effects of different sized plastic particles in terrestrial systems.

\subsubsection{Environmentally relevant concentrations of microplastics in soil}

When this PhD research started in 2016, research about microplastics in soil was scarce. The status of plastic mulch film residues is closely relevant to the amount of microplastics in soil. As seen in recent studies, plastic mulching in agriculture is one of the main entryways for microplastics in soil (Huang et al., 2020; Piehl et al., 2018; Zhou et al., 2020). With sixty collected soil samples, Zhou et al. (2020) found that mulching soils contained larger amounts of microplastics than non-mulching soils, with 571 pieces $\mathrm{kg}^{-1}$ and 263 pieces $\mathrm{kg}^{-1}$, respectively, on average. Even in a study site where microplastic-containing fertilizers and agricultural plastic applications were never used, researchers found 206 macroplastic pieces per hectare and $0.34 \pm 0.36$ microplastic particles $\mathrm{kg}^{-1}$ dry weight of soil (Piehl et al., 2018). Despite of the current status, the abundance of microplastics in soil will keep increasing over the coming decades, even centuries. Huang et al. (2020) found the abundances of microplastics increased over time in the farmlands where plastic mulching was continuously applied, with concentrations of $80.3 \pm 49.3,308 \pm 138.1$, and $1075.6 \pm 346.8$ pieces $\mathrm{kg}^{-1}$ soil in fields with 5,15 , and 24 years of continuous mulching, respectively. Overall, $1 \%(w / w)$ of plastic content was used as the practicable and instructive setting to simulate the plastic mulch film residues in agricultural soil. In addition, a gradient of plastic residues $(0.5 \%, 1 \%$ and $2 \% \mathrm{w} / \mathrm{w}$ ) was applied to study their effects on soil properties.

In the last several years, more studies examining microplastics in the soil-plant system have been conducted. de Souza Machado et al. (2019) added $0.2 \%$ polyester fibres and $2 \%$ polyamide beads and fragments of PE, PET, PP, PS of soil fresh weight individually to investigate effects of plastic on soil health and spring onion growth. They observed significant changes in plant biomass, tissue elemental composition, root traits, and soil microbial activities (de Souza Machado et al., 2019). Different from the size factor studied in this thesis, they found the impacts of microplastics on soil-plant system are also related to their shape, and microplastics with a shape similar to natural soil particles showed smaller differences than the control. Boots et al. (2019) studied the addition of $0.1 \%$ highdensity PE and polylactic acid and $0.001 \%$ synthetic fibres in dry soil in a mesocosm 
experiment with earthworms and perennial ryegrass. They found that three of the tested microplastics affected the plant growth, the health of earthworms and the soil properties (Boots et al., 2019). Together with the relatively high concentrations used in this thesis $(0.5 \%, 1 \%, 2 \%)$, it is interesting to testify various concentrations of microplastics in soil with a large gradient in one soil-plant system. One most relevant study to this issue, Kleunen et al. (2019), tested a perennial forb (Plantago lanceolata) with 10 different concentrations of plastic granules from $0,0.25,0.5,1,2,4,8,16,32$, up to $64 \% \mathrm{v} / \mathrm{v}$. They estimated the lethal concentrations (LC) of plastic for $P$. lanceolata while the plants were exposed to low and high nutrient conditions. In the low nutrient treatment, LC10, LC20 and LC50 values were $6.8 \%, 8.7 \%$ and $13.1 \%$, respectively, while in the high nutrient treatment they are $8.0 \%$, 9.6\% and 13.3\% (Kleunen et al., 2019). One limitation of this study was that they used an artificial substrate instead of natural soil (1:1 mixture of quartz sand and vermiculite). So far, studies that have focused on microplastics in the soil-plant system are scarce. It is tricky to determine whether the exposure dose of microplastics in a laboratory experiment is realistic or not, since there is very little global data concerning the contamination levels of microplastics in soil.

\subsection{Research challenges and future research directions}

There are still many questions that need to be answered in order to understand microplastics in the agroecosystem and some of them will be listed as suggestions for future research directions in the following paragraphs.

As discussed above, more field surveys involving different farming systems are needed to assess the global contamination levels of microplastics in soil. It is likely that farmlands with biosolid applications and plasticulture will contain large amounts of microplastics (Corradini et al., 2019b; Huang et al., 2020; Li et al., 2018b). However, not only these hot spots, but also general farmlands need to be inspected in order to discover the current status of microplastics in soil, considering the dynamic transport of microplastics between soil, water and air (Horton et al., 2017; Waldschlager et al., 2020). Along with this issue, the challenges in quantifying various types and shapes of microplastics in all kinds of soil matrixes need to be solved (Moller et al., 2020).

Many aspects concerning the fate of microplastics in soil need to be investigated: the horizontal and vertical transfer of microplastics by soil organisms, microbes, plant roots, and farming activities. It is also important to determine how microplastics leave the soil matrix: leakage into ground water, transport by wind erosion, etc. Initial studies have shown 
that microplastics in soil could be transferred by earthworms and Collembola and that there is a clear risk of microplastics leaching into the groundwater (Maass et al., 2017; Rillig et al., 2017b; Yu et al., 2019). In addition, a study on the transport of microplastics by wind erosion found microplastics in wind-eroded sediments in agricultural and natural areas and indicated the exposure risk to humans via direct inhalation of the particles transported with the dust (Rezaei et al., 2019). Furthermore, the cotransport of organic/inorganic pollutants adhered to the surface of plastic residues and incorporated additives may have important environmental consequences, which should also be further studied (Hahladakis et al., 2018; Zhu et al., 2019).

Currently, intensively studying the mechanisms through which plants, soil and plastic residues interact in soil ecosystems is a big challenge. This thesis provides new insights about rhizosphere interactions. The plant rhizosphere is where plant roots meet the soil. This is the space where plants uptake water and nutrients and interact with the soil, which is considered the second genome of plants (Zhang et al., 2017). Soil possesses the highest microbial diversity known to date and soil microbes can help plants overcome different stresses and improve growth. To achieve this, plants may recruit, activate, and assemble protective microbiomes when they are threatened by the presence of plastic residues. Further research encompassing prospective experimental designs focusing on the intricate interactions in the rhizosphere can broaden our understanding of plastic residues in the soilplant system and contribute to sustainable agricultural gains.

Crop productivity and soil quality are crucial aspects of agroecosystems. One way to further add to the knowledge gained through carrying out the research for this thesis would be to test the effects of microplastics on the soil-plant system with various soil organisms, plants, microbes separately or/and together. As discussed in Chapter 1, there are diverse pathways for microplastics to enter the soil such as through landfills, littering, sewage sludge disposal, and plastic mulching, just to name a few. It would be relevant to study all types, sizes, and shapes of plastic debris at different concentrations under different soil conditions to fully understand what is happening in agroecosystems.

\subsection{Broader implications and recommendations}

Because microplastics can be actively transferred between the land, water, and air, it is currently challenging to conduct research that incorporates all of the environmental compartments. Geologists, hydrologists, soil physicists, chemists, microbiologists, ecologists, agronomists and scientists from all disciplines could first study the respective processes independently and then come together to create a comprehensive understanding 
of microplastics in the environment. Since agroecosystems are widely acknowledged as the compartments that are the most vulnerable to the accumulation and deterioration of plastic residues, studies examining microplastics in soil are urgently needed to ensure food security and achieve sustainable agriculture.

Taking one biodegradable plastic mulch film as an example, this thesis suggested that the all-round assessment of biodegradable plastic mulch films based on comprehensive research is urgently needed before the films could be allowed to be commercialized. Since plastic mulch films have brought so many agronomic benefits, it is not realistic to demand that they simply stop being used in agriculture. Therefore, the most attractive solution to accumulated plastic residues derived from plastic mulching is to invent biodegradable ones which can be incorporated into soil directly. However, we currently know too little about the field performance and ecological effects of biodegradable plastic mulch films, especially concerning the long-term effects. We should learn our lesson from having rushed into the mass production of plastics in the last century. A fallacy today may become a big headache tomorrow.

In a broad sense, biodegradable plastics are not the one-fits-all solution for the current unsustainable management of post-consumer plastic wastes. People tend to overestimate the function of biodegradable plastics in order to lift the environmental responsibility from individuals. However, we cannot solve plastic pollution without abandoning the throw-away culture and narrow-minded consumerism.

Studies looking at degrading plastic residues using bacteria, fungi, worms and related enzymes are trying to find potential ways to solve the plastic pollution problem at the source. There have been some interesting findings in these studies, but any applications of possible solutions in the field are still far away (Huerta Lwanga et al., 2018; Wei and Zimmermann, 2017; Yang et al., 2014a; Yang et al., 2015). When we discuss the degradation of plastic materials, it is important to define to the extent, the time period, and the conditions under which plastic materials are degraded. Given time, it is likely that microplastics would be further degraded into sub-micrometer plastics, even nanoplastics, and the risks posed by nanoplastics in the environment are even less predictable. Recent studies have shown in controlled experiments that these miniscule plastic particles can be taken up by plants (Li et al., 2020; Sun et al., 2020), which implies that people ingesting those plants would then experience a build-up of plastics in their bodies. Therefore, it is essential to take positive actions to control plastic pollution before the problem gets worse.

When we look at the big picture, plastics produced for agricultural applications only account for a small portion of the global plastic market. For instance, packaging represented $39.9 \%$ 
of European plastic converters overall demand and agriculture only accounted for $3.4 \%$ of the demand in 2018 (PlasticsEurope, 2019). While facing the current problems posed by plastic pollution, I consider that calling on responsible consumer behaviour matters more than focusing all of the attention on agricultural activities. Plastic pollution could alter the environment around the world and microplastics, in particular, are the global environmental crisis of the 21st century. In my view, informing the public about the prospects and restraints of tackling plastic pollution in a responsible way is also the duty of the scientific community. Instead of propagating the bright future of biodegradable plastics, every member of our society needs to keep the 'three Rs' (Reduce, Reuse and Recycle) in mind in our daily life. Only with the joint efforts of the whole society can we solve this imperative microplastic crisis. 


\section{Literature cited}

Abdul-Baki, A., Spence, C., Hoover, R., 1992. Black polyethylene mulch doubled yield of fresh-market field tomatoes. Hortscience 27, 787-789.

Almajmaie, A., Hardie, M., Acuna, T., Birch, C., 2017. Evaluation of methods for determining soil aggregate stability. Soil and Tillage Research 167, 39-45.

Amaral-Zettler, L.A., Zettler, E.R., Mincer, T.J., 2020. Ecology of the plastisphere. Nature Reviews Microbiology, 1-13.

Aminabhavi, T., Balundgi, R., Cassidy, P., 1990. A review on biodegradable plastics. PolymerPlastics Technology and Engineering 29, 235-262.

Anderson, R., Emmert, E., 1994. The father of plastic greenhouses, The 25th National Agricultural Plastics Congress.

Andrady, A.L., 2003. Plastics and the Environment. John Wiley \& Sons.

Andrady, A.L., 2011. Microplastics in the marine environment. Mar Pollut Bull 62, 15961605.

Andrady, A.L., Neal, M.A., 2009. Applications and societal benefits of plastics. Philosophical Transactions of the Royal Society B: Biological Sciences 364, 1977-1984.

Anzalone, A., Cirujeda, A., Aibar, J., Pardo, G., Zaragoza, C., 2010. Effect of Biodegradable Mulch Materials on Weed Control in Processing Tomatoes. Weed Technology 24, 369377.

Arthur, C., Baker, J.E., Bamford, H.A., 2009. Proceedings of the International Research Workshop on the Occurrence, Effects, and Fate of Microplastic Marine Debris, September 9-11, 2008, University of Washington Tacoma, Tacoma, WA, USA.

Atkinson, C.J., Fitzgerald, J.D., Hipps, N.A., 2010. Potential mechanisms for achieving agricultural benefits from biochar application to temperate soils: a review. Plant and Soil 337, 1-18.

Auta, H.S., Emenike, C.U., Fauziah, S.H., 2017. Distribution and importance of microplastics in the marine environment: A review of the sources, fate, effects, and potential solutions. Environ Int 102, 165-176.

Bakker, M.G., Schlatter, D.C., Otto-Hanson, L., Kinkel, L.L., 2014. Diffuse symbioses: roles of plant-plant, plant-microbe and microbe-microbe interactions in structuring the soil microbiome. Mol Ecol 23, 1571-1583.

Bandopadhyay, S., Martin-Closas, L., Pelacho, A.M., DeBruyn, J.M., 2018. Biodegradable Plastic Mulch Films: Impacts on Soil Microbial Communities and Ecosystem Functions. Front Microbiol 9, 819. 
Barnes, D.K.A., Galgani, F., Thompson, R.C., Barlaz, M., 2009. Accumulation and fragmentation of plastic debris in global environments. Philosophical Transactions of the Royal Society B: Biological Sciences 364, 1985-1998.

Berg, G., 2009. Plant-microbe interactions promoting plant growth and health: perspectives for controlled use of microorganisms in agriculture. Applied Microbiology and Biotechnology 84, 11-18.

Bertrand, M., Barot, S., Blouin, M., Whalen, J., de Oliveira, T., Roger-Estrade, J., 2015. Earthworm services for cropping systems. A review. Agronomy for Sustainable Development 35, 553-567.

Besseling, E., Wang, B., Lurling, M., Koelmans, A.A., 2014. Nanoplastic Affects Growth of S. obliquus and Reproduction of D. magna. Environ Sci Technol 48, 12336-12343.

Bhattacharya, P., Lin, S.J., Turner, J.P., Ke, P.C., 2010. Physical Adsorption of Charged Plastic Nanoparticles Affects Algal Photosynthesis. Journal of Physical Chemistry C 114, 16556 16561.

Blasing, M., Amelung, W., 2018. Plastics in soil: Analytical methods and possible sources. Science of the Total Environment 612, 422-435.

Blouin, M., Hodson, M.E., Delgado, E.A., Baker, G., Brussaard, L., Butt, K.R., Dai, J., Dendooven, L., Peres, G., Tondoh, J.E., Cluzeau, D., Brun, J.J., 2013. A review of earthworm impact on soil function and ecosystem services. European Journal of Soil Science 64, 161-182.

Boots, B., Russell, C.W., Green, D.S., 2019. Effects of Microplastics in Soil Ecosystems: Above and Below Ground. Environ Sci Technol 53, 11496-11506.

Breiman, L., 2001. Random Forests. Machine Learning 45, 5-32.

Briassoulis, D., Dejean, C., 2010. Critical review of norms and standards for biodegradable agricultural plastics Part I. Biodegradation in soil. Journal of Polymers and the Environment 18, 384-400.

Briassoulis, D., Dejean, C., Picuno, P., 2010. Critical review of norms and standards for biodegradable agricultural plastics Part II: Composting. Journal of Polymers and the Environment 18, 364-383.

Brodhagen, M., Goldberger, J.R., Hayes, D.G., Inglis, D.A., Marsh, T.L., Miles, C., 2017. Policy considerations for limiting unintended residual plastic in agricultural soils. Environmental Science \& Policy 69, 81-84.

Browne, M.A., Crump, P., Niven, S.J., Teuten, E., Tonkin, A., Galloway, T., Thompson, R., 2011. Accumulation of Microplastic on Shorelines Woldwide: Sources and Sinks. Environ Sci Technol 45, 9175-9179.

Browne, M.A., Galloway, T., Thompson, R., 2007. Microplastic-an emerging contaminant of potential concern? Integrated environmental assessment and Management 3, 559561. 
Brussaard, L., de Ruiter, P.C., Brown, G.G., 2007. Soil biodiversity for agricultural sustainability. Agriculture, Ecosystems \& Environment 121, 233-244.

Bünemann, E.K., Bongiorno, G., Bai, Z., Creamer, R.E., De Deyn, G., de Goede, R., Fleskens, L., Geissen, V., Kuyper, T.W., Mäder, P., Pulleman, M., Sukkel, W., van Groenigen, J.W., Brussaard, L., 2018. Soil quality - A critical review. Soil Biology and Biochemistry 120, 105-125.

Cao, D., Wang, X., Luo, X., Liu, G., Zheng, H., 2017. Effects of polystyrene microplastics on the fitness of earthworms in an agricultural soil, IOP Conference Series: Earth and Environmental Science, 1 ed.

Čapka, D., Kisić, I., Zgorelec, Ž., Mesić, M., Jurišić, A., 2009. Determination of soil pH in dominant soil types in the republic of Croatia. Agriculturae Conspectus Scientificus 74, 13-19.

Carpenter, E.J., Anderson, S.J., Harvey, G.R., Miklas, H.P., Peck, B.B., 1972. Polystyrene spherules in coastal waters. Science 178, 749-750.

Carpenter, E.J., Smith, K.L., Jr., 1972. Plastics on the Sargasso sea surface. Science 175, 1240 1241.

Carpita, N., Sabularse, D., Montezinos, D., Delmer, D.P., 1979. Determination of the pore size of cell walls of living plant cells. Science 205, 1144-1147.

Carrión, V.J., Perez-Jaramillo, J., Cordovez, V., Tracanna, V., De Hollander, M., Ruiz-Buck, D., Mendes, L.W., van Ijcken, W.F., Gomez-Exposito, R., Elsayed, S.S., 2019. Pathogeninduced activation of disease-suppressive functions in the endophytic root microbiome. Science 366, 606-612.

Cha, J.-Y., Han, S., Hong, H.-J., Cho, H., Kim, D., Kwon, Y., Kwon, S.-K., Crüsemann, M., Bok Lee, Y., Kim, J.F., Giaever, G., Nislow, C., Moore, B.S., Thomashow, L.S., Weller, D.M., Kwak, Y.-S., 2016a. Microbial and biochemical basis of a Fusarium wilt-suppressive soil. ISME J 10, 119-129.

Cha, J.-Y., Han, S., Hong, H.-J., Cho, H., Kim, D., Kwon, Y., Kwon, S.-K., Crüsemann, M., Lee, Y.B., Kim, J.F., 2016b. Microbial and biochemical basis of a Fusarium wilt-suppressive soil. ISME J 10, 119-129.

Chen, H., 2016. Synergistic Effects of Microplastic and Glyphosate on Soil Microbial Activities in Chinese Loess Soil.

Claessens, M., Van Cauwenberghe, L., Vandegehuchte, M.B., Janssen, C.R., 2013. New techniques for the detection of microplastics in sediments and field collected organisms. Mar Pollut Bull 70, 227-233.

Cole, M., Lindeque, P., Halsband, C., Galloway, T.S., 2011. Microplastics as contaminants in the marine environment: a review. Mar Pollut Bull 62, 2588-2597.

Colton, J.B., Burns, B.R., Knapp, Frederick D., 1974. Plastic Particles in Surface Waters of the Northwestern Atlantic. Science 185, 491-497. 
Corradini, F., Bartholomeus, H., Lwanga, E.H., Gertsen, H., Geissen, V., 2019a. Predicting soil microplastic concentration using vis-NIR spectroscopy. Science of the Total Environment 650, 922-932.

Corradini, F., Meza, P., Eguiluz, R., Casado, F., Huerta-Lwanga, E., Geissen, V., 2019b. Evidence of microplastic accumulation in agricultural soils from sewage sludge disposal. Sci Total Environ 671, 411-420.

da Costa, J.P., Duarte, A.C., Rocha-Santos, T.A.P., 2017. Microplastics - Occurrence, Fate and Behaviour in the Environment, Characterization and Analysis of Microplastics. Elsevier, pp. 1-24.

de Souza Machado, A.A., Kloas, W., Zarfl, C., Hempel, S., Rillig, M.C., 2018a. Microplastics as an emerging threat to terrestrial ecosystems. Glob Chang Biol 24, 1405-1416.

de Souza Machado, A.A., Lau, C.W., Kloas, W., Bergmann, J., Bachelier, J.B., Faltin, E., Becker, R., Gorlich, A.S., Rillig, M.C., 2019. Microplastics Can Change Soil Properties and Affect Plant Performance. Environ Sci Technol 53, 6044-6052.

de Souza Machado, A.A., Lau, C.W., Till, J., Kloas, W., Lehmann, A., Becker, R., Rillig, M.C., $2018 \mathrm{~b}$. Impacts of Microplastics on the Soil Biophysical Environment. Environ Sci Technol 52, 9656-9665.

De Tender, C., Devriese, L.I., Haegeman, A., Maes, S., Vangeyte, J., Cattrijsse, A., Dawyndt, P., Ruttink, T., 2017. Temporal Dynamics of Bacterial and Fungal Colonization on Plastic Debris in the North Sea. Environ Sci Technol 51, 7350-7360.

Deacon, J., 1984. Managing disease. Nature 309, 732-732.

Dekker, L.W., Ritsema, C.J., Oostindie, K., Moore, D., Wesseling, J.G., 2009. Methods for determining soil water repellency on field-moist samples. Water Resources Research 45.

Delgado-Baquerizo, M., Oliverio, A.M., Brewer, T.E., Benavent-Gonzalez, A., Eldridge, D.J., Bardgett, R.D., Maestre, F.T., Singh, B.K., Fierer, N., 2018. A global atlas of the dominant bacteria found in soil. Science 359, 320-325.

Dong, H.D., Liu, T., Han, Z.Q., Sun, Q.M., Li, R., 2015. Determining time limits of continuous film mulching and examining residual effects on cotton yield and soil properties. Journal of Environmental Biology 36, 677-684.

Donn, S., Kirkegaard, J.A., Perera, G., Richardson, A.E., Watt, M., 2015. Evolution of bacterial communities in the wheat crop rhizosphere. Environ Microbiol 17, 610-621.

Duis, K., Coors, A., 2016. Microplastics in the aquatic and terrestrial environment: sources (with a specific focus on personal care products), fate and effects. Environmental Sciences Europe 28, 1.

Eerkes-Medrano, D., Thompson, R.C., Aldridge, D.C., 2015. Microplastics in freshwater systems: A review of the emerging threats, identification of knowledge gaps and prioritisation of research needs. Water Res 75, 63-82.

Ekebafe, L., Ogbeifun, D., Okieimen, F., 2011. Polymer applications in agriculture. Biokemistri 23. 
Elert, A.M., Becker, R., Duemichen, E., Eisentraut, P., Falkenhagen, J., Sturm, H., Braun, U., 2017. Comparison of different methods for MP detection: What can we learn from them, and why asking the right question before measurements matters? Environ Pollut 231, 1256-1264.

Espi, E., 2006. PLastic Films for Agricultural Applications. Journal of Plastic Film and Sheeting 22, 85-102.

European Bioplastics, 2020. Bioplastics Facts and figures.

European Commission, 2016. COMMISSION STAFF WORKING DOCUMENT IMPACT ASSESSMENT Accompanying the document Proposal for a Regulation of the European Parliament and of the Council laying down rules on the making available on the market of CE marked fertilising.

Fan, K., Weisenhorn, P., Gilbert, J.A., Chu, H., 2018. Wheat rhizosphere harbors a less complex and more stable microbial co-occurrence pattern than bulk soil. Soil Biology and Biochemistry 125, 251-260.

Fincheira, P., Quiroz, A., 2018. Microbial volatiles as plant growth inducers. Microbiol Res 208, 63-75.

Fründ, H.-C., Butt, K., Capowiez, Y., Eisenhauer, N., Emmerling, C., Ernst, G., Potthoff, M., Schädler, M., Schrader, S., 2010. Using earthworms as model organisms in the laboratory: recommendations for experimental implementations. Pedobiologia 53, 119125.

Fuller, S., Gautam, A., 2016. A Procedure for Measuring Microplastics using Pressurized Fluid Extraction. Environ Sci Technol 50, 5774-5780.

Gao, H.H., Yan, C.R., Liu, Q., Ding, W.L., Chen, B.Q., Li, Z., 2019. Effects of plastic mulching and plastic residue on agricultural production: A meta-analysis. Science of the Total Environment 651, 484-492.

Gerngross, T.U., 1999. Can biotechnology move us toward a sustainable society? Nature Biotechnology 17, 541-544.

GESAMP, 2015. Sources, fate and effects of microplastics in the marine environment: a global assessment, Reports and Studies 90. IMO/FAO/UNESCOIOC/UNIDO/WMO/IAEA/UN/UNEP/UNDP Joint Group of Experts on the Scientific Aspects of Marine Environmental Protection, London.

Ghorbani, R., Wilcockson, S., Koocheki, A., Leifert, C., 2008. Soil management for sustainable crop disease control: a review. Environmental Chemistry Letters 6, 149-162.

Gil-Delgado, J.A., Guijarro, D., Gosálvez, R.U., López-lborra, G.M., Ponz, A., Velasco, A., 2017. Presence of plastic particles in waterbirds faeces collected in Spanish lakes. Environ Pollut 220, 732-736.

Gomez Exposito, R., de Bruijn, I., Postma, J., Raaijmakers, J.M., 2017. Current Insights into the Role of Rhizosphere Bacteria in Disease Suppressive Soils. Front Microbiol 8, 2529. 
Gouda, S., Kerry, R.G., Das, G., Paramithiotis, S., Shin, H.S., Patra, J.K., 2018. Revitalization of plant growth promoting rhizobacteria for sustainable development in agriculture. Microbiol Res 206, 131-140.

Gregory, M.R., 1978. Accumulation and distribution of virgin plastic granules on New Zealand beaches. New Zealand Journal of Marine and Freshwater Research 12, 399-414. Habib, D., Locke, D.C., Cannone, L.J., 1998. Synthetic fibers as indicators of municipal sewage sludge, sludge products, and sewage treatment plant effluents. Water, Air, and Soil Pollution 103, 1-8.

Hahladakis, J.N., Velis, C.A., Weber, R., lacovidou, E., Purnell, P., 2018. An overview of chemical additives present in plastics: Migration, release, fate and environmental impact during their use, disposal and recycling. J Hazard Mater 344, 179-199.

Haider, T.P., Volker, C., Kramm, J., Landfester, K., Wurm, F.R., 2019. Plastics of the Future? The Impact of Biodegradable Polymers on the Environment and on Society. Angew Chem Int Ed Engl 58, 50-62.

Hale, R.C., Seeley, M.E., La Guardia, M.J., Mai, L., Zeng, E.Y., 2020. A global perspective on microplastics. Journal of Geophysical Research: Oceans 125.

Harper, P., Fowler, J., 1987. Plastic pellets in New Zealand storm-killed prions (Pachyptila spp.). Notornis 34, 65-70.

Hayes, D., Flury, M., 2018. Summary and assessment of EN 17033: 2018. a new standard for biodegradable plastic mulch films. Biodegradablemulch. org.

Hodson, M.E., Duffus-Hodson, C., Clark, A., Prendergast-Miller, M., Thorpe, K.L., 2017. Plastic bag derived-microplastics as a vector for metal exposure in terrestrial invertebrates. Environ Sci Technol.

Hopen, H.J., Oebker, N.F., 1976. Vegetable crop responses to synthetic mulches, an annotated bibliography. Spec Publ Coll Agric Univ III Urbana Champaign.

Hopewell, J., Dvorak, R., Kosior, E., 2009. Plastics recycling: challenges and opportunities. Philosophical Transactions of the Royal Society B: Biological Sciences 364, 2115-2126.

Horton, A.A., Walton, A., Spurgeon, D.J., Lahive, E., Svendsen, C., 2017. Microplastics in freshwater and terrestrial environments: Evaluating the current understanding to identify the knowledge gaps and future research priorities. Science of the Total Environment.

Hosler, D., Burkett, S.L., Tarkanian, M.J., 1999. Prehistoric Polymers: Rubber Processing in Ancient Mesoamerica. Science 284, 1988-1991.

Huang, J.-C., Shetty, A.S., Wang, M.-S., 1990. Biodegradable plastics: A review. Advances in Polymer Technology 10, 23-30.

Huang, S., Li, J., Wang, J., Jin, S., 2019. Effects of Residual Plastic Film in Soil on Growth and Yield of Potato. Chinese Potato 33, 28-33.

Huang, Y., Liu, Q., Jia, W., Yan, C., Wang, J., 2020. Agricultural plastic mulching as a source of microplastics in the terrestrial environment. Environ Pollut 260, 114096. 
Huerta Lwanga, E., Gertsen, H., Gooren, H., Peters, P., Salanki, T., van der Ploeg, M., Besseling, E., Koelmans, A.A., Geissen, V., 2016. Microplastics in the Terrestrial Ecosystem: Implications for Lumbricus terrestris (Oligochaeta, Lumbricidae). Environ Sci Technol 50, 2685-2691.

Huerta Lwanga, E., Gertsen, H., Gooren, H., Peters, P., Salanki, T., van der Ploeg, M., Besseling, E., Koelmans, A.A., Geissen, V., 2017a. Incorporation of microplastics from litter into burrows of Lumbricus terrestris. Environ Pollut 220, 523-531.

Huerta Lwanga, E., Mendoza Vega, J., Ku Quej, V., Chi, J.L.A., Sanchez Del Cid, L., Chi, C., Escalona Segura, G., Gertsen, H., Salanki, T., van der Ploeg, M., Koelmans, A.A., Geissen, V., 2017b. Field evidence for transfer of plastic debris along a terrestrial food chain. Sci Rep 7, 14071.

Huerta Lwanga, E., Thapa, B., Yang, X., Gertsen, H., Salanki, T., Geissen, V., Garbeva, P., 2018. Decay of low-density polyethylene by bacteria extracted from earthworm's guts: $A$ potential for soil restoration. Sci Total Environ 624, 753-757.

Humphreys, M.T., Raun, W.R., Martin, K.L., Freeman, K.W., Johnson, G.V., Stone, M.L., 2011. Indirect Estimates of Soil Electrical Conductivity for Improved Prediction of Wheat Grain Yield. Communications in Soil Science and Plant Analysis 35, 2639-2653.

Hussain, N., Jaitley, V., Florence, A.T., 2001. Recent advances in the understanding of uptake of microparticulates across the gastrointestinal lymphatics. Advanced Drug Delivery Reviews 50, 107-142.

Ilangumaran, G., Smith, D.L., 2017. Plant Growth Promoting Rhizobacteria in Amelioration of Salinity Stress: A Systems Biology Perspective. Frontiers in Plant Science 8.

Jiang, X.J., Liu, W., Wang, E., Zhou, T., Xin, P., 2017. Residual plastic mulch fragments effects on soil physical properties and water flow behavior in the Minqin Oasis, northwestern China. Soil and Tillage Research 166, 100-107.

Jochum, M.D., McWilliams, K.L., Borrego, E.J., Kolomiets, M.V., Niu, G., Pierson, E.A., Jo, Y.K., 2019. Bioprospecting Plant Growth-Promoting Rhizobacteria That Mitigate Drought Stress in Grasses. Front Microbiol 10.

Jones, D.L., Nguyen, C., Finlay, R.D., 2009. Carbon flow in the rhizosphere: carbon trading at the soil-root interface. Plant and soil 321, 5-33.

Kai, M., Effmert, U., Berg, G., Piechulla, B., 2007. Volatiles of bacterial antagonists inhibit mycelial growth of the plant pathogen Rhizoctonia solani. Arch Microbiol 187, 351-360.

Kale, S.K., Deshmukh, A.G., Dudhare, M.S., Patil, V.B., 2015. Microbial degradation of plastic: a review. Journal of Biochemical Technology 6, 952-961.

Kapanen, A., Schettini, E., Vox, G., Itavaara, M., 2008. Performance and Environmental Impact of Biodegradable Films in Agriculture: A Field Study on Protected Cultivation. Journal of Polymers and the Environment 16, 109-122.

Kasirajan, S., Ngouajio, M., 2012. Polyethylene and biodegradable mulches for agricultural applications: a review. Agron. Sustainable Dev. 32, 501. 
Kaushal, M., Wani, S.P., 2016. Rhizobacterial-plant interactions: Strategies ensuring plant growth promotion under drought and salinity stress. Agriculture Ecosystems \& Environment 231, 68-78.

Kemper, W., Rosenau, R., 1986. Aggregate stability and size distribution.

Kinkel, L.L., Bakker, M.G., Schlatter, D.C., 2011. A Coevolutionary Framework for Managing Disease-Suppressive Soils, in: VanAlfen, N.K., Bruening, G., Leach, J.E. (Eds.), Annual Review of Phytopathology, Vol 49, pp. 47-67.

Kleunen, M., Brumer, A., Gutbrod, L., Zhang, Z., 2019. A microplastic used as infill material in artificial sport turfs reduces plant growth. Plants, People, Planet 2, 157-166.

Klute, A., Dinauer, R.C., 1986. Physical and mineralogical methods. Planning 8, 79.

Klute, A., Dirksen, C., 1986. Hydraulic conductivity and diffusivity: Laboratory methods. Methods of soil analysis: part 1-physical and mineralogical methods, 687-734.

Koelmans, A.A., Gouin, T., Thompson, R., Wallace, N., Arthur, C., 2014. Plastics in the marine environment. Environmental Toxicology and Chemistry 33, 5-10.

Koelmans, A.A., Kooi, M., Law, K.L., van Sebille, E., 2017. All is not lost: deriving a top-down mass budget of plastic at sea. Environmental Research Letters 12.

Koelmans, A.A., Nor, N.H.M., Hermsen, E., Kooi, M., Mintenig, S.M., De France, J., 2019. Microplastics in freshwaters and drinking water: Critical review and assessment of data quality. Water Res 155, 410-422.

Kursa, M.B., Rudnicki, W.R., 2010. Feature Selection with the Boruta Package. Journal of Statistical Software 36, 1-13.

Lambert, S., Wagner, M., 2016a. Characterisation of nanoplastics during the degradation of polystyrene. Chemosphere 145, 265-268.

Lambert, S., Wagner, M., 2016b. Formation of microscopic particles during the degradation of different polymers. Chemosphere 161, 510-517.

Lambert, S., Wagner, M., 2017. Environmental performance of bio-based and biodegradable plastics: the road ahead. Chemical Society Reviews 46, 6855-6871.

Larue, C., Laurette, J., Herlin-Boime, N., Khodja, H., Fayard, B., Flank, A.M., Brisset, F., Carriere, M., 2012. Accumulation, translocation and impact of $\mathrm{TiO} 2$ nanoparticles in wheat (Triticum aestivum spp.): Influence of diameter and crystal phase. Science of the Total Environment 431, 197-208.

Laugale, V., Strautina, S., Krasnova, I., Seglina, D., Kampuss, K., 2014. The influence of cultivation system on biochemical content of strawberry fruits. Journal of Horticultural Research 22, 85-92.

Law, K.L., Thompson, R.C., 2014. Microplastics in the seas. Science 345, 144-145.

Lehmann, A., Fitschen, K., Rillig, M.C., 2019. Abiotic and Biotic Factors Influencing the Effect of Microplastic on Soil Aggregation. Soil Systems 3.

Li, C., Moore-Kucera, J., Lee, J., Corbin, A., Brodhagen, M., Miles, C., Inglis, D., 2014a. Effects of biodegradable mulch on soil quality. Applied Soil Ecology 79, 59-69. 
Li, C., Moore-Kucera, J., Miles, C., Leonas, K., Lee, J., Corbin, A., Inglis, D., 2014b. Degradation of potentially biodegradable plastic mulch films at three diverse US locations. Agroecology and sustainable food systems 38, 861-889.

Li, L., Luo, Y., Li, R., Zhou, Q., Peijnenburg, W.J.G.M., Yin, N., Yang, J., Tu, C., Zhang, Y., 2020. Effective uptake of submicrometre plastics by crop plants via a crack-entry mode. Nature Sustainability.

Li, Q., Li, H., Zhang, L., Zhang, S., Chen, Y., 2018a. Mulching improves yield and water-use efficiency of potato cropping in China: A meta-analysis. Field Crops Research 221, 50-60.

Li, X., Chen, L., Mei, Q., Dong, B., Dai, X., Ding, G., Zeng, E.Y., 2018b. Microplastics in sewage sludge from the wastewater treatment plants in China. Water Res 142, 75-85.

Littell, R.C., Milliken, G.A., Stroup, W.W., Wolfinger, R.D., Schabenberger, O., 2006. SAS for mixed models. SAS institute Cary, NC.

Liu, E., He, W., Yan, C., 2014. 'White revolution'to 'white pollution'-agricultural plastic film mulch in China. Environmental Research Letters 9, 091001.

Liu, H., Brettell, L.E., Qiu, Z., Singh, B.K., 2020. Microbiome-Mediated Stress Resistance in Plants. Trends Plant Sci.

Liu, H., Yang, X., Liu, G., Liang, C., Xue, S., Chen, H., Ritsema, C.J., Geissen, V., 2017a. Response of soil dissolved organic matter to microplastic addition in Chinese loess soil. Chemosphere.

Liu, H.F., Yang, X.M., Liu, G.B., Liang, C.T., Xue, S., Chen, H., Ritsema, C.J., Geissen, V., 2017b. Response of soil dissolved organic matter to microplastic addition in Chinese loess soil. Chemosphere 185, 907-917.

Liu, M., Lu, S., Song, Y., Lei, L., Hu, J., Lv, W., Zhou, W., Cao, C., Shi, H., Yang, X., He, D., 2018. Microplastic and mesoplastic pollution in farmland soils in suburbs of Shanghai, China. Environmental Pollution (Barking, Essex : 1987) 242, 855-862.

Lugtenberg, B., Kamilova, F., 2009. Plant-Growth-Promoting Rhizobacteria, Annual Review of Microbiology. Annual Reviews, Palo Alto, pp. 541-556.

Lugtenberg, B., Rozen, D.E., Kamilova, F., 2017. Wars between microbes on roots and fruits. F1000Research 6.

Maass, S., Daphi, D., Lehmann, A., Rillig, M.C., 2017. Transport of microplastics by two collembolan species. Environ Pollut 225, 456-459.

Mahon, A.M., O'Connell, B., Healy, M.G., O'Connor, I., Officer, R., Nash, R., Morrison, L., 2017. Microplastics in Sewage Sludge: Effects of Treatment. Environ Sci Technol 51, 810818.

Martín-Sánchez, L., Ariotti, C., Garbeva, P., Vigani, G., 2020. Investigating the effect of belowground microbial volatiles on plant nutrient status: perspective and limitations. Journal of Plant Interactions 15, 188-195.

Massalha, H., Korenblum, E., Tholl, D., Aharoni, A., 2017. Small molecules below-ground: the role of specialized metabolites in the rhizosphere. Plant J 90, 788-807. 
Mato, Y., Isobe, T., Takada, H., Kanehiro, H., Ohtake, C., Kaminuma, T., 2001. Plastic Resin Pellets as a Transport Medium for Toxic Chemicals in the Marine Environment. Environ Sci Technol 35, 318-324.

Meeks, D., Hottle, T., Bilec, M.M., Landis, A.E., 2015. Compostable biopolymer use in the real world: Stakeholder interviews to better understand the motivations and realities of use and disposal in the US. Resources, Conservation and Recycling 105, 134-142.

Mendes, R., Garbeva, P., Raaijmakers, J.M., 2013. The rhizosphere microbiome: significance of plant beneficial, plant pathogenic, and human pathogenic microorganisms. FEMS Microbiol Rev 37, 634-663.

Miao, Y., Stewart, B.A., Zhang, F., 2010. Long-term experiments for sustainable nutrient management in China. A review. Agronomy for Sustainable Development 31, 397-414.

Miles, C., DeVetter, L., Ghimire, S., Hayes, D.G., 2017. Suitability of biodegradable plastic mulches for organic and sustainable agricultural production systems. Hortscience 52, 10-15.

Miles, C., Wallace, R., Wszelaki, A., Martin, J., Cowan, J., Walters, T., Inglis, D., 2012. Deterioration of potentially biodegradable alternatives to black plastic mulch in three tomato production regions. Hortscience 47, 1270.

Moller, J.N., Loder, M.G.J., Laforsch, C., 2020. Finding Microplastics in Soils: A Review of Analytical Methods. Environ Sci Technol 54, 2078-2090.

Mooers, C., Washko, J., Young, J., 1948. Effects of wheat straw, lespedeza sericea hay, and farmyard manure, as soil mulches, on the conservation of moisture and the production of nitrates. Soil Science 66, 307-316.

Mooney, B.P., 2009. The second green revolution? Production of plant-based biodegradable plastics. Biochem J 418, 219-232.

Moreno, M.M., González-Mora, S., Villena, J., Campos, J.A., Moreno, C., 2017. Deterioration pattern of six biodegradable, potentially low-environmental impact mulches in field conditions. Journal of Environmental Management 200, 490-501.

Muroi, F., Tachibana, Y., Kobayashi, Y., Sakurai, T., Kasuya, K., 2016. Influences of poly(butylene adipate-co-terephthalate) on soil microbiota and plant growth. Polymer Degradation and Stability 129, 338-346.

Nan, D., Xie, H., Gao, L., Zhang, D., Zhao, H., Ren, P., Chai, S., 1996. Study of the Influence of the Residue Film on Soil and Cotton Growth In the Cotton Fields. Acta Gossypii Sinica 8, 50-54.

Napper, I.E., Thompson, R.C., 2019. Environmental Deterioration of Biodegradable, Oxobiodegradable, Compostable, and Conventional Plastic Carrier Bags in the Sea, Soil, and Open-Air Over a 3-Year Period. Environ Sci Technol 53, 4775-4783.

Nerin, C., Tornés, A., Domeno, C., Cacho, J., 1996. Absorption of pesticides on plastic films used as agricultural soil covers. Journal of Agricultural and Food Chemistry 44, 40094014. 
Ng, E.-L., Huerta Lwanga, E., Eldridge, S.M., Johnston, P., Hu, H.-W., Geissen, V., Chen, D., 2018. An overview of microplastic and nanoplastic pollution in agroecosystems. Science of the Total Environment 627, 1377-1388.

Nizzetto, L., Futter, M., Langaas, S., 2016a. Are Agricultural Soils Dumps for Microplastics of Urban Origin? Environ Sci Technol 50, 10777-10779.

Nizzetto, L., Langaas, S., Futter, M., 2016b. Pollution: Do microplastics spill on to farm soils? Nature 537, 488-488.

O'Hara, L.E., Paul, M.J., Wingler, A., 2013. How Do Sugars Regulate Plant Growth and Development? New Insight into the Role of Trehalose-6-Phosphate. Molecular Plant 6, 261-274.

Ossowicki, A., Tracanna, V., Petrus, M.L.C., van Wezel, G., Raaijmakers, J.M., Medema, M.H., Garbeva, P., 2020. Microbial and volatile profiling of soils suppressive to Fusarium culmorum of wheat. Proc Biol Sci 287, 20192527.

Otey, F.H., Mark, A.M., Mehltretter, C.L., Russell, C.R., 1974. Starch-Based Film for Degradable Agricultural Mulch. Product R\&D 13, 90-92.

Overbeck, V., Schmitz-Eiberger, M.A., Blanke, M.M., 2013. Reflective mulch enhances ripening and health compounds in apple fruit. Journal of the Science of Food and Agriculture 93, 2575-2579.

Parvathy, P.C., Jyothi, A.N., John, K.S., Sreekumar, J., 2014. Cassava Starch Based Superabsorbent Polymer as Soil Conditioner: Impact on Soil Physico-Chemical and Biological Properties and Plant Growth. Clean-Soil Air Water 42, 1610-1617.

Philippot, L., Raaijmakers, J.M., Lemanceau, P., van der Putten, W.H., 2013. Going back to the roots: the microbial ecology of the rhizosphere. Nature Reviews Microbiology 11, 789-799.

Piehl, S., Leibner, A., Loder, M.G.J., Dris, R., Bogner, C., Laforsch, C., 2018. Identification and quantification of macro- and microplastics on an agricultural farmland. Scientific Reports 8.

Pii, Y., Cesco, S., Mimmo, T., 2015. Shoot ionome to predict the synergism and antagonism between nutrients as affected by substrate and physiological status. Plant Physiology and Biochemistry 94, 48-56.

PlasticsEurope, 2008. The Compelling Facts About Plastics 2007: An analysis of plastics production, demand and recovery for 2007 in Europe.

PlasticsEurope, 2009. The Compelling Facts About Plastics 2009: An analysis of European plastics production, demand and recovery for 2008.

PlasticsEurope, 2010. Plastics - the Facts 2010: An analysis of European plastics production, demand and recovery for 2009.

PlasticsEurope, 2011. Plastics - the Facts 2011: An analysis of European plastics production, demand and recovery for 2010. 
PlasticsEurope, 2019. Plastics - the Facts 2019: An analysis of European plastics production, demand and waste data.

Pluskal, T., Castillo, S., Villar-Briones, A., Oresic, M., 2010. MZmine 2: modular framework for processing, visualizing, and analyzing mass spectrometry-based molecular profile data. BMC Bioinformatics 11, 395.

Qi, R.M., Jones, D.L., Li, Z., Liu, Q., Yan, C.R., 2020a. Behavior of microplastics and plastic film residues in the soil environment: A critical review. Science of the Total Environment 703.

Qi, Y., Beriot, N., Gort, G., Huerta Lwanga, E., Gooren, H., Yang, X., Geissen, V., 2020b. Impact of plastic mulch film debris on soil physicochemical and hydrological properties. Environ Pollut 266, 115097.

Qi, Y., Ossowicki, A., Yang, X., Huerta Lwanga, E., Dini-Andreote, F., Geissen, V., Garbeva, P., 2020c. Effects of plastic mulch film residues on wheat rhizosphere and soil properties. J Hazard Mater 387, 121711.

Qi, Y., Yang, X., Pelaez, A.M., Huerta Lwanga, E., Beriot, N., Gertsen, H., Garbeva, P., Geissen, V., 2018. Macro- and micro- plastics in soil-plant system: Effects of plastic mulch film residues on wheat (Triticum aestivum) growth. Sci Total Environ 645, 1048-1056.

Raaijmakers, J.M., Paulitz, T.C., Steinberg, C., Alabouvette, C., Moënne-Loccoz, Y., 2009. The rhizosphere: a playground and battlefield for soilborne pathogens and beneficial microorganisms. Plant and soil 321, 341-361.

Ren, X., 2003. Biodegradable plastics: a solution or a challenge? Journal of Cleaner Production 11, 27-40.

Research, T.M., 2013. Agricultural Films (LDPE, LLDPE, HDPE, EVA/EBA, Reclaims and Others) Market for Greenhouse, Mulching and Silage Applications - Global Industry Analysis, Size, Share, Growth, Trends and Forecast, 2013 - 2019.

Restrepo-Flórez, J.-M., Bassi, A., Thompson, M.R., 2014. Microbial degradation and deterioration of polyethylene-A review. International Biodeterioration \& Biodegradation 88, 83-90.

Rezaei, M., Riksen, M.J., Sirjani, E., Sameni, A., Geissen, V., 2019. Wind erosion as a driver for transport of light density microplastics. Science of the Total Environment 669, 273281.

Rico, C.M., Majumdar, S., Duarte-Gardea, M., Peralta-Videa, J.R., Gardea-Torresdey, J.L., 2011. Interaction of nanoparticles with edible plants and their possible implications in the food chain. Journal of Agricultural and Food Chemistry 59, 3485-3498.

Rillig, M.C., 2012. Microplastic in Terrestrial Ecosystems and the Soil? Environ Sci Technol 46, 6453-6454.

Rillig, M.C., 2018. Microplastic Disguising As Soil Carbon Storage. Environ Sci Technol 52, 6079-6080. 
Rillig, M.C., de Souza Machado, A.A., Lehmann, A., Klümper, U., 2018. Evolutionary implications of microplastics for soil biota. Environmental Chemistry.

Rillig, M.C., Ingraffia, R., Machado, A.A.D., 2017a. Microplastic Incorporation into Soil in Agroecosystems. Frontiers in Plant Science 8.

Rillig, M.C., Lehmann, A., 2020. Microplastic in terrestrial ecosystems. Science 368, 14301431.

Rillig, M.C., Lehmann, A., de Souza Machado, A.A., Yang, G., 2019. Microplastic effects on plants. New Phytol 223, 1066-1070.

Rillig, M.C., Ziersch, L., Hempel, S., 2017b. Microplastic transport in soil by earthworms. Scientific Reports 7.

Ritsema, C., Dekker, L., Oostindie, K., Moore, D., Leinauer, B., 2008. Soil water repellency and critical soil water content. Book Chapter p 97-112 in. Soil Science: Step-by-step Field Analysis.

Rocha-Santos, T., Duarte, A.C., 2015. A critical overview of the analytical approaches to the occurrence, the fate and the behavior of microplastics in the environment. TrAC Trends in Analytical Chemistry 65, 47-53.

Rochman, C.M., 2018. Microplastics research-from sink to source. Science 360, 28-29.

Rodriguez-Seijo, A., Lourenco, J., Rocha-Santos, T.A.P., da Costa, J., Duarte, A.C., Vala, H., Pereira, R., 2017. Histopathological and molecular effects of microplastics in Eisenia andrei Bouche. Environ Pollut 220, 495-503.

Rodríguez-Seijo, A., Santos, B., Ferreira da Silva, E., Cachada, A., Pereira, R., 2019. Lowdensity polyethylene microplastics as a source and carriers of agrochemicals to soil and earthworms. Environmental Chemistry 16.

Roper, S., Parker, C., 2006. How (and where) the mighty have fallen: branded litter. Journal of Marketing Management 22, 473-487.

Roper, S., Parker, C., 2008. The rubbish of marketing. Journal of Marketing Management 24, 881-892.

Ruíz-Machuca, L.M., Ibarra-Jiménez, L., Valdez-Aguilar, L.A., Robledo-Torres, V., BenavidesMendoza, A., Cabrera-De La Fuente, M., 2015. Cultivation of potato-use of plastic mulch and row covers on soil temperature, growth, nutrient status, and yield. Acta Agriculturae Scandinavica, Section B-Soil \& Plant Science 65, 30-35.

Ryan, P., Moloney, C., 1990. Plastic and other artefacts on South African beaches: Temporal trends in abundance and composition. S. AFR. J. SCI. 86, 450-452.

Ryan, P.G., 1987. The incidence and characteristics of plastic particles ingested by seabirds. Marine Environmental Research 23, 175-206.

Ryan, P.G., Moloney, C.L., 1993. Marine litter keeps increasing. Nature 361, 23-23.

Ryan, P.G., Moore, C.J., van Franeker, J.A., Moloney, C.L., 2009. Monitoring the abundance of plastic debris in the marine environment. Philosophical Transactions of the Royal Society B: Biological Sciences 364, 1999-2012. 
Scarascia-Mugnozza, G., Sica, C., Russo, G., 2011. Plastic materials in European agriculture: actual use and perspectives. Journal of Agricultural Engineering 42, 15-28.

Scheurer, M., Bigalke, M., 2018. Microplastics in Swiss Floodplain Soils. Environ Sci Technol 52, 3591-3598.

Schlatter, D., Kinkel, L., Thomashow, L., Weller, D., Paulitz, T., 2017. Disease Suppressive Soils: New Insights from the Soil Microbiome. Phytopathology 107, 1284-1297.

Schulz-Bohm, K., Gerards, S., Hundscheid, M., Melenhorst, J., de Boer, W., Garbeva, P., 2018. Calling from distance: attraction of soil bacteria by plant root volatiles. ISME J 12, 1252-1262.

Schulz-Bohm, K., Zweers, H., de Boer, W., Garbeva, P., 2015. A fragrant neighborhood: volatile mediated bacterial interactions in soil. Front Microbiol 6, 1212.

Schwaferts, C., Niessner, R., Elsner, M., Ivleva, N.P., 2019. Methods for the analysis of submicrometer- and nanoplastic particles in the environment. TrAC Trends in Analytical Chemistry 112, 52-65.

Shah, A.A., Hasan, F., Hameed, A., Ahmed, S., 2008. Biological degradation of plastics: a comprehensive review. Biotechnology advances 26, 246-265.

Shan, J.J., Zhao, J.B., Liu, L.F., Zhang, Y.T., Wang, X., Wu, F.C., 2018. A novel way to rapidly monitor microplastics in soil by hyperspectral imaging technology and chemometrics. Environ Pollut 238, 121-129.

Sharma, S., Chatterjee, S., 2017. Microplastic pollution, a threat to marine ecosystem and human health: a short review. Environmental Science and Pollution Research 24, 21530 21547.

Singh, B., Sharma, N., 2008. Mechanistic implications of plastic degradation. Polymer Degradation and Stability 93, 561-584.

Singh, P.K., Vyas, D., 2009. Biocontrol of plant diseases and sustainable agriculture. Proceedings of the National Academy of Sciences India Section B-Biological Sciences 79, 110-128.

Singh, S., 1992. Studies on mulching of vegetable crops-a review. Advances in horticulture and forestry 2, 115-143.

Sintim, H.Y., Flury, M., 2017. Is Biodegradable Plastic Mulch the Solution to Agriculture's Plastic Problem? Environ Sci Technol 51, 1068-1069.

Sjollema, S.B., Redondo-Hasselerharm, P., Leslie, H.A., Kraak, M.H.S., Vethaak, A.D., 2016. Do plastic particles affect microalgal photosynthesis and growth? Aquatic Toxicology 170, 259-261.

Steinmetz, Z., Wollmann, C., Schaefer, M., Buchmann, C., David, J., Troger, J., Munoz, K., Fror, O., Schaumann, G.E., 2016. Plastic mulching in agriculture. Trading short-term agronomic benefits for long-term soil degradation? Sci Total Environ 550, 690-705.

Summers, C.G., Mitchell, J.P., Stapleton, J.J., 2005. Mulches reduce aphid-borne viruses and whiteflies in cantaloupe. California Agriculture 59, 90-94. 
Sun, X.-D., Yuan, X.-Z., Jia, Y., Feng, L.-J., Zhu, F.-P., Dong, S.-S., Liu, J., Kong, X., Tian, H., Duan, J.-L., Ding, Z., Wang, S.-G., Xing, B., 2020. Differentially charged nanoplastics demonstrate distinct accumulation in Arabidopsis thaliana. Nature Nanotechnology.

Syberg, K., Khan, F.R., Selck, H., Palmqvist, A., Banta, G.T., Daley, J., Sano, L., Duhaime, M.B., 2015. Microplastics: addressing ecological risk through lessons learned. Environmental Toxicology and Chemistry 34, 945-953.

Tao, Z., Cao, X., Luo, X., Li, X.D., ZHOU, Z., 2012. Responses of three enzyme activities to lower molecular weight polyethylene added in pot-cultured horse bean soil. Chinese Journal of Soil Science 43, 1104-1110.

Team, R.C., 2013. R: A language and environment for statistical computing.

Thompson, A.A., Samuelson, M.B., Kadoma, I., Soto-Cantu, E., Drijber, R., Wortman, S.E., 2019. Degradation Rate of Bio-based Agricultural Mulch is Influenced by Mulch Composition and Biostimulant Application. Journal of Polymers and the Environment 27, 498-509.

Thompson, R., Moore, C., Andrady, A., Gregory, M., Takada, H., Weisberg, S., 2005. New directions in plastic debris. Science 310, 1117-1117.

Thompson, R.C., Moore, C.J., Vom Saal, F.S., Swan, S.H., 2009a. Plastics, the environment and human health: current consensus and future trends. Philosophical Transactions of the Royal Society B: Biological Sciences 364, 2153-2166.

Thompson, R.C., Olsen, Y., Mitchell, R.P., Davis, A., Rowland, S.J., John, A.W., McGonigle, D., Russell, A.E., 2004. Lost at sea: where is all the plastic? Science 304, 838-838.

Thompson, R.C., Swan, S.H., Moore, C.J., vom Saal, F.S., 2009b. Our plastic age. Philos Trans R Soc Lond B Biol Sci 364, 1973-1976.

Topp, G., Zebchuk, W., 1979. The determination of soil-water desorption curves for soil cores. Canadian Journal of Soil Science 59, 19-26.

van Dam, N.M., Bouwmeester, H.J., 2016. Metabolomics in the Rhizosphere: Tapping into Belowground Chemical Communication. Trends Plant Sci 21, 256-265.

van Dam, N.M., Weinhold, A., Garbeva, P., 2016. Calling in the Dark: The Role of Volatiles for Communication in the Rhizosphere, in: Blande, J.D., Glinwood, R. (Eds.), Deciphering Chemical Language of Plant Communication. Springer International Publishing, Cham, pp. 175-210.

van den Berg, P., Huerta-Lwanga, E., Corradini, F., Geissen, V., 2020. Sewage sludge application as a vehicle for microplastics in eastern Spanish agricultural soils. Environ Pollut 261, 114198.

van den Oever, M., Molenveld, K., van der Zee, M., Bos, H., 2017. Bio-based and biodegradable plastics: facts and figures: focus on food packaging in the Netherlands. Wageningen Food \& Biobased Research.

van Ginkel, C., 2007. Ultimate biodegradation of ingredients used in cleaning agents, Handbook for cleaning/decontamination of surfaces. Elsevier, pp. 655-694. 
van Groenigen, J.W., Lubbers, I.M., Vos, H.M., Brown, G.G., De Deyn, G.B., van Groenigen, K.J., 2014. Earthworms increase plant production: a meta-analysis. Sci Rep 4, 6365.

Van Sebille, E., Wilcox, C., Lebreton, L., Maximenko, N., Hardesty, B.D., Van Franeker, J.A., Eriksen, M., Siegel, D., Galgani, F., Law, K.L., 2015. A global inventory of small floating plastic debris. Environmental Research Letters 10, 124006.

Verschoor, A., 2015. Towards a definition of microplastics: Considerations for the specification of physico-chemical properties. RIVM letter report 2015-0116.

Vert, M., Doi, Y., Hellwich, K.-H., Hess, M., Hodge, P., Kubisa, P., Rinaudo, M., Schué, F., 2012. Terminology for biorelated polymers and applications (IUPAC Recommendations 2012). Pure and Applied Chemistry 84, 377-410.

Vespermann, A., Kai, M., Piechulla, B., 2007. Rhizobacterial volatiles affect the growth of fungi and Arabidopsis thaliana. Appl Environ Microbiol 73, 5639-5641.

Vigani, G., Di Silvestre, D., Agresta, A.M., Donnini, S., Mauri, P., Gehl, C., Bittner, F., Murgia, I., 2017. Molybdenum and iron mutually impact their homeostasis in cucumber (Cucumis sativus) plants. New Phytologist 213, 1222-1241.

Waggoner, P.E., Miller, P.M., De Roo, H., 1960. C. Plastic mulching: principles and benefits. Bulletin. Connecticut Agricultural Experiment Station 634

Waldschlager, K., Lechthaler, S., Stauch, G., Schuttrumpf, H., 2020. The way of microplastic through the environment - Application of the source-pathway-receptor model (review). Science of the Total Environment 713.

Wang, J., Luo, Y., Teng, Y., Ma, W., Christie, P., Li, Z., 2013. Soil contamination by phthalate esters in Chinese intensive vegetable production systems with different modes of use of plastic film. Environ Pollut 180, 265-273.

Wegner, A., Besseling, E., Foekema, E.M., Kamermans, P., Koelmans, A.A., 2012. Effects of nanopolystyrene on the feeding behavior of the blue mussel (Mytilus edulis L.). Environ Toxicol Chem 31, 2490-2497.

Wei, R., Zimmermann, W., 2017. Microbial enzymes for the recycling of recalcitrant petroleum-based plastics: how far are we? Microb Biotechnol 10, 1308-1322.

Weisskopf, L., Ryu, C.M., Raaijmakers, J.M., Garbeva, P., 2016. Editorial: Smelly Fumes: Volatile-Mediated Communication between Bacteria and Other Organisms. Front Microbiol 7, 2031.

Weller, D.M., Raaijmakers, J.M., Gardener, B.B.M., Thomashow, L.S., 2002. MICROBIAL POPULATIONS RESPONSIBLE FOR SPECIFIC SOIL SUPPRESSIVENESS TO PLANT PATHOGENS. Annual Review of Phytopathology 40, 309-348.

Wien, H., Minotti, P., Grubinger, V., 1993. Polyethylene mulch stimulates early root growth and nutrient uptake of transplanted tomatoes. Journal of the American Society for Horticultural Science 118, 207-211.

Wittwer, S.H., 1993. World-wide use of plastics in horticultural production. Horttechnology 3, 6-19. 
Wright, S.L., Thompson, R.C., Galloway, T.S., 2013. The physical impacts of microplastics on marine organisms: A review. Environ Pollut 178, 483-492.

Xiang, Z., Li, Q., Liu, L., 1992. The effects of residual plastic mulch film pollution on maize growth and yield in agricultural soil. Agro-environmental Protection 11, 179-180.

$\mathrm{Xu}$, Y., 1985. Residual plastic mulch film is the enemy of soil. Agriculture Scientific Experiment 09, 18-19.

Yan, C., He, W., Turner, N., 2014. Plastic-film mulch in Chinese agriculture: Importance and problems. World Agriculture 4, 32-36.

Yang, J., Yang, Y., Wu, W.-M., Zhao, J., Jiang, L., 2014a. Evidence of polyethylene biodegradation by bacterial strains from the guts of plastic-eating waxworms. Environ Sci Technol 48, 13776-13784.

Yang, N., Sun, Z.-X., Feng, L.-S., Zheng, M.-Z., Chi, D.-C., Meng, W.-Z., Hou, Z.-Y., Bai, W., Li, K.-Y., 2014b. Plastic Film Mulching for Water-Efficient Agricultural Applications and Degradable Films Materials Development Research. Materials and Manufacturing Processes 30, 143-154.

Yang, X., Bento, C.P.M., Chen, H., Zhang, H., Xue, S., Lwanga, E.H., Zomer, P., Ritsema, C.J., Geissen, V., 2018. Influence of microplastic addition on glyphosate decay and soil microbial activities in Chinese loess soil. Environ Pollut 242, 338-347.

Yang, X.M., Lwanga, E.H., Bemani, A., Gertsen, R., Salanki, T., Guo, X.T., Fu, H.M., Xue, S., Ritsema, C., Geissen, V., 2019. Biogenic transport of glyphosate in the presence of LDPE microplastics: A mesocosm experiment. Environ Pollut 245, 829-835.

Yang, Y., Liu, W., Zhang, Z., Grossart, H.P., Gadd, G.M., 2020. Microplastics provide new microbial niches in aquatic environments. Appl Microbiol Biotechnol.

Yang, Y., Yang, J., Wu, W.M., Zhao, J., Song, Y., Gao, L., Yang, R., Jiang, L., 2015. Biodegradation and Mineralization of Polystyrene by Plastic-Eating Mealworms: Part 1. Chemical and Physical Characterization and Isotopic Tests. Environ Sci Technol 49, 12080-12086.

Ye, S., Andrady, A.L., 1991. Fouling of floating plastic debris under Biscayne Bay exposure conditions. Mar Pollut Bull 22, 608-613.

Yu, M., van der Ploeg, M., Lwanga, E.H., Yang, X., Zhang, S., Ma, X., Ritsema, C.J., Geissen, V., 2019. Leaching of microplastics by preferential flow in earthworm (Lumbricus terrestris) burrows. Environmental Chemistry 16.

Zhang, D., Liu, H.B., Hu, W.L., Qin, X.H., Ma, X.W., Yan, C.R., Wang, H.Y., 2016. The status and distribution characteristics of residual mulching film in Xinjiang, China. Journal of Integrative Agriculture 15, 2639-2646.

Zhang, D., Ng, E.L., Hu, W., Wang, H., Galaviz, P., Yang, H., Sun, W., Li, C., Ma, X., Fu, B., Zhao, P., Zhang, F., Jin, S., Zhou, M., Du, L., Peng, C., Zhang, X., Xu, Z., Xi, B., Liu, X., Sun, S., Cheng, Z., Jiang, L., Wang, Y., Gong, L., Kou, C., Li, Y., Ma, Y., Huang, D., Zhu, J., Yao, J., Lin, C., Qin, S., Zhou, L., He, B., Chen, D., Li, H., Zhai, L., Lei, Q., Wu, S., Zhang, Y., Pan, J., 
Gu, B., Liu, H., 2020a. Plastic pollution in croplands threatens long-term food security. Glob Chang Biol 26, 3356-3367.

Zhang, G.S., Liu, Y.F., 2018. The distribution of microplastics in soil aggregate fractions in southwestern China. Science of the Total Environment 642, 12-20.

Zhang, G.S., Zhang, F.X., Li, X.T., 2019. Effects of polyester microfibers on soil physical properties: Perception from a field and a pot experiment. Sci Total Environ 670, 1-7.

Zhang, J., Guo, T., Fan, T., Zhao, G., Dang, Y., Wang, L., Li, S., 2014. The Effect of the Agricultural Residual Plastic Film on Maize Growth and Development and Soil Moisture Movement. Journal of Irrigation and Drainage 33, 100-102.

Zhang, R., Vivanco, J.M., Shen, Q., 2017. The unseen rhizosphere root-soil-microbe interactions for crop production. Current opinion in microbiology 37, 8-14.

Zhang, S., Yang, X., Gertsen, H., Peters, P., Salanki, T., Geissen, V., 2018. A simple method for the extraction and identification of light density microplastics from soil. Sci Total Environ 616-617, 1056-1065.

Zhang, Y., Kang, S., Allen, S., Allen, D., Gao, T., Sillanpää, M., 2020b. Atmospheric microplastics: A review on current status and perspectives. Earth-Science Reviews 203, 103118.

Zhang, Z., Luo, X., Fan, Y., Wu, Q., 2015. Cumulative effects of powders of degraded PE mulching-films on chemical properties of soil. Environ Sci Technol 38, 115-119.

Zhao, S., Zhang, S., Xu, X., Xu, L., Zhang, D., Zhang, X., Wang, J., Xu, L., Qi, Y., 1998. Study on the Agricultural Plastic Sheeting Residue Pollution. AGRO-ENVIRONMENT \& DEVELOPMENT 15, 7-10.

Zhao, S., Zhu, L., Li, D., 2016. Microscopic anthropogenic litter in terrestrial birds from Shanghai, China: Not only plastics but also natural fibers. Science of the Total Environment 550, 1110-1115.

Zhou, B., Wang, J., Zhang, H., Shi, H., Fei, Y., Huang, S., Tong, Y., Wen, D., Luo, Y., Barcelo, D., 2020. Microplastics in agricultural soils on the coastal plain of Hangzhou Bay, east China: Multiple sources other than plastic mulching film. J Hazard Mater 388, 121814.

Zhou, Q., Zhang, H.B., Fu, C.C., Zhou, Y., Dai, Z.F., Li, Y., Tu, C., Luo, Y.M., 2018. The distribution and morphology of microplastics in coastal soils adjacent to the Bohai Sea and the Yellow Sea. Geoderma 322, 201-208.

Zhu, D., Bi, Q.F., Xiang, Q., Chen, Q.L., Christie, P., Ke, X., Wu, L.H., Zhu, Y.G., 2018a. Trophic predator-prey relationships promote transport of microplastics compared with the single Hypoaspis aculeifer and Folsomia candida. Environ Pollut 235, 150-154.

Zhu, D., Chen, Q.L., An, X.L., Yang, X.R., Christie, P., Ke, X., Wu, L.H., Zhu, Y.G., 2018b. Exposure of soil collembolans to microplastics perturbs their gut microbiota and alters their isotopic composition. Soil Biology and Biochemistry 116, 302-310.

Zhu, F., Zhu, C., Wang, C., Gu, C., 2019. Occurrence and Ecological Impacts of Microplastics in Soil Systems: A Review. Bull Environ Contam Toxicol 102, 741-749. 
Zubris, K.A.V., Richards, B.K., 2005. Synthetic fibers as an indicator of land application of sludge. Environ Pollut 138, 201-211. 


\section{English summary}

For decades, the rapidly increasing production of plastics combined with the unsustainable management of post-consumer plastic wastes has contributed to the current state of plastic pollution worldwide. Microplastics, commonly defined as plastic particles with diameters smaller than $5 \mathrm{~mm}$, have aroused an upsurge in public attention. Microplastics can reach the environment via direct disposal (primary) or through the degradation of larger plastic items (secondary). So far, most of the studies about microplastics have focused on aquatic ecosystems. Our knowledge of the ecological impacts of microplastics in terrestrial ecosystems is still in its infancy. However, much more plastic waste has been disposed of on land rather than in the oceans. In fact, the mass of microplastics currently stored in agricultural soils alone could actually turn out to be more than the microplastics stored in oceanic basins. Since agroecosystems are widely acknowledged as the environmental compartments that are the most vulnerable to the accumulation and deterioration of plastic residues, studies focusing on microplastics in agricultural soil are urgently needed to ensure food security and achieve sustainable agriculture.

Plastic mulching is one of the main sources of microplastics in agricultural soil. Since plastic mulch films have brought so many agronomic benefits, it is not realistic to demand that they simply stop being used in agriculture. Therefore, biodegradable plastic mulch films were developed as promising alternatives for conventional plastics. When they were created, biodegradable plastic mulch films were expected to maintain the agronomic benefits of conventional plastic films while avoiding the accumulation of plastic residues in soils. However, the lack of knowledge about the ecological impacts of both conventional and biodegradable plastic mulch films on agroecosystems is surprising. To ensure their safe and sustainable application in agroecosystems, comprehensive research about all aspects of plastic mulch films is urgently needed. This PhD thesis aims to fill some of the gaps in our knowledge about microplastics in the agroecosystem and give new insights into the use of plastic mulching in sustainable agriculture. Laboratory and greenhouse experiments were conducted to provide direct evidence and contribute to a comprehensive understanding of the effects of plastic residues on the soil-plant system. In this thesis, effects of plastic residues on the soil-plant system were investigated with respect to plant growth, soil organisms, rhizosphere microbiomes, rhizosphere volatile profiles, soil physicochemical and hydrological properties as well as soil suppressiveness.

When this thesis started in 2016, research on microplastics in the agroecosystem was scarce and there were barely any experimental studies that had been carried out concerning 
microplastics in the soil-plant system. To begin with, a pot experiment was designed and performed in a climate chamber for four months to determine what effect plastic residues mixed with agricultural soil would have on wheat growth (Chapter 2 ). $1 \%(\mathrm{w} / \mathrm{w}$ ) of plastic content was used as the practical and realistic context in which to simulate the plastic mulch film residues found in agricultural soil according to field surveys and a literature review. We used macro- (rectangular pieces with side length around $5 \mathrm{~mm}$ ) and micro-sized (powders with particle size ranging from $50 \mu \mathrm{m}$ to $1 \mathrm{~mm}$ ) plastic residues from one low-density polyethylene (LDPE) and one starch-based biodegradable mulch film in this study. Considering the promising interactions between earthworms and microplastics, treatments in the presence and absence of earthworms were carried out. The results showed that the presence of $1 \%(\mathrm{w} / \mathrm{w})$ plastic mulch film residues negatively affected wheat growth and development. Both macro- and micro-sized plastic residues of both LDPE and biodegradable mulch films affected the above- and below-ground biomass of wheat during both vegetative and reproductive growth. The biodegradable plastic mulch film residues showed stronger negative effects as compared to LDPE residues for both macro- and micro- sizes. Earthworms chiefly alleviated the impairments for wheat caused by plastic residues.

Many promising research directions were revealed during this pot experiment and we decided to further explore the underlying reasons why the wheat growth was negatively affected by the presence of plastic residues. Alterations in soil physics, chemistry, biology, and their interactions could have all been possible reasons. Therefore, Chapter 3 further explored the effects of the same plastic residues on the rhizosphere microbiome, rhizosphere volatile profiles and soil chemical properties. The composition and structure of wheat rhizosphere bacterial communities were strongly changed by the presence of plastic residues, especially biodegradable ones. Different sizes of the same type of plastic residues exerted different impacts on the rhizosphere microbiome. Variations observed for rhizosphere volatiles and other abiotic parameters (i.e. $\mathrm{pH}$, electrical conductivity and C:N ratio) were also speculated to contribute to the poor wheat growth. Although we are still far away from understanding the complex interactions that take place in the soil-plant system, this chapter provides evidence that highlights how plants, soil microbes and soil chemistry respond to these plastic residues under controlled experimental conditions.

To further explore the effects of these plastic residues on soil physicochemical and hydrological properties, Chapter 4 delineates the measurements of the parameters for soil structure, water infiltration, soil water retention, soil water repellency and soil chemical properties ( $\mathrm{pH}$ and electrical conductivity) in the presence of plastic residues with a content gradient $(0.5 \%, 1 \%$ and $2 \% \mathrm{w} / \mathrm{w})$ under laboratory conditions. The main factor affecting porosity, dry bulk density $(\rho \mathrm{b})$ and saturated hydraulic conductivity (ks) was the size of the plastic residues. For the field capacity (FC), water drop penetration time (WDPT) and $\mathrm{pH}$, 
the type of plastic was the most important factor affecting measurements. For instance, the presence of LDPE debris decreased FC, while biodegradable plastic debris increased it. The content of the plastic residues played a major role in the porosity, pb, ks, FC and WDPT and always interacted with the Type factor. The results showed that both LDPE and biodegradable plastic mulch film in either macro- or micro- sizes had noticeable effects on soil physicochemical and hydrological parameters and these soil properties nonmonotonically responded to the residual amounts of plastic.

Subsequently, the effects of plastic residues on soil function and sustainable agriculture were further explored in Chapter 5. Suppressive soil is of great agronomic interest and has the potential to help manage soilborne plant pathogens in a sustainable way. Using wheat as a model host plant along with an agricultural soil suppressive to Fusarium culmorum, we conducted a pot experiment to test if the addition of our plastic residues at a concentration of $1 \% \mathrm{w} / \mathrm{w}$ in suppressive soil could affect soil suppressiveness. Although the presence of $1 \%(w / w)$ plastic mulch film residues did not affect the disease infection level of wheat in the soil suppressive to $F$. culmorum in this pot experiment, the plant biomasses decreased in the presence of both LDPE and biodegradable plastic residues. Moreover, the plant nutrient content was also affected by the presence of these plastic residues. Interestingly, the rhizosphere bacterial and fungal communities were not significantly changed but the plastispheres in Bio_Ma treatment formed very different microbial communities. The fact that in Chapter 5, we did not observe a significant effect of plastic residues on the rhizosphere microbiome could have been due to the fact that we performed a short-term experiment (two weeks for activation and three weeks for infection). However, it is plausible that in the long term, the presence of plastic residues may cause strong effects. The fact that the plastispheres attracted and possibly activated specific microorganisms indicates the potential of plastic pollution to influence the soil microbiome. This initial research brings new insights and raises questions for further studies of microplastics in agroecosystems. It is of great agronomic interest to further explore the effects of plastic residues on soil suppressiveness and other soil functions.

To conclude, this thesis provided experimental evidence that plastic mulch film residues affected physical, chemical and biological processes in the soil-plant system. Despite the lack of knowledge, it is clear with the incipient evidence that both macroplastics and microplastics derived from LDPE and biodegradable plastic mulch films could be detrimental to agricultural productivity, soil biodiversity and soil biogeochemical cycles. Moreover, the insights developed during this PhD research are a valuable contribution to a framework for the systematic analysis of the effects of microplastics on the soil-plant system and a holistic approach to study interrelated physical, chemical and biological processes in the agroecosystem. 


\section{Acknowledgements}

Doing a PhD is by no means a flat journey and a lot of things happened during past four years. I could not complete this thesis without enormous help and support from so many great people, one way or another. Although only some of their names will appear in the following lines, my deepest and sincere gratitude to all of these amazing people.

First of all, I would like to express my sincere and deepest gratitude to my fantastic supervision team Violette, Paolina, Xiaomei and Esperanza. This is a perfect team in every aspect. (maybe except for gender balance. ${ }^{\wedge}{ }^{\wedge}$ ) I have learnt so much from each of you. Dear Violette, thank you for giving me the opportunity to start this PhD. Your extrovert and positive personality, and your 'the sky is the limit' spirit taught me a lot and gave me always confidence. Dear Paolina, thank you for all the way leading me to be a good researcher, your view and attitude had a great influence on me. Your passion on both professional and personal life have inspired me a lot and will benefit me for my whole life. Dear Xiaomei, I still think our meeting in Wuhan Botanical Garden is magical. Thank you for introducing me to Violette and Wageningen University, this story is never to happen without you. Dear Esperanza, it is really a pity that we couldn't list you as a member of the thesis committee because of the regulations, but you're an indispensable part of my supervision team. All in all, so many thanks to my beloved ladies for all your valuable supervisions, comments, suggestions, inputs and discussions to make my PhD journey so enjoyable and productive.

Scientific research is definitely a teamwork. Besides my supervision team, there are a lot of brilliant people directly involved into this PhD research. Thanks to dear Amalia, we had so many happy memories and the pot experiment we did together is fundamental to this study. Thanks to Henny for your assistance in preparing the plastic materials. Thanks to Harm and Piet for setting up the experiment and transporting materials for the first paper. Thanks to Rinie, Taede and other people working in Unifarm, for your help to the pot experiments in climate chamber. My sincere gratitude goes to all co-authors of the second paper. It took so many efforts to get this work published, and it's never to happen without all your consistent inputs, revisions, suggestions and supports. Thank you, Nicolas! For your help in harvesting plants for wheat growth experiment, for your great work of soil properties experiment, for finding nice courses and so many new experiences, your hard-working spirit always inspire me to further efforts. Thanks to Gerrit for your strong support on statistics. 
Thanks to Harm again for your help in soil properties experiment. Thank you, Adam! I'm so grateful for all your help in lab work, in pot experiment, in bioinformatics, in graphs, etc. You're not only a nice colleague to work with, but also a caring and humorous friend to stay with. Thanks to Étienne for providing amplicon sequencing and thanks to Gianpiero for ionome analysis in soil suppressiveness experiment. A special thank you to Robin Palmer for providing language editing for all the chapters of this thesis.

The papers published or in preparation can help me memorize most of the people directly involved in this study, but I also want to thank those people who have contributed to the initial explorations. Although most of the trials at the beginning of my PhD were not presented in this thesis, these explorations are very valuable to bring this research on the right track. Sanna Kosh is the first student came to help at the very beginning of my PhD. I really want to thank her for the company and support during the trial stage of this study. Thanks to Henk Jalink for the measurements and analyses for chlorophyll fluorescence. Thanks to Binita Thapa sharing her experience and lab skills. Thanks to Sidharam Pujari for sharing his knowledge about FTIR. I'm so grateful that they helped me for pure interest and kindness, with no thought of a reward.

I would like to thank all the staff and students from the SLM group for all your help and support, and all the happy memories together for the lunch meetings, group outings, SLM Borrels, Christmas dinners, etc. Thanks to Coen for leading SLM group as a big family and providing a nice environment to work. Thanks to Marnella and Rianne for bureaucratic issues and all your help which made my PhD life more smooth and easy. Thanks to Henny, Harm and Piet for all your technical assistance. Thanks to Klaas for all the nice figures, your expertise in water repellency and editing my PhD thesis. Thank you dear Ricardo for being my officemate all the time. Thanks also goes to people shared office with me for short or long period, Hongming, Rens, Esperanza, Rasha, Hoda, Godeberthe, Qian, Jiaoyang, Xiaolin. Thanks to other fellow PhD colleagues in SLM group. Sija, Celia, Kaveh, Karrar, Mousumi, Carlos, Coleen, Corjan, Mirzo, Zeinab, Tesfaye, Ammar, Meskerem, Govinda, Raoul, Roger, Suhad, Pavan, Pop, Vera, Fabio, Daniel, Meindert, Darrel, Nikola, Isabel, and many others. It was a great cultural experience and pleasure to meet so many $\mathrm{PhDs}$ from different countries. Many Chinese PhDs come and go in SLM, Lingtong, Fanrong, Jianhong, Miao, Hao, Yan, Qian, Jiaoyang, Jinfeng, Ke, Hui, Zhenni, and visiting Chinese scholars, Hongming, Shaoliang, Haimei, Yonghui, Lihua, Jiabin, Xiaolin, thank you for all the happy moments and delicious foods we shared together. A special thank you to Pavan, the leader of our PokemonGo team, and the members Pop and Lingtong. PokemonGo had brought me so many happy memories and it was not only about the game, but also about your warmest company. 
I'm also grateful for all the help and support from NIOO and ME department. I feel so lucky to be a joint PhD student in NIOO, one of the best ecological research platforms in the world. I enjoyed so much with all kinds of activities in NIOO, the weekly ME labmeeting, PhD double seminar, drinking and outing, NIOO research day, NIOO open day, weaving hedge, Christmas party, etc. Thanks to technicians and analysts in NIOO, Mattias, Hans, Iris, Saskia, Maria, Gregor and many others, for all you help in the lab work, pot experiment and technical assistance. In this context, I want to thank all colleagues at ME department for the fantastic scientific atmosphere. Thanks to senior researchers Jos, Wietse and Eiko for your interests in my PhD research and all the encouraging words. Thanks to fellow PhDs Je-Seung, Mariana, Anna, Azkia, Cristina, Raul, German, Marcelle, Kay, Alex, Han, Haymanti, Letusa, Sytske, and many others for the interesting discussions about culture and science. A big thank you goes to the Garbeva group, Ruth, Kristin, Purva, Olaf, Adam, Lara, Ana, Muhammad and all the students for your help and supports in NIOO and the fun at dinners and drinks outside NIOO. A special thank you also goes to the Chinese PhDs Xiaojiao, Manqi, Peiyu, Wei, Libin, Hui, Keli, Kaiyi, Han, Shuwen, Zhipeng, Qing, Zhikang and Chinese scholars Jing, Minggang, Xu, Rongjun, Xianling and Hui in NIOO.

I would like to thank other Chinese friends in Holland and Europe: Jinghui, Peipei, Hui, Yu, Minghai, Yilina, Yun, Chunfeng, Ke, Jiyao, Shanshan, Xun, Ke, Liangfu, Qian, Guanying, and many others for all the happy time we spent together. Although I didn't go back China during this $\mathrm{PhD}, \mathrm{I}$ also received enormous supports from old friends in China: Xiaoshen, Chanchan, Huihui, my roommates in university, Fengqin, Ying, Mingzhu, Ting, my colleagues in Wuhan Botanical Garden, and many others for all the spiritual communications via text, voice call and video chat. Looking back at the four years of my life in Wageningen, a special thank you goes to my beloved feeders: Miao, Lingtong, Hui and Yu. Without your love and food, literally I couldn't survive. ${ }^{\wedge}{ }^{\wedge}$

Last but most important, I would like to thank my family, my mother, my father, my sisters, my brother, my sister-in-law, my brothers-in-law, my nephews and nieces. I feel so lucky to have such a warm and loving big family. Your unconditional love and support encouraged me to go through all my adventures. I love you three thousand! 


\section{About the author}

Yueling Qi was born on 29 $9^{\text {th }}$ June, 1989 in Yongcheng Henan, China. In 2009, she left her hometown and started to study Biological Science at Henan Agricultural University in Zhengzhou, the capital city of Henan province. After four years' bachelor study, she continued to study the master degree in Pollution Ecology Group, Wuhan Botanical Garden, Chinese Academy of Sciences. During her master, she spent one year in Beijing for courses and two years in Wuhan for experiments and research. In 2016, she obtained the financial support from China Scholarship Council (CSC) and she joined the Soil Physics and Land Management Group of Wageningen University, the Netherlands, to start her PhD research. During her PhD, she worked on the effects of plastic mulch film residues with different sizes, types and doses on soil-plant system in greenhouse and laboratory. To gain more knowledge of microbial ecology for her $\mathrm{PhD}$ research, she also registered as a guest $\mathrm{PhD}$ in the Netherlands Institute of Ecology (NIOO-KNAW) since 2017.

Her contact email address is: qiyueling13@mails.ucas.ac.cn

\section{Scientific Publications}

Qi, Y., Ossowicki, A., Yergeau, É., Vigani., G, Geissen, V. \& Garbeva, P. (2020). Plastic mulch film residues in agriculture: impact on soil suppressiveness and ecosystem functioning. (To be submitted)

Qi, Y., Beriot, N., Gort, G., Lwanga, E. H., Gooren, H., Yang, X., \& Geissen, V. (2020). Impact of plastic mulch film debris on soil physicochemical and hydrological properties. Environmental Pollution, 115097.

Qi, Y., Ossowicki, A., Yang, X., Lwanga, E. H., Dini-Andreote, F., Geissen, V., \& Garbeva, P. (2020). Effects of plastic mulch film residues on wheat rhizosphere and soil properties. Journal of Hazardous Materials, 387, 121711.

Qi, Y., Yang, X., Pelaez, A. M., Lwanga, E. H., Beriot, N., Gertsen, H., Garbeva, P., \& Geissen, V. (2018). Macro-and micro-plastics in soil-plant system: effects of plastic mulch film residues on wheat (Triticum aestivum) growth. Science of the Total Environment, 645, 10481056. 
Qi, Y., Owino, A. A., Makokha, V. A., Shen, Y., Zhang, D., \& Wang, J. (2016). Occurrence and risk assessment of polycyclic aromatic hydrocarbons in the Hanjiang River Basin and the Danjiangkou Reservoir, China. Human and Ecological Risk Assessment: An International Journal, 22(5), 1183-1196.

Cao, X., Qi, Y., Xu, C., Yang, Y., \& Wang, J. (2017). Transcriptome and metabolome responses of Shewanella oneidensis MR-1 to methyl orange under microaerophilic and aerobic conditions. Applied microbiology and biotechnology, 101(8), 3463-3472.

Sun, H., Qi, Y., Zhang, D., Li, Q. X., \& Wang, J. (2016). Concentrations, distribution, sources and risk assessment of organohalogenated contaminants in soils from Kenya, Eastern Africa. Environmental Pollution, 209, 177-185.

Makokha, V. A., Qi, Y., Shen, Y., \& Wang, J. (2016). Concentrations, distribution, and ecological risk assessment of heavy metals in the East Dongting and Honghu Lake, China. Exposure and Health, 8(1), 31-41. 


\section{Co-author affiliations}

Violette Geissen

Soil Physics and Land Management Group, Wageningen University \& Research, P.O. Box 47, 6700AA Wageningen, The Netherlands

Paolina Garbeva

Department of Microbial Ecology, Netherlands Institute of Ecology (NIOO-KNAW), 6700 AB Wageningen, The Netherlands

Xiaomei Yang

Soil Physics and Land Management Group, Wageningen University \& Research, P.O. Box 47, 6700AA Wageningen, The Netherlands

College of Natural Resources and Environment, Northwest A\&F University, 712100 Yangling, China

Esperanza Huerta Lwanga

Soil Physics and Land Management Group, Wageningen University \& Research, P.O. Box 47, 6700AA Wageningen, The Netherlands

Agroecología, El Colegio de la Frontera Sur, Unidad Campeche, Campeche, Mexico

Adam Ossowicki

Department of Microbial Ecology, Netherlands Institute of Ecology (NIOO-KNAW), 6700 AB Wageningen, The Netherlands

Nicolas Beriot

Soil Physics and Land Management Group, Wageningen University \& Research, P.O. Box 47, 6700AA Wageningen, The Netherlands

Gestión, Aprovechamiento y Recuperación de Suelos y Aguas, Universidad Politécnica de Cartagena, Spain

\section{Francisco Dini-Andreote}

Department of Plant Science, The Pennsylvania State University, University Park, PA, USA Huck Institutes of the Life Sciences, The Pennsylvania State University, University Park, PA, USA 
Gerrit Gort

Biometris, Wageningen University \& Research, P.O. Box 16, 6700 AA Wageningen, The Netherlands

Étienne Yergeau

Centre Armand-Frappier Santé Biotechnologie, Institut national de la recherche scientifique, Laval, QC, Canada

Gianpiero Vigani

University of Turin, Plant Physiology Unit, Department of Life Sciences and Systems Biology, 10135 Turin, Italy 


\section{SENSE}

Netherlands Research School for the

Socio-Economic and Natural Sciences of the Environment

\section{I P L O M A \\ for specialised PhD training}

The Netherlands research school for the Socio-Economic and Natural Sciences of the Environment

(SENSE) declares that

\section{Yueling Qi}

born on 29 June 1989 in Henan, China

has successfully fulfilled all requirements of the educational PhD programme of SENSE.

Wageningen, 8 December 2020
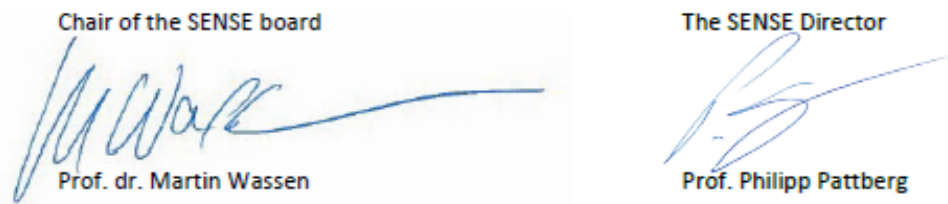

The SENSE Research School hes been accredited by the Royal Netheriands Academy of Arts and Sciences (KNAW) 


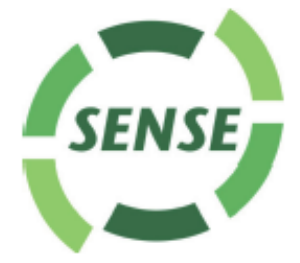

The SENSE Research School declares that Yueling Qi has successfully fulfilled all requirements of the educational PhD programme of SENSE with a work load of $39.7 \mathrm{EC}$, including the following activities:

\section{SENSE PhD Courses}

- Environmental research in context (2017)

- Multivariate Analysis (2017)

- Model training for scenario analyses (2018)

- Research in context activity: "Creating accessible video presentation on Microplastics in Agroecosystems for the purpose of communicating PhD research with larger audience' (2020)

Other PhD and Advanced MSc Courses

- The Essentials of Scientific Writing and Presenting, Wageningen Graduate Schools (2017)

- Reviewing a Scientific Paper, Wageningen Graduate Schools (2018)

- New Frontiers in Microbial Ecology, RSEE graduate school (2018)

- Plant Nutrients in Terrestrial Ecosystems - acquisition and turnover, PE\&RC Graduate School and University of Copenhagen (2018)

- Soil Ecology: The Multifunctional Potential of Soils, Graduate Schools PE\&RC and WIMEK (2019)

- Root Ecology University of Copenhagen, PE\&RC Graduate School and University of Copenhagen (2019)

\section{Selection of Oral Presentations}

- Microplastics in terrestrial ecosystem: effect of plastic mulch residues on plant growth. BONARES Conference 2018: Soil as a Sustainable Resource. 26-28 February 2018, Berlin, Germany

- Microplastics in terrestrial ecosystem: effects of macro-and micro-plastic residues on wheat growth. FAO Global Symposium on Soil Pollution 2018: Be the Solution to Soil Pollution , 2-4 May 2018, Rome, Italy

- Effects of plastic mulch film residues on wheat growth and rhizosphere microbiome. Netherlands Annual Ecology Meeting, 11-12 February 2020, Lunteren, The Netherlands

SENSE coordinator PhD education

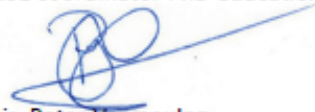

Dr. ir. Peter vermeulen 
The research described in this thesis was conducted at Soil Physics and Land Management Group, Wageningen University, and the Department of Microbial Ecology of the Netherlands Institute of Ecology (NIOO-KNAW).

This research described in this thesis was financially supported by China Scholarship Council (CSC: 201604910510).

This is NIOO thesis number 181.

Printed by: DigiForce | www.proefschriftmaken.nl 

